\title{
National Fire Research Laboratory Commissioning Project: Testing Steel Beams under Localized Fire Exposure
}

Lisa Choe, Selvarajah Ramesh, Matthew Hoehler, Mina Seif, John Gross, Chao Zhang, and Matthew Bundy

Fire Research Division Engineering Laboratory, NIST

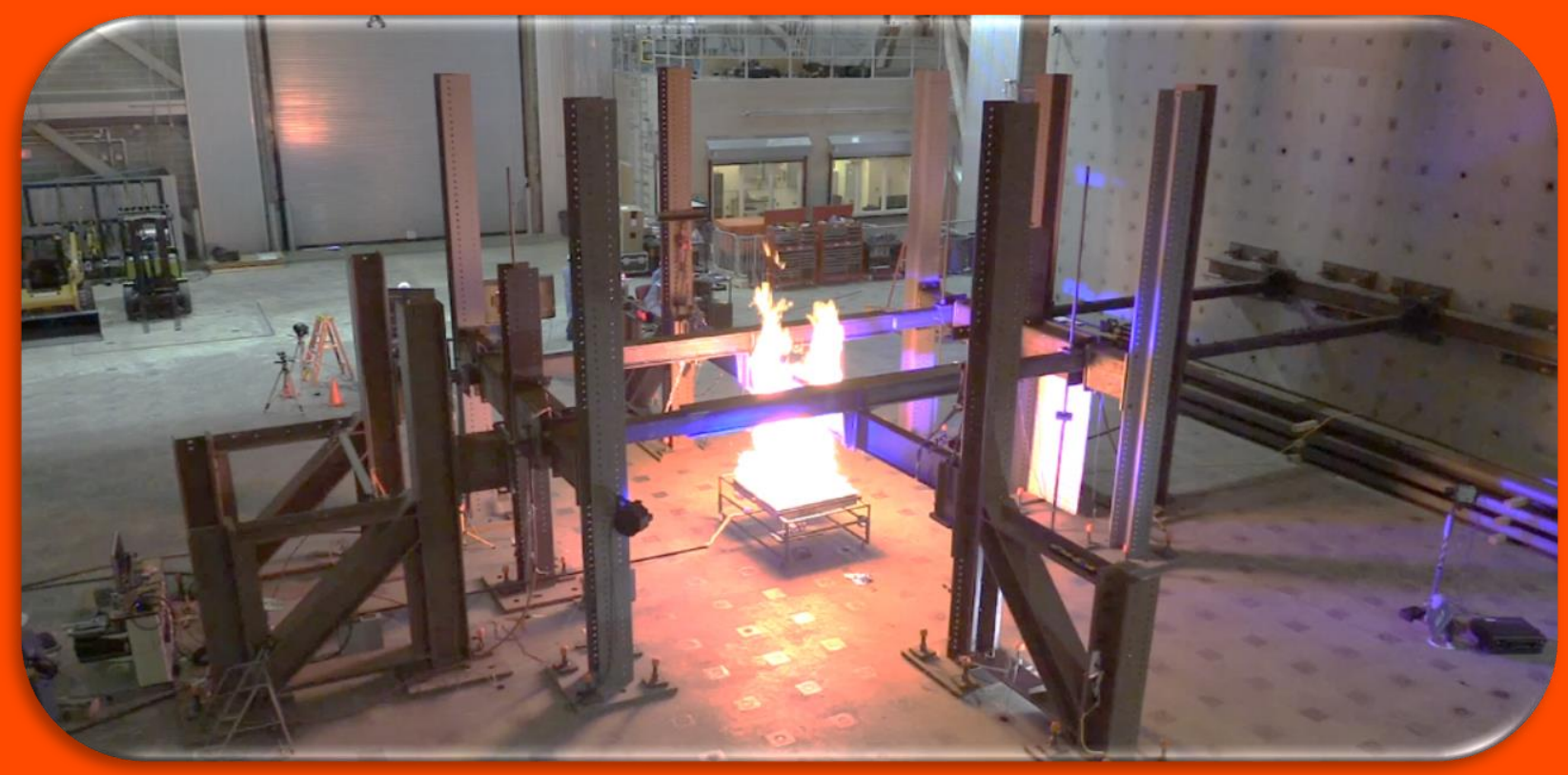

This publication is available free of charge from: https://doi.org/10.6028/NIST.TN.1983

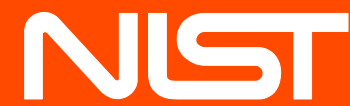

National Institute of Standards and Technology U.S. Department of Commerce 

NIST Technical Note 1983

\section{National Fire Research Laboratory Commissioning Project: Testing Steel Beams under Localized Fire Exposure}

Lisa Choe, Selvarajah Ramesh, Matthew Hoehler, Mina Seif, John Gross, Chao Zhang, and Matthew Bundy

Fire Research Division Engineering Laboratory, NIST

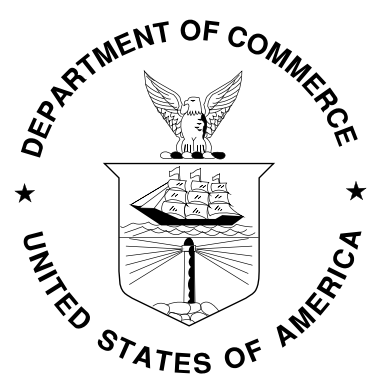

U.S. Department of Commerce Wilbur L. Ross, Jr., Secretary 
The policy of the National Institute of Standards and Technology is to use metric units in all its published materials. Because this report is intended for the U.S. building construction industry, which uses inch-pound units, it is more practical and less confusing to use inch-pound units, in some cases, rather than metric units. However, in most cases, units are presented in both metric and the inch-pound system.

Certain commercial entities, equipment, products, or materials are identified in this document in order to describe a procedure or concept adequately. Such identification is not intended to imply recommendation or endorsement by the National Institute of

Standards and Technology, nor is it intended to imply that the entities, products, materials, or equipment are necessarily the best available for the purpose.

Another policy of the National Institute of Standards and Technology is to include statements of uncertainty with all NIST measurements. In this document, however, some measurements of authors outside of NIST are presented,

for which uncertainties were not reported and are unknown.

National Institute of Standards and Technology Technical Note 1983 Natl. Inst. Stand. Technol. Tech. Note 1983, 117 pages (February 2018) CODEN: NTNOEF 


\section{AbStRACt}

This report presents the experimental design and results of a series of localized fire tests on structural steel I-shaped beams. A total of nine tests were conducted in the National Fire Research Laboratory, including thermal tests (Tests 1 through 5) and four-point bending tests at ambient (Test 6) and elevated temperatures (Tests 7 through 9). The specimens were nominally 6.2-m long W16×26 beams made of ASTM A992 steel. Each specimen was vertically supported with either a (i) simple support condition, or (ii) double-angles bolted to laterally braced support columns. The thermally-loaded specimens were exposed to fire generated using a natural gas burner. The burner had an area of $1 \mathrm{~m}^{2}$ and was located $1.1 \mathrm{~m}$ below the bottom flange of the beam at midspan. A four-point flexural loading scheme was used to apply concentrated forces at two locations $2.44 \mathrm{~m}$ apart around midspan. The recorded data included temperatures, heat release rates from the burner, and structural measurements including forces, displacements and strains. The repeatability of several measurements was evaluated. The test results indicated that the heating rate of the specimen was sensitive to the prescribed heat release rate versus time relationship used in each test. However, the thermal gradient developed in the fire-exposed cross sections of the beam never achieved linearity under the localized fire exposure. When the exposed (bottom) flange temperature was maintained to $616{ }^{\circ} \mathrm{C}$, the load-bearing capacity of the simply-supported beam was reduced to $67 \%$ of its room-temperature capacity. When the same simply-supported beam was initially loaded to $67 \%$ of its room-temperature capacity and then exposed to a growing ( $t$-squared) fire, the exposed flange temperature of the beam at failure was $663{ }^{\circ} \mathrm{C}$. When the beam specimen was supported by double-angle connections and subjected to the same bending moment, its fire resistance (failure temperature) was decreased to $90 \%$ of that of the simply-supported beam. Regardless of the connection types and fire conditions (steady-state or transient-state fire), the beam specimens failed by lateral torsional buckling with rapidly increasing vertical displacements.

Keywords: Structural-fire experiment; localized fire exposure; structural steel beam; inelastic buckling; thermal strain; steel connection; structural fire resistance 
This page intentionally left blank. 


\section{TABLE OF CONTENTS}

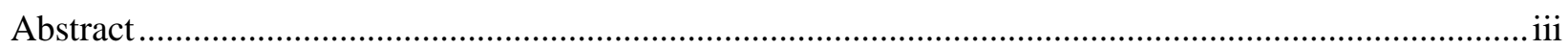

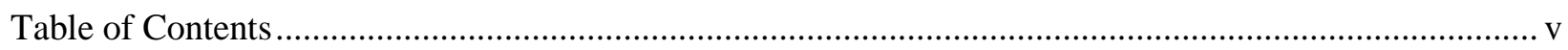

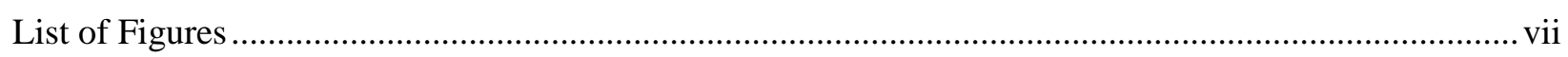

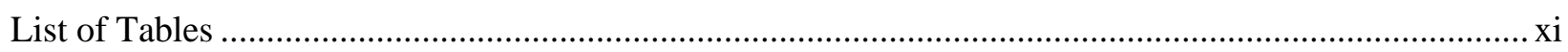

Chapter 1 Introduction................................................................................................

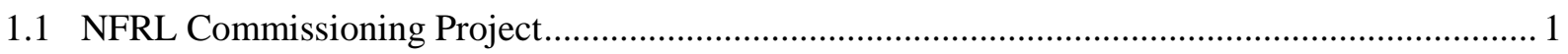

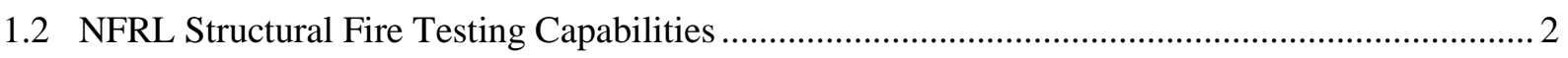

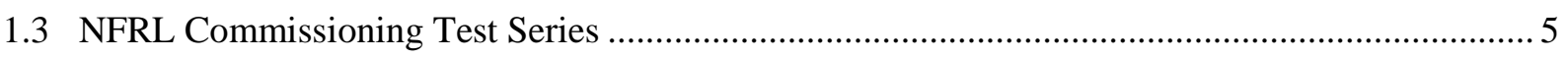

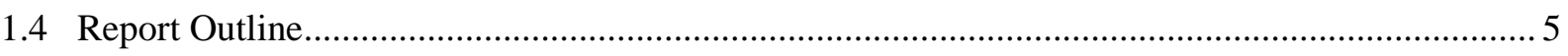

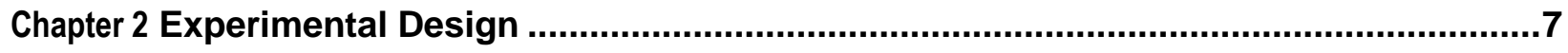

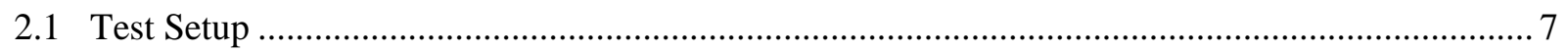

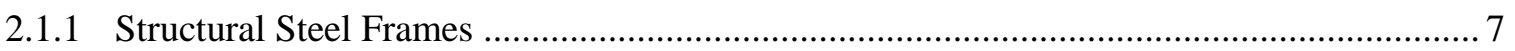

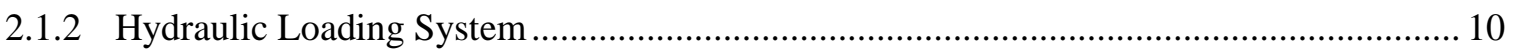

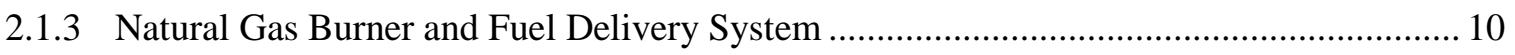

2.2 Test Matrix, Specimens, Loading Configurations .............................................................. 12

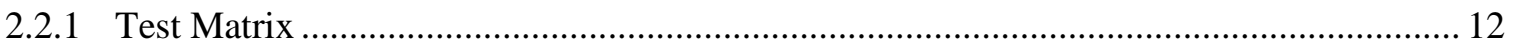

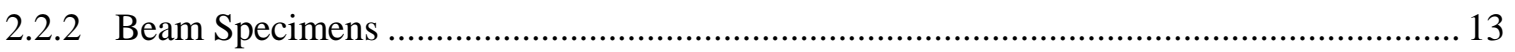

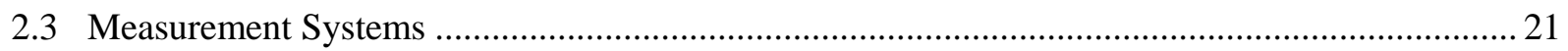

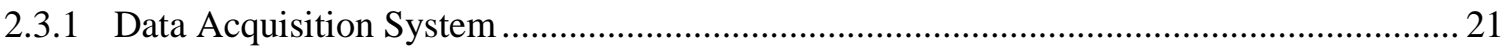

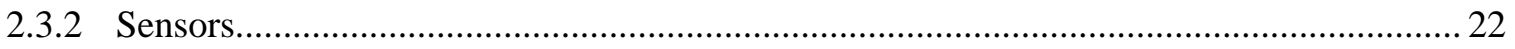

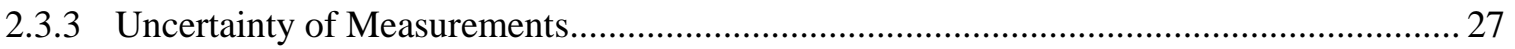

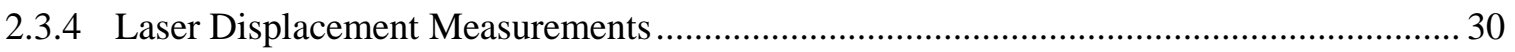

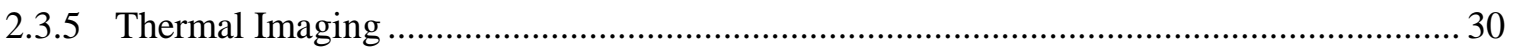

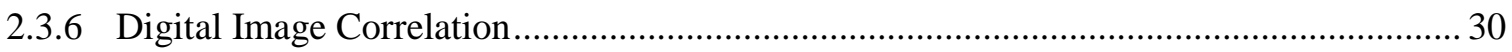

2.3.7 Effect of Thermocouple Installation Method on Steel Temperature Measurement ........... 31

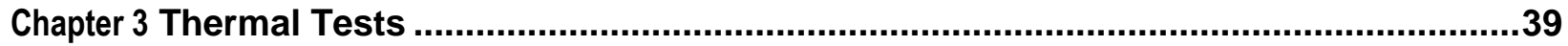

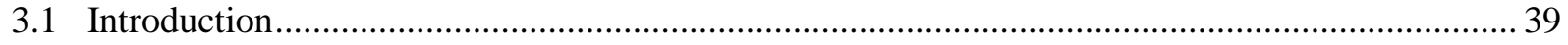

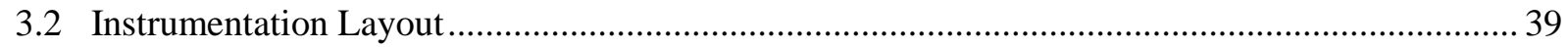

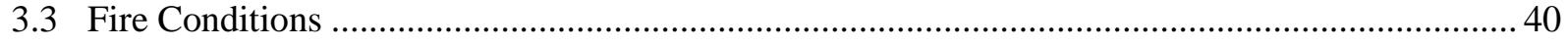




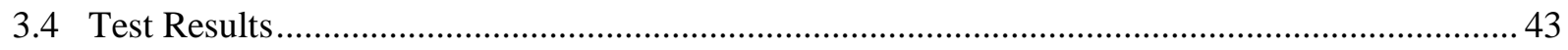

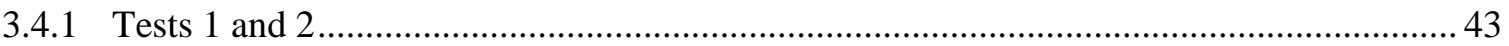

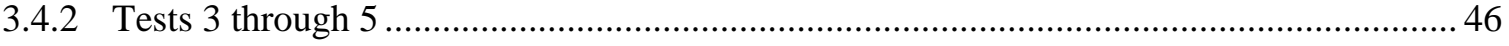

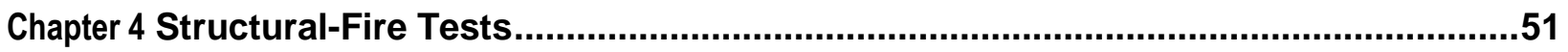

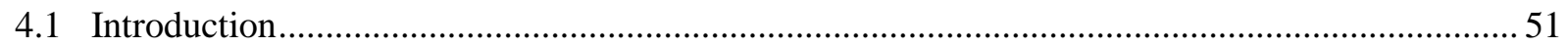

4.2 Test 6: Four Point Bending Test at Ambient Temperature …..................................................5 52

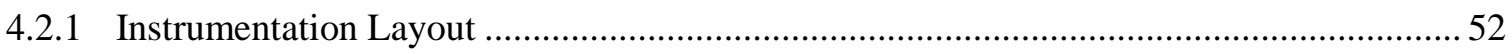

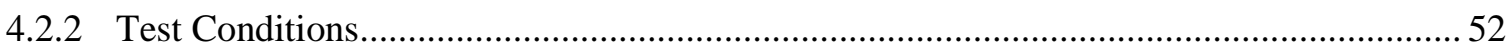

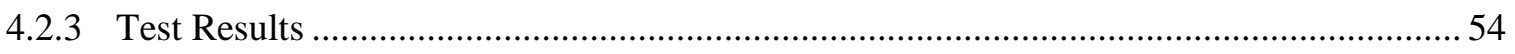

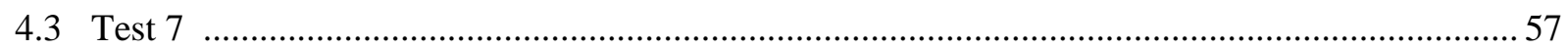

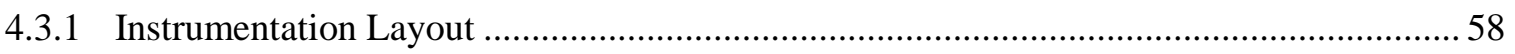

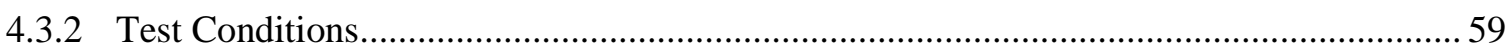

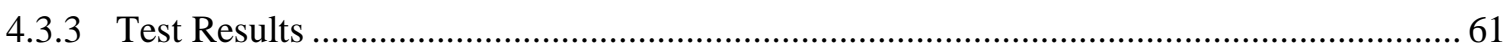

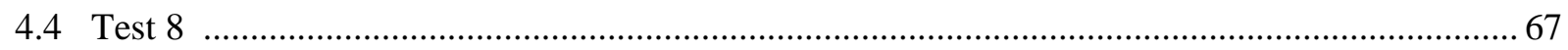

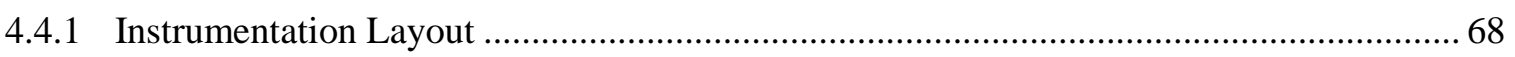

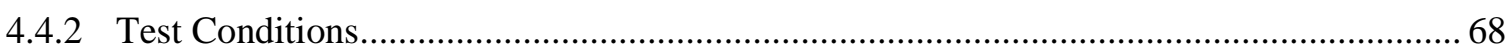

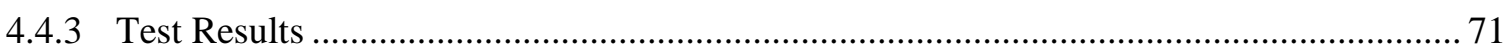

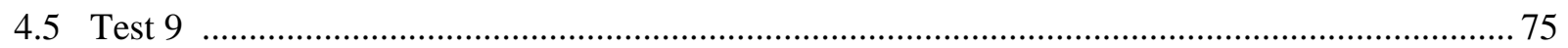

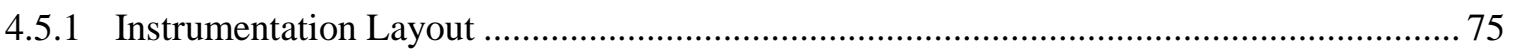

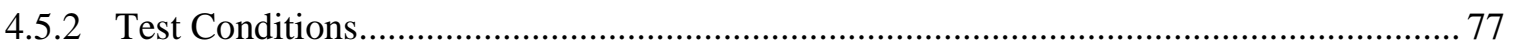

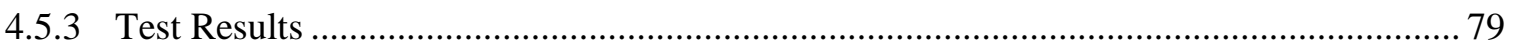

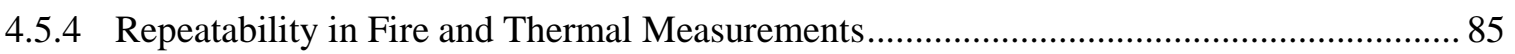

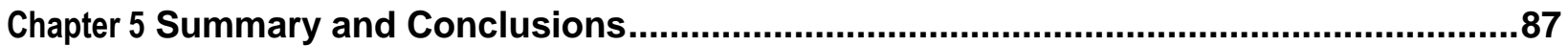

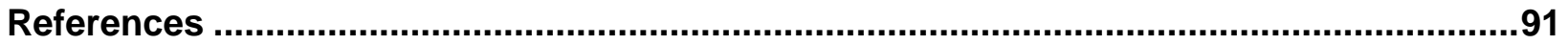

APPENDIX A Drawings For Test Setup, Specimens, And Connections................................93

APPENDIX B Instrumentation Layout, Sensor Labels, And Measurements Made In The Tests 


\section{LIST OF FIGURES}

Figure 1-1 Cross-sectional view of expanded NFRL..................................................................... 2

Figure 1-2 Photograph of the testing area showing the strong floor, strong wall, and hood. ....................... 3

Figure 1-3 Actuator mounted on yoke located in basement underneath strong floor............................... 4

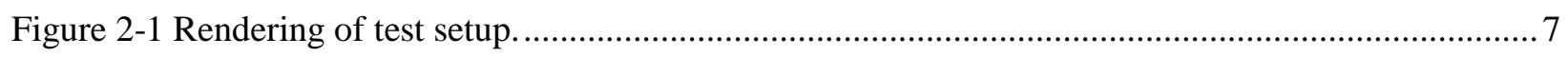

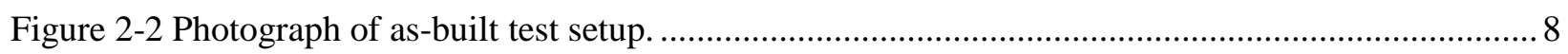

Figure 2-3 Actuator mounted underneath the strong floor and (b) detail of rod coupler........................... 9

Figure 2-4 Top view and (b) side view of HSS loading beams. ........................................................ 9

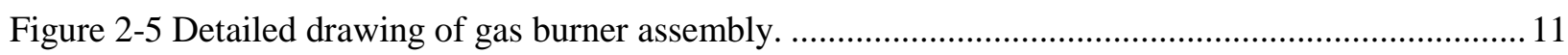

Figure 2-6 Photograph of burner in the test setup............................................................................ 11

Figure 2-7 Dimensions of W16×26 beam specimen (unit: $\mathrm{cm}$ ) ...................................................... 14

Figure 2-8(a) Top view and (b) bottom view of seated connection..................................................... 15

Figure 2-9 (a) Photograph of Specimen 5 and (b) details of all-bolted double-angle connection. ............. 16

Figure 2-10 Structural loading arrangement. Strong floor, supporting columns, braces, and guide frames

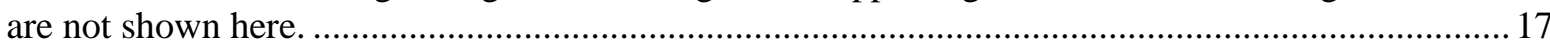

Figure 2-11 Stress-strain curves (a) showing the curves until fracture and (b) showing the initial portion of

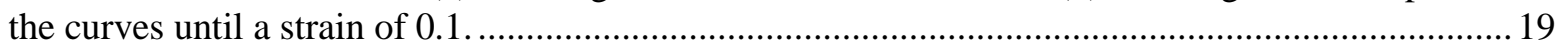

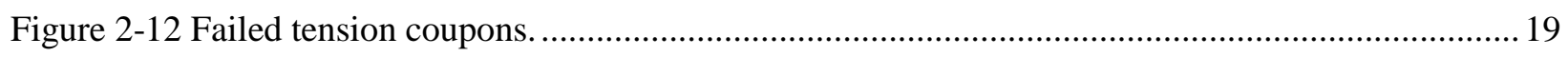

Figure 2-13 Arrangement of the W16x26 beams for sweep and camber measurements.........................20

Figure 2-14 Typical temperature sensors: (a) thermocouple peened into drill hole in web of beam, (b)

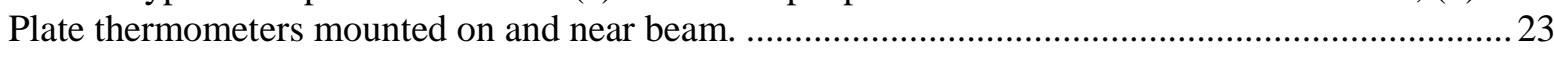

Figure 2-15 Strain gauges installed near end of beam specimen. .......................................................2 24

Figure 2-16 Inclinometer attached to the top flange of a beam specimen. ............................................2 24

Figure 2-17 Linear potentiometer attached to the bottom flange of a beam specimen............................25

Figure 2-18 Setup for vertical and transverse beam displacement measurements at mid-span: (a) overview, (b) paired string potentiometers to measure transverse displacements, (c) paired string potentiometers to measure vertical displacements..................................................................... 26

Figure 2-19 Setup for vertical and transverse beam displacement measurements at mid-span: (a) photo illustrating fiber paths, (b) detail of fiber to beam connections. ......................................................2 27

Figure 2-20 FLIR SC8000 series thermal imaging camera (source: http://www.flir.com). .................... 30

Figure 2-21 Digital Image Correlation system: (a) Typical setup for Dantec Q-400 DIC system (source: http://nevatec.ru), (b) center portion of beam specimen painted with black-white pattern illuminated with narrow-spectrum blue light.

Figure 2-22 Thermocouple layout with units in $\mathrm{mm}$. Standard uncertainty in dimensions was $\pm 2 \mathrm{~mm}$ (95\% confidence interval). 
Figure 2-23 Thermocouples installed on the web of the beam

Figure 2-24 The measured burner HRR versus steel temperatures and photograph of the specimen exposed to a fire.

Figure 2-25 Temperature variation between thermocouples at different ranges of HRR and average temperature as a function of the burner HRR at the (a) lower flange (LF), (b) lower web (LW), (c) middle web (MW), and (d) upper web (UW). Error bars indicates the standard deviation.

Figure 2-26 Temperature change in response to the burner HRR at the locations of (a) lower flange (LF), (b) lower web (LW), (c) middle web (MW), and (d) upper web (UW). The standard deviation of temperature readings at $\mathrm{LF}, \mathrm{LW}, \mathrm{MW}$, and $\mathrm{UW}$ locations is $3{ }^{\circ} \mathrm{C}, 2{ }^{\circ} \mathrm{C}, 9^{\circ} \mathrm{C}$, and $1{ }^{\circ} \mathrm{C}$, respectively.

Figure 2-27 Temperature change $(\Delta \mathrm{T})$ measured by thermocouples mounted in the location of MW from (a) $1505 \mathrm{sec}$ to $1646 \mathrm{sec}$ and from (b) $1650 \mathrm{sec}$ to $1750 \mathrm{sec}$. Values after \pm symbol indicate standard deviation.

Figure 2-28 Web temperature measured using the FLIR camera and thermocouple readings at 1765 sec 37

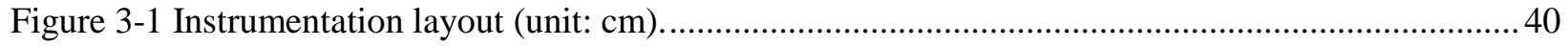

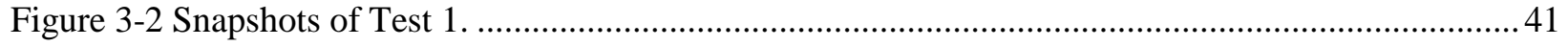

Figure 3-3(a) Recorded burner HRR versus time relation and (b) comparison of Tests 1 and 2...............41

Figure 3-4 Recorded burner HRR versus time relation of Tests 3 through 5 ....................................... 42

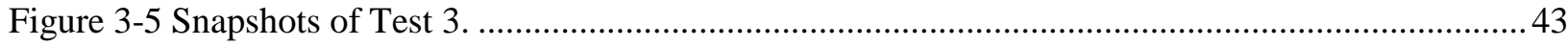

Figure 3-6 Temperature contours of the beam specimen exposed to a localized fire with increasing heat

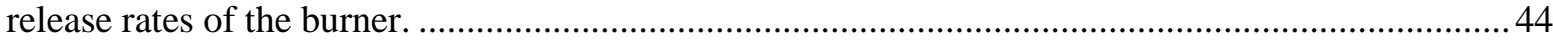

Figure 3-7(a) Temperature-time responses of the fire-exposed midspan and (b) The average temperatures

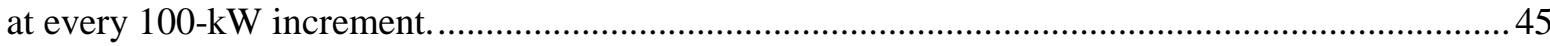

Figure 3-8(a) Axial and (b) vertical displacements of the beam specimen.............................................46

Figure 3-9 Temperature contours of the beam specimen exposed to a localized fire with the burner heat release rate of $400 \mathrm{~kW}$.

Figure 3-10 Temperature-time responses of the fire-exposed midspan and (b) the average temperatures at

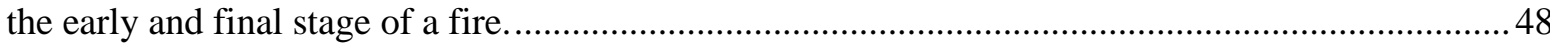

Figure 3-11 Location of plate thermometers used in Tests 3 through 5 and (b) measured adiabatic surface temperatures as a function of fire exposure time. Error bars indicate the standard deviation among Tests 3 through 5 .

Figure 3-12(a) Axial and (b) vertical displacements of the beam specimen. Error bars indicate the standard deviation among Tests 3 through 5.

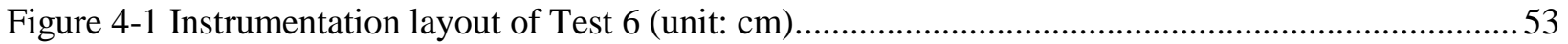

Figure 4-2 Average and standard deviation of forces provided by individual actuators in Test 6 ............53

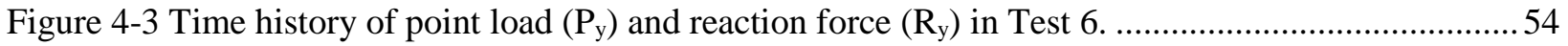

Figure 4-4 Photographs of (a) W16 $\times 26$ beam specimen in the test setup during the test, (b) local distortion of top flange at midspan after test, and (c) the final deflected shape of the specimen after test.........55

Figure 4-5(a) Reaction force versus vertical displacement and (b) reaction force versus lateral displacement of the specimen. 
Figure 4-6(a) Reaction forces at the beam ends versus strains in the mid-section and (b) location of strain gauges used in Test 6 .

Figure 4-7 Instrumentation layout for test 7. (unit: $\mathrm{cm}$ ).................................................................. 58

Figure 4-8 Measured burner HRR, average point load $\left(\mathrm{P}_{\mathrm{y}}\right)$, and average reaction force $\left(\mathrm{R}_{\mathrm{y}}\right)$ as a function of test time. The standard deviation of $\mathrm{P}_{\mathrm{y}}$ and $\mathrm{R}_{\mathrm{y}}$ data was $0.28 \mathrm{kN}$, and $0.81 \mathrm{kN}$, respectively........59

Figure 4-9 (a) Average actuator force and standard deviation as a function of test time and (b) average reaction force and point load as a function of test time along with the differences $\left(\Delta \mathrm{P}_{\mathrm{y}}\right)$ of two points loads at the location of loading beams and the difference $\left(\Delta \mathrm{R}_{\mathrm{y}}\right)$ in reaction forces at beam ends...... 60

Figure 4-10 The beam specimen exposed to an open flame natural gas fire with the views looking toward the east direction (top) and the north direction (bottom).

Figure 4-11 Temperature contours of the beam specimen in Test 7.

Figure 4-12 (a) Location of temperature measurement in fire-exposed midspan sections (unit: $\mathrm{cm}$ ), (b) time histories of temperatures in fire-exposed midspan sections, and (c) average temperatures in fireexposed midspan sections under structural loading. The error bars indicate the standard deviation of temperature readings during the structural loading phase.

Figure 4-13 Time history of average adiabatic surface temperature measured using plate thermometers near the lower flange of the specimen at midspan.

Figure 4-14 (a) Snapshots of a test video showing the specimen deformation at $14 \mathrm{~min}, 20 \mathrm{~min}, 25 \mathrm{mins}$, and $30 \mathrm{~min}$, (b) time histories of the upper (UF) and the lower flange (LF) temperatures in the fireexposed sections and the point load $\left(\mathrm{P}_{\mathrm{y}}\right)$, (c) the point load versus displacement curves, and (d) the point load versus end rotations about the strong and the weak axes.

Figure 4-15 Photographs of overall deflected shape of the specimen after cooling (above) and local flange deformations in the fire-exposed midspan (below)....

Figure 4-16 Instrumentation layout for Test 8. (unit: $\mathrm{cm}$ ).

Figure 4-17 Measured HRR of the burner, average point load $\left(\mathrm{P}_{\mathrm{y}}\right)$, and average reaction force $\left(\mathrm{R}_{\mathrm{y}}\right)$ as a function of test time. The standard deviation of $\mathrm{P}_{\mathrm{y}}$ and $\mathrm{R}_{\mathrm{y}}$ values were $0.35 \mathrm{kN}$ and $1.2 \mathrm{kN}$, respectively.

Figure 4-18 (a) Average actuator force and standard deviation as a function of test time and (b) average reaction force $\left(\mathrm{R}_{\mathrm{y}}\right)$ and point load $\left(\mathrm{P}_{\mathrm{y}}\right)$ over the test period along with the difference $\left(\Delta \mathrm{P}_{\mathrm{y}}\right)$ in two points loads and the difference $\left(\Delta R_{y}\right)$ in reaction forces at the beam ends.

Figure 4-19 (a) a snapshot of Test 8 with view looking down to the beam specimen and (b) comparison of the programmed and measured HRR of the burner. .................................................................... 71

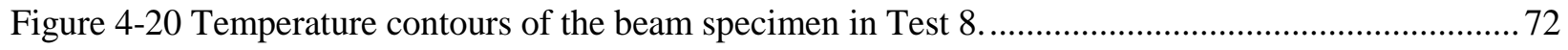

Figure 4-21(a) Measured steel temperatures in Test 8 and (b) 1 minute-average temperatures in fire exposed cross sections at the specimen failure.

Figure 4-22(a) Snapshots of a video showing the specimen behavior, (b) time histories of the upper and the lower flange temperatures in the fire-exposed sections and the point load $\left(\mathrm{P}_{\mathrm{y}}\right)$, and (c) the upper flange temperature versus displacement curves.

Figure 4-23 Snapshots of a test video showing the fire-exposed middle portion of the beam specimen (right) and the overall deflected shape of the specimen (left) ........................................................ 75

Figure 4-24 Instrumentation layout used in Test 9. (unit: $\mathrm{cm}$ ). ............................................................ 76 
Figure 4-25 Measured HRR of the burner and the average point load $\left(\mathrm{P}_{\mathrm{y}}\right)$ as a function of test time. The standard deviation of $\mathrm{P}_{\mathrm{y}}$ values was $1.2 \mathrm{kN}$, respectively.

Figure 4-26 (a) The time series of average actuator force and standard deviation and (b) average point load $\left(\mathrm{P}_{\mathrm{y}}\right)$ over test period along with the differences $\left(\Delta \mathrm{P}_{\mathrm{y}}\right)$ of two points loads at the location of loading beams.

Figure 4-27(a) Snapshot of Test 9 with view looking down to the beam specimen and (b) comparison of the programmed and measured HRR of the burner.

Figure 4-28 Temperature contours of the beam specimen in Test 9.

Figure 4-29 (a) Temperature rise in the fire-exposed midspan in Test 9 and (b) average thermal gradient in the fire exposed cross sections at the specimen failure

Figure 4-30 (a) Snapshots showing the specimen behavior under fire condition, the time histories of (b) the upper and the lower flange temperatures at midspan and the point load $\left(\mathrm{P}_{\mathrm{y}}\right)$, and (c) displacements, (d) end rotations of the beam specimen.

Figure 4-31 Deflected shape of the specimen after cool-down (top) and ductile fracture failure at midspan (bottom)

Figure 4-32 Strains developed in the steel angle (left) and pried steel angles after test (right)..... 84

Figure 4-33 Double-angle connections at the beam end 84

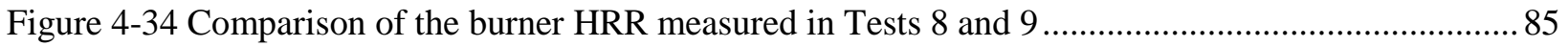

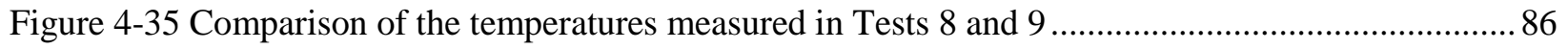

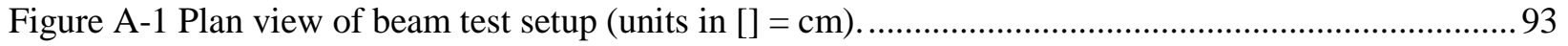

Figure A-2 Elevation view of test setup for simply-supported beam (units in [] = cm). ........................94

Figure A-3 Elevation view of test setup for the simply-supported beam (units in []$=\mathrm{cm}$ )..................95

Figure A-4 Elevation view of buide frames for loading beam (units in []$=\mathrm{cm}$ ). ...............................96

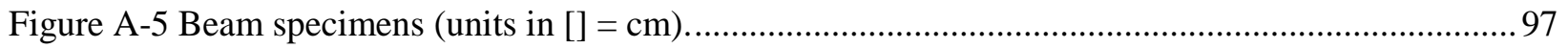

Figure A-6 Beam end support conditions (units in []$=\mathrm{cm}$ ) .............................................................. 97

Figure B-1 Locations of thermocouple sections in the W16X26 beam specimens (units in []$=\mathrm{cm}$ ).......99

Figure B-2 Location of thermocouples in beam cross-sections (units in []$=\mathrm{cm}$ ) ..............................99

Figure B-3 Labels of thermocouples.

Figure B-4 Locations and labels of plate thermometers mounted at halfway between Sections 6 and 7

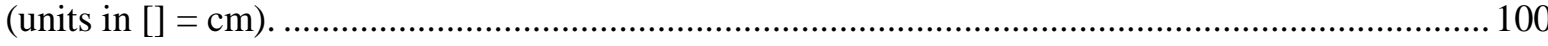

Figure B-5 Location and labels of displacement and rotation transducers (units in []$=\mathrm{cm}$ ). .............. 101

Figure B-6 Locations and labels of strain gauges used in Test 6 (units in []$=\mathrm{cm}$ ) ........................... 102

Figure B-7 Locations and labels of strain gauges used in Test 9 (units in [] $=\mathrm{cm}$ ). 102 


\section{LIST OF TABLES}

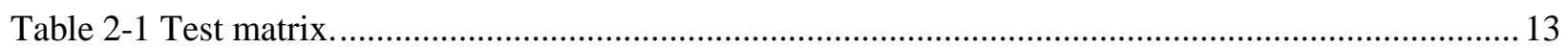

Table 2-2 Weight of two HSS loading beam assemblies (2w) placed on the top of the beam specimen... 18

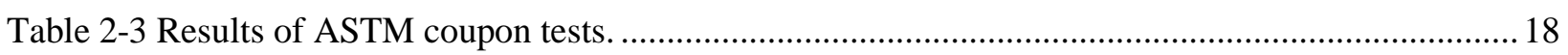

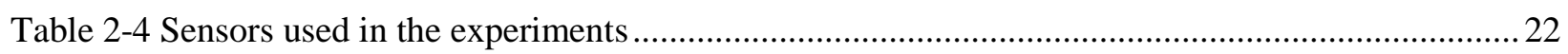

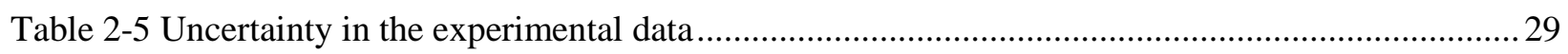

Table 3-1 The target, average, and coefficient of variation (CV) of the burner HRR values from Tests 1

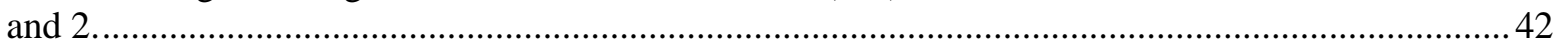

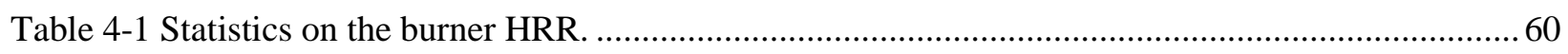

Table B-1 Steel temperature measurements made in the tests (" $x$ " indicates the sensor used in the test).

Table B-2 Adiabatic surface temperature measurements made in the tests (" $x$ " indicates the sensor used in

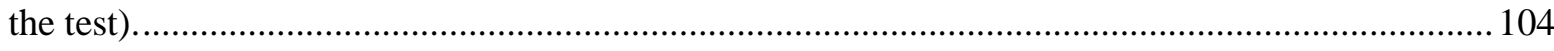

Table B-3 Displacement and rotation measurement made in the tests (" $x$ " indicates the sensor used in the

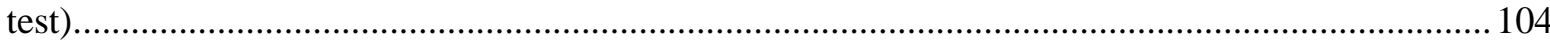

Table B-4 Strain and force measurements made in the tests (" $x$ " indicates the sensor used in the test). . 105 
This page intentionally left blank. 


\section{Chapter 1 \\ INTRODUCTION}

\subsection{NFRL COMMISSIONING PROJECT}

Currently, there are a limited number of experimental facilities in the world to conduct research on the response of large structural systems to realistic fire and mechanical loading under controlled laboratory conditions. Expansion of the National Fire Research Laboratory (NFRL) located on National Institute of Standards and Technology (NIST) Gaithersburg, Maryland campus allows for the testing of multistory structures under fires up to $20 \mathrm{MW}$. The newly-commissioned facility allow researchers to (1) explore innovative measurement techniques to characterize fire-structure interaction, (2) develop an experimental database on the performance of structural components and systems under realistic fire and mechanical loads, (3) validate physics-based computational models to predict the fire resistance of structures, (4) enable performance-based standards for fire resistance design of structures, and (5) foster innovations in design and construction.

The NFRL Infrastructure and Commissioning project delivered a fully operational laboratory in 2016. This project was conducted in three phases:

- Phase I: Outfitting of laboratory infrastructure including installation of (i) health monitoring of the building to monitor the laboratory environmental conditions including humidity and temperature, (ii) video monitoring system, (iii) calorimetry instrumentation, (iv) control room equipment, (v) exhaust hood skirts.

- Phase II: Verification of the operation and calibration of fire-related systems (oxygen depletion calorimetry, calibration burner), and structural systems (hydraulic loading system, reaction frames, boundary support conditions).

- $\quad$ Phase III: Testing of a simple structural configuration to verify our ability to safely test structures under combined fire and mechanical loading; including shakedown of the instrumentation, data acquisition system, and loading and safety systems. Lessons learned during commissioning provided the basis for operational procedures for the NFRL.

The outcome of the Phases I and II commissioning is summarized in Section 1.2. The remainder of this report presents the Phase III NFRL commissioning. 


\section{$1.2 \quad$ NFRL STRUCTURAL FIRE TESTING CAPABILITIES}

The laboratory expansion features a strong floor, a strong wall, a compartmented basement, a hydraulic loading system, an exhaust hood along with a fire calorimetry system, an emission control system (ECS), controlled gas and liquid fuel burners, water suppression systems, overhead cranes and a specimen conditioning space.

Fig. 1-1 presents a cross-sectional view of the laboratory, and Fig 1-2 shows a photograph of the newly constructed structural-fire testing area. The strong-floor is $1.2 \mathrm{~m} \mathrm{(4ft)} \mathrm{thick,} 18.3 \mathrm{~m} \mathrm{(60 \textrm {ft } )}$

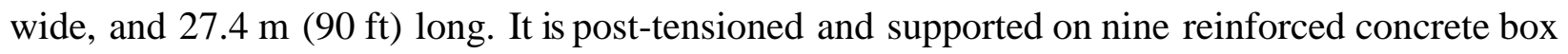
girders spaced at $3.0 \mathrm{~m}(10 \mathrm{ft})$ on-center. The basement ceiling height is $2.7 \mathrm{~m}(9 \mathrm{ft})$. The strong floor has a total of 1218 anchor points spaced on a $0.61 \mathrm{~m} \times 0.61 \mathrm{~m}(2 \mathrm{ft} \times 2 \mathrm{ft})$ grid. The sleeves that form the anchor points have an inside diameter of $76 \mathrm{~mm}$ (2.9 in). Each anchor point has an allowable tension capacity of $445 \mathrm{kN}$ (100 kips), an allowable shear capacity of $222 \mathrm{kN}$ (50 kips) at the top of the slab, and an allowable moment capacity of $136 \mathrm{kN}-\mathrm{m}$ (100 ft kips) at the center of gravity of the strong floor.

\section{Smoke capture hood to ECS Strong wall Overhead crane}

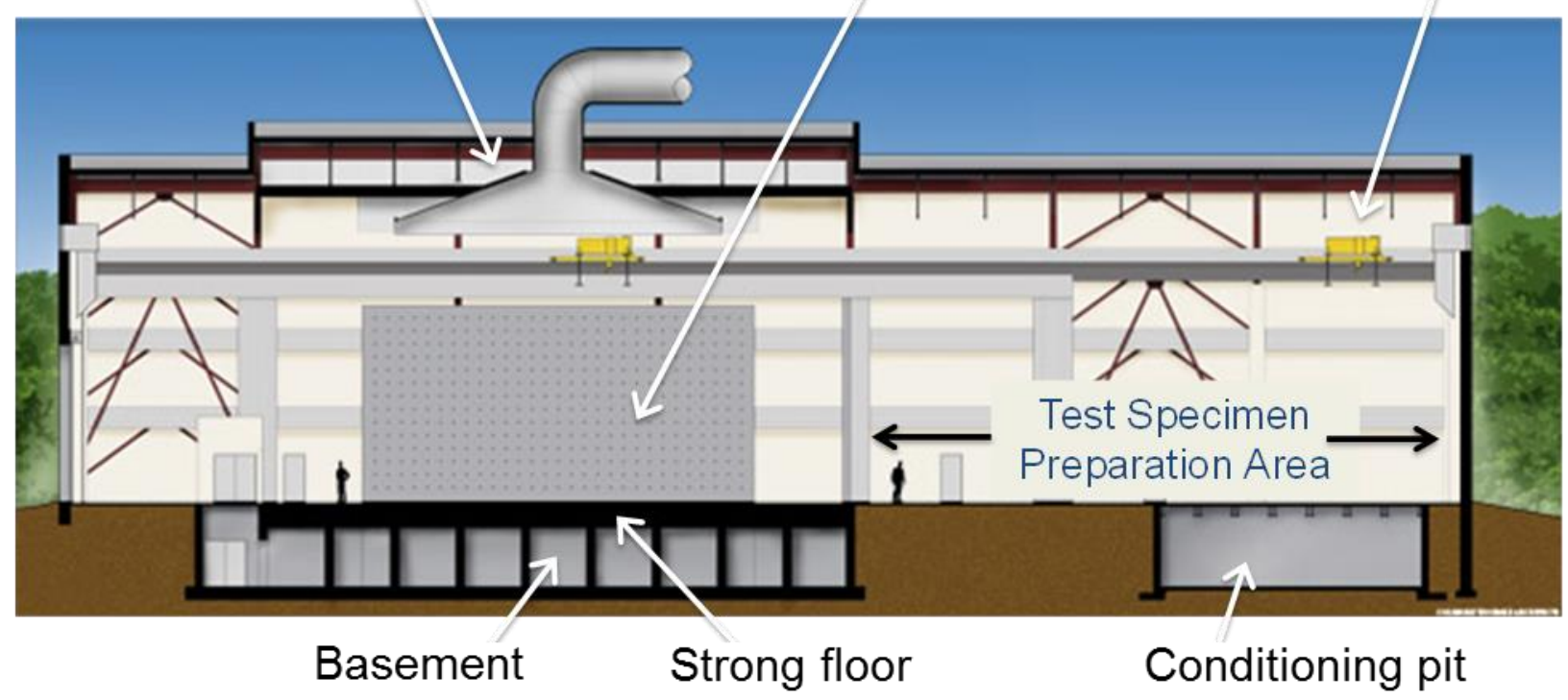

Figure 1-1 Cross-sectional view of expanded NFRL. 


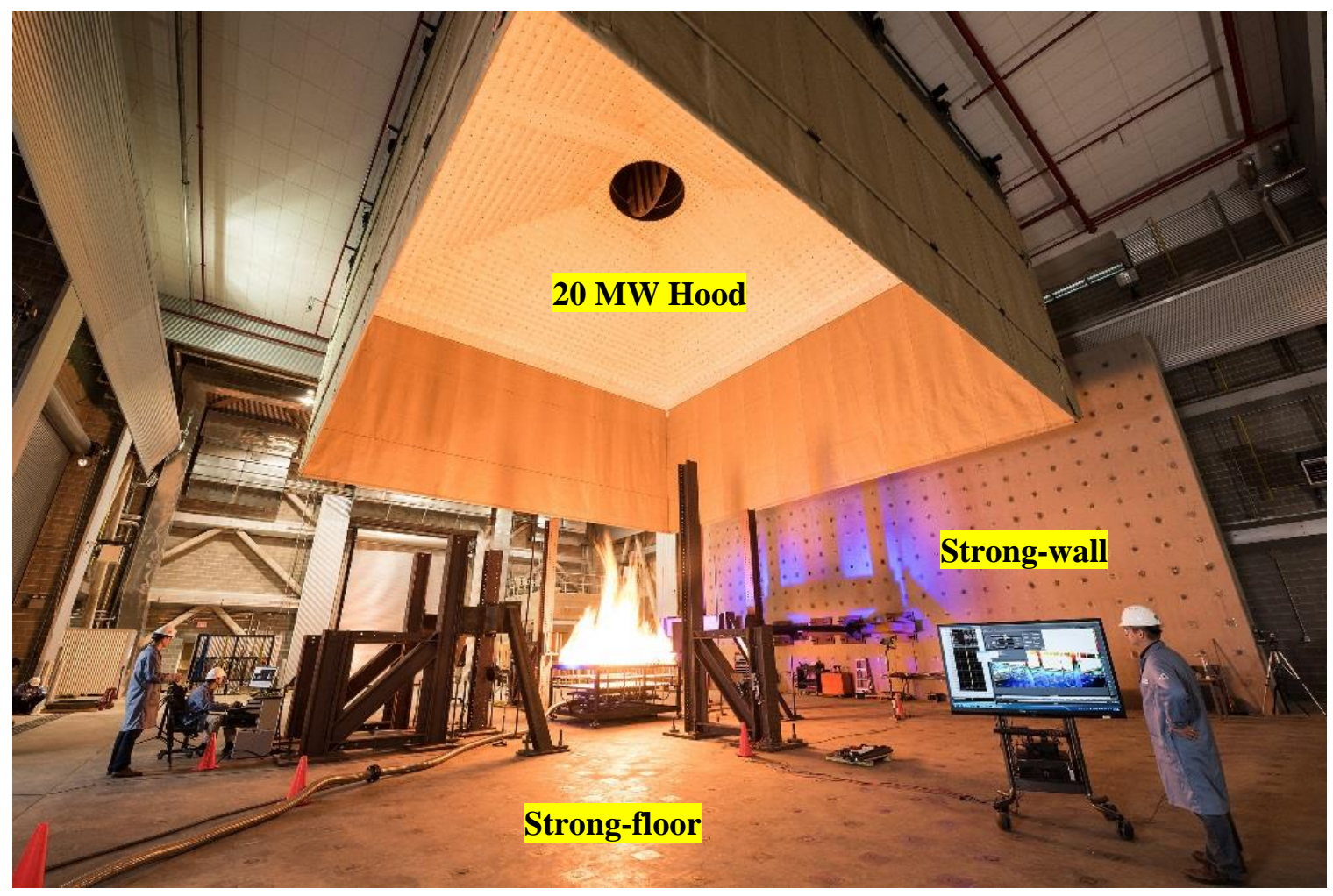

Figure 1-2 Photograph of the testing area showing the strong floor, strong wall, and hood.

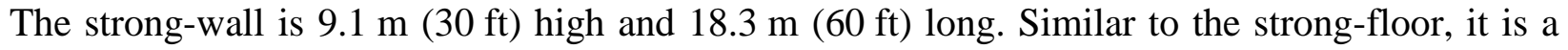
$1.2 \mathrm{~m}(4 \mathrm{ft})$ thick post-tensioned concrete element, and is located along the edge of the strong-floor (see Figs 1-1 and 1-2). It has a total of 420 anchor points, also spaced on a $0.61 \mathrm{~m} \times 0.61 \mathrm{~m}$ $(2 \mathrm{ft} \times 2 \mathrm{ft})$ grid. The strong-wall provides lateral support for test specimens and facilitates the application of lateral loads to simulate forces resulting from events such as earthquakes or wind. The wall has a horizontal load capacity of $146 \mathrm{kN} / \mathrm{m}$ (10 kips per linear ft) at a height of $9.1 \mathrm{~m}$ $(30 \mathrm{ft})$ above the strong floor.

The laboratory is equipped with a hydraulic loading system which consists of a $340 \mathrm{~L} / \mathrm{min}$ (90 GPM) hydraulic power unit, manifolds and controller, and double-acting actuators with $762 \mathrm{~mm}$ (30 in) total stroke. The actuators include: eight hydraulic actuators with a capacity of $240 \mathrm{kN}$ (55 kip) in tension and $365 \mathrm{kN}$ (80 kip) in compression, two actuators with a capacity of $445 \mathrm{kN}$ (100 kip) tension and $650 \mathrm{kN}$ (145 kip) compression; and two actuators with a capacity of $956 \mathrm{kN}$ (215 kip) in tension and $1470 \mathrm{kN}$ (330 kip) in compression. To protect the hydraulic actuators from fire, stiff steel frames (yokes) are used to mount the actuators to the ceiling of the basement, as shown in Fig. 1-3. The yokes attach to the anchor points of the basement's ceiling (the bottom of the strong floor), where the actuators can be used to pull down, through the anchor points, on the structural specimens placed on the strong-floor. 


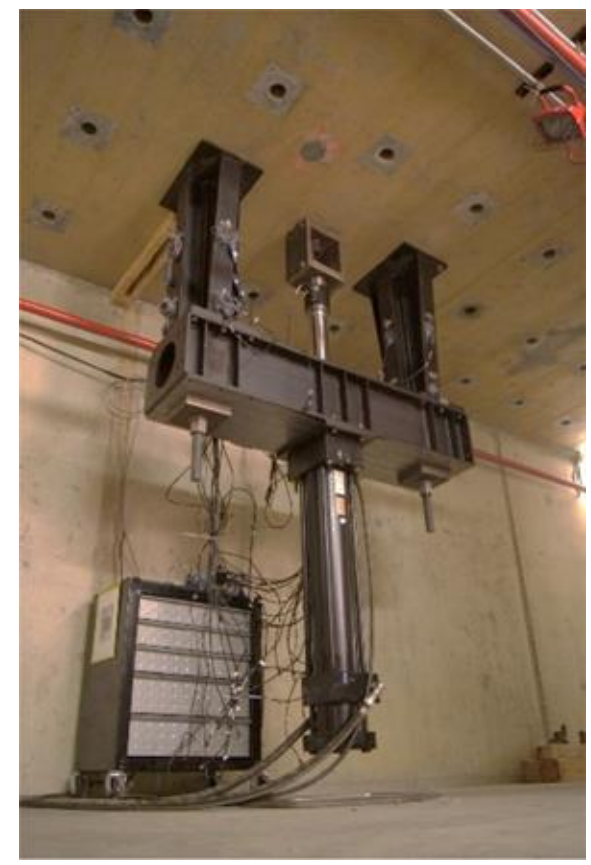

Figure 1-3 Actuator mounted on yoke located in basement underneath strong floor.

The laboratory fire suppression system consists of eight fire monitor nozzles and an overhead deluge sprinkler system that can deliver up to $11350 \mathrm{~L} / \mathrm{min}$ (3000 GPM) water. The fire monitor nozzles are aimed at the test space below the exhaust hood. While conducting an experiment, the deluge suppression system can be activated using manual pull stations. Infrared flame detectors and linear beam smoke detectors are used to automatically activate the deluge suppression system in the event of an unplanned fire.

An insulated steel hood that is $15.2 \mathrm{~m}(50 \mathrm{ft})$ long and $13.7 \mathrm{~m}(45 \mathrm{ft})$ wide is located $12.5 \mathrm{~m} \mathrm{(41} \mathrm{ft)}$ (excluding skirts) above the strong-floor. The hood captures the fire effluents and allows for the measurement of the heat release rate. It is equipped with retractable side skirts that can be lowered

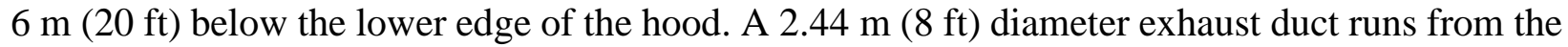
hood horizontally across the roof where an instrumentation station measures gas concentrations $\left(\mathrm{CO}_{2}, \mathrm{CO}, \mathrm{O}_{2}\right)$, temperature, and velocity, from which the heat release rate can be determined. The system is designed to withstand a $20 \mathrm{MW}$ fire for a duration up to four hours.

The smoke and combustion by-products are processed using an after-burner, acid-gas spray dryer absorber (SDA), and a bag house rated at a maximum flow of $5100 \mathrm{~m}^{3} / \mathrm{min}(180000 \mathrm{CFM})$. Four $186 \mathrm{~kW}(250 \mathrm{HP})$ induced draft fans are used to generate the required exhaust flow. Fresh make up air is supplied to the lab through 12 intake vents that can be independently controlled. These vents are located around the perimeter of the laboratory near the ceiling. The emissions control system (ECS) is capable of treating $5.4 \mathrm{~kg} / \mathrm{h}$ of hydrochloric acid gas and removing $180 \mathrm{~kg} / \mathrm{h}$ of 
particulate soot. Natural gas burners, designed to provide a dynamically-controlled flow of natural gas are used to generate the fire loads (see Fig. 1-2).

Two bridge cranes, each with a capacity of 18.1 metric tons (20 ton) are located $11.2 \mathrm{~m}$ (36 ft-8 in)

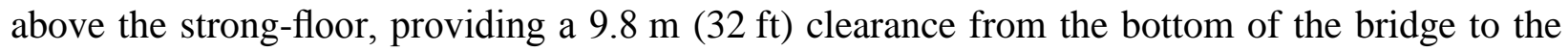
floor. The lab also has a $12.2 \mathrm{~m}$ (40 ft) long, $11.0 \mathrm{~m}$ (35 ft) wide, and $3 \mathrm{~m} \mathrm{(10} \mathrm{ft)} \mathrm{deep} \mathrm{specimen}$ conditioning pit, where concrete specimens can be dried under controlled temperature and humidity conditions. The removable panels forming the ceiling of the pit are an integrated part of the lab's floor, thus specimens can be stored in the pit for curing without impacting operating floor space (see Fig. 1-1).

\subsection{NFRL COMMISSIONING TEST SERIES}

The main objective of the Phase III NFRL commissioning tests was to verify the structural-fire testing and measurement capabilities in the new NFRL structural fire test bay. The Phase III commissioning consisted of a series localized fire tests on $6.2 \mathrm{~m}$ span structural steel beams with W16x26 section made of ASTM A992 steel (ASTM (2012)).

The test series were divided into two parts: (i) thermal tests and (ii) structural-fire tests. The thermal tests measured the thermal responses of the steel beam specimen exposed to localized fire with controlled heat release rates (HRR). No mechanical load was applied except the self-weight of the beam specimen. The structural-fire test was conducted such that the flexural loads and the fire were applied to the midspan (i.e., expected plastic hinge zone) of the specimen to measure the behavior and the flexural strength of the specimens. Each specimen was supported by steel columns using one of two beam-to-column connection types: (a) a seated connection simulating simply-supported boundary conditions, and (b) a bolted double-angle connection. The data produced from the tests were used for validation of the computational models developed by Zhang et al. (2017).

\section{$1.4 \quad$ REPORT OUTLINE}

This report presents the NFRL commissioning tests on steel beams subjected to localized fire exposure. The outline of the report is as follows:

- Chapter 2 describes the experimental design of the localized fire tests on steel beams, including structural loading test setup, fuel delivery system, test matrix, specimen design, and measurement and data acquisition system. 
- Chapter 3 presents the thermal tests on the identical W16x26 beam specimen subjected to localized fire produced by natural gas burners. Test results included thermal responses and fire-induced displacements of the simply-supported beam specimen.

- Chapter 4 presents the four-point bending tests that were conducted on the W16×26 beam specimens at room-temperature and localized, open flame fire exposure to their critical sections using natural gas burners. Test results included both thermal and structural responses. The effects of the beam end restraints on the fire behavior of the beam specimens were also measured.

- Chapter 5 provides a summary and conclusions of the report. 


\section{Chapter 2 \\ EXPERIMENTAL DESIGN}

\section{$2.1 \quad$ TEST SETUP}

\subsubsection{Structural Steel Frames}

Fig. 2-1 shows a rendering of the test setup which was erected under the $20 \mathrm{MW}$ exhaust hood in the high bay of the NIST National Fire Research Laboratory. The setup consisted of a W16×26 beam specimen, two loading beams made of hollow structural section (HSS), and a system of columns, connections, and braces that served to support and restrain the specimen. The components of structural steel frames were designed and fabricated in accordance with the American National Standards Institute (ANSI) - American Institute of Steel Construction (AISC) standard ANSI/AISC-360 (2010). The beam specimen was supported by the W12×106 columns. The column displacements in the direction of the strong axis were restrained by bracing modules $1.83 \mathrm{~m}$ high by $1.83 \mathrm{~m}$ wide. The bases of supporting columns and brace modules were fixed to the laboratory strong-floor by tensioning high-strength steel anchor rods to approximately $445 \mathrm{kN}$ each. Fig. 2-2 shows a photograph of the test setup.

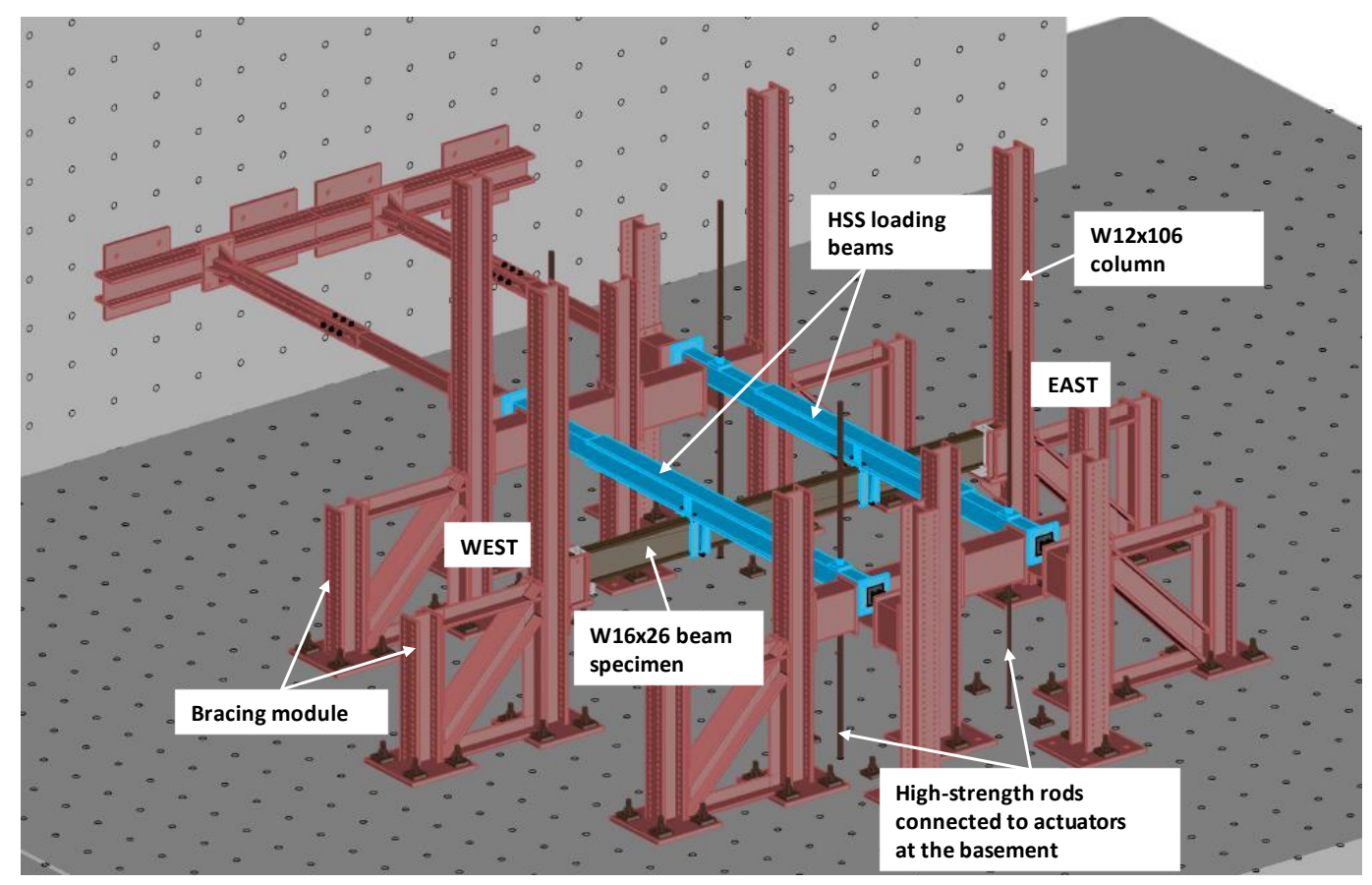

Figure 2-1 Rendering of test setup. 


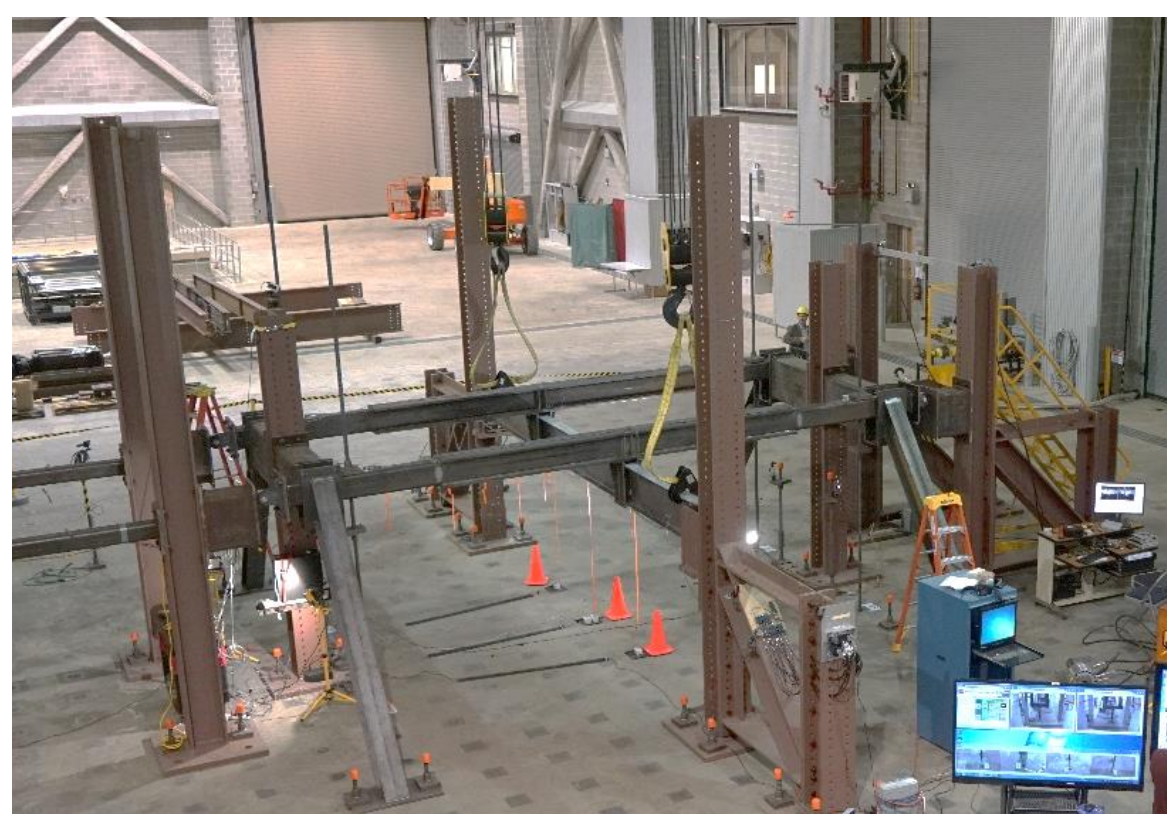

Figure 2-2 Photograph of as-built test setup.

Two pairs of hydraulic actuators were used to apply mechanical loads to the beam specimen. To protect the actuators from the fire, two $6.7 \mathrm{~m}$-long HSS loading beams with roller bearings were fabricated to span across the top of the specimen in the heated zone. Each end of the loading beams was connected to a hydraulic actuator (four total), which was mounted underneath the strong floor on a yoke (Fig. 2-3). High-strength steel rods were used to connect the loading beams and the actuators. The rods passed through steel sleeves inside the loading beam near its two ends. Couplers (Fig. 2-3) were used to connect the opposite ends of rods (below the strong floor) to the actuators. The connections of the steel rods to the loading beams and actuators were designed to approximate pinned connections. The loading beams were guided by steel frames to allow movement in the vertical direction only. To minimize friction, roller bearings and ball bearing plates were mounted at the end plates and two sides of each loading beam end (Fig. 2-4). During the fire tests, the loading beams were cooled by flowing water through them. Detailed drawings of the beam test setup, specimens, and connections are presented in Appendix A. 


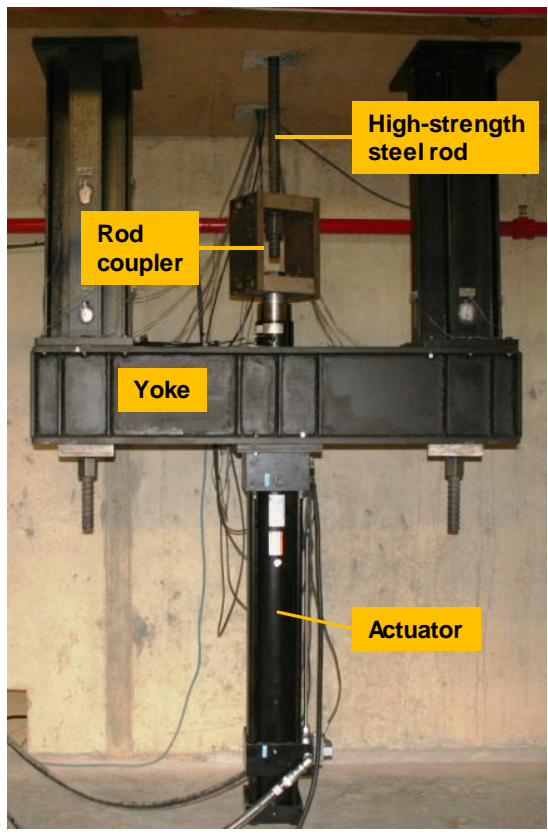

(a)

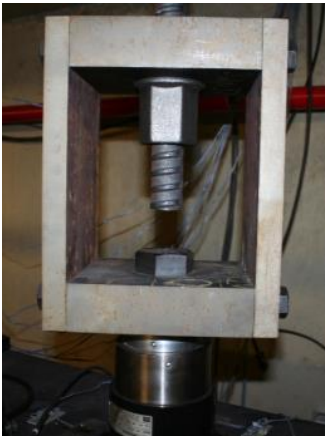

(b)

Figure 2-3 Actuator mounted underneath the strong floor and (b) detail of rod coupler.

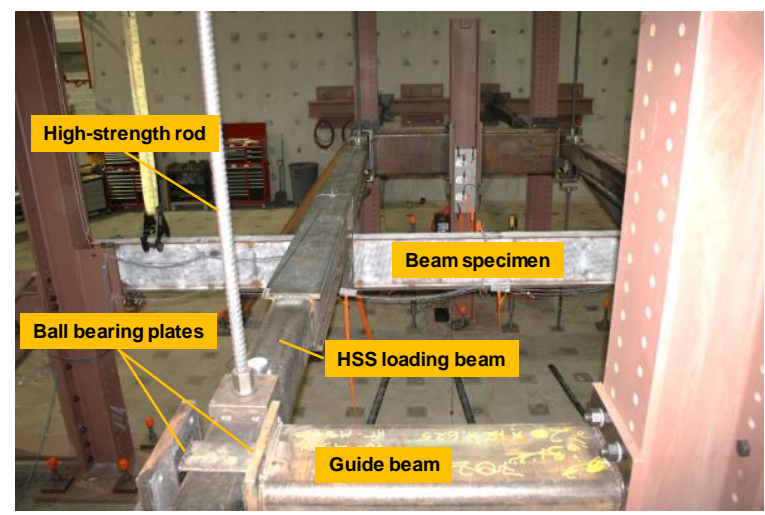

(a)

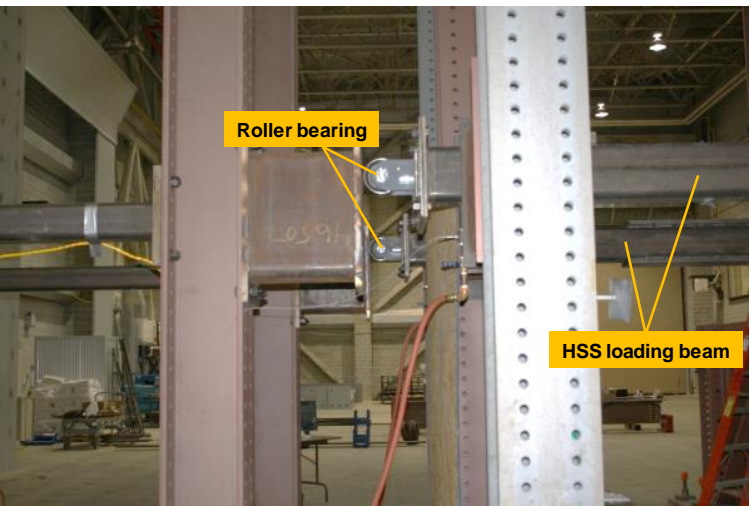

(b)

Figure 2-4 Top view and (b) side view of HSS loading beams. 


\subsubsection{Hydraulic Loading System}

A total of four double-acting hydraulic actuators (201.35T model, manufactured by MTS Systems Corporation) were used to apply the mechanical loads to the beam specimen using either forcecontrol or displacement-control. Each actuator was integrated with MTS 661.22D-01 load cell for force measurement. The maximum tensile and compressive force capacities are $240 \mathrm{kN}$ and $365 \mathrm{kN}$, respectively. Each actuator has the maximum stroke (displacement) of $760 \mathrm{~mm}$ and has a built-in position sensor for displacement measurements. MTS software was used to control the actuators, monitor the force and displacement measurements, and record the measurements. Those measurements were also transferred to the NFRL in-house data recording software in real-time during the test.

\subsubsection{Natural Gas Burner and Fuel Delivery System}

The fire was controlled using a diffusion burner supplied by a natural gas fuel delivery system. The gas flow was controlled using a computer controller pneumatic valve. The gas mass flow rate was measured using a positive displacement rotary flow meter, pressure gauge and thermistor. The energy value of the natural gas was determined from historical average values of gas composition from gas chromatograph measurements in previous years. The gas composition was not measured for these experiments.

The burner was made from two stainless steel sheet metal boxes measuring $0.5 \mathrm{~m}$ by $1 \mathrm{~m}$ in plan each. The fuel inlet tube was located at the bottom of the burner box. Steel mesh screens were used to keep the blanket in place. A detailed drawing of the burner design is shown in Fig. 2-5. The burner boxes were assembled so that there was a $25 \mathrm{~mm}$ gap between the two boxes to allow room for displacement measurements as presented in Section 2.3.

As shown in Fig. 2-6, the burner with the nominal area of $1 \mathrm{~m}^{2}$ was located at the midspan of the specimen on the floor. The burner is placed at $1.1 \mathrm{~m}$ below the lower flange of the specimen. The distance from the centroid of the beam cross section to the strong floor was $1.8 \mathrm{~m}$. 


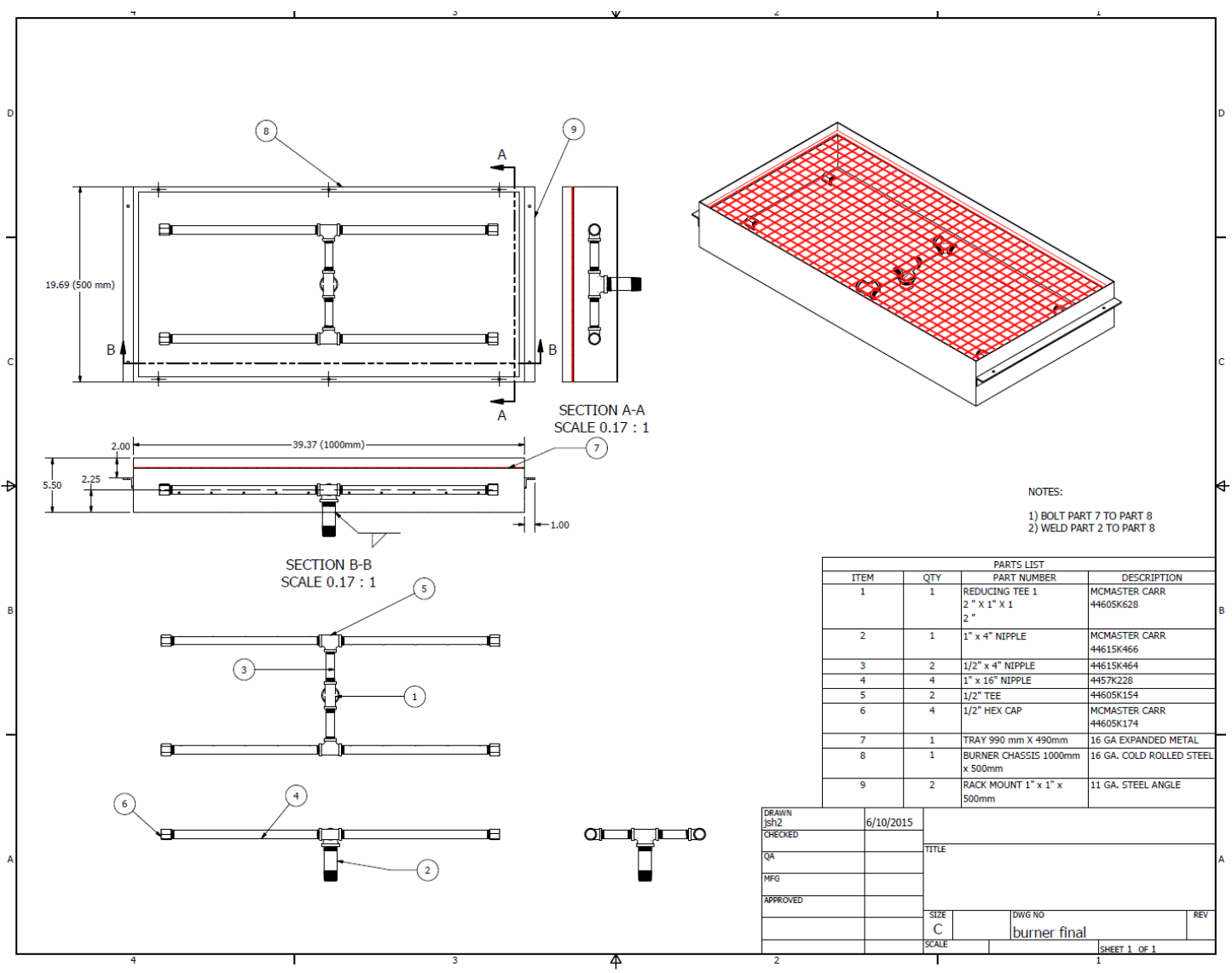

Figure 2-5 Detailed drawing of gas burner assembly.

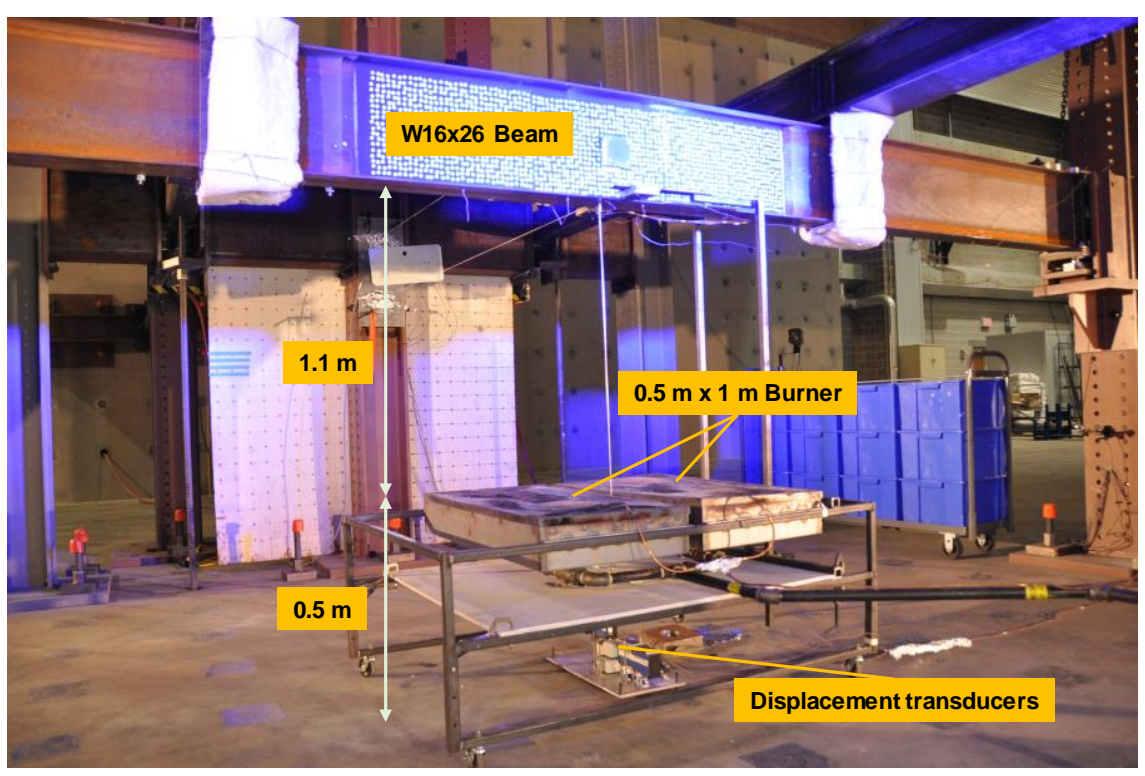

Figure 2-6 Photograph of burner in the test setup. 


\section{$2.2 \quad$ TEST MATRIX, SPECIMENS, LOADING CONFIGURATIONS}

\subsubsection{Test Matrix}

Table 2-1 shows the test matrix including nine tests on the $6.17 \mathrm{~m}$-long W16×26 structural steel beam specimens with varying beam support conditions, structural loads, and fire. The first five tests were the thermal tests conducted on the same specimen (Specimen 1) which was exposed to a natural gas fire at its midspan. No mechanical load was applied except the self-weight of the specimen. Two different fire conditions were considered. In Tests 1 and 2, the heat release rate (HRR) of the burner was increased in increments of $100 \mathrm{~kW}$ until any of thermocouples installed at the specimen indicated a temperature of $500{ }^{\circ} \mathrm{C}$. Tests 3 through 5 were conducted such that the burner HRR was set to $400 \mathrm{~kW}$ throughout the test until the maximum temperature measured by a thermocouple reached $500{ }^{\circ} \mathrm{C}$. The test results were used to evaluate the repeatability of the fire tests and uncertainty in the temperature and displacement measurements of the beam specimens.

The test matrix also included the room-temperature beam test (Test 6) on Specimen 2. This test was designed (i) to commission the steel reaction frames and the hydraulic loading system and (ii) to measure the room-temperature behavior and strength of the beam specimen as a baseline to compare with data from the structural-fire tests.

Tests 7 through 9 were the structural-fire beam tests where the beam specimens were subjected to mechanical load and localized fire exposure simultaneously. The locations of mechanical loads, i.e., the locations of HSS loading beams, on the specimen were identical to those used in Test 6 (room-temperature test). The burner location relative to the beam specimen remained unchanged from the thermal-only tests (Test 1 to 5). Test variables included the end supports of the beam specimens (simply-supported boundary condition versus bolted double-angle connections) and time-dependence of the burner HRR (constant HRR versus time-varying HRR). In Tests 7 and 8, the beam specimens were simply supported; Test 9 used bolted double-angle connections. Test 7 was a steady-state fire test in which the structural loads were increased to failure of the beam specimen exposed to a 700-kW fire at its midspan. Both Tests 6 and 7 used the loading rate of individual actuators set to $1.45 \mathrm{kN} / \mathrm{min}$. Tests 8 and 9 were transient-state fire tests where the fire intensity and the specimen temperature were increased to failure of the beam specimens which was loaded to $67 \%$ of their room-temperature capacity throughout the test. In those two tests, the burner HRR was increased following a quadratic relationship with time ( $t$-squared fire). The timedependent function of the burner HRR was designed so that the beam specimen was exposed to a growing fire for about $30 \mathrm{~min}$ prior to its failure. It should be noted that the $t$-squared fire used in the tests were intended for verification of measurement and testing apparatus and for producing the data necessary for validation of computational models developed by Zhang et al (2017). 
Table 2-1 Test matrix.

\begin{tabular}{|c|c|c|c|c|c|c|}
\hline $\begin{array}{l}\text { Test } \\
\text { No. }\end{array}$ & $\begin{array}{l}\text { Specimen } \\
\text { No. }\end{array}$ & Test Date & $\begin{array}{l}\text { Beam end } \\
\text { support }\end{array}$ & $H R R-t^{a}$ relationship & $P / P_{u}^{b}$ & Note \\
\hline 1 & 1 & $08 / 12 / 2015$ & $\begin{array}{c}\text { Simply- } \\
\text { supported }\end{array}$ & $\begin{array}{c}100 \mathrm{~kW} \text { increments at every } \\
t=5 \mathrm{~min}\end{array}$ & - & \\
\hline 2 & 1 & $08 / 14 / 2015$ & $\begin{array}{l}\text { Simply- } \\
\text { supported }\end{array}$ & $\begin{array}{c}100 \mathrm{~kW} \text { increments at every } \\
t=5 \mathrm{~min}\end{array}$ & - & $\begin{array}{l}\text { Repeated test of } \\
\text { Thermal Test } 1\end{array}$ \\
\hline 3 & 1 & $08 / 26 / 2015$ & $\begin{array}{l}\text { Simply- } \\
\text { supported }\end{array}$ & $400 \mathrm{~kW}$ & - & \\
\hline 4 & 1 & $08 / 26 / 2015$ & $\begin{array}{l}\text { Simply- } \\
\text { supported }\end{array}$ & $400 \mathrm{~kW}$ & - & $\begin{array}{l}\text { Repeated test of } \\
\text { Thermal Test } 3\end{array}$ \\
\hline 5 & 1 & $08 / 27 / 2015$ & $\begin{array}{l}\text { Simply- } \\
\text { supported }\end{array}$ & $400 \mathrm{~kW}$ & - & $\begin{array}{l}\text { Repeated test of } \\
\text { Thermal Test } 3\end{array}$ \\
\hline 6 & 2 & $01 / 14 / 2016$ & $\begin{array}{l}\text { Simply- } \\
\text { supported }\end{array}$ & - & 1 & $\begin{array}{l}\text { Room-temperature } \\
\text { beam test }\end{array}$ \\
\hline 7 & 3 & 03/03/2016 & $\begin{array}{l}\text { Simply- } \\
\text { supported }\end{array}$ & $700 \mathrm{~kW}$ & 0.67 & $\begin{array}{l}\text { Steady-state fire } \\
\text { test }\end{array}$ \\
\hline 8 & 4 & $05 / 11 / 2016$ & $\begin{array}{l}\text { Simply- } \\
\text { supported }\end{array}$ & $\begin{array}{c}\left(4.5 \cdot t^{2}+250\right) \mathrm{kW} \\
\mathrm{kW}\end{array}$ & 0.67 & $t$-squared fire test \\
\hline 9 & 5 & $05 / 18 / 2016$ & $\begin{array}{c}\text { Bolted } \\
\text { double-angle }\end{array}$ & $\begin{array}{c}\left(4.5 \cdot t^{2}+250\right) \mathrm{kW} \leq 1600 \\
\mathrm{~kW}\end{array}$ & 0.67 & $t$-squared fire test \\
\hline
\end{tabular}

\subsubsection{Beam Specimens}

(i) Dimensions

Fig. 2-7 shows the dimensions of the W16×26 beam specimens. The beam specimens were cut to a length of $6.17 \mathrm{~m}$. No fire protection was applied. No stiffeners were welded to the Specimen 1. To prevent the local failure of the beam cross sections where the forces were applied, Specimens 2 through 4 had $0.63-\mathrm{cm}$ thick steel bearing stiffeners welded to the beam cross sections at four different locations along the length. The HSS loading beam was placed at the location of intermediate stiffeners which were $243.8 \mathrm{~cm}$ apart. The Specimens 2 through 4 had the bearingto-bearing length of $5.87 \mathrm{~m}$, i.e. the distance between end stiffeners. Specimen 5 had intermediate stiffeners only, with bolted double-angle connections at beam ends. Drawing of the specimens are shown in Appendix A. 


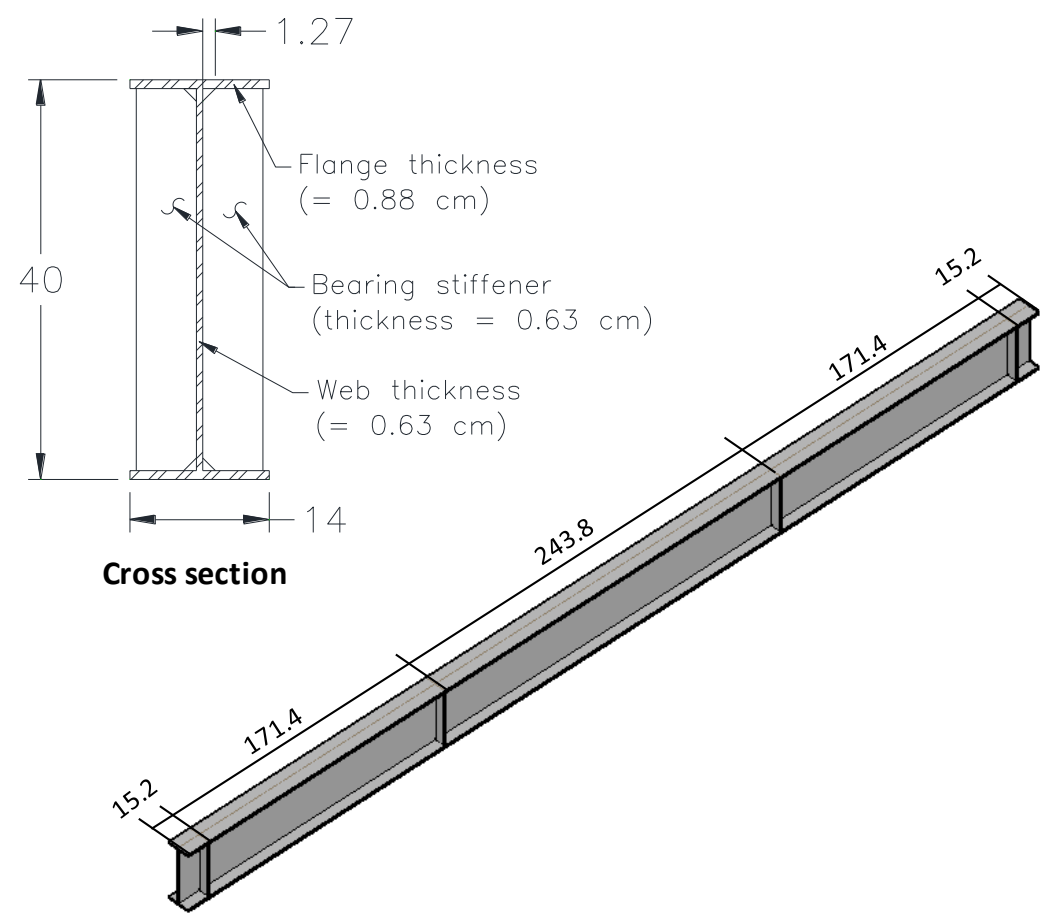

Figure 2-7 Dimensions of W16×26 beam specimen (unit: $\mathrm{cm}$ ).

(ii)

\section{Beam end supports}

The W16×26 beam specimens were attached to supporting columns using one of two connection types. For Tests 1 through 8, a seated connection (Fig. 2-8) was used for simulating simplysupported boundary conditions. With this connection type, both the rotation about the longitudinal axis of the beam (i.e. twisting) and the lateral displacement were restrained at the ends. Under fire, structural loading, or both, the beam ends were free to rotate about the principal axes of the cross section and freely elongated or shortened. As shown in Fig. 2-8, a 220-kN load cell was installed at each of two ends of the beam specimen to measure the vertical reaction forces during Tests 6 through 8 . The bearings were greased to minimize the friction in contact areas. 


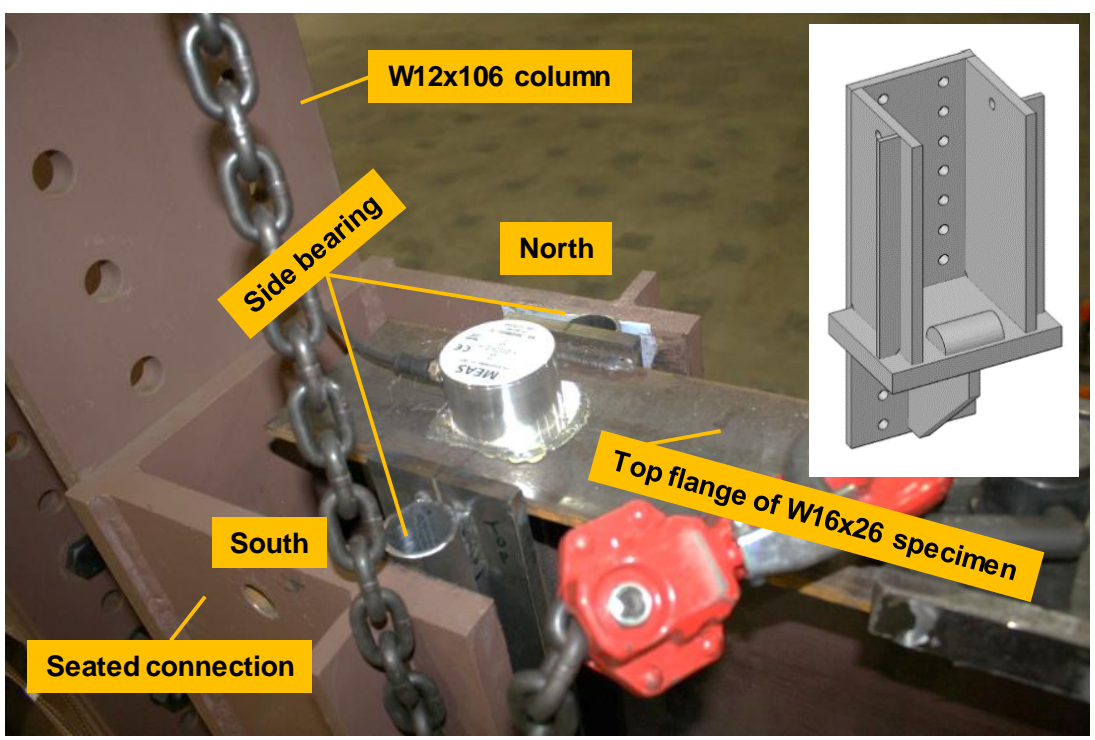

(a)

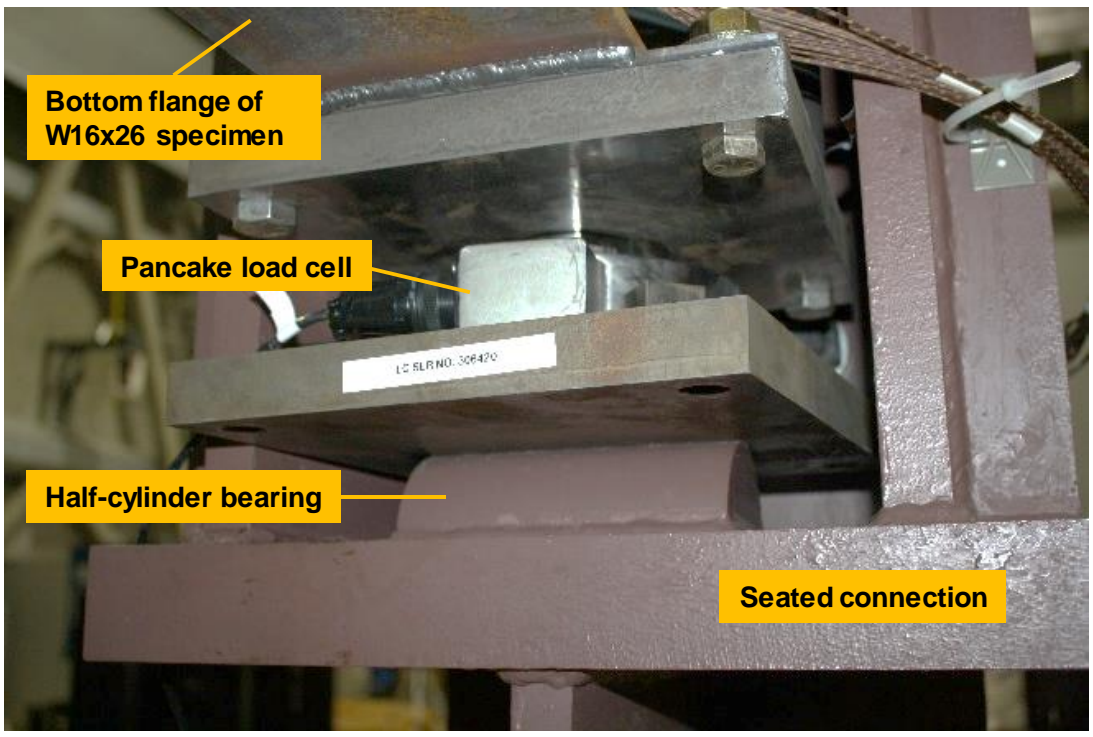

(b)

Figure 2-8(a) Top view and (b) bottom view of seated connection.

The connection type used in Test 9 was an all-bolted double-angle connection, one of the common shear connection types used in steel frame buildings, to provide the axial restraint to thermal elongation of the beam specimen. There was no additional side bearing installed to provide the lateral constraints at the beam ends in the north-south direction. Refer to Fig. 2-9(a) for a photograph of the double-angle connection provided at the end of the beam. The bolted doubleangle shear connection was designed in accordance with ANSI/AISC 360 (2010) for a 6.2-m long W16×26 girder to resist the factored gravity loads using the load combination prescribed in the American Society of Civil Engineers (ASCE) standard Minimum design loads for buildings and 
other structures (ASCE, 2016). The service loads assumed for the design included the self-weight of the steel beam, a superimposed dead load of $480 \mathrm{~Pa}$ (10 psf), and a live load of $3350 \mathrm{~Pa}$ (70 psf) for a typical office building. The dimensions of the connection are shown in Fig. 2-9(b). A 229mm long double-angle with L5×5×5/16 section and three 19-mm diameter ASTM A325 bolts (ASTM, 2010) spaced at $76 \mathrm{~mm}$ was designed for the test specimen.

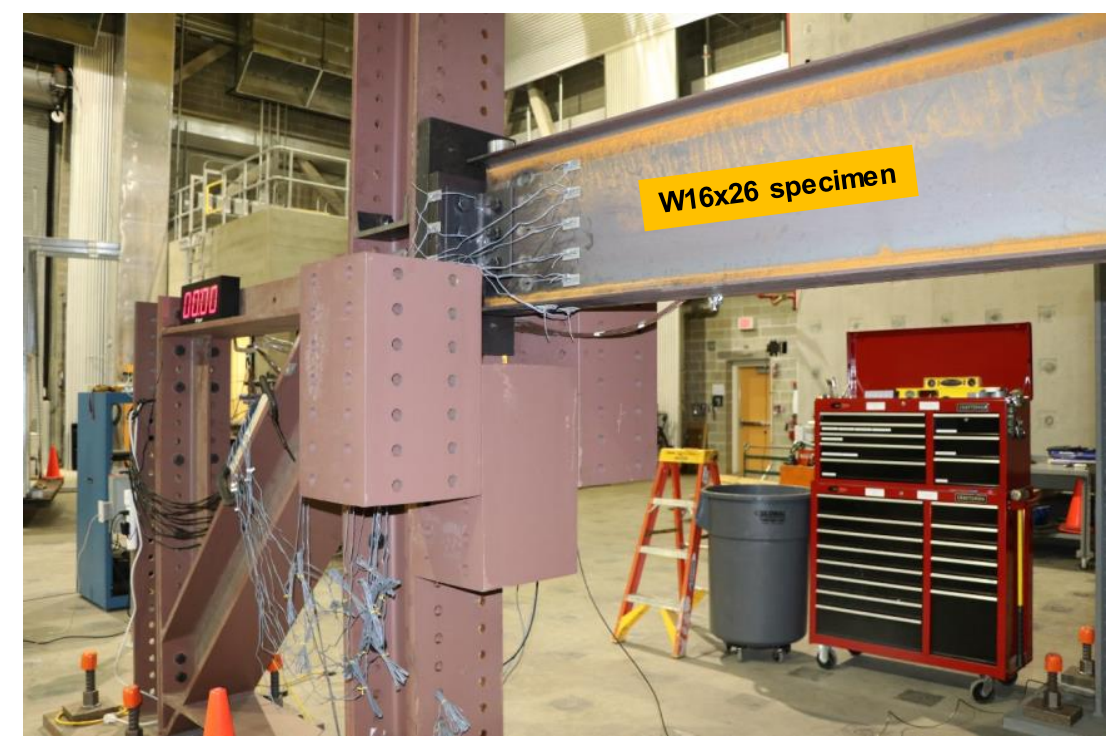

(a)

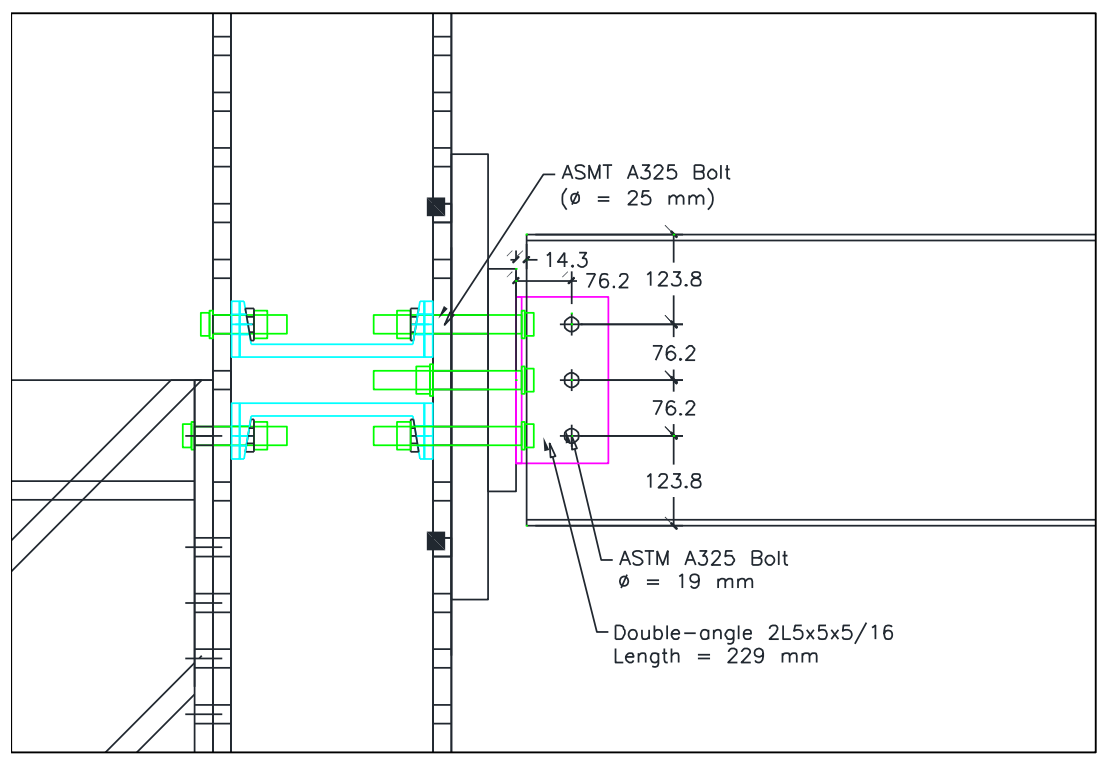

(b)

Figure 2-9 (a) Photograph of Specimen 5 and (b) details of all-bolted double-angle connection. 


\section{(iii) Structural loading arrangements}

The four-point flexural loading scheme was designed such that two point loads were simultaneously applied at $2.44 \mathrm{~m}$ apart around the midspan of the beam. As described in Section 2.1.1 and Fig. 2-10, the vertical point loads were provided by actuators via the HSS loading beams. The magnitude of each point load $(P)$ was the summation tensile forces $(F)$ provided by two connected actuators and the weight of single HSS loading beam assembly $(w)$. Table 2-2 summarizes the measured weight of each component used in the tests. Note that weight listed in Tests 7 and 8 included the weight of water $\left(w_{\text {water }}\right)$ flowing through HSS loading beams. The magnitude of $w_{\text {water }}$ included in Tests 7 and 8 was $3.9 \mathrm{kN}$ and $3.2 \mathrm{kN}$, respectively. A resulting moment over the middle portion of the beam specimen between two-point loads is theoretically uniform if the effects of moment due to the self-weight of the specimen, $2.43 \mathrm{kN}$, are ignored.

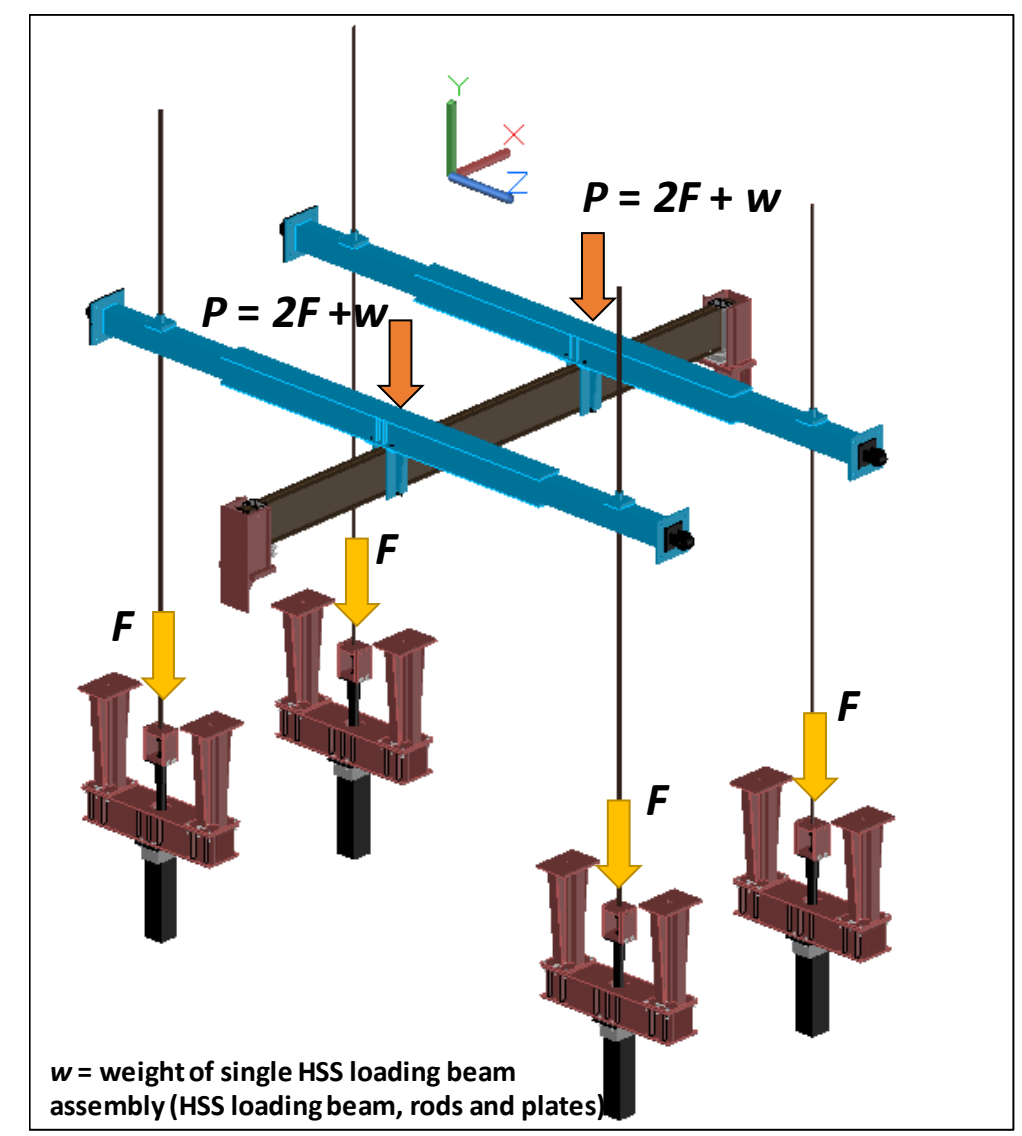

Figure 2-10 Structural loading arrangement. Strong floor, supporting columns, braces, and guide frames are not shown here. 
Table 2-2 Weight of two HSS loading beam assemblies $(2 w)$ placed on the top of the beam specimen.

\begin{tabular}{cc}
\hline Test No. & $\mathbf{2 w}(\mathbf{k N})$ \\
\hline 6 & 27 \\
7 & 31 \\
8 & 30 \\
\hline
\end{tabular}

(iv) Material properties at ambient temperature

All the W16×26 beam specimens presented in this report were fabricated from the same heat of steel. Tensile coupon tests were conducted by following the ASTM E8 specification (ASTM, 2016) to measure the room-temperature mechanical properties. A total of sixteen flat tensile "dogbone" specimens with standard gauge length of $200 \mathrm{~mm}$ were cut and machined in accordance of ASTM E8. Table 2-3 summarizes the test results of eight specimens each cut from the web and flange.

Table 2-3 Results of ASTM coupon tests.

\begin{tabular}{ccccc}
\hline Specimen & $\begin{array}{c}\text { Young's } \\
\text { modulus (GPa) }\end{array}$ & $\begin{array}{c}\text { Yield strength } \\
\text { (MPa) }\end{array}$ & $\begin{array}{c}\text { Tensile strength } \\
\text { (MPa) }\end{array}$ & Elongation (\%) \\
\hline B1-.2501-1 & 191.7 & 395.6 & 487.7 & 27.0 \\
B1-.250-2 & 206.8 & 451.9 & 509.2 & 22.0 \\
B1-.250-3 & 205.5 & 447.3 & 520.2 & 24.0 \\
B1-.250-4 & 194.4 & 441.6 & 501.0 & 24.0 \\
B2-.250-1 & 206.2 & 390.0 & 473.6 & 26.0 \\
B2-.250-2 & 168.9 & 390.1 & 464.7 & 29.0 \\
B2-.250-3 & 213.7 & 374.9 & 467.9 & 27.0 \\
B2-.250-4 & 236.5 & 374.9 & 463.2 & 28.0 \\
B1-.31252-1 & 197.9 & 367.8 & 478.8 & 28.0 \\
B1-.3125-2 & 219.3 & 384.3 & 479.9 & 29.0 \\
B1-.3125-3 & 184.8 & 384.6 & 482.8 & 30.0 \\
B1-.3125-4 & 206.8 & 374.0 & 473.3 & 27.0 \\
B2-.3125-1 & 187.5 & 365.2 & 464.6 & 26.0 \\
B2-.3125-2 & 236.5 & 365.5 & 463.1 & 25.0 \\
B2-.3125-3 & 182.7 & 376.2 & 465.8 & 24.0 \\
B2-.3125-4 & 213.0 & 379.2 & 467.5 & 26.0 \\
\hline
\end{tabular}

${ }^{1}$ Thickness of the web specimen was $(6.35 \pm 1.6) \mathrm{mm}$ or $(1 / 4 \pm 1 / 16)$ inch, where values after \pm symbol indicates standard deviation.

${ }^{2}$ Thickness of the flange specimen was $(7.94 \pm 1.6) \mathrm{mm}$ or $(5 / 16 \pm 1 / 16)$ inch, where values after \pm symbol indicates standard deviation. 
The data analysis showed that Young's modulus, yield strength, and tensile strength of the beam were $(210 \pm 25) \mathrm{GPa}$, $(390 \pm 27) \mathrm{MPa}$, and $(480 \pm 18) \mathrm{MPa}$, respectively. The values after \pm symbol indicates the standard deviation.

Fig. 2-11 shows the complete room-temperature stress-strain curves of individual specimens. Fig. 2-12 shows photographs of the specimens after tests, which failed by ductile fracture with (26.4 \pm $1.2) \%$ of elongation on average. The values after \pm symbol indicates the standard deviation.
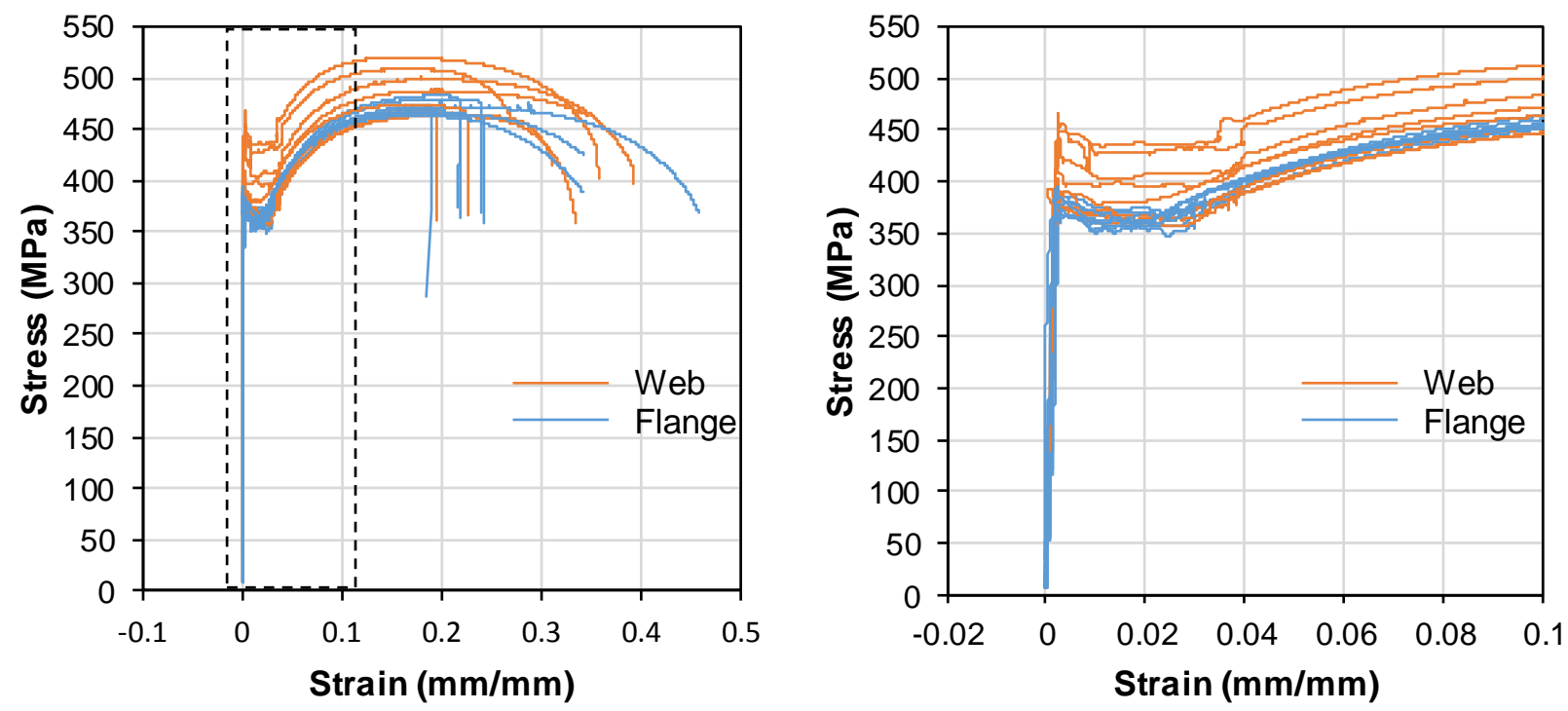

Figure 2-11 Stress-strain curves (a) showing the curves until fracture and (b) showing the initial portion of the curves until a strain of 0.1 .

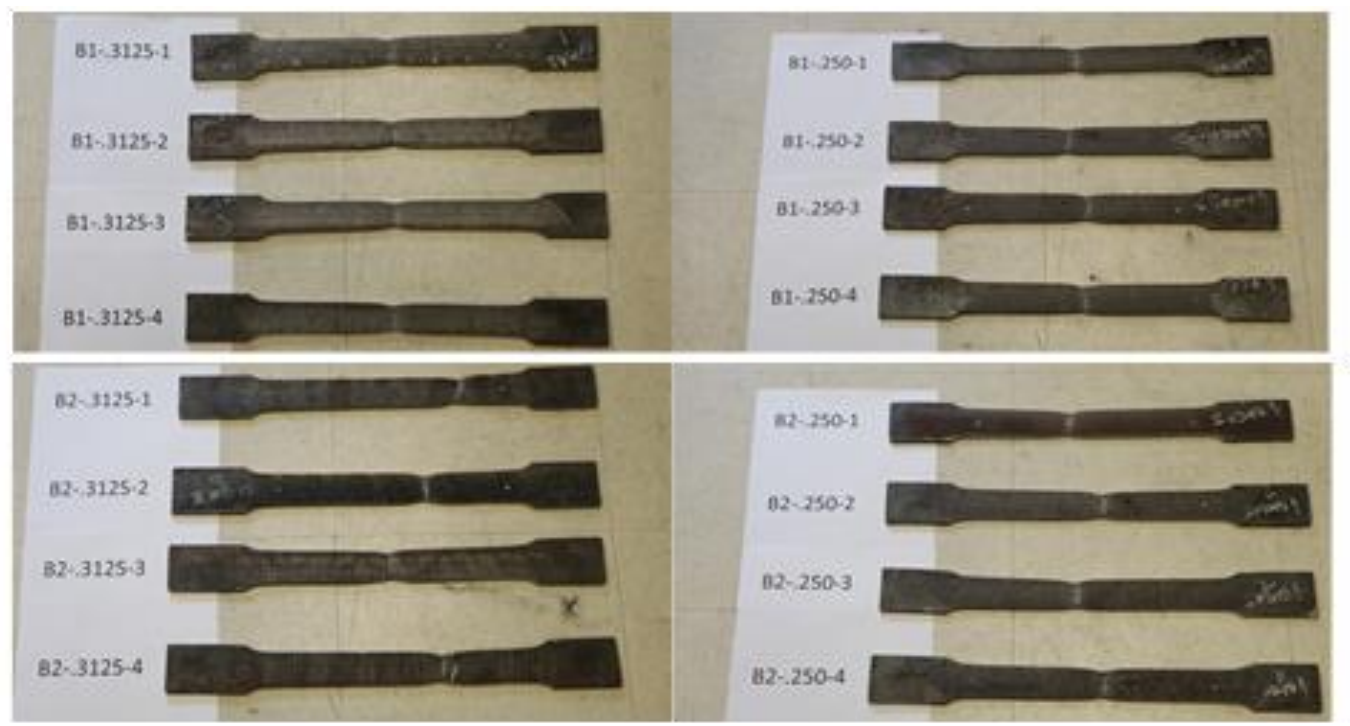

Figure 2-12 Failed tension coupons. 


\section{(v) Geometric imperfection}

Prior to the tests, a ISAT API Laser Tracker having a manufacture's specified accuracy of \pm 10 microns/meter (with two standard deviations) was used to measure the global geometric imperfections of the W16×26 beam specimen. Fig. 2-13 shows the arrangement of the beams for the camber and sweep measurements. For measuring sweep (i.e., the maximum deformation of the beam in the direction of the weak-axis of the cross section), one of the flanges rested on the floor to minimize the effect of the deflection due to the beam self-weight as shown in Fig. 2-13(a). Coordinate measurements were taken at eleven sections along the beam on each side of flanges as shown in Fig. 2-13(c). Similar procedure was followed for measuring the camber (i.e., the maximum deformation of the beam in the direction of the strong-axis of the cross section) as shown in Fig. 2-13(b). The measured value of the camber and sweep of the W16 $\times 26$ beam specimen was $(1.7 \pm 0.1) \mathrm{mm}$ and $(4.4 \pm 1.2) \mathrm{mm}$, respectively. The values after \pm symbol indicates the total expanded uncertainty with two standard deviation.

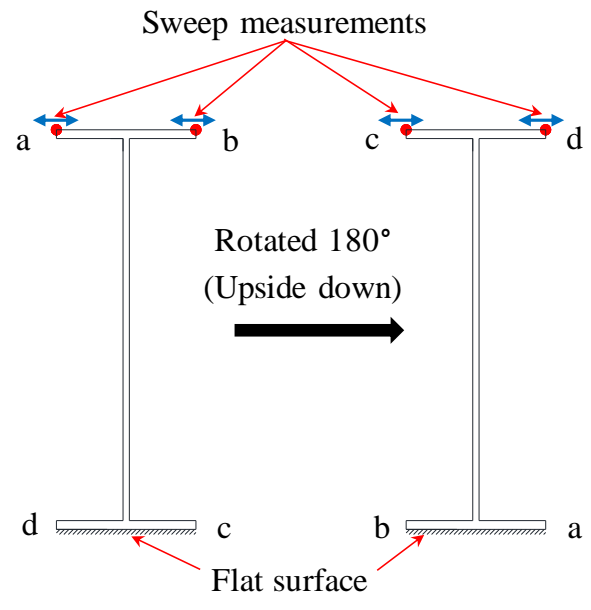

(a)

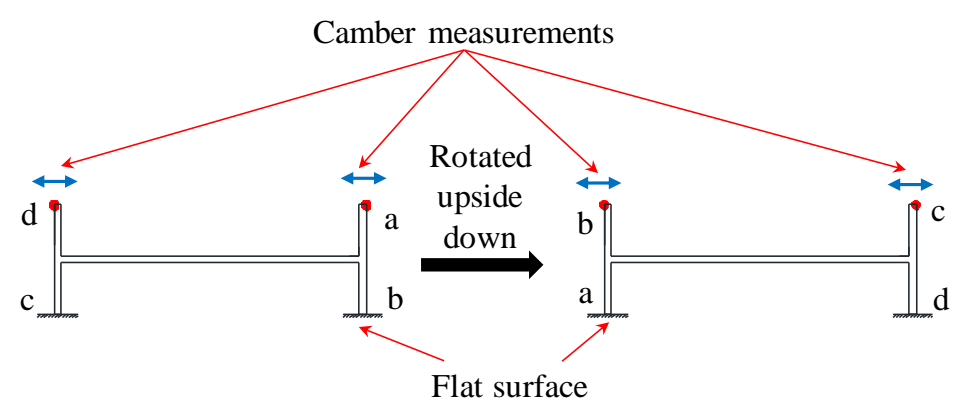

(b)

$6172 \mathrm{~mm}(243 \mathrm{in.})$

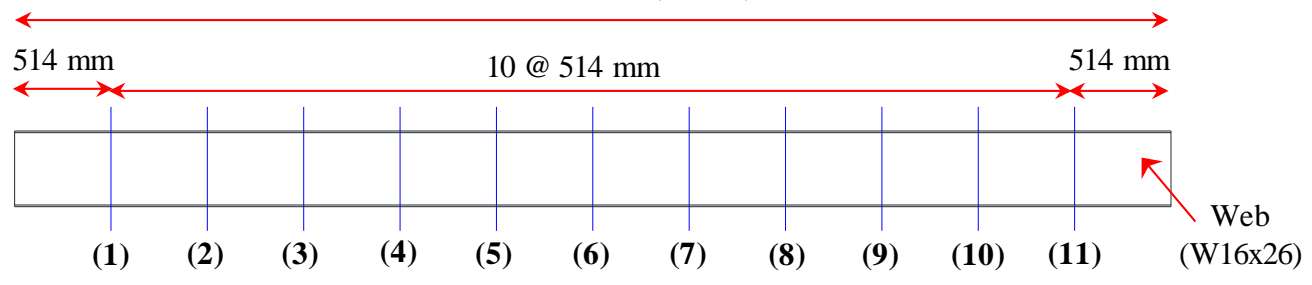

(c)

Figure 2-13 Arrangement of the W16x26 beams for sweep and camber measurements. 


\subsection{MEASUREMENT SYSTEMS}

During the tests, data was collected from multiple systems: (1) Fire related (heat release rate and temperature measurements), (2) Mechanical-loading system related, (3) Specimen and test setup related, (4) Laser displacement measurements, (5) Digital Image Correlation, (6) Thermal imaging, and (7) Networked and handheld cameras. All systems are briefly described, however, the focus of the data reported in this document is on the non-optical systems (Systems 1 to 3).

\subsubsection{Data Acquisition System}

The data acquisition systems dedicated to capturing information about the fire loading (System 1) and the mechanical loading (System 2) recorded more information than is germane to the experiments documented in this report. For this reason, key channels from those systems were digitized and ported to the data acquisition system dedicated to specimen and test setup related measurements (System 3) and recorded.

Measurements from the beam specimens and the test setup were acquired using National Instruments cDAQ-9188 chasses populated with the following I/O-Modules: NI-9213 (thermocouples), NI-9237 (strain gages and load cells), and NI-9205 (voltage sensors such as displacement sensors and inclinometers). An in-house software developed in LabVIEW ${ }^{\mathrm{TM}}$ was used to allocate channels and control the data acquisition. During the laboratory tests, data were recorded at $1 \mathrm{~Hz}$.

For tests with only thermal loading (Test 1 to 5), in addition to the Heat Release Rate (HRR) measured by the NFRL calorimeter, the burner heat release rate (HRRburner), and a timing signal from a heat flux gauge pointed at the burner (HeatFluxTiming), which were ported from System 1, were recorded. These data channels included data from thermocouples, plate thermometers, inclinometers, and displacement measurement devices. Additionally, several values calculated from the measured channels were recorded for each of the test series. A detailed listing of the channels for each test is provided in the Appendix B.

For Test 6 where only mechanical loading was applied, in addition to the actuator forces, actuator displacements and a timing signal measured by the hydraulic loading system, which were ported from System 2, were recorded. These channels included data from strain gauges, load cells, and displacement measurement devices. 
For tests with combined thermal and mechanical loading (Test 7 to 9), in addition to the channels ported from System 1 and System 2 described above recorded. These measurement channels included data from a combination of the above-described sensor types.

\subsubsection{Sensors}

Table 2-4 provides an overview of each sensor type used in the experiments. Heat release rate (HRR), steel surface temperature, adiabatic surface temperature, load, displacement, rotation, and strains were measured using the sensors listed in the table.

Table 2-4 Sensors used in the experiments

\begin{tabular}{ccccc}
\hline Sensor description & Manufacturer & Model & $\begin{array}{c}\text { Full Scale } \\
\text { Value }\end{array}$ & Remarks \\
\hline HRR & NIST & - & - & Heat release rate (HRR) from calorimeter \\
HRRburner & NIST & - & - & Heat release rate (HRR) from gas mass flow \\
Thermocouple & Omega & GG-K-24 & $1250^{\circ} \mathrm{C}$ & \\
Plate Thermometer & NIST & - & & Adiabatic surface temperature \\
Load cell & MTS & $201.35 \mathrm{TS}$ & $240 \mathrm{kN}(\mathrm{T})$ & Actuator force (T=tension; C=Compression) \\
Potentiometer & MTS & $201.35 \mathrm{TS}$ & $762 \mathrm{~mm}$ & Actuator displacement \\
String potentiometer & UniMeasure & PA10 & $10 \mathrm{in}$. & \\
String potentiometer & UniMeasure & PA30 & $30 \mathrm{in}$. & \\
Displacement Transducer & Novotechnik & TR 25 & $25 \mathrm{~mm}$ & \\
Displacement Transducer & Novotechnik & TR 50 & $50 \mathrm{~mm}$ & \\
Linear position sensor & BEI Sensors & 9615 & $1.5 \mathrm{in}$. & \\
Linear position sensor & BEI Sensors & 9605 & $0.5 \mathrm{in}$. & \\
Inclinometer & Meas.Specialties & G-NSDMG-023 & $\pm 30^{\circ}$ & \\
Load Cell & Omega & LCHD-50K & $50 \mathrm{kip}$ & \\
Strain gage & Texas Measurements & FLA-6-11 & $50,000 \mu \varepsilon$ & \\
& & &
\end{tabular}

${ }^{\mathrm{a}} 1$ in. $=25.4 \mathrm{~mm} ; 1 \mathrm{kip}=1000 \mathrm{lbs}=4.5 \mathrm{kN}$.

\section{(i) Temperature}

The thermocouples used in all the beam specimen tests were glass-sheathed, K-type, 24-gauge, bare-bead thermocouples. Prior to testing, a study was conducted to investigate the influence of the method of attachment of the thermocouples to the specimen. The results of this study are provided in Section 2.3.7. No correction for radiation on the bead temperature was performed. In most cases, it was not relevant since the bead was embedded in the specimen and shielded from radiation, as shown in Fig. 2-14(a). 
Plate thermometers constructed at NIST were used to measure adiabatic surface temperate. They consisted of a glass-sheathed, K-type, 24-gauge, thermocouple welded to an Inconel (nickelchromium alloy) plate with dimensions of $100 \mathrm{~mm} \times 100 \mathrm{~mm} \times 0.7 \mathrm{~mm}$ and insulating material on the back, as shown in Fig. 2-14(b).

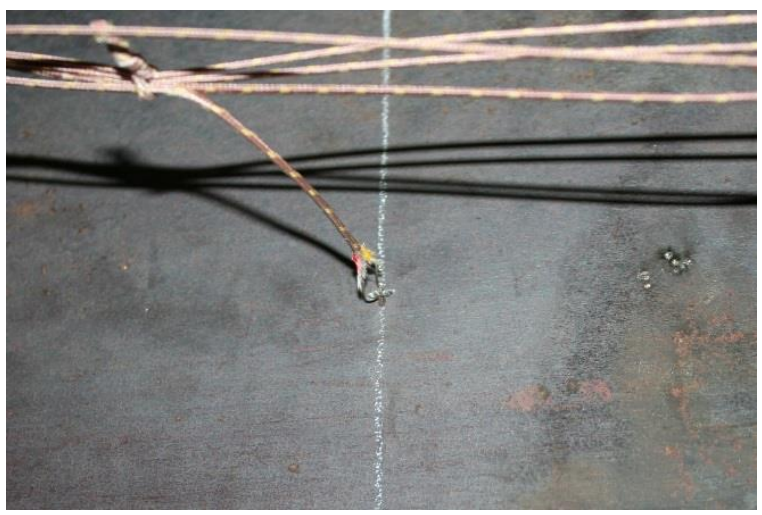

(a)

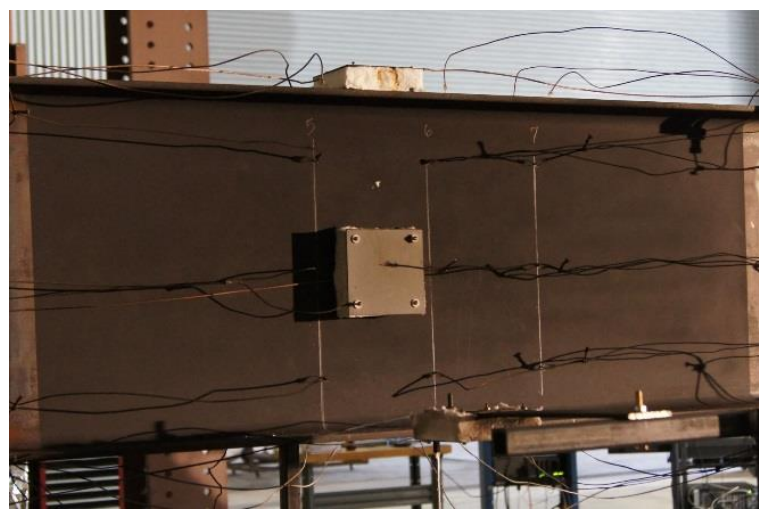

(b)

Figure 2-14 Typical temperature sensors: (a) thermocouple peened into drill hole in web of beam, (b) Plate thermometers mounted on and near beam.

\section{(ii) Force}

The load applied by the hydraulic actuators were measured using MTS 661.22D-01 model force transducers attached to each actuator. Refer to Section 2.1.2 for details of the MTS hydraulic actuators. The reaction forces at the end of the simply supported specimens were measured using load cells between the bottom flange of the beam and the support. A photograph of a load cell mounted near the end of the beam specimen is shown in Fig. 2.8(b). Omega LCHD-50K model load cells were used to measure the reaction.

\section{(iii) Strain}

Strains developed in the specimens and loading fixtures due to the applied forces were measured using the surface attached strain gages. FLA-6-11 linear strain gages with a nominal resistance of $120 \mathrm{ohm}$ manufactured by Texas Measurements were attached to the steel surfaces. A photograph of strain gages installed near the end of the specimen is shown in Fig. 2.15. The manufacturespecified operating temperature range of the strain gage is $-196{ }^{\circ} \mathrm{C}$ to $150{ }^{\circ} \mathrm{C}$. The strain gages were at $(25 \pm 10){ }^{\circ} \mathrm{C}$ during testing. 


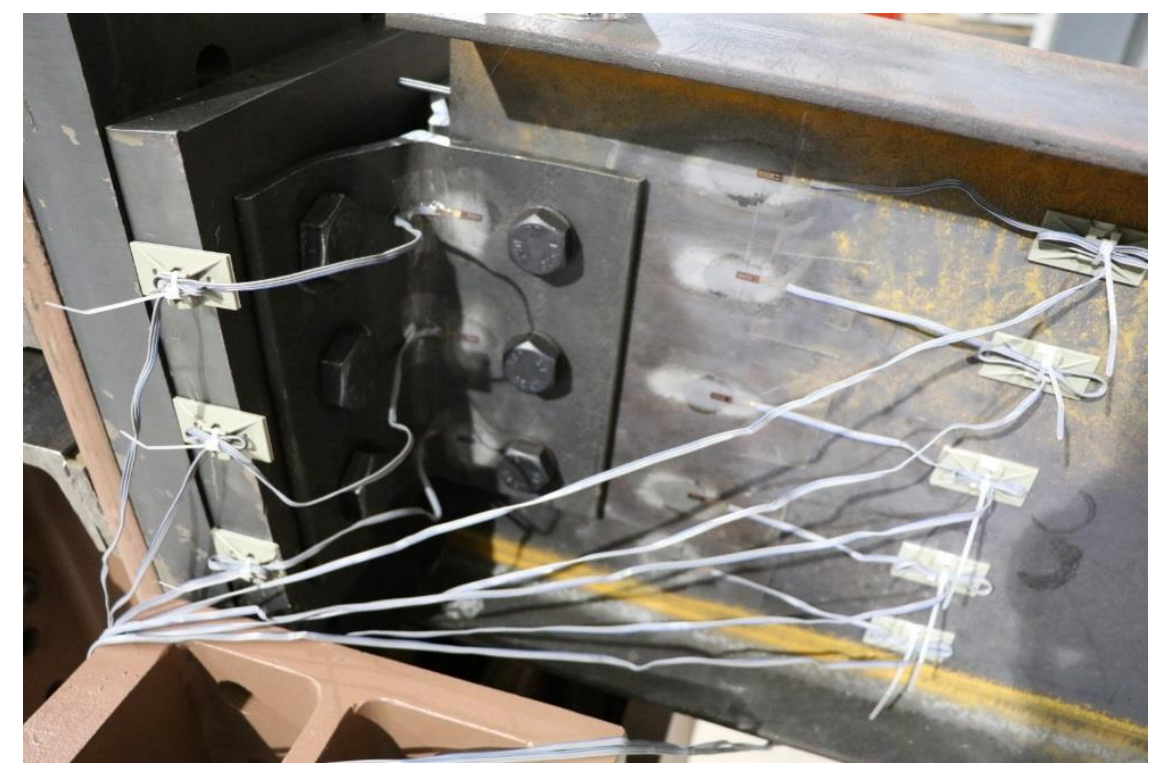

Figure 2-15 Strain gauges installed near end of beam specimen.

\section{(iv) Rotation}

Inclinometers attached to the top flange of the beam specimens along the centerline at each end were used to measure the rotation of the beam as it deformed (Fig. 2-16). The inclinometers from Measurement Specialties, Inc. (model G-NSDMG-023) were used to measure the rotation during the tests.

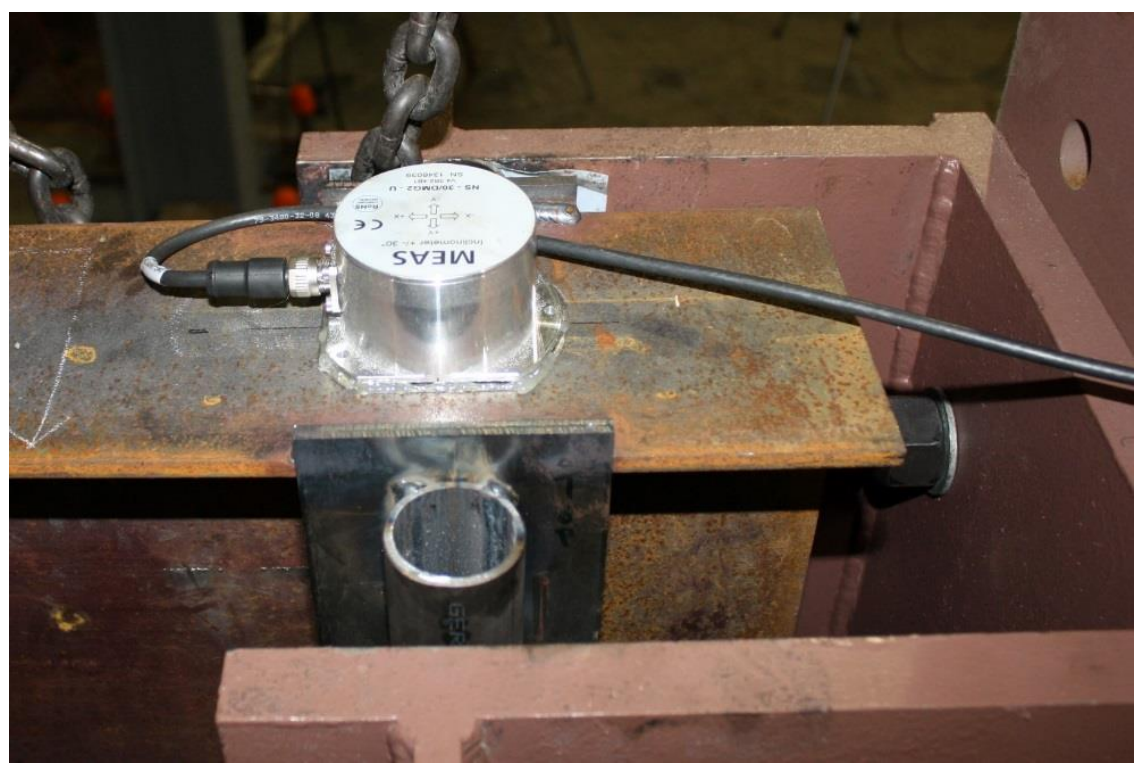

Figure 2-16 Inclinometer attached to the top flange of a beam specimen. 


\section{(v) Displacement}

Several sensor types were used to measure displacement of the test specimens. These included linear potentiometers, string potentiometers, laser-based displacement sensors and Digital Image Correlation. The sensor type was dictated primarily by the desired measurand; however, these experiments were also used to compare and improve structural displacement measurements in the presence of real fire load. The optical measurement systems (laser-based sensors and Digital Image Correlation) are described in the subsequent sub-sections.

Axial elongation of the beam was measured using linear potentiometers attached to the flanges of the beam specimens along the centerline as shown in Fig 2-17. The sensors were Novotechnik model TR 25 (refer to Table 2-5 for specifications).

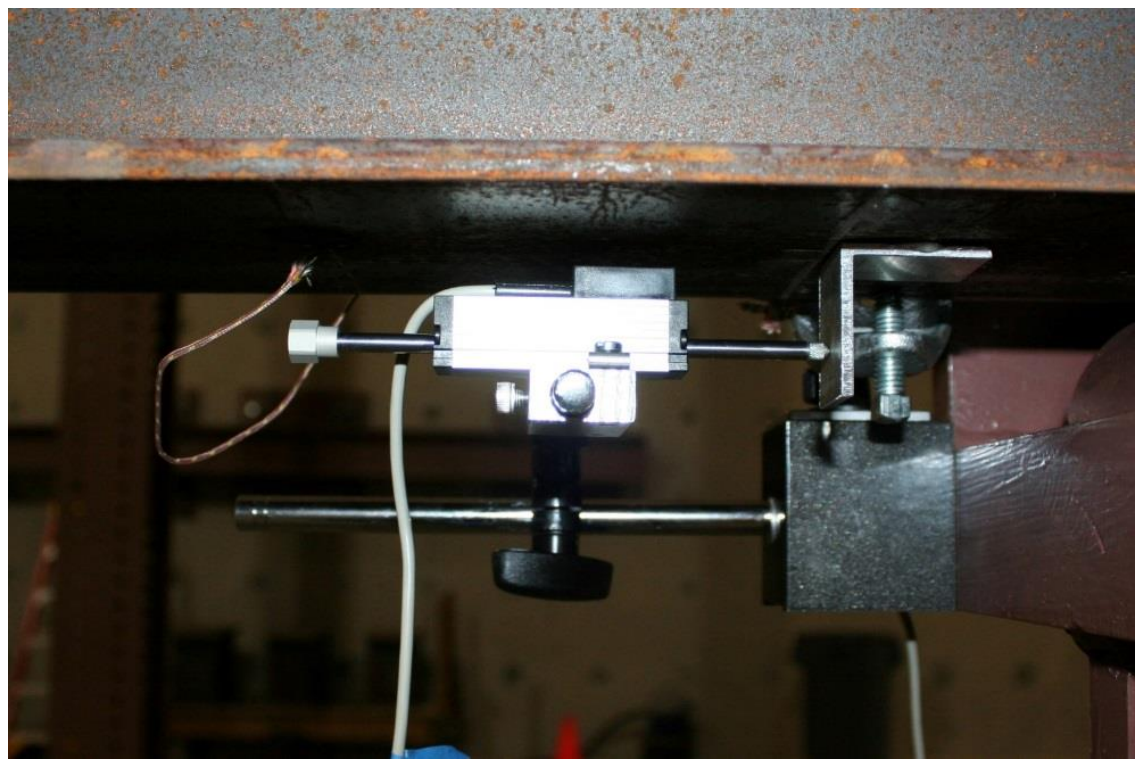

Figure 2-17 Linear potentiometer attached to the bottom flange of a beam specimen.

Downward displacement of the beam specimen as well as movement of the top and bottom beam flanges transverse to the beam's strong axis were measured at midspan of the beam (three locations total) using potentiometers with special temperature-compensated probes. For each measured displacement in the heated zones, two potentiometers were mechanically connected to the point of interest with probes made of silicon carbide or aluminum oxide fibers. The fibers spanned from the potentiometers and the specimen (Fig. 2-18 and Fig. 2-19). The fibers exhibited different and approximately linear thermal expansion at the gas temperatures present in the fire. Because each pair of fibers was co-located and thus subjected to nearly identical temporal and spatial thermal variations in the fire, the two measurements could be used to correct for the influence of thermal 
expansion of the probes thus reducing error by more than two orders of magnitude. Previous studies of the fiber probes in a tube furnace indicate that the probe-induced error is less than \pm 0.02 $\mathrm{mm}$ per meter of heated length up to $1200{ }^{\circ} \mathrm{C}$. In the thermal-only tests (Test 1 to 5), Novotechnik model TR-050 linear potentiometers were used. In the subsequent tests (Test 6 to 9), UniMeasure string potentiometers (model PA10 or PA30) were used. Because the length of the probe subject to flames was less than $1 \mathrm{~m}$, the uncertainty in these displacement measurements can be estimated by adding a standard uncertainty of $\pm 0.02 \mathrm{~mm}$ to the sensor uncertainty in Table 2-5.

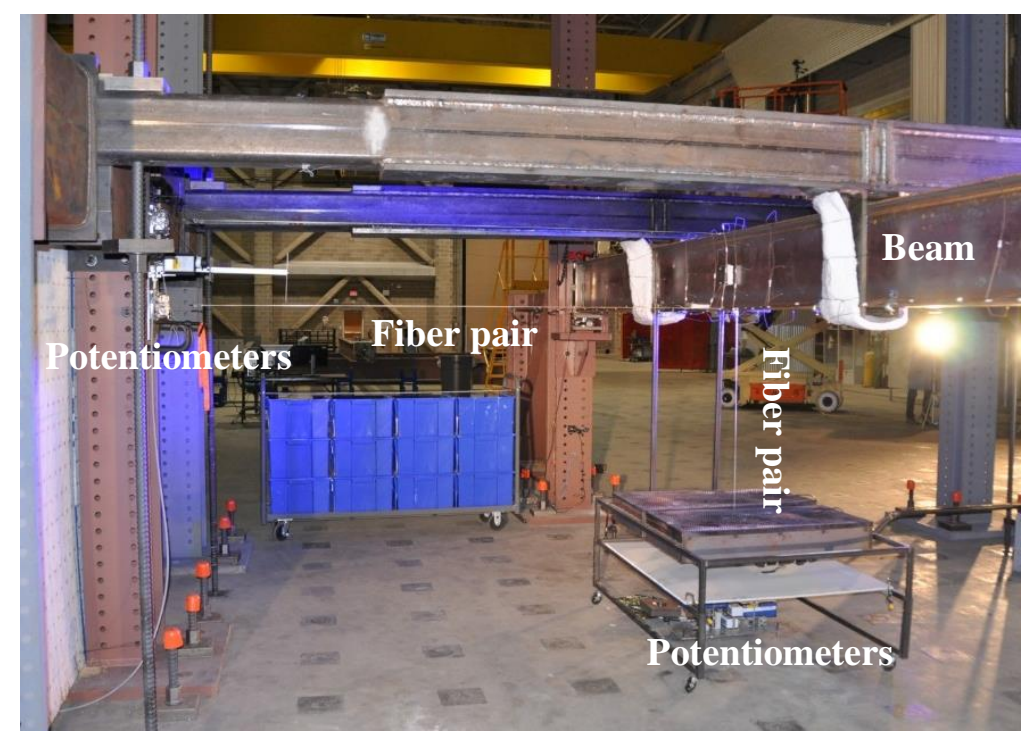

(a)

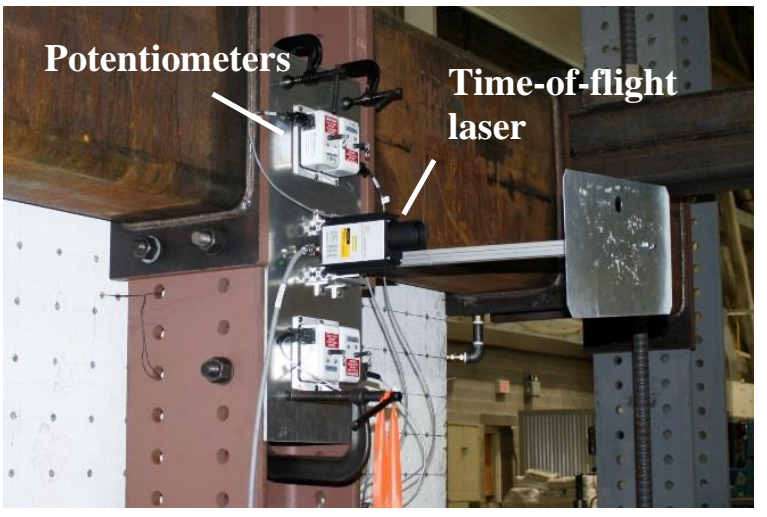

(b)
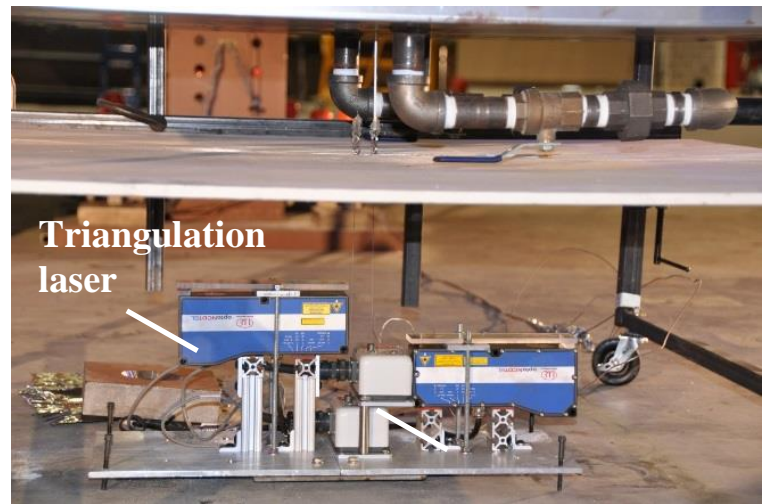

(c)

Figure 2-18 Setup for vertical and transverse beam displacement measurements at mid-span: (a) overview, (b) paired string potentiometers to measure transverse displacements, (c) paired string potentiometers to measure vertical displacements. 


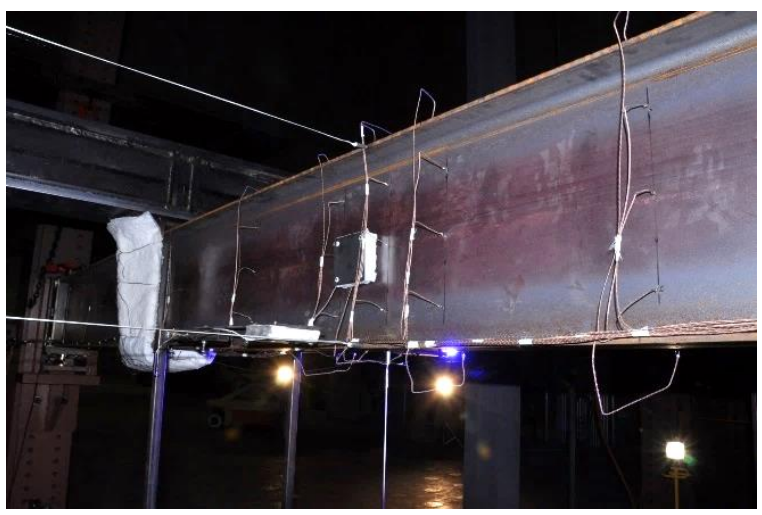

(a)

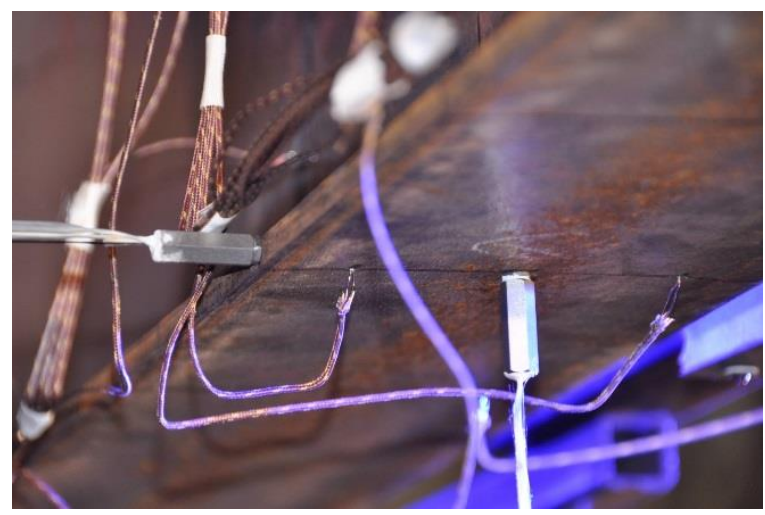

(b)

Figure 2-19 Setup for vertical and transverse beam displacement measurements at mid-span: (a) photo illustrating fiber paths, (b) detail of fiber to beam connections.

\subsubsection{Uncertainty of Measurements}

The experimental results presented in this report include temperatures, strains, mechanical forces, displacements, rotations, and heat release rates from the burners. For each measurand, Type A and Type B uncertainties, combined standard uncertainties, and total expanded uncertainties were estimated. As defined in Taylor and Kuyatt (1994), Type A uncertainty was evaluated using statistical methods; Type B uncertainty was estimated by other means such as the information available in manufacturer's specifications or from past experience. The combined standard uncertainty was estimated by combining the individual uncertainties using "root-sum-of-squares" (Taylor and Kuyatt, 1994). The expended uncertainty was then computed by multiplying the combined uncertainty by a coverage factor of 2 corresponding to an approximately $95 \%$ confidence interval.

Table 2-5 summarizes various components of the measurement uncertainty. The zero and calibration elements were derived from instrument specifications. All resistive-based sensors used in this test program, such as strain gauges, load cells, and displacement and rotation transducers, have a linear calibration factor at ambient temperature (in the range of $20{ }^{\circ} \mathrm{C}$ to $45{ }^{\circ} \mathrm{C}$ ). The estimated calibration uncertainty was less than or approximately equal to $\pm 1 \%$. In this test program, those sensors were protected against excessive radiant heat from a fire or placed in the cool zone where the temperature exceeded no greater than $40{ }^{\circ} \mathrm{C}$. Other components, such as the position of thermocouples and strain gauges and use of the temperature compensation technique for string potentiometers, were estimated based upon past experience and previous data. The random and repeatability elements were statistically determined. 
The combined standard uncertainty for steel temperature includes a component related to the position of thermocouples mounted in the steel beam specimen. A thermocouple having the nominal diameter of $0.51 \mathrm{~mm}$ was placed into a small blind hole (the nominal diameter of $1.5 \mathrm{~mm}$ ) drilled in the specimen. The edge of the hole was then peened by use of a punch. If the hole was not completely closed on the surface, the thermocouple would be partially exposed to either hot or cool surrounding air temperature. This effect could result a higher or cooler temperature than the reported steel temperature. With extra care and quality control checks during the installation process, such as use of the single size of the drill bit having a marking of the hole depth (nominally equal to $2.5 \mathrm{~mm}$ ), this uncertainty was estimated to be $\pm 2 \%$. The measurements with the thermocouple embedded into the steel specimen were highly repeatable and resulted an estimate of $\pm 12 \%$ total expanded uncertainty for the lab.

The combined standard uncertainty in the strain measurement also includes a component associated with the mounting method of strain gauges. Given that the linear strain gauge was carefully aligned along the longitudinal axis of a testing substrate (with the maximum 5 degrees of angular misalignment), and the bonding quality of attached strain gauges was checked against the manufacture's installation guideline, the minimum estimated uncertainty attributed to the installation was $\pm 1 \%$. The strain measurement was highly repeatable at ambient temperature and resulted an estimate of $\pm 5 \%$ total expanded uncertainty.

String potentiometers with special temperature-compensated probes were used for the displacement measurements in the heated zones. Refer to Section 2.3.2 for the details of the measurement method. The length of the probe subject to flames was less than $1 \mathrm{~m}$. The standard uncertainty in the displacement measurements associated with the temperature compensation was estimated as $\pm 2 \%$ for a displacement range of $1 \mathrm{~mm}$ to $100 \mathrm{~mm}$. Also, when exposed to the fire plume, the tensioned string was subject to vibration. At the burner heat release rate of $400 \mathrm{~kW}$, the position of the string used in this test program [refer to Fig. 2-18(a)] resulted the displacement fluctuation (random error) of $\pm 5 \%$. The total expanded uncertainty for the test setup used in this study was estimated to be $\pm 15 \%$.

The uncertainty in the measurement of mechanical forces, including the point load imposed in the specimen and the vertical reaction force at the specimen end, was estimated at the manufacturer's specified operating temperature $\left(20^{\circ} \mathrm{C}\right.$ to $\left.40{ }^{\circ} \mathrm{C}\right)$. The point load was measured using the built-in load cell of the actuator mounted in the basement [Fig. 2-3 (a)]; the reaction force at the specimen end was measured using the pancake load cell [Fig. 2-8 (b)]. The temperature in supporting steel frames remained cool during the fire test. The force measurement was highly repeatable at ambient temperature and resulted an estimate of $\pm 10 \%$ total expanded uncertainty for the test configuration 
used in this study. Also, to measure the rotation of the beam specimen, the inclinometer was placed at the end of the beam specimen where the temperature remained cool during the fire test. The total expanded uncertainty estimated at the normal operating temperature was $\pm 8 \%$.

For the measurement of the burner heat release rate, the observed random error was small when the heat release rate was set to a constant value or was incremented slowly. This measurement was highly repeatable when a computerized pneumatic valve was used to control the gas flow. The estimated total expanded uncertainty was $\pm 7 \%$.

Table 2-5 Uncertainty in the experimental data

\begin{tabular}{|c|c|c|c|c|}
\hline Measurement / Component & $\begin{array}{l}\text { Estimation } \\
\text { Method of } \\
\text { Uncertainty }\end{array}$ & $\begin{array}{l}\text { Component } \\
\text { Standard } \\
\text { Uncertainty }\end{array}$ & $\begin{array}{l}\text { Combined } \\
\text { Standard } \\
\text { Uncertainty }\end{array}$ & $\begin{array}{c}\text { Total } \\
\text { Expanded } \\
\text { Uncertainty } \\
(\mathrm{k}=2)\end{array}$ \\
\hline $\begin{array}{l}\text { Steel Temperature } \\
\text { Calibration } \\
\text { Installation } \\
\text { Random } \\
\text { Repeatability }\end{array}$ & $\begin{array}{l}\text { Type B } \\
\text { Type B } \\
\text { Type A } \\
\text { Type A }\end{array}$ & $\begin{array}{l} \pm 1 \% \\
\pm 2 \% \\
\pm 2 \% \\
\pm 5 \%\end{array}$ & $\pm 6 \%$ & $\pm 12 \%$ \\
\hline $\begin{array}{l}\text { Strain } \\
\qquad \begin{array}{l}\text { Calibration } \\
\text { Installation } \\
\text { Random } \\
\text { Repeatability }\end{array}\end{array}$ & $\begin{array}{l}\text { Type B } \\
\text { Type B } \\
\text { Type A } \\
\text { Type A }\end{array}$ & $\begin{array}{l} \pm 0.5 \% \\
\pm 1 \% \\
\pm 1 \% \\
\pm 2 \%\end{array}$ & $\pm 2 \%$ & $\pm 5 \%$ \\
\hline $\begin{array}{l}\text { Reaction force } \\
\text { Zero } \\
\text { Calibration } \\
\text { Random } \\
\text { Repeatability }\end{array}$ & $\begin{array}{l}\text { Type B } \\
\text { Type B } \\
\text { Type A } \\
\text { Type A }\end{array}$ & $\begin{array}{l} \pm 0.2 \% \\
\pm 1 \% \\
\pm 1 \% \\
\pm 5 \%\end{array}$ & $\pm 5 \%$ & $\pm 10 \%$ \\
\hline $\begin{array}{l}\text { Point load } \\
\text { Zero } \\
\text { Calibration } \\
\text { Random } \\
\text { Repeatability }\end{array}$ & $\begin{array}{l}\text { Type B } \\
\text { Type B } \\
\text { Type A } \\
\text { Type A }\end{array}$ & $\begin{array}{l} \pm 0.2 \% \\
\pm 1 \% \\
\pm 2 \% \\
\pm 4 \%\end{array}$ & $\pm 5 \%$ & $\pm 10 \%$ \\
\hline $\begin{array}{l}\text { Displacement (String Potentiometer) } \\
\text { Zero } \\
\text { Calibration } \\
\text { Temperature compensation } \\
\text { Random } \\
\text { Repeatability }\end{array}$ & $\begin{array}{l}\text { Type B } \\
\text { Type B } \\
\text { Type B } \\
\text { Type A } \\
\text { Type A }\end{array}$ & $\begin{array}{l} \pm 1 \% \\
\pm 0.1 \% \\
\pm 2 \% \\
\pm 5 \% \\
\pm 5 \%\end{array}$ & $\pm 7 \%$ & $\pm 15 \%$ \\
\hline $\begin{array}{l}\text { Rotation } \\
\text { Zero } \\
\text { Calibration } \\
\text { Random } \\
\text { Repeatability }\end{array}$ & $\begin{array}{l}\text { Type B } \\
\text { Type B } \\
\text { Type A } \\
\text { Type A }\end{array}$ & $\begin{array}{l} \pm 1 \% \\
\pm 0.1 \% \\
\pm 2 \% \\
\pm 3 \%\end{array}$ & $\pm 4 \%$ & $\pm 8 \%$ \\
\hline $\begin{array}{c}\text { Burner Heat Release Rate } \\
\text { Mass flow rate } \\
\text { Random } \\
\text { Repeatability }\end{array}$ & $\begin{array}{l}\text { Type B } \\
\text { Type A } \\
\text { Type A }\end{array}$ & $\begin{array}{l} \pm 1 \% \\
\pm 1 \% \\
\pm 3 \%\end{array}$ & $\pm 3 \%$ & $\pm 7 \%$ \\
\hline
\end{tabular}




\begin{tabular}{|c|c|c|c|c|}
\hline Instrument Location & Type A & $\pm 2 \%$ & $\pm 5 \%$ & $\pm 11 \%$ \\
Random & Type A & $\pm 5 \%$ & & \\
Repeatability & & & \\
\hline
\end{tabular}

\subsubsection{Laser Displacement Measurements}

Two types of commercially-available laser ranging systems were used to explore their applicability to large-scale live fire tests. The transverse movement of the web of the beam specimen at midspan was measured using a time-of flight sensor manufactured by Micro-Epsilon (ILR 1182-30). The sensor is shown in Fig. 2-19. Measurements of the downward movement of the bottom flange of the beam specimen at mid-span at the edges of the flange were made using blue laser triangulation sensors manufactured by Micro-Epsilon (ILD 1700-750BL). The laser uses a blueviolet $(405 \mathrm{~nm})$ diode light source and has a measurement range of $750 \mathrm{~mm}$. This approach was successfully demonstrated in benchtop scale tests [Hoehler and Smith, 2016]. The two sensors are shown in Fig. 2-18(c). For detailed information about the specifications of these lasers, the reader can visit the manufacturer's website.

\subsubsection{Thermal Imaging}

Thermal imaging of the beam specimens was performed using a high-speed infrared camera (FLIR SC8300HD; Fig. 2-20). For detailed information about the specifications of this camera, the reader can visit the manufacturer's website.

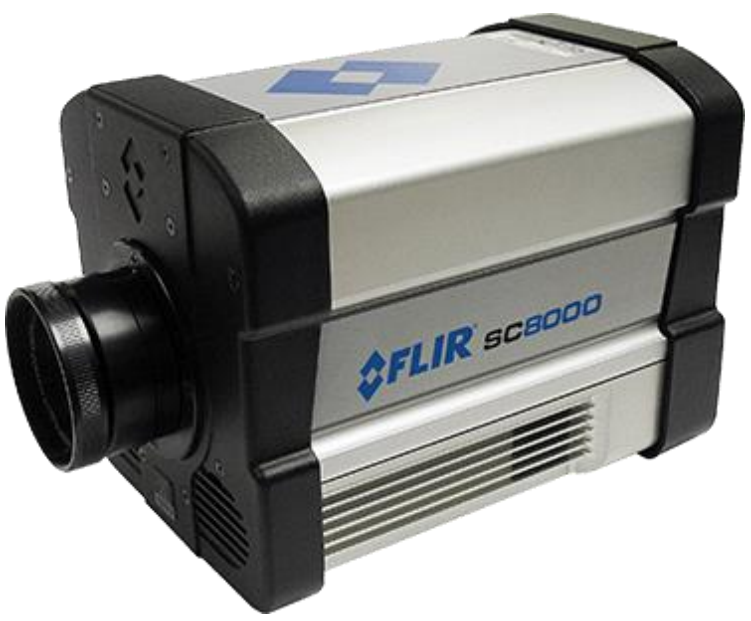

Figure 2-20 FLIR SC8000 series thermal imaging camera (source: http://www.flir.com).

\subsubsection{Digital Image Correlation}

The beam specimens were used for exploratory investigations with Digital Image Correlation (DIC) augmented by narrow-spectrum illumination to measure surface deformations and strains 
of objects engulfed in flames. Digital Image Correlation is an optical measuring technique for true full-field, non-contact and three-dimensional measurement of shape, displacements and strains. A commercially-available digital 3D image correlation system from Dantec Dynamics (Q-400) was used to capture and analyze the images (Fig. 2-21). The Q-400 system was augmented using highintensity, narrow-spectrum blue light (450 $\mathrm{nm}$ wavelength) and optical filters.

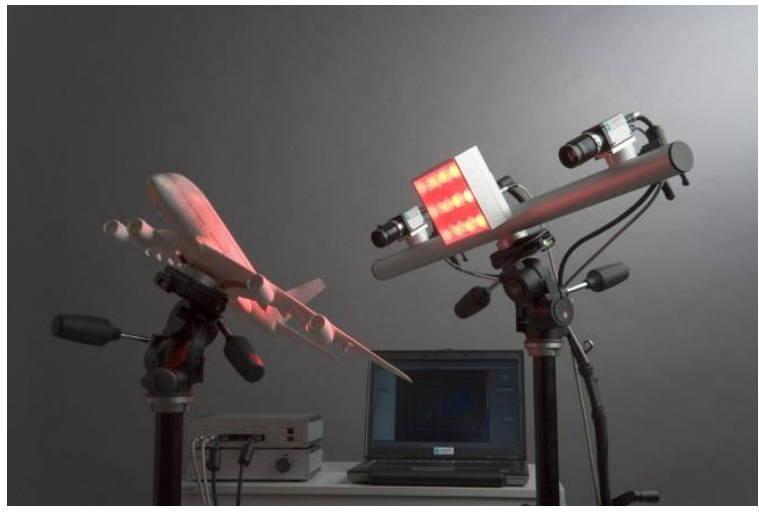

(a)

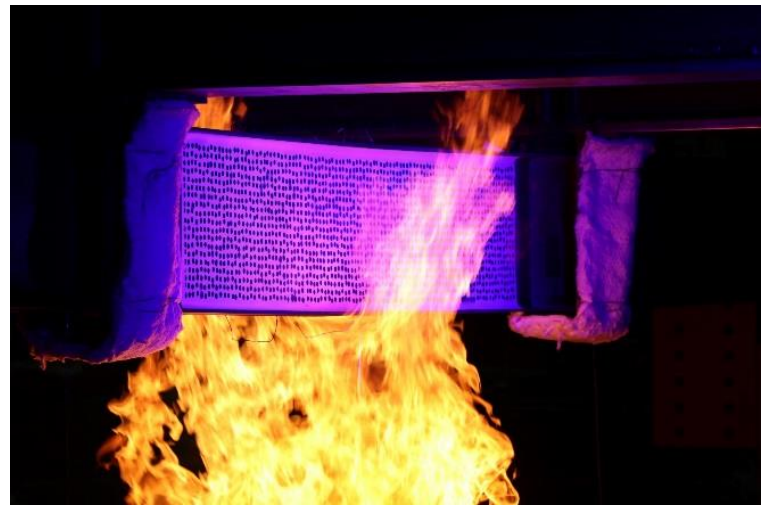

(b)

Figure 2-21 Digital Image Correlation system: (a) Typical setup for Dantec Q-400 DIC system (source: http://nevatec.ru), (b) center portion of beam specimen painted with black-white pattern illuminated with narrow-spectrum blue light.

\subsubsection{Effect of Thermocouple Installation Method on Steel Temperature Measurement}

Various mounting methods of thermocouples were explored to investigate their effects on steel temperature measurements. Fig. 2-22 shows the layout of thermocouples in this study. A total of seventeen Type-K thermocouples were installed in the midspan cross sections of the beam specimen. They were grouped into five different regions of cross section with respect to the location of the burner, such as upper flange (UF), upper web (UW), middle web (MW), lower web (LW), and lower flange (LF). The locations of those five regions were consistent with those used for temperature measurements presented in Chapters 3 and 4. There were ten thermocouples installed in the middle web. The spacing of thermocouples was $(2.5 \pm 0.2) \mathrm{cm}$, (where 0.2 is the standard deviation), which was determined to be a working distance for installing two adjacent thermocouples by peening. The temperature variation within the required distance was deemed negligible. To measure the thermal gradient through the full-depth of the W16 $\times 26$ section, two thermocouples each were installed at upper web, lower web, and lower flange, whereas there was single thermocouple at upper flange. Table 2-6 summarizes test variables including location, installation and protection method, bead size, direction of thermocouple wire relative to the steel surface, and the presence of an additional thermocouple junction within the fire zone. 


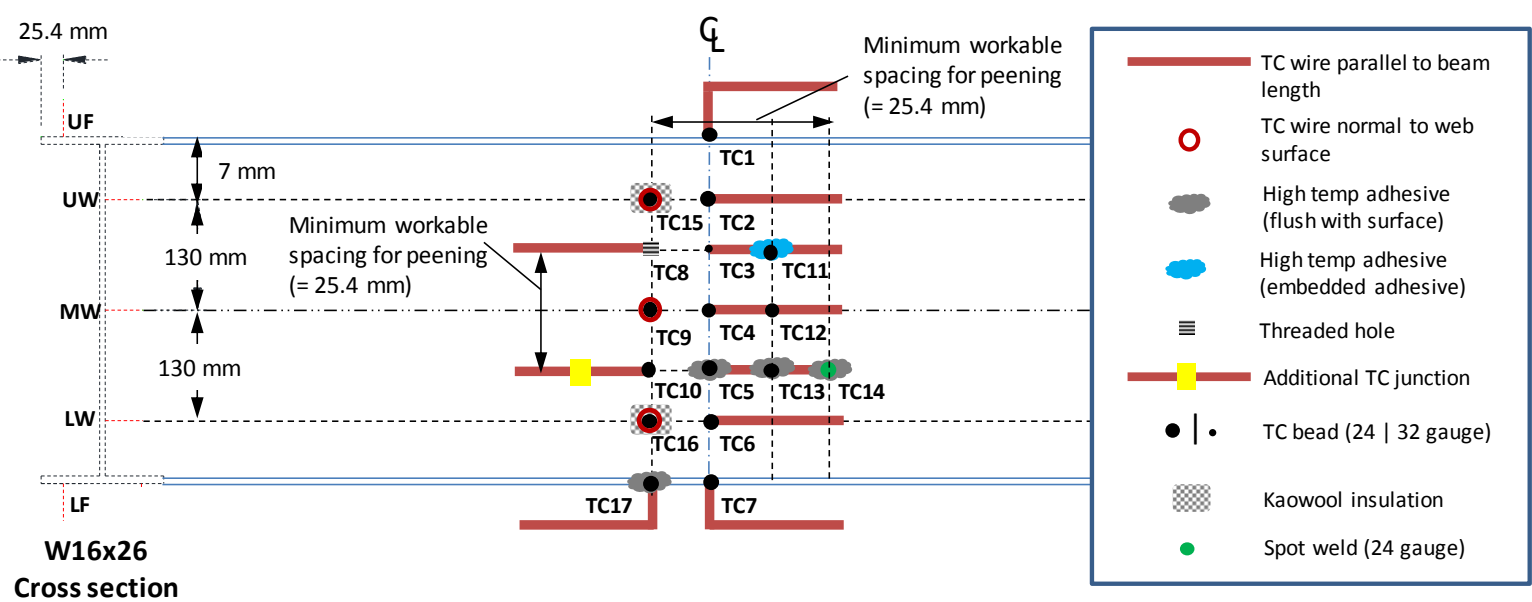

Figure 2-22 Thermocouple layout with units in $\mathrm{mm}$. Standard uncertainty in dimensions was $\pm 2 \mathrm{~mm}(95 \%$ confidence interval).

Table 2-6 Variables of temperature measurement.

\begin{tabular}{ccccccc}
\hline Channel & Location & $\begin{array}{c}\text { Installation } \\
\text { technique }\end{array}$ & Insulation technique & $\begin{array}{c}\text { Wire } \\
\text { gauge }\end{array}$ & $\begin{array}{c}\text { Orientation of } \\
\text { wire }\end{array}$ & $\begin{array}{c}\text { Additional } \\
\text { Junction }\end{array}$ \\
\hline TC1 & UF & Peening & - & 24 & Parallel & - \\
TC2 & UW & Peening & - & 24 & Parallel & - \\
TC3 & MW & Peening & - & 32 & Parallel & - \\
TC4 & MW & Peening & - & 24 & Parallel & - \\
TC5 & MW & Peening & Adhesive on peened hole & 24 & Parallel & - \\
TC6 & LW & Peening & - & 24 & Parallel & - \\
TC7 & LF & Peening & - & 24 & Parallel & - \\
TC8 & MW & Bolt-on & - & 24 & Perpendicular & - \\
TC9 & MW & Peening & - & 24 & Perpendicular & - \\
TC10 & MW & Peening & - & 24 & Parallel & Yes \\
TC11 & MW & Peening & Embedded adhesive & 24 & Parallel & - \\
TC12 & MW & Spot weld & & 24 & Parallel & - \\
TC13 & MW & Peening & Adhesive on peened hole & 24 & Parallel & - \\
TC14 & MW & Peening & & 24 & Parallel & - \\
TC15 & UW & Peening & Kaowool piece & 24 & Perpendicular & - \\
TC16 & LW & Peening & Kaowool piece & 24 & Perpendicular & - \\
TC17 & LF & Peening & Adhesive on peened hole & 24 & Parallel & - \\
\hline UF = upper flange; UW = upper web; MW = middle web: LW = lower web; LF = lower flange
\end{tabular}

Fig. 2-23 shows photographs of the thermocouples installed in the web of the beam specimen. In this study, three different methods were used to mount thermocouples as follows. 
- Peening: thermocouples were placed in small holes (nominal diameter of $1.5 \mathrm{~mm}$ ) drilled on the steel surface and secured by peening.

- Spot weld: a thermocouple junction was directly welded to the steel surface.

- Bolt-on: a thermocouple junction was clamped into the threaded hole of the steel beam using a screw (nominal diameter of $3.2 \mathrm{~mm}$ ).

Various insulation methods were used for protecting thermocouple junctions, which included (i) applying a high temperature cement on the peened holes, (ii) coating the thermocouple bead with a ceramic epoxy before peening, and (iii) covering the peened holes with a piece of Kaowool blanket. Other variables were also investigated, such as thermocouples wire gauges (24 or 32 gauges), thermal gradient along the extended thermocouple wire (thermocouple wire running normal to or parallel with the fire-exposed steel surface), and presence of an additional junction within the fire-exposed region.

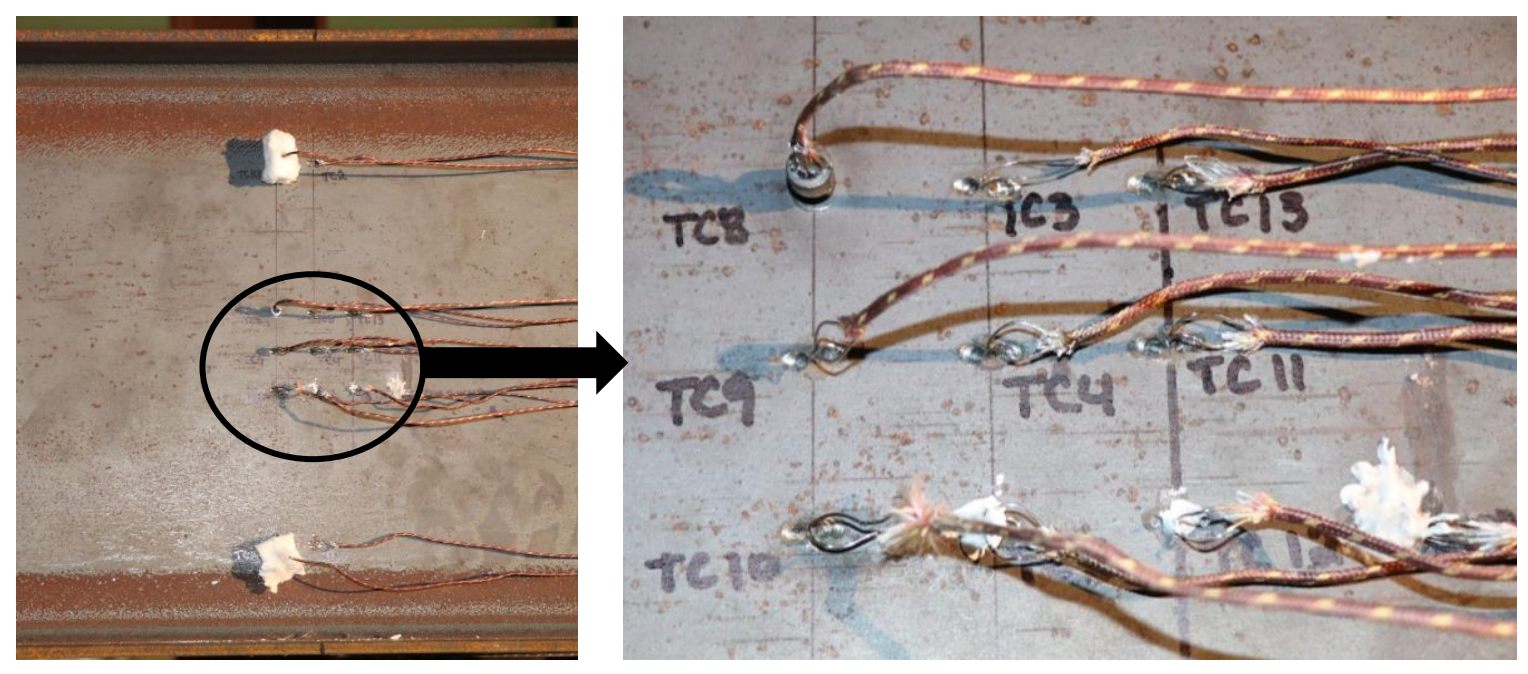

Figure 2-23 Thermocouples installed on the web of the beam

An open flame localized fire was used to check the effect of insulation methods on the temperature readings of the thermocouples attached to the steel beam. The location of the natural gas burner was presented in Section 2.1.3. Fig. 2-24 shows the measured HRR of the burner and the corresponding steel temperatures measured by seventeen thermocouples grouped into five different regions in the cross section. An open flame fire was produced by following the same burner HRR-time relation as used in Tests 8 and 9. The burner HRR was increased to $1350 \mathrm{~kW}$, and then the fire was maintained about $7 \mathrm{~min}$ before the burner was manually turned off. After that, the burner was turned on and off two times (period of each cycle was about $26.5 \mathrm{~s}$ on average) 
to measure the steel temperature using thermal imaging camera. The burner was completely turned off about $31 \mathrm{~min} \pm 10 \mathrm{~s}$ after its ignition.
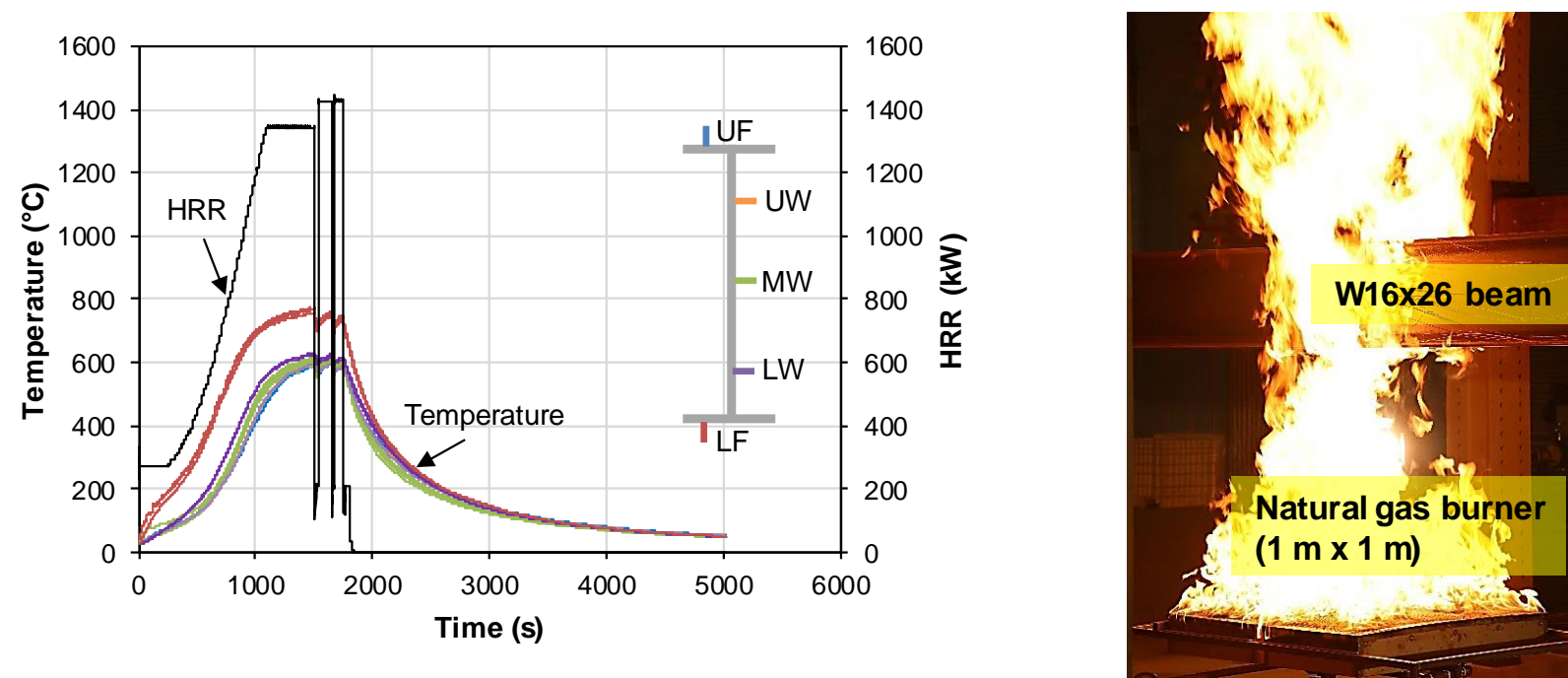

Figure 2-24 The measured burner HRR versus steel temperatures and photograph of the specimen exposed to a fire.

Fig. 2-25 shows the average temperatures at various locations (LF, LW, MW, and UW) across the beam section exposed to a fire as a function of the burner HRR values. The column plots in this figure indicate variation in temperatures measured by the thermocouples at the similar location. At each location (LF, LW, MW, and UW), maximum temperature difference between two or more thermocouples was calculated at each time stamp, and averaged over different ranges of HRR indicated in the X-axis of Fig. 2-25. The temperature data at the location of UF was not included since only one thermocouple (TC1) was installed.

The magnitude of variation in measured temperature was influenced by the location of thermocouples (relative to the burner location). As shown in the column plots for the locations of LF, LW, and UW where two thermocouples each were installed, the temperature variation at LF was $16{ }^{\circ} \mathrm{C}$ on average in the full range of the burner HRR. The temperature deviation at LW and UW indicated less than $5{ }^{\circ} \mathrm{C}$ on average for the entire range of the burner HRR used in the test.

At the location of LF, the temperature difference among thermocouples was more sensitive to the applied HRR level. It appeared to be the greatest at the early stage of a fire (less than $400 \mathrm{~kW}$ at which fire was not impinged on the lower flange) and decreased with increasing HRR. The temperature difference was to $3{ }^{\circ} \mathrm{C}$ on average when the beam was fully engulfed by a fire. 
Around the centerline of the web (MW) where ten thermocouples were mounted with various methods, the maximum temperature difference between the ten thermocouples was $9{ }^{\circ} \mathrm{C}$ on average throughout the duration of the test.
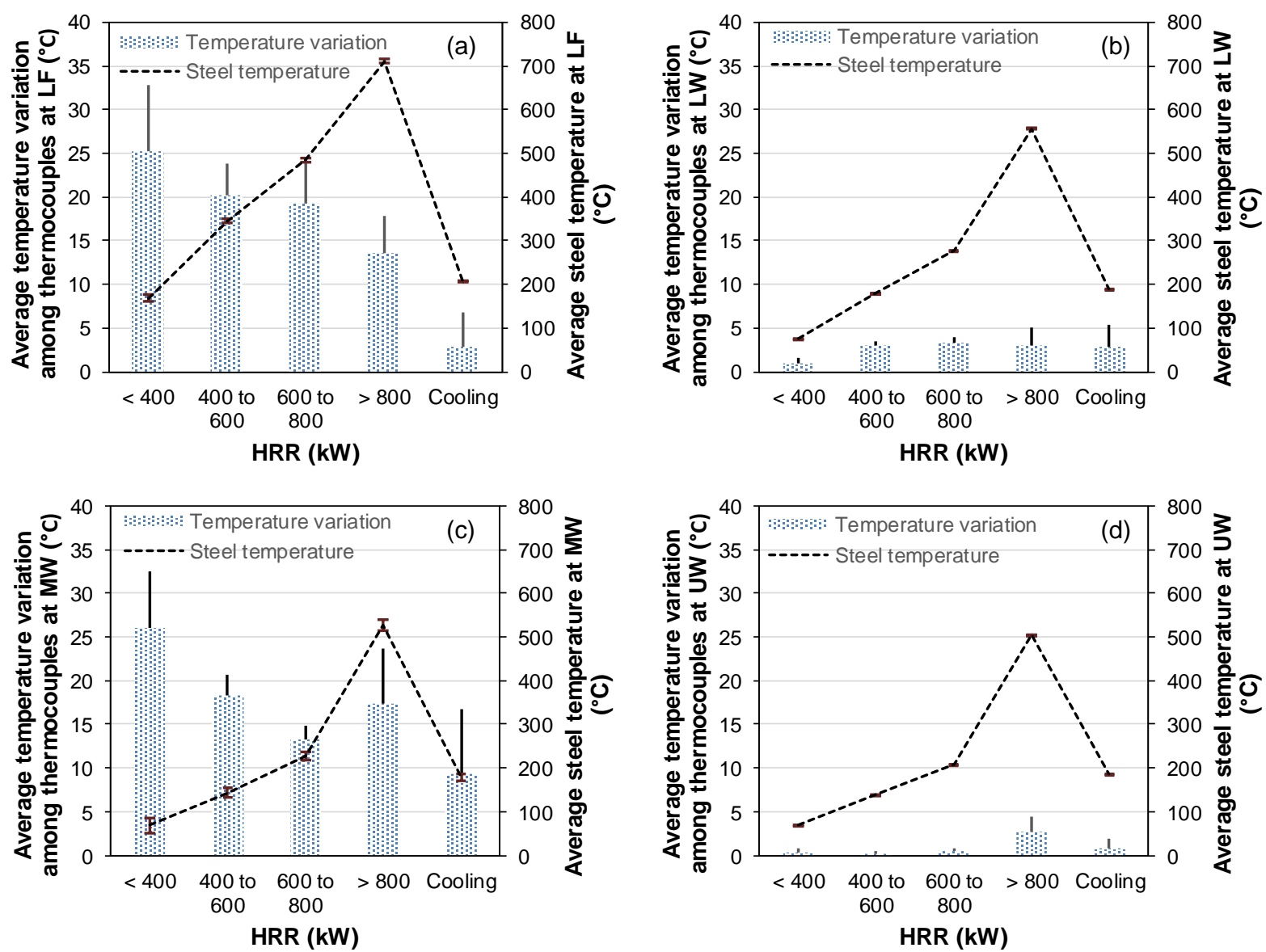

Figure 2-25 Temperature variation between thermocouples at different ranges of HRR and average temperature as a function of the burner HRR at the (a) lower flange (LF), (b) lower web (LW), (c) middle web (MW), and (d) upper web (UW). Error bars indicates the standard deviation.

As shown in Fig.2-24, the burner was turned off twice with each at $1505 \mathrm{~s}$ and at $1647 \mathrm{~s}$. The fire was out after $1754 \mathrm{~s}$ after ignition of the burner. Fig. 2-26 shows the graphs of temperature changes within four discrete locations (LF, LW, MW, and UW) of the cross section during two short cycles of the burner HRR control. In each graph, the green lines indicate the data from individual thermocouples and the black line is the averaged values. The temperature in the location of LF dropped by $(54 \pm 12){ }^{\circ} \mathrm{C}$ in about $30 \mathrm{~s}$ when the fire was suppressed. The temperature in other locations dropped by $35^{\circ} \mathrm{C}$ on average. 


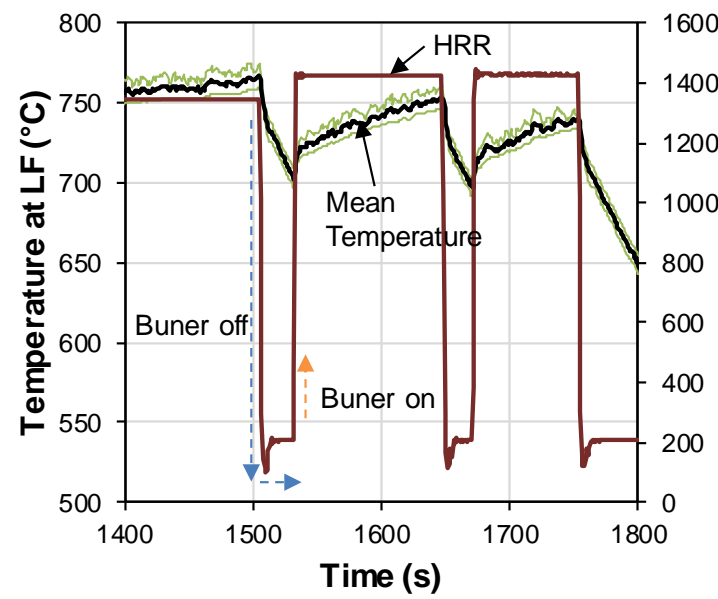

(a) $\mathbf{L F}$

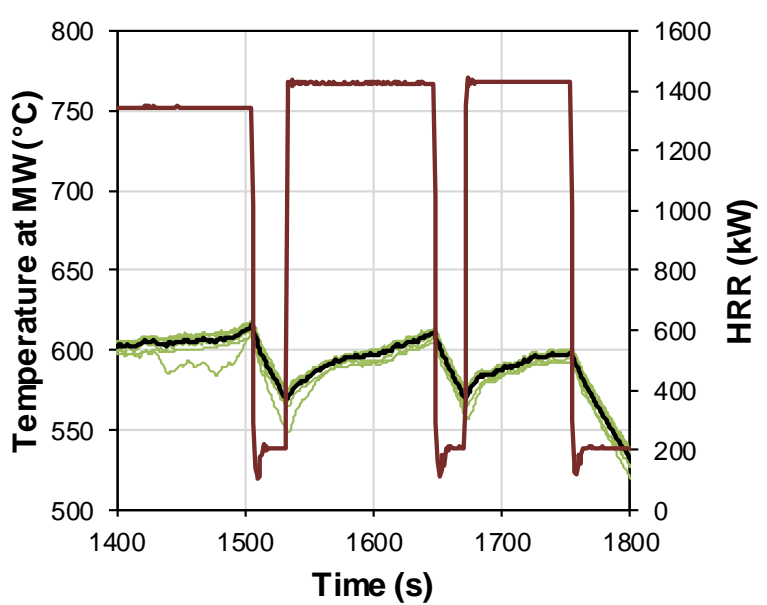

(c) MW

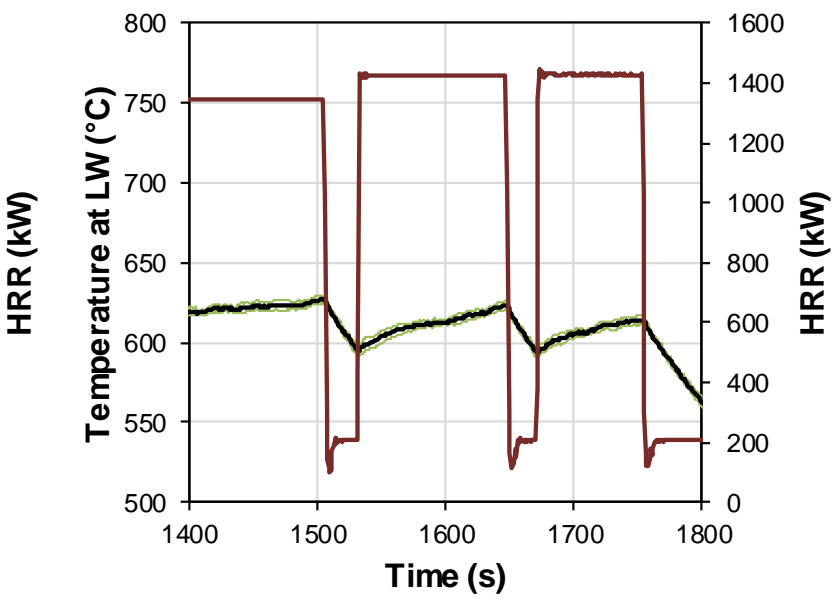

(b) $\mathbf{L W}$

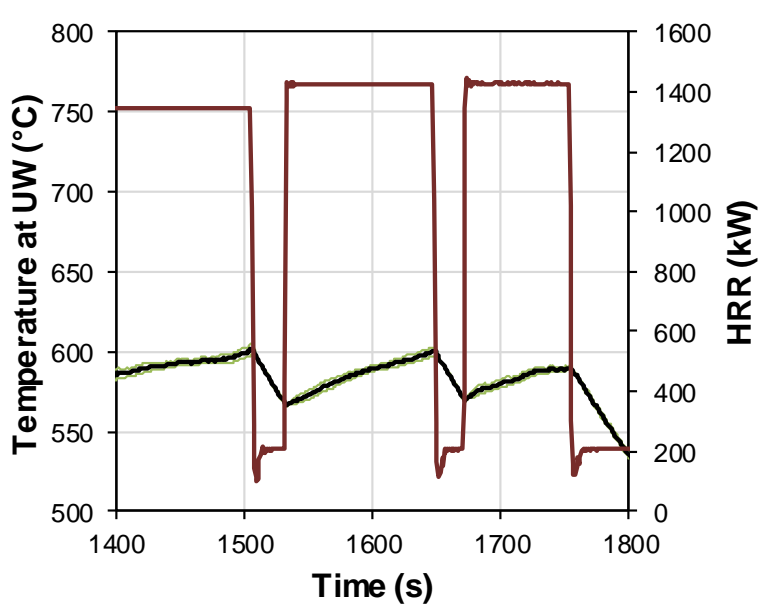

(d) UW

Figure 2-26 Temperature change in response to the burner HRR at the locations of (a) lower flange (LF), (b) lower web (LW), (c) middle web (MW), and (d) upper web (UW). The standard deviation of temperature readings at $\mathrm{LF}, \mathrm{LW}, \mathrm{MW}$, and $\mathrm{UW}$ locations is $3^{\circ} \mathrm{C}, 2^{\circ} \mathrm{C}, 9^{\circ} \mathrm{C}$, and $1^{\circ} \mathrm{C}$, respectively.

The mounting and insulation techniques of thermocouples also influenced the temperature measurement in the middle web (MW) of the beam specimen. Fig. 2-27 illustrates the measured temperature change $(\Delta T)$ measured by individual thermocouples mounted at the location of middle web during two cycles of the burner controls. The first cycle took place from $1500 \mathrm{~s}$ to $1650 \mathrm{~s}$ and the second cycle took place from $1650 \mathrm{~s}$ to $1750 \mathrm{~s}$ in test time. The average values of $\Delta T$ measured by all thermocouples are indicated as dashed lines. The results showed that TC 8 mounted using a threaded bolt was highly sensitive to change in gas temperature which would require additional insulation to minimize an error in the measurements of steel temperatures. Other thermocouples revealed similar magnitude of temperature changes resulted from either cooling or heating. 


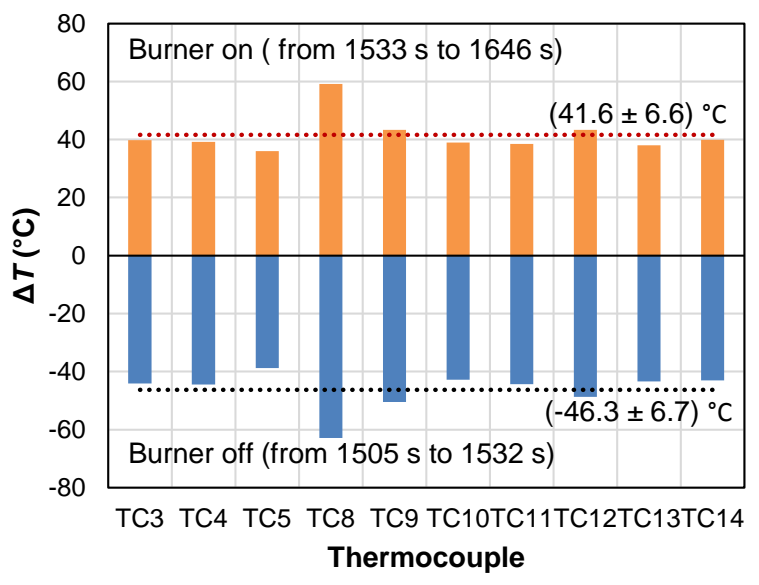

(a)

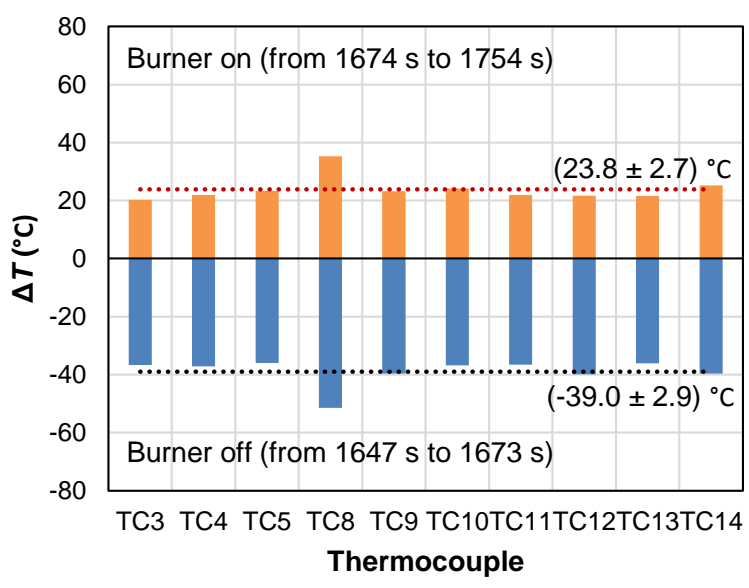

(b)

Figure 2-27 Temperature change ( $\Delta T$ ) measured by thermocouples mounted in the location of MW from (a) $1505 \mathrm{sec}$ to $1646 \mathrm{sec}$ and from (b) $1650 \mathrm{sec}$ to $1750 \mathrm{sec}$. Values after \pm symbol indicate standard deviation.

Fig. 2-28 shows some comparison of the instantaneous web temperature measured using the FLIR camera (with emissivity of 0.8 ) to thermocouple readings at $1765 \mathrm{~s}$ when the burner was off. The data from the FLIR camera were comparable to that using thermocouples. The FLIR data drops at the locations of thermocouples as shown in Fig. 2-28 are due to conductive and radiative cooling along the thermocouple wires and material emissivity.
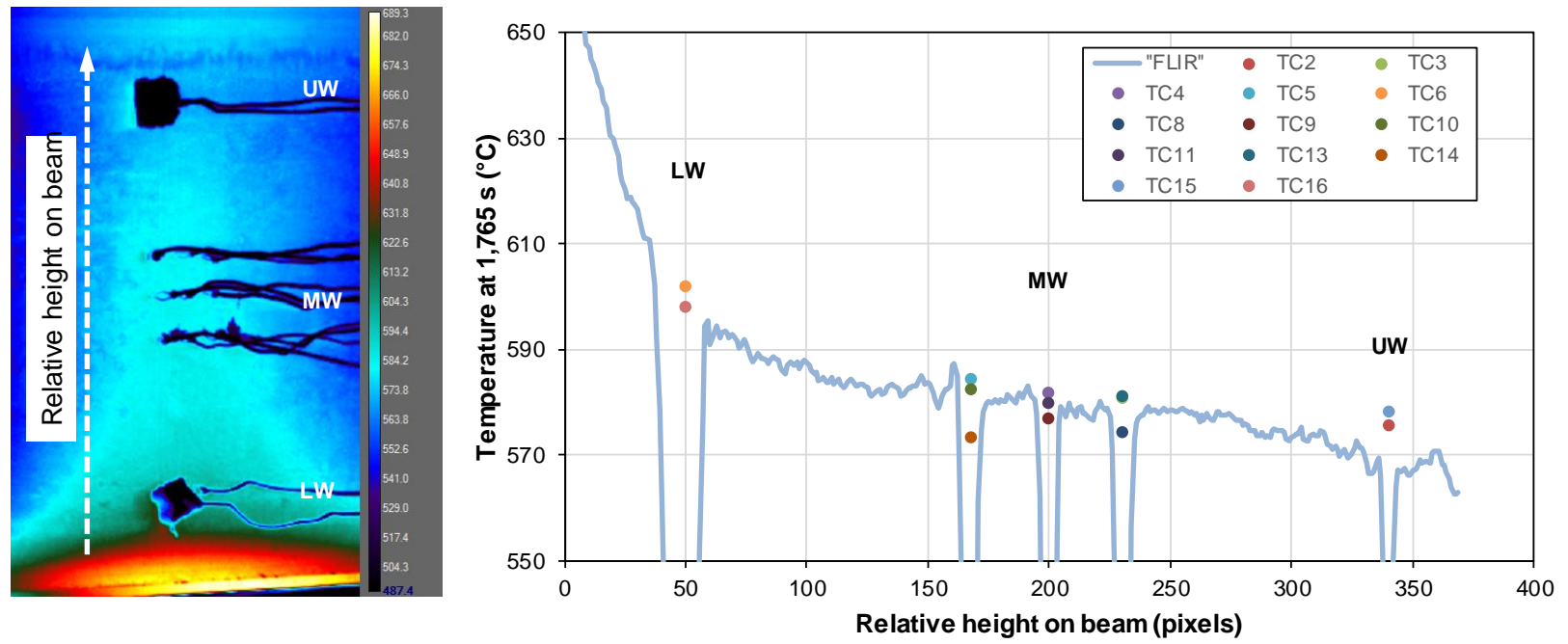

Figure 2-28 Web temperature measured using the FLIR camera and thermocouple readings at 1765 sec 
This page intentionally left blank. 


\section{Chapter 3 \\ THERMAL TESTS}

\section{$3.1 \quad$ INTRODUCTION}

This chapter presents the thermal tests on 6.17 m-long $\mathrm{W} 16 \times 26$ beam specimen exposed to a natural gas fire. These tests were intended to evaluate the temperature-time responses of the steel beam specimen and quantify the repeatability of fire, temperature, and displacement measurements. A total of five tests were conducted on the simply supported beam specimen as follows:

- Tests 1 and 2: Two repeated fire tests were conducted on the unloaded W16×26 beam specimen exposed to a fire at its midspan. The heat release rate of the burner increased in the increments of $100 \mathrm{~kW}$ by manually regulating a flow valve of a natural gas pipe.

- Tests 3 through 5: Three repeated fire tests on the unloaded W16×26 beam specimen exposed to fire maintained at the burner heat release rate of $400 \mathrm{~kW}$.

All the tests were terminated when any one of the thermocouples installed at the specimen indicated about $500{ }^{\circ} \mathrm{C}$. Test results included (i) the thermal responses measured using thermocouples installed in the steel beam and plate thermometers mounted at the midspan of the beam and (ii) the fire-induced axial and vertical displacements of the beam specimen. The uncertainties in the experimental measurements were also estimated.

\section{$3.2 \quad$ INSTRUMENTATION LAYOUT}

Fig. 3-1 shows the instrumentation layout of the beam specimen. For temperature measurements, a total of forty-five, Type-K, 24-gauge thermocouples were installed at eleven different crosssections along the beam length. All the thermocouples were installed by peening as described in Section 2.3.8. Only for Tests 3 through 5 , four $10 \mathrm{~cm} \times 10 \mathrm{~cm}$ plate thermometers were mounted to measure the adiabatic surface temperature at the cross-section located $7.6 \mathrm{~cm}$ away from the midspan of the beam specimen. For displacement measurements, linear string potentiometers with temperature compensated dual cords, as described in Section 2.3.2, were used to measure the vertical displacement at the fire-exposed midspan of the beam specimen. Four $25 \mathrm{~mm}$ linear position sensors were mounted at the beam ends to measure axial displacement of the beam 
specimen during the fire exposure. Detailed drawings of test setup and locations of individual sensors are reported in Appendices.

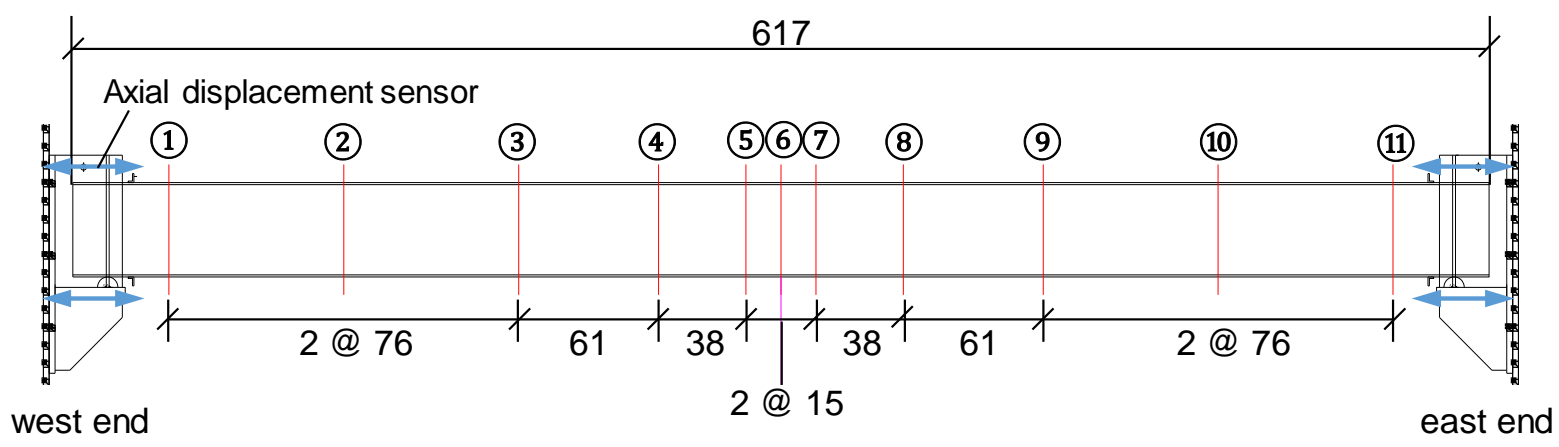

Thermocouples

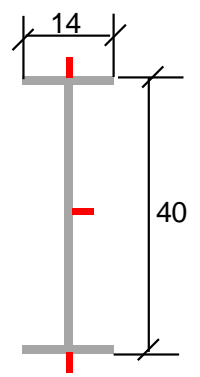

Sections $1-3 \&$ 9-11

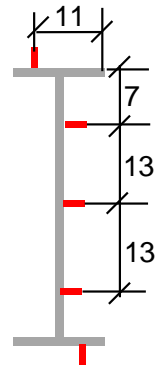

Sections 4, 5, $7 \& 8$
Plate thermometers

(Test 3-5 only)

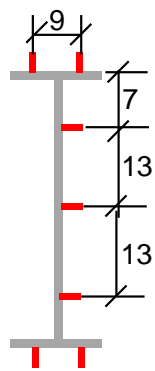

Section 6

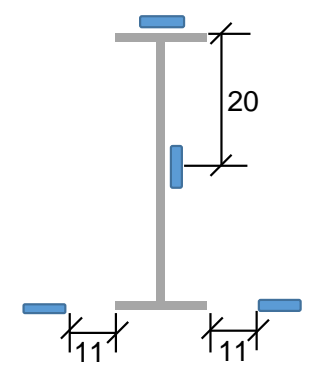

Halfway between Sections 6 and 7
String potentiometers

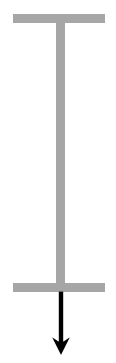

Section 6

(midpsan)

Figure 3-1 Instrumentation layout (unit: $\mathrm{cm}$ ).

\subsection{FIRE CONDITIONS}

Fig. 3-2 shows snapshots of a video recorded during Test 1 to show the flame height of a fire produced at each level of the burner heat release rate (HRR). In both Tests1 and 2, the burner HRR was increased in the increment of $100 \mathrm{~kW}$ up to $500 \mathrm{~kW}$ by manually regulating a flow valve of a natural gas pipe. The burner was turned off when the maximum steel temperature (recorded using thermocouples) reached about $500{ }^{\circ} \mathrm{C}$. Both tests lasted about $28 \mathrm{~min}$. Fig.3-3(a) shows the burner HRR versus time relation recorded during Tests 1 and 2. Fig. 3-3(b) shows a direct comparison of the burner HRR measurement between two tests. The results showed that manually controlling the burner HRR produced repeatable fire conditions. For this particular fire curve, the difference in the burner HRR measurements between two repeated tests was $1.2 \%$. 

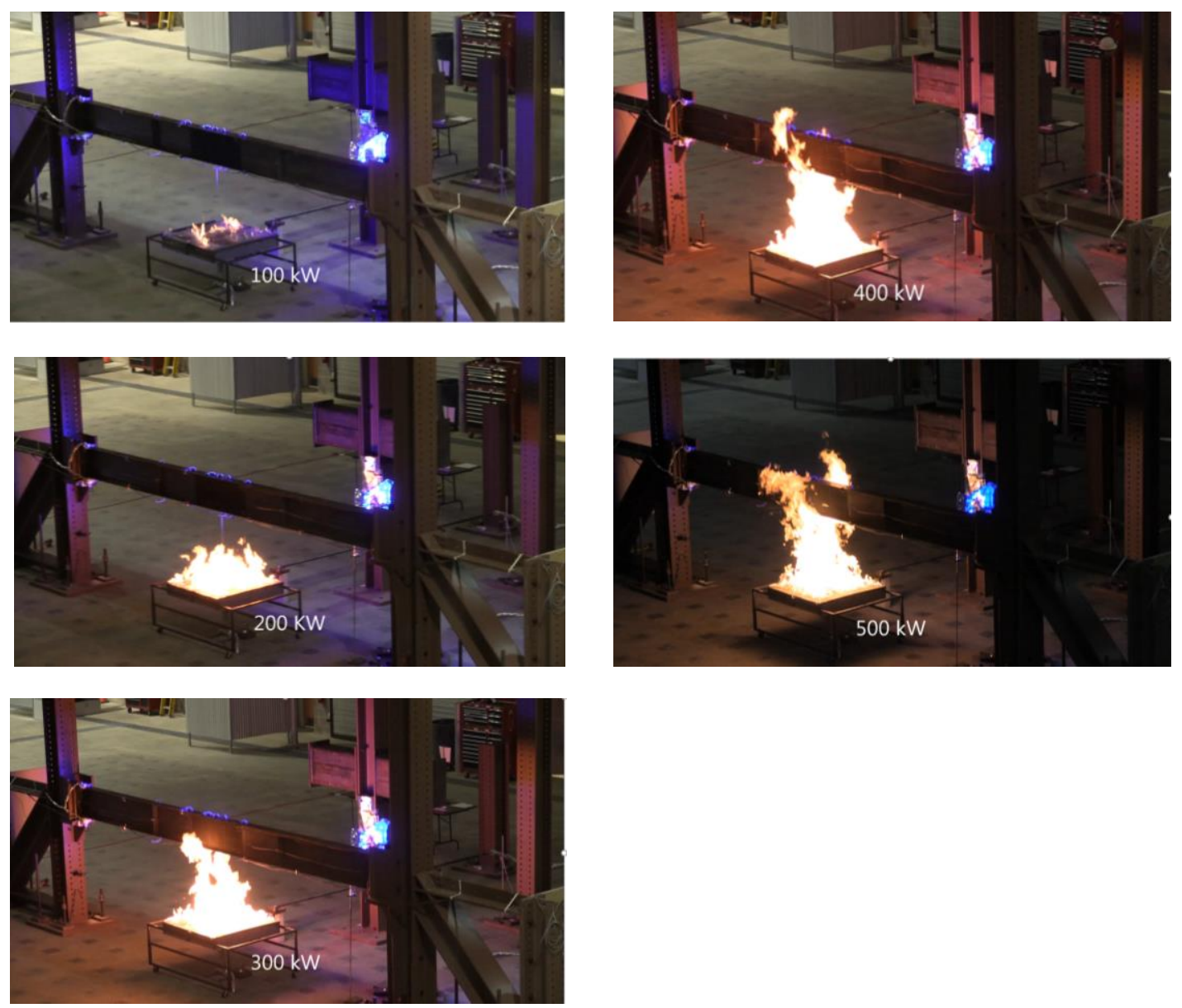

Figure 3-2 Snapshots of Test 1.

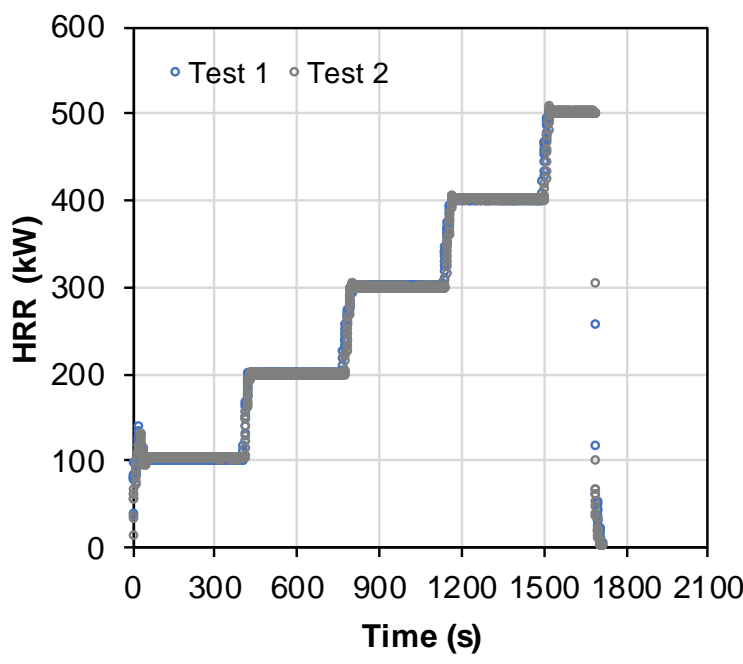

(a)

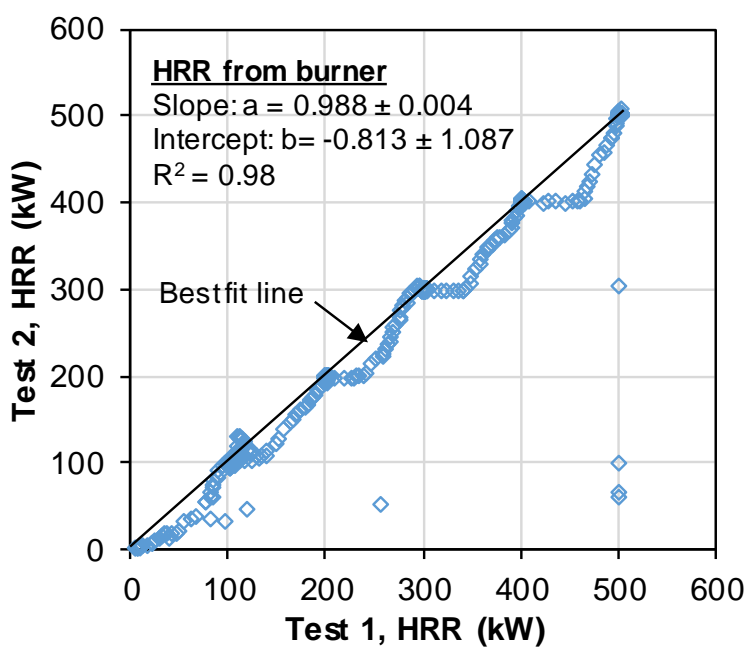

(b)

Figure 3-3(a) Recorded burner HRR versus time relation and (b) comparison of Tests 1 and 2. 
Table 3-1 summarizes the average and the coefficient of variation (CV) of the measured burner HRR values over a certain duration of each target HRR level.

Table 3-1 The target, average, and coefficient of variation (CV) of the burner HRR values from Tests 1 and 2.

\begin{tabular}{cccc}
\hline $\begin{array}{c}\text { Duration } \\
(\mathbf{s e c})\end{array}$ & $\begin{array}{c}\text { Target HRR } \\
(\mathbf{k W})\end{array}$ & $\begin{array}{c}\text { Average HRR } \\
(\mathbf{k W})\end{array}$ & $\begin{array}{c}\mathbf{C V} \\
(\mathbf{\%})\end{array}$ \\
\hline $50-400$ & 100 & 102 & 0.38 \\
$450-750$ & 200 & 200 & 0.16 \\
$820-1,120$ & 300 & 301 & 0.07 \\
$1200-1490$ & 400 & 402 & 0.04 \\
$1530-1680$ & 500 & 502 & 0.06 \\
\hline
\end{tabular}

Tests 3 through 5 were the repeated tests in which the steel beam specimen was exposed to a 400kW fire. Fig. 3-4 shows the measured burner HRR as a function of time. As shown, the burner HRR was maintained to $400 \mathrm{~kW}$ on average from $60 \mathrm{~s}$ to $1500 \mathrm{~s}$. The standard deviation of the measured burner HRR values during this period was $1 \mathrm{~kW}$. Fig. 3-5 shows snapshots of a video recorded during Test 3. Although the burner HRR was set to $400 \mathrm{~kW}$, the burner developed a flame that had a distinct pulse.

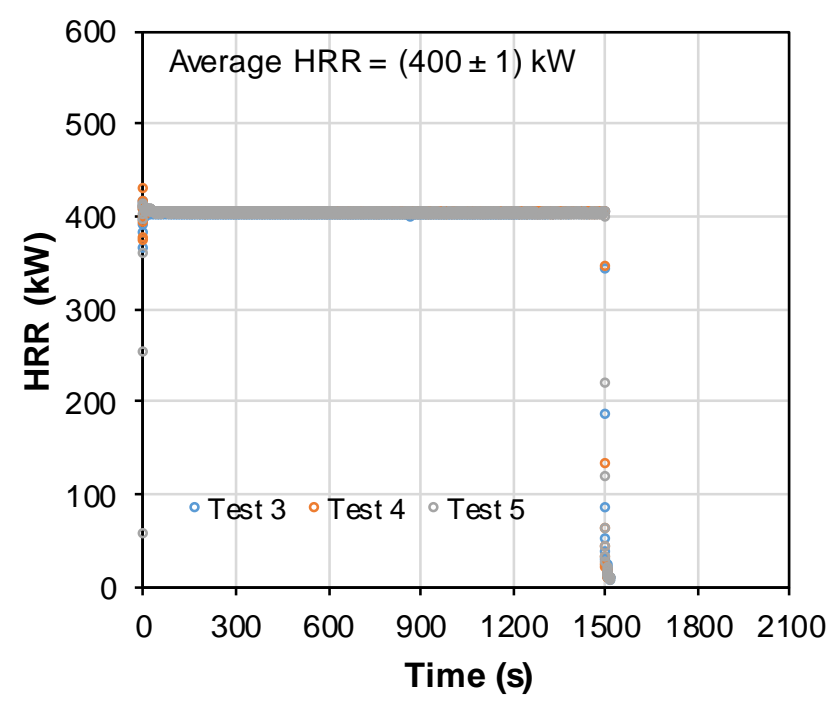

Figure 3-4 Recorded burner HRR versus time relation of Tests 3 through 5. 


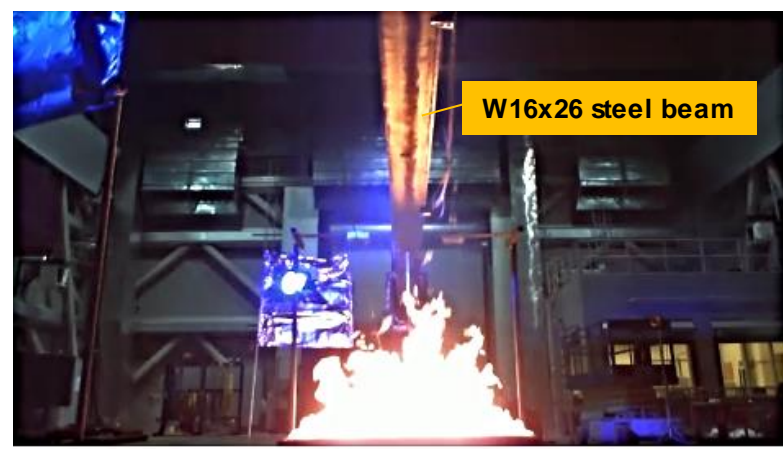

14:27.30/30:33.06 त्र

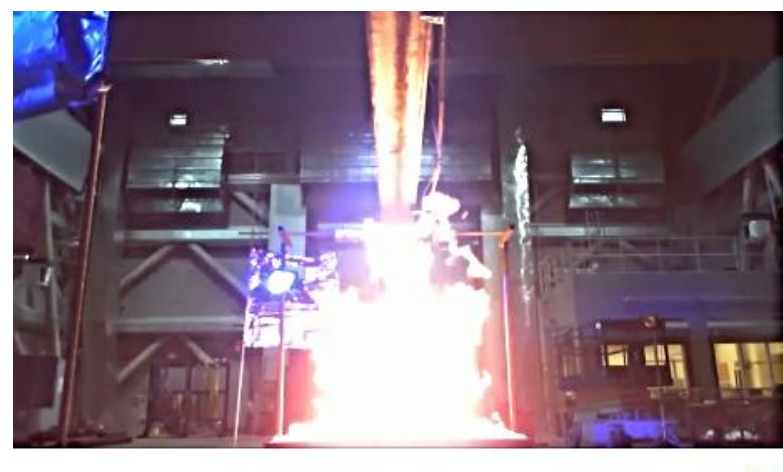

14:27.50/30:33.06 주

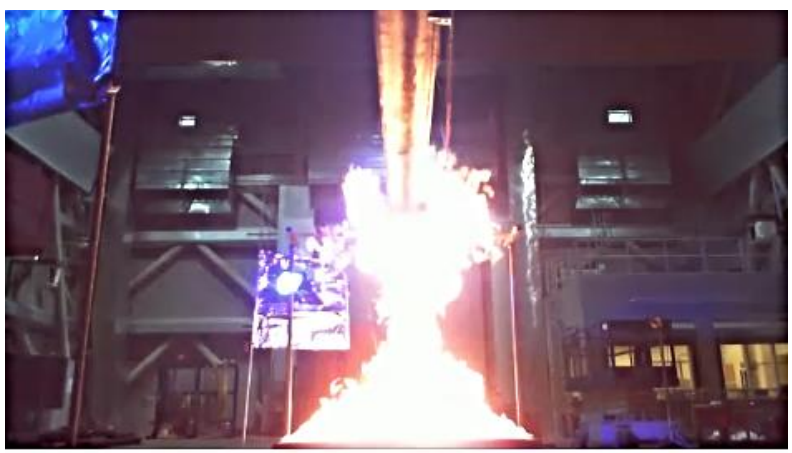

14:27.73/30:33.06

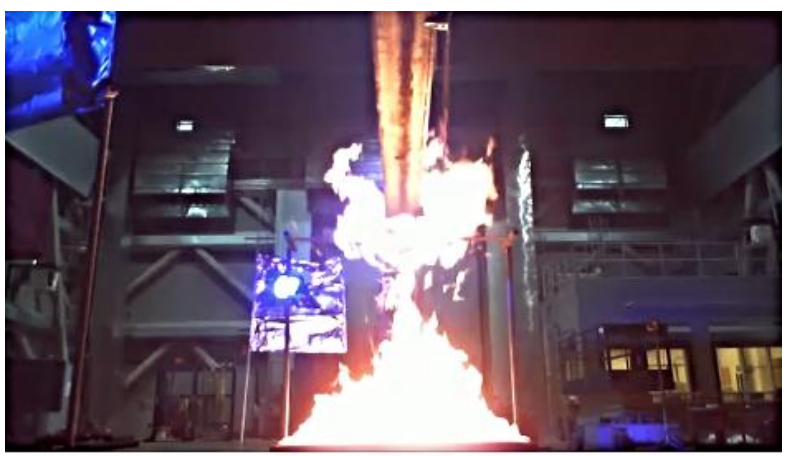

14:27.83/30:33.06 त्र

Figure 3-5 Snapshots of Test 3.

\section{$3.4 \quad$ TEST RESULTS}

\subsubsection{Tests 1 and 2}

Fig. 3-6 shows temperature contours of the steel beam specimen exposed to a fire at $220 \mathrm{~s}, 970 \mathrm{~s}$, and $1600 \mathrm{~s}$ when a target HRR of the burner was $100 \mathrm{~kW}, 300 \mathrm{~kW}$, and $500 \mathrm{~kW}$, respectively. The average values of temperature recorded from two repeated tests were plotted. In this figure, the vertical axis is the distance from the bottom flange (facing the strong floor) to the top flange of the specimen. The bottom horizontal axis is the distance from the west to the east ends of the specimen. The top horizontal axis indicates each location of thermocouple sections shown in Fig 3-1. A white line indicates the location of the specimen midspan.

As shown in Fig. 3-6, the non-uniform thermal gradient was developed through the section depth and along the beam length. Since the burner was located under the center of the specimen, the largest temperature rise of the specimen was located at the lower portion of sections 5 through 7 . Until the burner HRR increased to $500 \mathrm{~kW}$, the heated surface was limited to the region between sections 3 and 9. There was no noticeable increase in temperatures towards the beam ends. 
Fig. 3-7(a) shows the temperature-time response of the specimen midspan at various locations across the section, including UF (upper flange), UW (upper web), MW (middle web), LW (lower web), and LF (lower flange) as shown in Fig. 2-21. Each graph in Fig. 3-7(a) indicates the average temperature reading from Tests 1 and 2. As shown, the temperature increased near linearly with time although the burner HRR was increased in steps of $100 \mathrm{~kW}$ [Refer to Fig. 3-3(a)]. Fig. 3-7(b) shows the average temperature at five different locations in the cross section when the burner HRR was maintained at each target value. The error bars indicate the standard deviation of temperature readings at sections 5 through 7 [Refer to Fig. 3-1] from two repeated tests. As shown, the magnitude of error bars varied with locations of thermocouples and the burner HRR levels. The maximum standard deviation was $28^{\circ} \mathrm{C}$ at the lower flange when the burner HRR was maintained at $500 \mathrm{~kW}$.
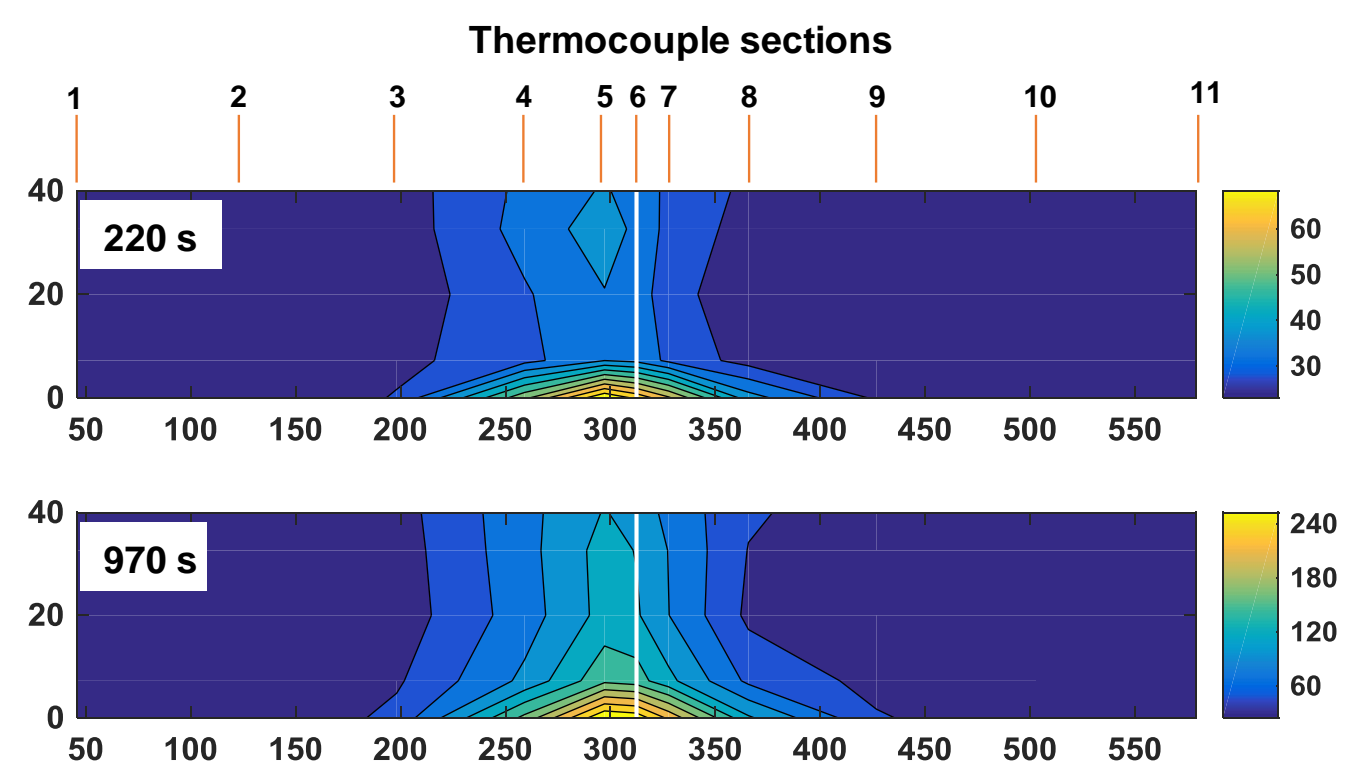

\section{Upper}

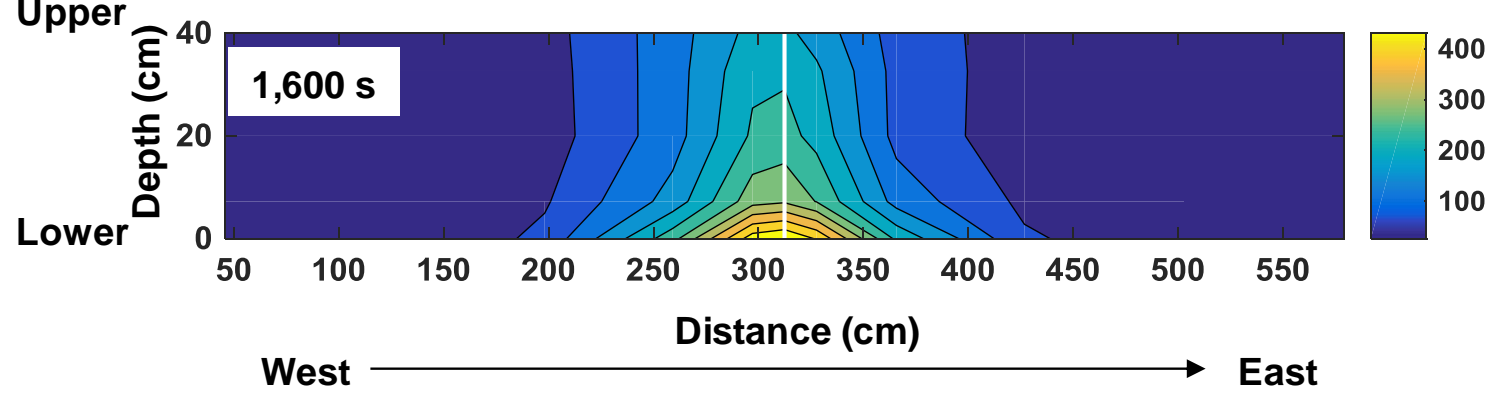

Figure 3-6 Temperature contours of the beam specimen exposed to a localized fire with increasing heat release rates of the burner. 


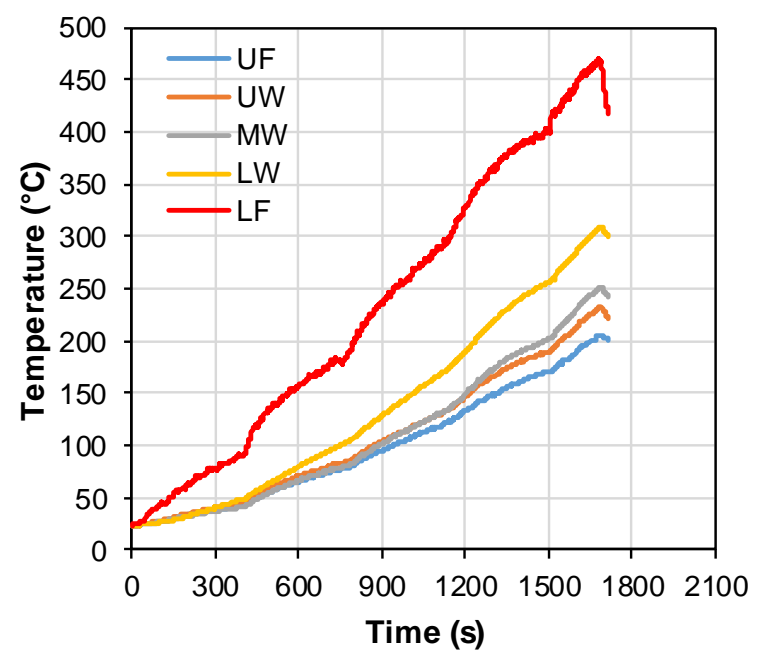

(a)

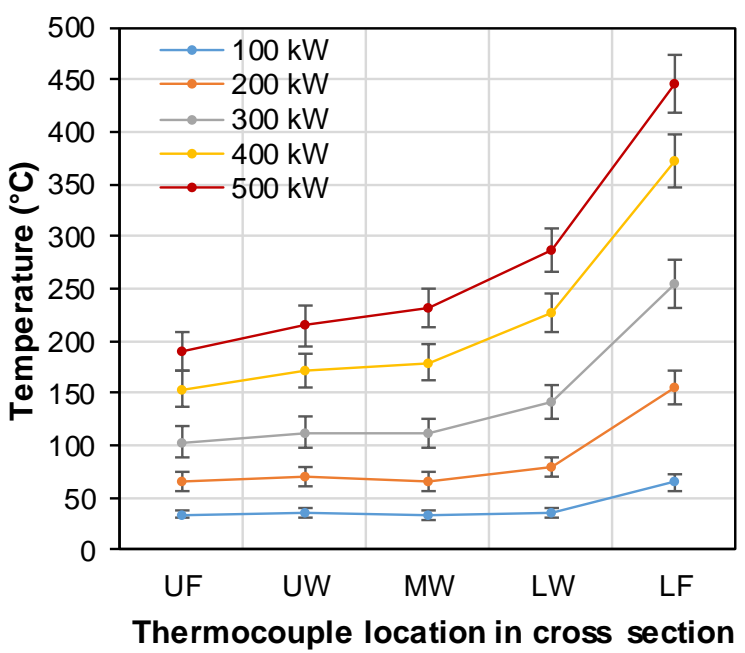

(b)

Figure 3-7(a) Temperature-time responses of the fire-exposed midspan and (b) The average temperatures at every 100-kW increment.

Fig. 3-8 shows the axial displacement at the beam ends and the vertical displacements at midspan. Since the lower portion of the midspan cross section was hotter than its upper portion (Fig. 3-7), the bottom flange elongated more than the top flange as shown in Fig. 3-8(a). This non-uniform elongation also caused the beam to bend toward the hotter side. This thermal bowing effect can be seen in Fig. 3-8(b) that the vertical displacement at midspan continuously increased throughout the test.

The values presented in Fig. 3-8 are the average displacements of two repeated tests, Tests 1 and 2. Error bars in each graph indicate the standard deviation of displacement data when the burner HRR was maintained at each target value. At the burner HRR of $500 \mathrm{~kW}$, the standard deviation of the axial and the vertical displacements was $0.30 \mathrm{~mm}$ and $0.65 \mathrm{~mm}$, respectively. The standard deviation of the midspan vertical displacement was and. 


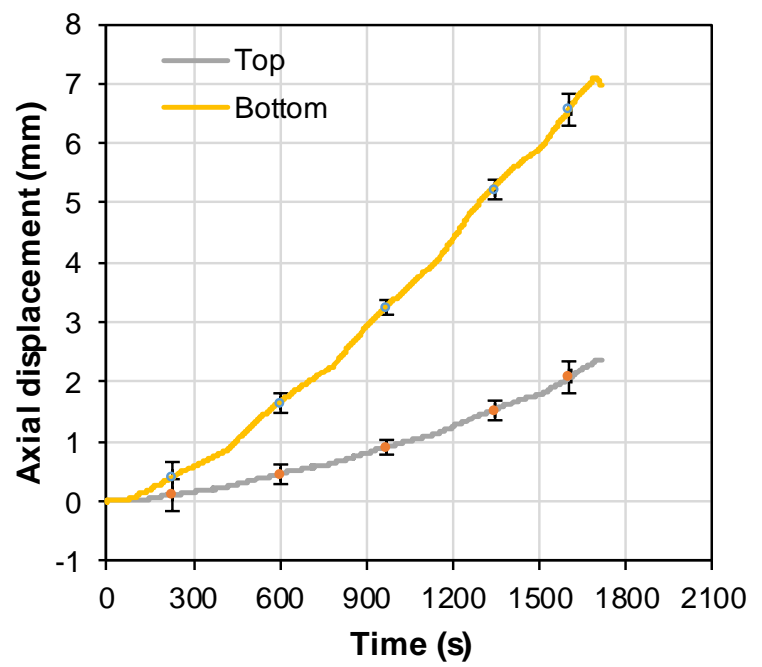

(a)

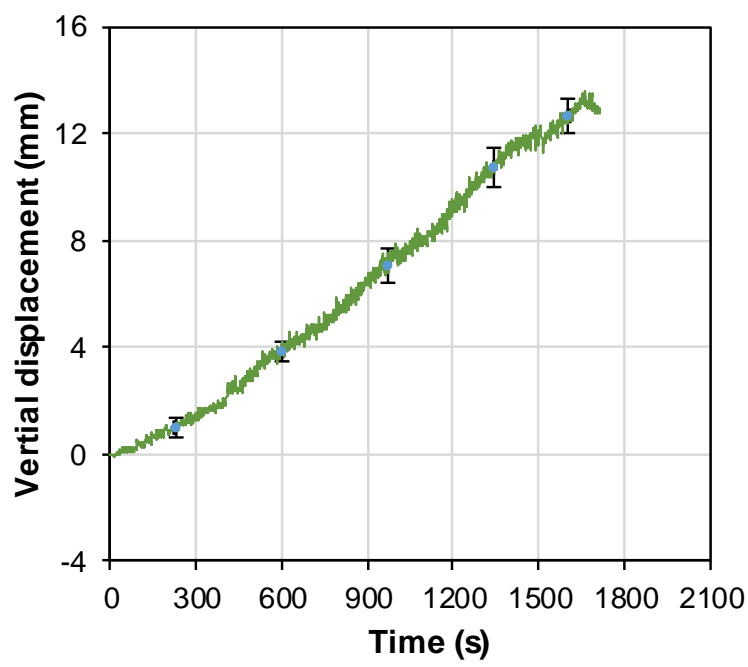

(b)

Figure 3-8(a) Axial and (b) vertical displacements of the beam specimen.

\subsubsection{Tests 3 through 5}

In Tests 3 through 5, the burner HRR was fixed at $400 \mathrm{~kW}$. The specimen temperature was measured using the same thermocouples installed in Tests 1 and 2 as shown in Fig. 3-1. Fig. 3-9 shows temperature contours of the specimen at $220 \mathrm{~s}, 970 \mathrm{~s}$, and $1500 \mathrm{~s}$ after ignition of a fire. The temperature values were the average temperatures recorded from three repeated tests. The axes of the contour plots are explained in Section 3.4.1.

Similar to Tests 1 and 2, thermal gradient was developed through the section depth and along the length. Only the middle portion of the beam (between sections 3 through 9) heated because of the location of a fire source. As can be seen in Fig. 3-9, the temperature distribution along the beam length was symmetric with respect to the center line of the beam specimen (white solid line). 


\section{Thermocouple sections}
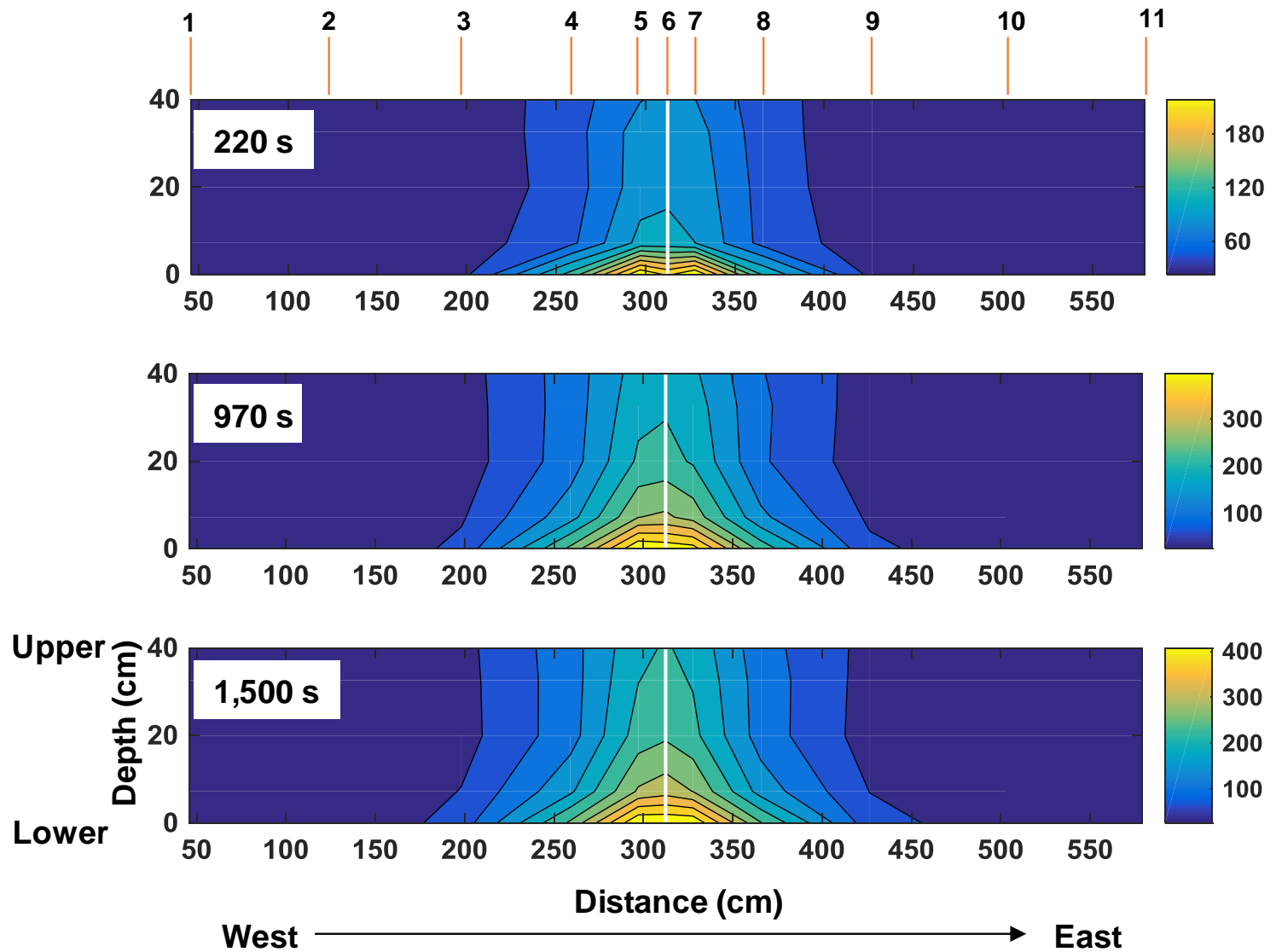

Figure 3-9 Temperature contours of the beam specimen exposed to a localized fire with the burner heat release rate of $400 \mathrm{~kW}$.

Fig. 3-10(a) shows the temperature data at various locations in the fire-exposed mid-section. The data presented in the graph were the average values of temperature measured using thermocouples mounted in the sections 5 through 7 at five different locations, i.e., UF, UW, MW, LW, and LF (Refer to Fig. 2-21). As shown, the temperature rise in the mid-section was nonlinear with respect to the fire exposure time, given that the burner HRR was set to $400 \mathrm{~kW}$. It can be also seen that the temperature increased rapidly until the fire exposure time reached about $300 \mathrm{~s}$. The increase in temperature tapered off after 10 min passed from ignition.

Fig. 3-10(b) shows the average cross-sectional temperature at the early stage (from $50 \mathrm{~s}$ to $400 \mathrm{~s}$ ) and the final stage (from $1200 \mathrm{~s}$ to $1490 \mathrm{~s}$ ) of fire exposure. The error bars indicate the standard deviation of temperature readings from three repeated tests. The standard deviation of the temperature at the location of LF was $12{ }^{\circ} \mathrm{C}$ during the last 5 min before the burner was shut off. 


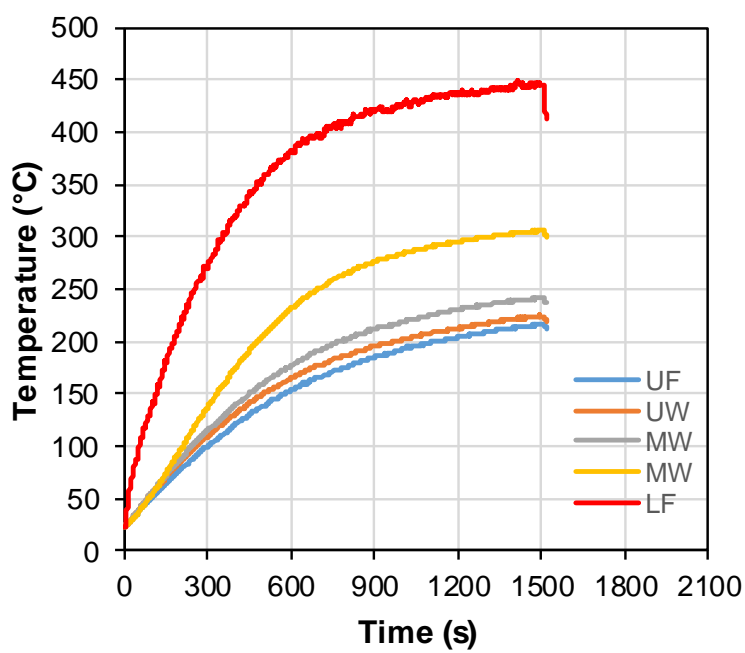

(a)

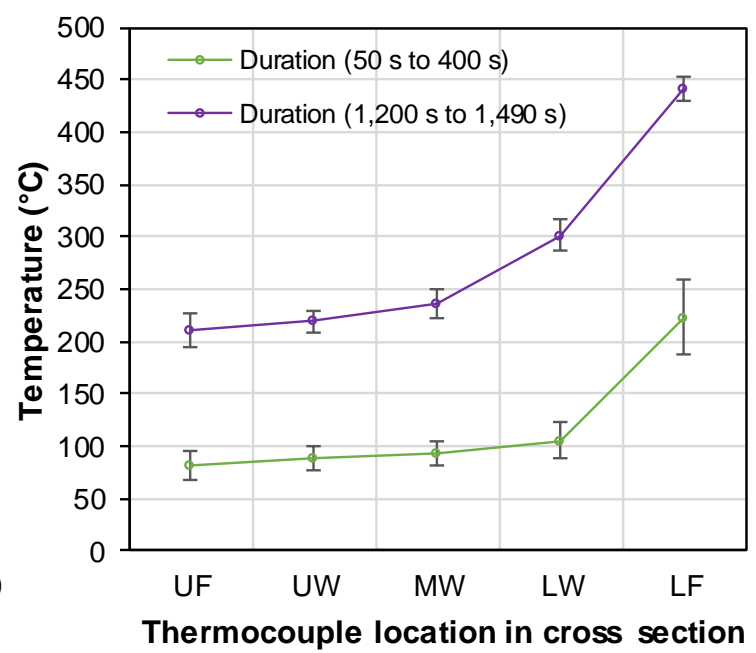

(b)

Figure 3-10 Temperature-time responses of the fire-exposed midspan and (b) the average temperatures at the early and final stage of a fire.

Fig. 3-11(a) shows a photograph of plate thermometers installed at four different locations at the specimen midspan, including the lower flange at north $\left(\mathrm{LF} \_\mathrm{N}\right)$, the lower flange at south (LF_S), middle web (MW), and upper flange (UF). Figure 3-12(b) shows the measured adiabatic surface temperature (AST) as a function of fire exposure time. The plotted data are the average AST values from three repeated tests. The error bars shown in the figure are the standard deviation computed using the data recorded at four different periods, including from $50 \mathrm{~s}$ to $400 \mathrm{~s}$, from $450 \mathrm{~s}$ to 750 $\mathrm{s}$, from $820 \mathrm{~s}$ to $1120 \mathrm{~s}$, and from $1200 \mathrm{~s}$ to $1490 \mathrm{~s}$. As shown, the AST values measured at the location of LF_S were higher than that measured at LF_N, with the average difference of $82{ }^{\circ} \mathrm{C}$. The average AST from $600 \mathrm{~s}$ to $1500 \mathrm{~s}$ was $(460 \pm 26){ }^{\circ} \mathrm{C}$ at LF_N, $(540 \pm 14){ }^{\circ} \mathrm{C}$ at LF_S, $(140 \pm 10){ }^{\circ} \mathrm{C}$ at $\mathrm{UF}$, and $(230 \pm 26){ }^{\circ} \mathrm{C}$ at MW. The higher adiabatic surface temperature at LF_S than at LF_N is due to the flame lean toward the south during the test.

Fig. 3-12 shows the axial displacement at the beam ends and the vertical displacements at midspan when the specimen was exposed to a $400 \mathrm{~kW}$ fire. The data shown in the graph was the average displacement measured from repeated tests. The error bar in the graph indicate the one-standard deviation of the averaged values over a certain period of fire exposure. Like Tests 1 and 2, the bottom flange of the beam specimen elongated more than the top flange. The beam deflected downwards because of non-uniform elongation in the cross section. The standard uncertainty (with one standard deviation) in the displacement measurements, estimated using the data recorded from $600 \mathrm{~s}$ to $1500 \mathrm{~s}$ in three tests, was $0.2 \mathrm{~mm}$ for the top flange elongation, $0.3 \mathrm{~mm}$ for the bottom flange elongation, and $0.6 \mathrm{~mm}$ for the vertical displacement at midspan. 


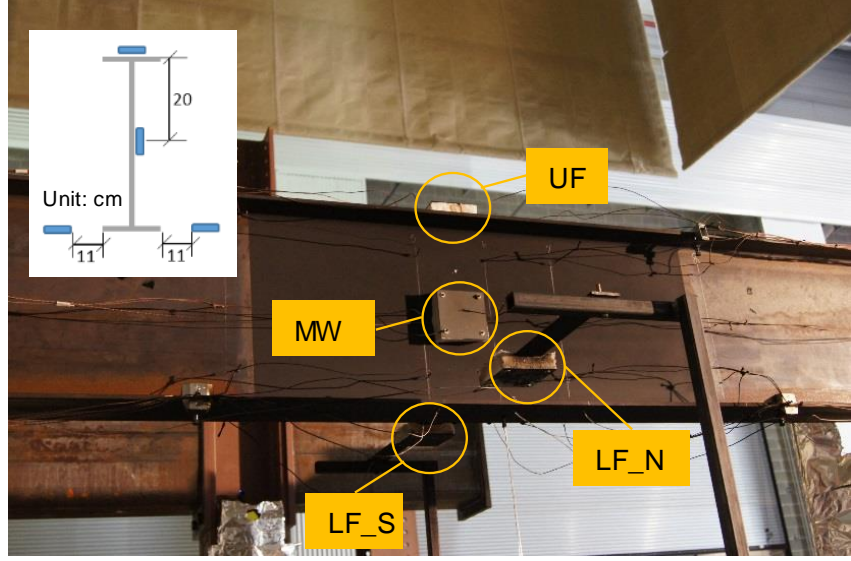

(a)

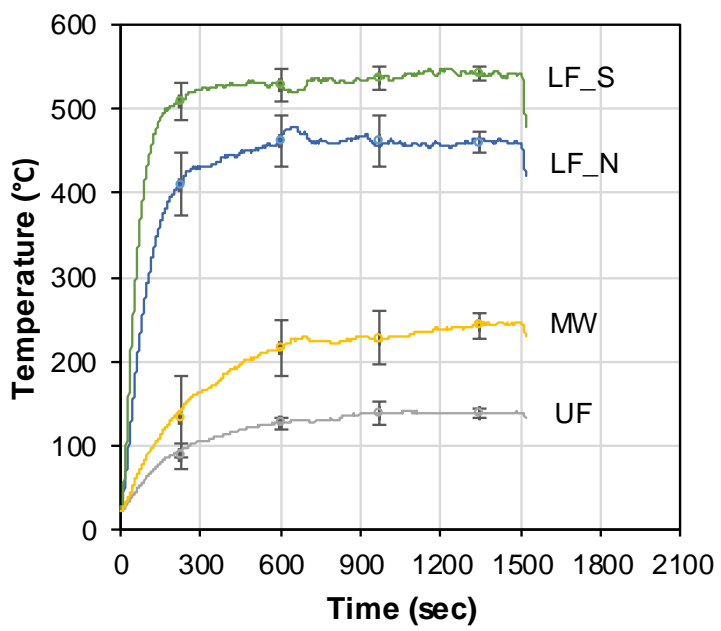

(b)

Figure 3-11 Location of plate thermometers used in Tests 3 through 5 and (b) measured adiabatic surface temperatures as a function of fire exposure time. Error bars indicate the standard deviation among Tests 3 through 5.

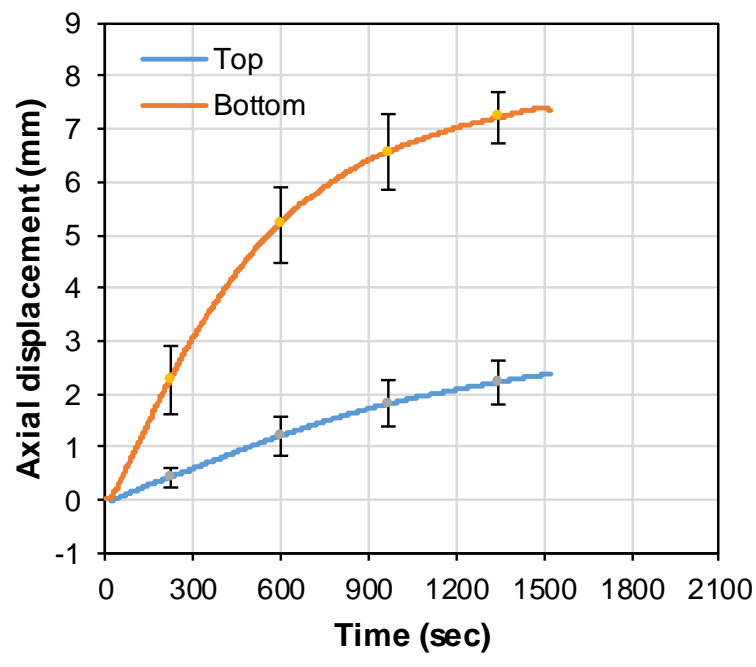

(a)

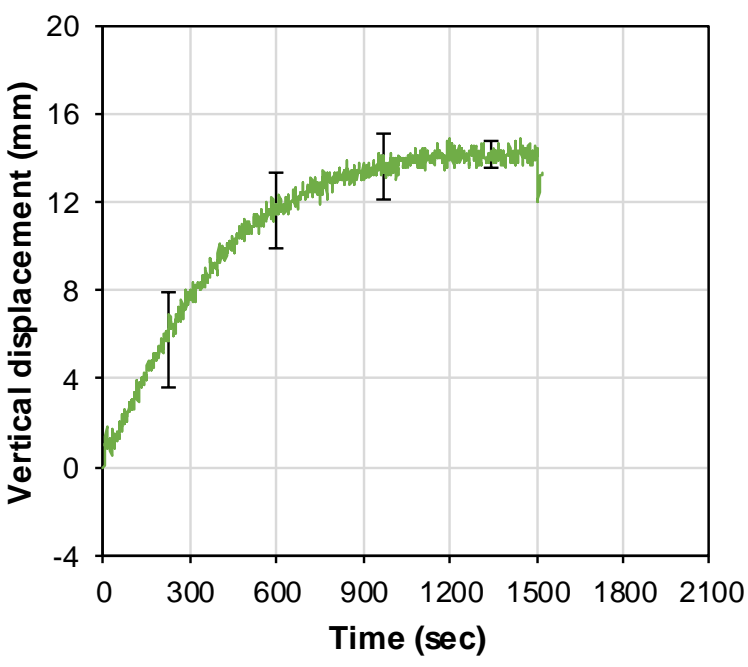

(b)

Figure 3-12(a) Axial and (b) vertical displacements of the beam specimen. Error bars indicate the standard deviation among Tests 3 through 5. 
This page intentionally left blank. 


\section{Chapter 4 \\ STRUCTURAL-FIRE TESTS}

\subsection{INTRODUCTION}

This chapter presents four-point bending tests on the W16×26 beam specimens at roomtemperature and localized fire conditions. As described in Chapter 2, two loading beams with hollow structural section (HSS) were used to apply point loads on the steel beam at two locations $2.44 \mathrm{~m}$ apart around midspan. In the localized fire tests, the same natural gas burner used in the thermal tests (Chapter 3) produced an open flame, localized fire exposure directly to the mid portion of the specimen. The natural gas burner was located $1.1 \mathrm{~m}$ below the bottom flange of the beam specimen at midspan. Each specimen was supported by columns with one of two connection types, including (i) purpose-built seated connection to provide the simply supported boundary condition and (ii) all-bolted double angles.

Each of structural-fire tests are briefly summarized as follows:

- Test 6: The beam specimen was loaded to its ultimate moment capacity at ambient temperature. The beam was simply supported.

- Test 7: The beam specimen was loaded to its ultimate moment capacity under the localize fire condition in which the burner heat release rate was fixed at $700 \mathrm{~kW}$. The beam was simply supported.

- Tests 8: The beam specimen was loaded to $67 \%$ of its ultimate strength at ambient temperature (from Test 6 ) and then exposed to increasing temperature from a growing fire (i.e. $t$-squared fire) until failure occurred. The beam was simply supported.

- Test 9: The beam specimen was tested under the same loading and fire conditions as Test 8, but the beam was supported by columns through bolted double angles.

All the specimens were fabricated from the same heat and the room-temperature material properties are presented in Section 2.2.2. Test results included (i) thermal responses such as steel temperature and adiabatic surface temperature and (ii) structural responses including forces, strains and displacements. Note that in this chapter the values after \pm symbol indicate the standard 
deviation of the data that was used to compute the average values of temperatures, heat release rates, forces, displacements or strains measured over a certain period. The uncertainty in the measurement with specific sensors was summarized in Table 2-5. The complete data set is reported in Choe and Ramesh (2017). Appendix B provides the instrumentation layout and the complete list of sensors used in each test.

\subsection{TEST 6: FOUR POINT BENDING TEST AT AMBIENT TEMPERATURE}

Test 6 was the room-temperature bending test on the simply supported W16×26 beam specimen. The specimen was loaded at the location of each HSS loading beam which was $2.44 \mathrm{~m}$ apart around midspan. Loading was applied using a displacement control, and the displacement rate of all four actuators was synchronized throughout the test. Details of the beam support conditions, the roomtemperature mechanical properties of steel, and the structural loading arrangement are described in Section 2.2.2 and Appendix A.

\subsubsection{Instrumentation Layout}

Fig. 4-1 shows the instrumentation layout. A total of eighteen linear strain gauges were installed in sections 1 through 5. A total of six linear displacement transducers (i.e., string potentiometers) were installed at the specimen midspan and the location of point loads to measure the vertical and lateral displacements. A 222-kN load cell was mounted below the specimen ends to measure the vertical reaction forces. The magnitudes of reaction forces were compared with that of the loads transferred by the HSS loading beams. The applied loads and displacements at the ends of each HSS loading beam were measured using MTS actuators.

\subsubsection{Test Conditions}

Two HSS loading beams placed on the specimen were used to apply point loads $2.44 \mathrm{~m}$ apart around the midspan of the beam. As shown in Fig.2-9 in Section 2.2.2, four MTS actuators were connected at each end of two loading beams through high-strength steel tension rods. The actuators were programmed to increase a load at a displacement rate of $1.3 \mathrm{~mm} / \mathrm{min}$ in the elastic regime and at a displacement rate of $0.25 \mathrm{~mm} / \mathrm{min}$ in the inelastic regime.

Fig. 4-2 shows the average actuator force $(\mu)$ measured during the test, along with the one-standard deviation $(\sigma)$ among four actuators. As shown, the peak actuator force of $(67 \pm 1.5) \mathrm{kN}$ was measured at 128 min when the beam buckled. Loading continued in the post-buckling phase until the actuator force reached about $80 \%$ of its peak value, $(52 \pm 1.7) \mathrm{kN}$. 

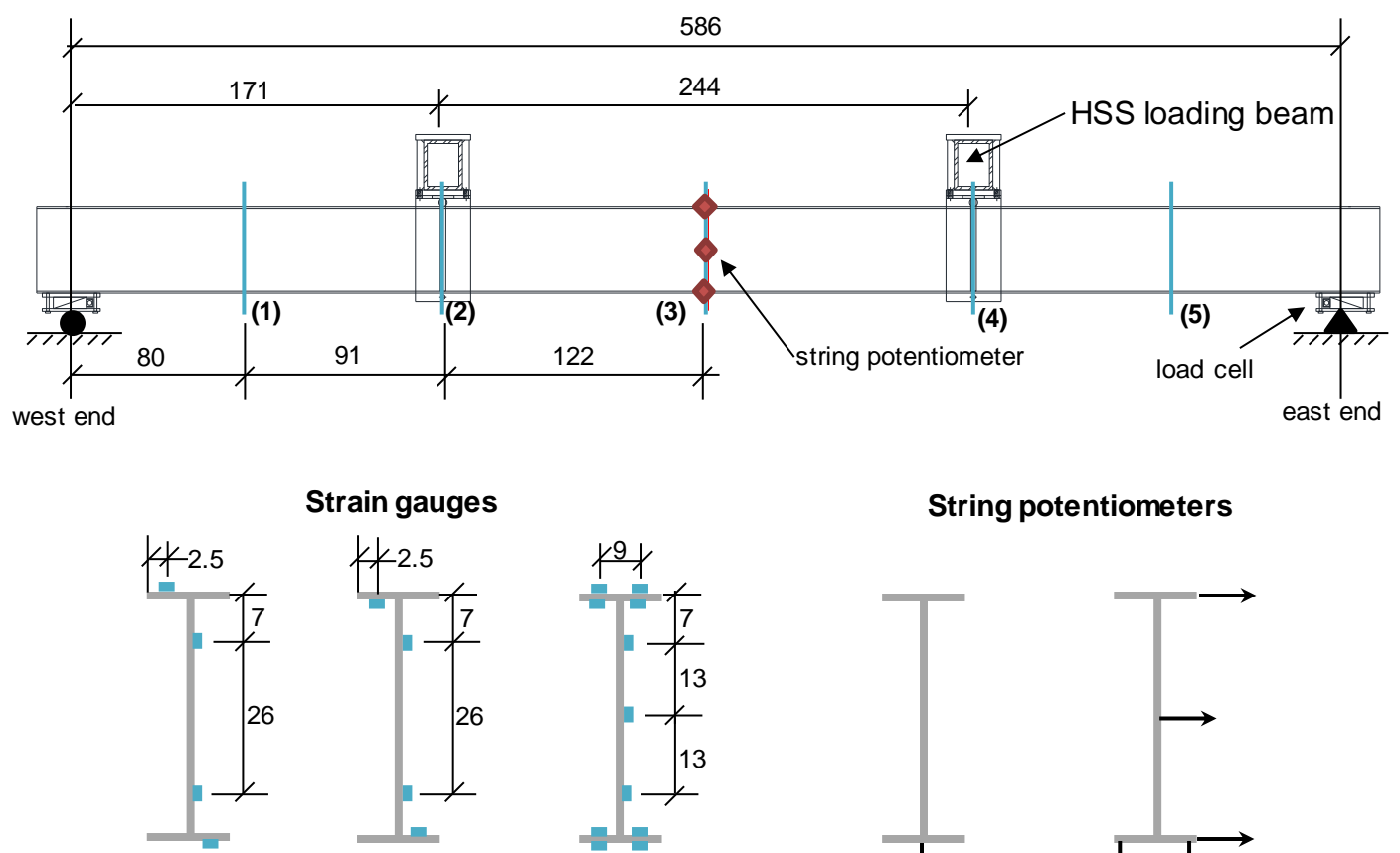

String potentiometers

Sections (1), (5) Sections (2), (3) Section $3 \quad$ Section (2), (4) Section (3)

Figure 4-1 Instrumentation layout of Test 6 (unit: cm).

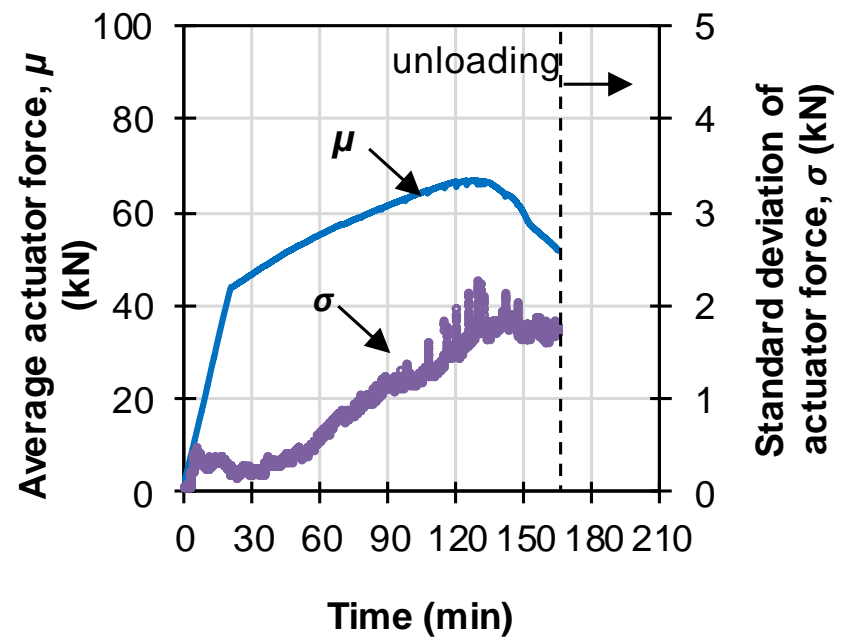

Figure 4-2 Average and standard deviation of forces provided by individual actuators in Test 6. 


\subsubsection{Test Results}

Fig. 4-3 shows the time history of applied point loads $\left(P_{y}\right)$ on the specimen at the location of HSS loading beams and the reaction forces $\left(R_{y}\right)$ measured at the specimen ends. The values of $P_{y}$ and $R_{y}$ were the average values of two-point loads on the beam and the average values of reaction forces measured at the east and west ends, respectively. The maximum point load was $133 \mathrm{kN}$, and the corresponding reaction force was $146 \mathrm{kN}$.

As described in Section 2.2.2, the beam specimen supported the weight of two HSS loading beam and the beam specimen in addition to the loads applied by actuators. The magnitude of $\left(R_{y}-P_{y}\right)$ included a half of the weight imposed on the beam and some friction effects, and it measured (14 $\pm 1.3) \mathrm{kN}$ on average throughout the test.

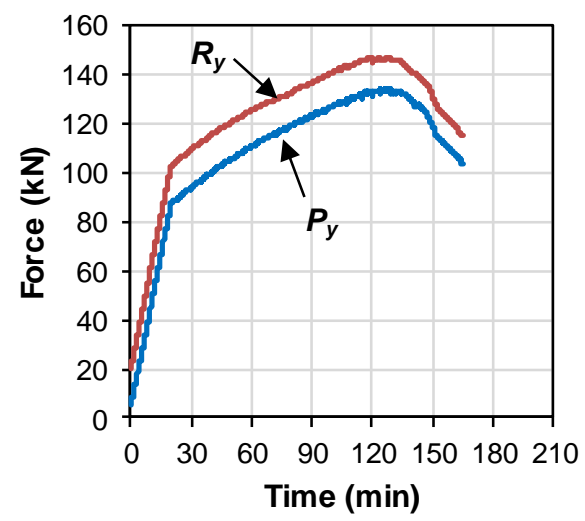

Figure 4-3 Time history of point load $\left(P_{y}\right)$ and reaction force $\left(R_{y}\right)$ in Test 6.

Fig. 4-4(a) shows a photograph of the beam specimen in Test 6. In the elastic regime, the specimen deflected vertically downward with increasing loads. When loaded to its ultimate capacity, the specimen laterally deflected (toward the north), and simultaneously twisted about its longitudinal axis. The beam finally lost its structural stability indicating the lateral-torsional buckling failure.

Figs. 4-4(b) show photographs of the local buckling failure in the top flange at midspan. This was caused by large compressive forces as a bending moment increased. Fig. 4-4(c) shows the final deflected shape of the beam (after test with the view looking along the beam length). 


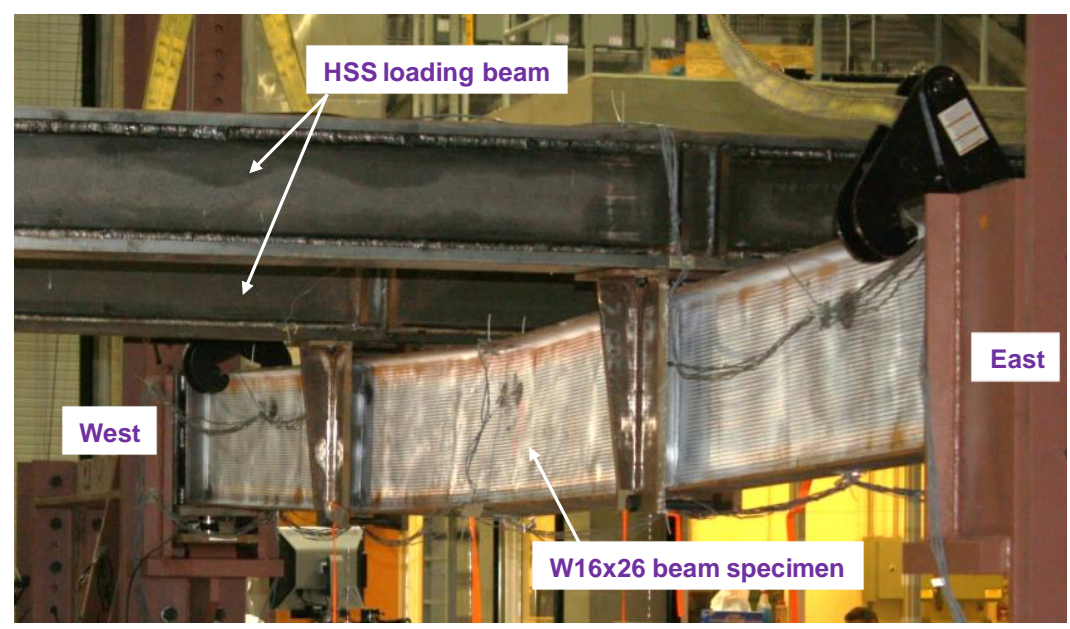

(a)

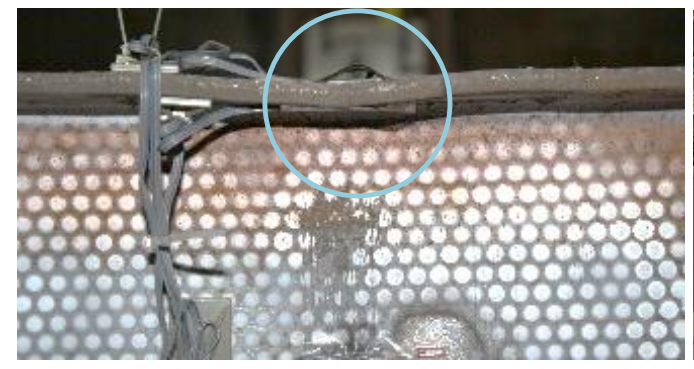

(b)

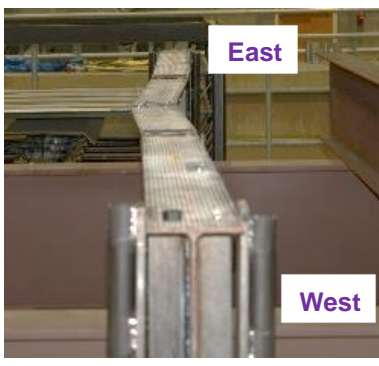

(c)

Figure 4-4 Photographs of (a) W16×26 beam specimen in the test setup during the test, (b) local distortion of top flange at midspan after test, and (c) the final deflected shape of the specimen after test.

Fig. 4-5(a) shows a graph of the average reaction force at the beam ends versus the vertical displacements measured at four discrete locations (i.e., the east and west loading points and the south and the north tip of the lower flange at midspan). In response to flexural loading, the vertical displacements continuously increased throughout the test. Note that the vertical displacements at the east and west loading points are almost identical to each other.

Fig. 4-5(b) shows a graph of the average reaction force versus the lateral displacements at three different locations (i.e., the top flange, web, and bottom flange of the cross section at midspan). The lateral displacements did not increase until the force increased to $146 \mathrm{kN}$ at which buckling failure occurred. After failure, the lateral displacements at all three locations in the mid-section increased although the forces in the beam decreased. However, it should be noted that, in the postbuckling phase, the magnitude of displacements at three locations was different as a result of twisting of the beam. 


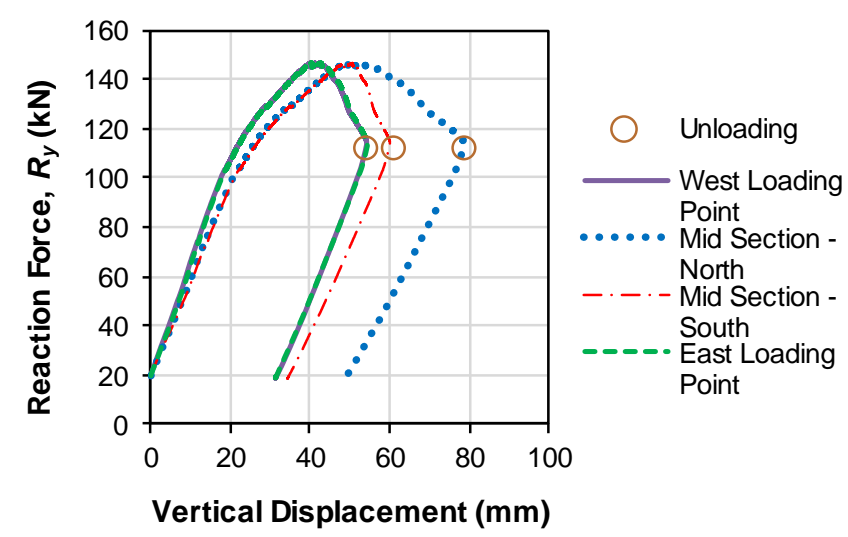

(a)

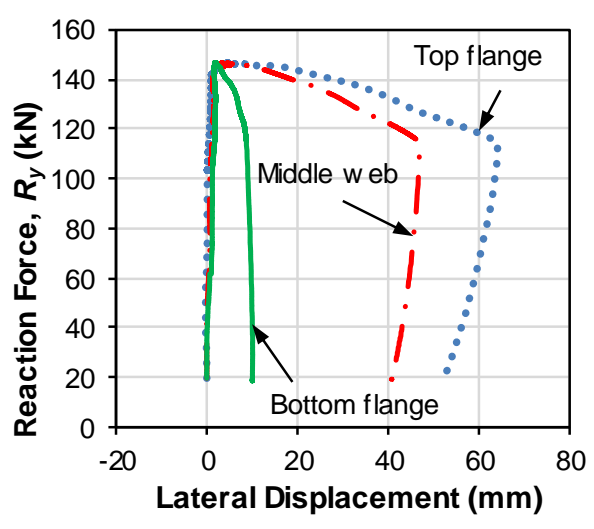

(b)

Figure 4-5(a) Reaction force versus vertical displacement and (b) reaction force versus lateral displacement of the specimen.

Fig. 4-6 shows axial strains at various locations in the mid-section of the beam specimen. The stains presented in Fig. 4-6(a) were induced by bending moments as the point load (at the location of HSS loading beams) increased. The initial strains resulting from the weight of two loading beams and the specimen and preloading by actuators were excluded. The negative values shown in the figure represent compressive strains; the positive values are tensile strains. It can be seen that the beam had elastic bending about its strong-axis of the cross section until the reaction force was about $100 \mathrm{kN}$.

When the reaction force reached $146 \mathrm{kN}$, however, strain reversal occurred at the north tip of the top flange (refer to the location of SG 9 and SG18 in Fig. 4-6(b)), indicating lateral-torsional buckling of the beam. The strains in the south tip of the top flange (refer to the location of SG10 and SG11) continued to increase in compression. It is important to note that the web and the lower flange remained elastic since strains in those locations were smaller than the nominal yield strain of $0.2 \%$. 


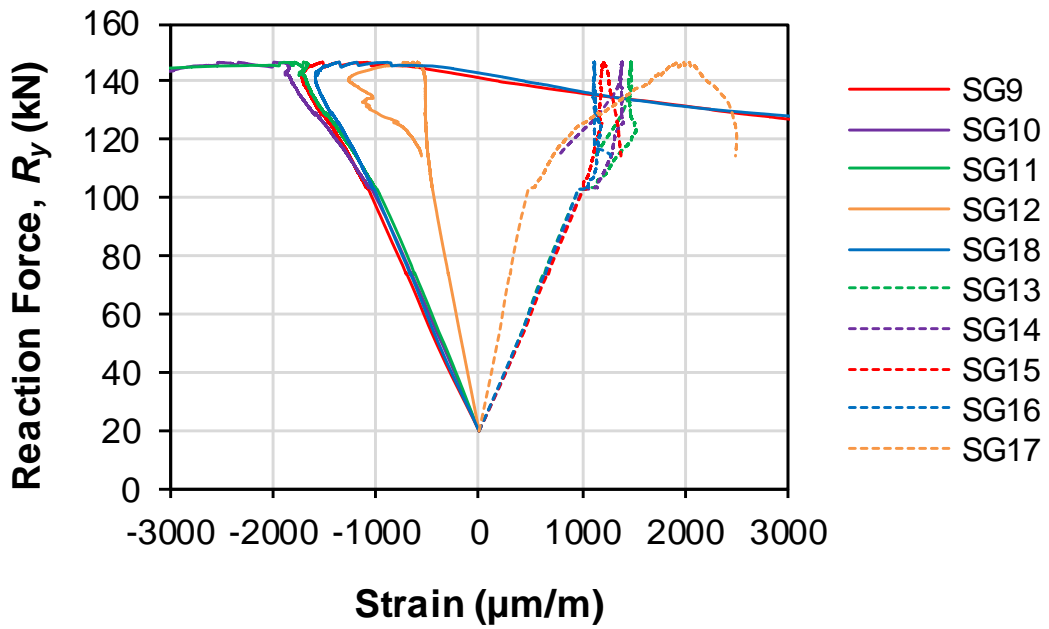

(a)

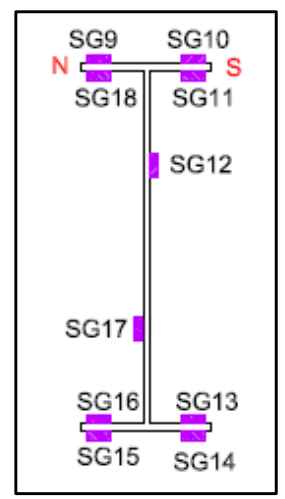

(b)

\section{Figure 4-6(a) Reaction forces at the beam ends versus strains in the mid-section and (b) location of strain gauges used in Test 6.}

\subsection{TEST 7}

Test 7 was the steady-state fire test in which the simply supported W16×26 beam specimen was exposed to constant heat from a fire while subjected to increasing flexural loads. For localized fire exposure, the same natural gas burner as used in thermal tests was placed $1.1 \mathrm{~m}$ below the bottom flange of the beam at midspan. The structural loading arrangement remained unchanged from Test 6. Actuators were operated using force control so that the applied loading rate at each end of the HSS loading beams was identical. The testing procedure and condition was as follows:

1) The heat release rate of the burner increased to $700 \mathrm{~kW}$ prior to structural loading. At this stage, the beam specimen freely expanded as steel temperature increased.

2) Once the temperature rose in the bottom flange at midspan became $2{ }^{\circ} \mathrm{C} / \mathrm{min}$ under the $700 \mathrm{~kW}$ fire, the point loads increased at a rate of $8.90 \mathrm{kN} / \mathrm{min}$ until failure occurred.

Details of the support conditions, the room-temperature mechanical properties, and the structural loading arrangement of the beam specimen are described in Section 2.2.2 and Appendix A. 


\subsubsection{Instrumentation Layout}

Fig. 4-7 shows the instrumentation layout. A total of thirty-nine, Type-K, 24-gauge thermocouples were installed at nine different cross sections (i.e., sections 2 through 10). Four plate thermometers, which had the surface area of $10 \mathrm{~cm} \times 10 \mathrm{~cm}$ each, were installed at halfway between sections 6 and 7 to measure the adiabatic surface temperature. The point loads were applied via two HSS loading beams located at $244 \mathrm{~cm}$ apart as shown in Fig. 4-7. As discussed in Section 2.2.2, the actuator was connected at each end of the loading beams. The magnitude of the applied point load was equal to the summation of the loads applied by two actuators connected to the same loading beam. Individual actuators were programmed to increase a load with the rate of $4.45 \mathrm{kN} / \mathrm{min}$. The vertical reaction forces at the beam ends were measured using the same pancake load cells as used in Test 6 . The string potentiometers with temperature compensation were used to measure the vertical and lateral displacements of the specimen at midspan. Two inclinometers were also mounted on the top flange near the beam ends.

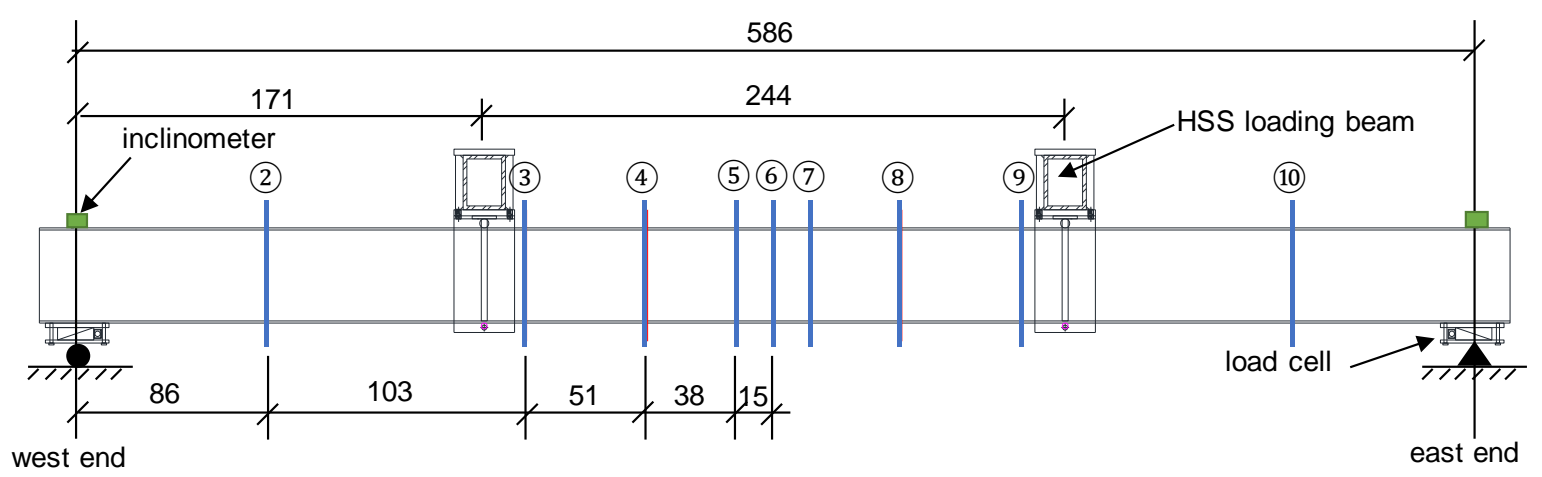

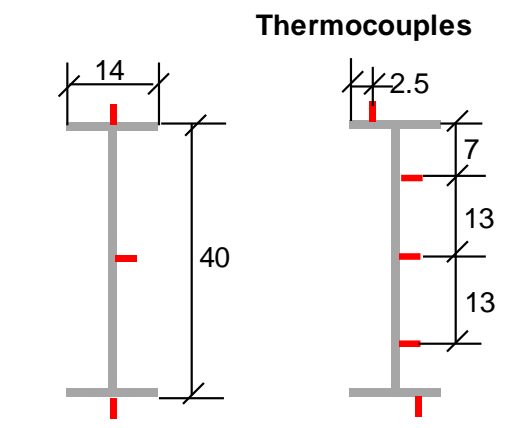

Sections $2,3,9,10$
Sections 4,5,7,8
Plate thermometers

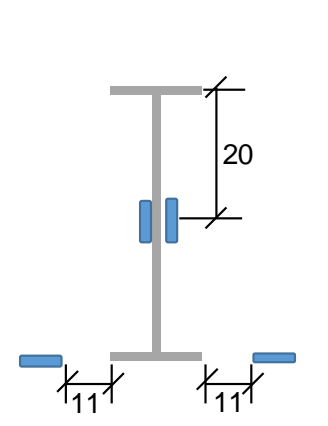

Halfway between Sections 6 and 7
String potentiometers

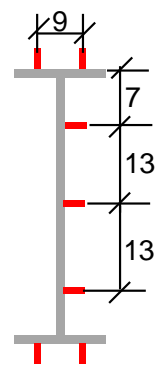

Section 6 (midpsan)

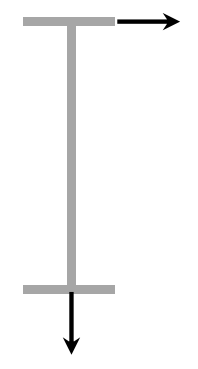

Section 6 (midpsan)

Figure 4-7 Instrumentation layout for test 7. (unit: cm). 


\subsubsection{Test Conditions}

Fig. 4-8 shows the applied point loads $\left(P_{y}\right)$ at the location of the HSS loading beam, the vertical reaction forces $\left(R_{y}\right)$ at the beam end, and the heat release rate (HRR) of the burner recorded over the test period. The values of $P_{y}$ and $R_{y}$ are the average values of forces measured at the locations of the loading beams and at the supports, respectively.

For steady-state fire testing, thermal loading was applied in three steps: (i) the burner HRR was initially set to $600 \mathrm{~kW}$ and lasted about $11 \mathrm{~min}$, (ii) then increased to $650 \mathrm{~kW}$ and maintained for another $4.6 \mathrm{~min}$, and (iii) was finally fixed at a target HRR of $700 \mathrm{~kW}$ about $17 \mathrm{~min}$ after ignition of a fire. About 3 mins passed after the burner HRR was set to $700 \mathrm{~kW}$, the heating rate of the exposed lower flange at midspan became $2{ }^{\circ} \mathrm{C} / \mathrm{min}$, approximately. Table 4-1 summarizes some statistics on the burner HRR data, including the average $(\mu)$, standard deviation $(\sigma)$, and coefficient of variation $(\mathrm{CV})$, when the burner HRR was set to a target HRR value of $600 \mathrm{~kW}, 650 \mathrm{~kW}$, or $700 \mathrm{~kW}$. The quantity of samples used in the analysis was equal to the actual duration of each HRR level in seconds. During the structural loading, the fire was maintained at the burner HRR of (700 $\pm 1) \mathrm{kW}$.

Due to the preload of actuators (less than $4.5 \mathrm{kN}$ ) and the self-weight of steel components, the vertical reaction force $\left(R_{y}\right)$ was $(17 \pm 1.2) \mathrm{kN}$ while the burner HRR was increased to $700 \mathrm{~kW}$, as shown in Fig. 4-8. About 20 min after initiation of a fire, the point loads $\left(P_{y}\right)$ increased at the rate of $(8.88 \pm 0.003) \mathrm{kN} / \mathrm{min}$. The peak point load (at the onset of failure) was $90 \mathrm{kN}$ recorded at 31 min, and the corresponding reaction force was $100 \mathrm{kN}$. The fire and mechanical loading was removed approximately at $31 \mathrm{~min}$.

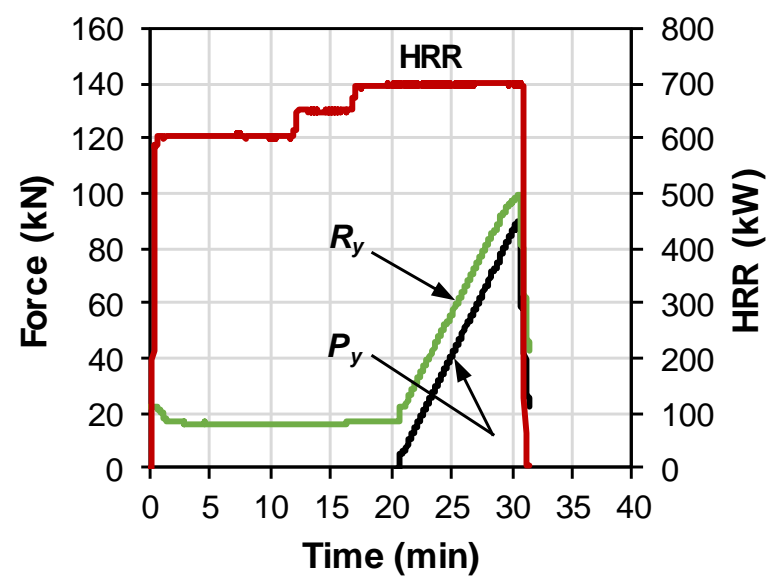

Figure 4-8 Measured burner HRR, average point load $\left(P_{y}\right)$, and average reaction force $\left(R_{y}\right)$ as a function of test time. The standard deviation of $P_{y}$ and $R_{y}$ data was $0.28 \mathrm{kN}$, and $0.81 \mathrm{kN}$, respectively. 
Table 4-1 Statistics on the burner HRR.

\begin{tabular}{ccccc}
\hline $\begin{array}{c}\text { Target HRR } \\
(\mathrm{kW})\end{array}$ & $\begin{array}{c}\text { Number of data } \\
\text { points }\end{array}$ & $\mu(\mathrm{kW})$ & $\sigma(\mathrm{kW})$ & $\mathrm{CV}(\%)$ \\
\hline 600 & 675 & 604 & 1.3 & $0.22 \%$ \\
650 & 277 & 651 & 1.08 & $0.17 \%$ \\
700 & 621 & 700 & 1.13 & $0.16 \%$ \\
\hline
\end{tabular}

Structural loading under fire condition was further evaluated. Fig. 4-9(a) shows the average actuator force $(\mu)$ at the ends of the HSS loading beams. The standard deviation $(\sigma)$ of the load data from four actuators was plotted in the same figure. As shown, all four actuators applied consistent loading throughout the test with the coefficient of variations $(\sigma / \mu)$ less than $1 \%$.

To compare the forces applied at each location of the HSS loading beams, Fig. 4-9(b) shows the difference in the applied point loads $\left(\Delta P_{y}\right)$ at the location of the east and west HSS loading beam and the difference in the reaction forces $\left(\Delta R_{y}\right)$ at the east and west beam ends. It was overserved that the values of $\Delta P_{y}$ remained within $\pm 1 \mathrm{kN}$ (about $1 \%$ of the peak value of $P_{y}$ ). The maximum value of $\Delta R_{y}$ was $6 \mathrm{kN}$ (about $6 \%$ of the peak $R_{y}$ ) at the onset of failure of the specimen. However, it should be noted that the value of $\Delta R_{y}$ could be resulted from experimental errors, such as the friction in the steel surfaces.

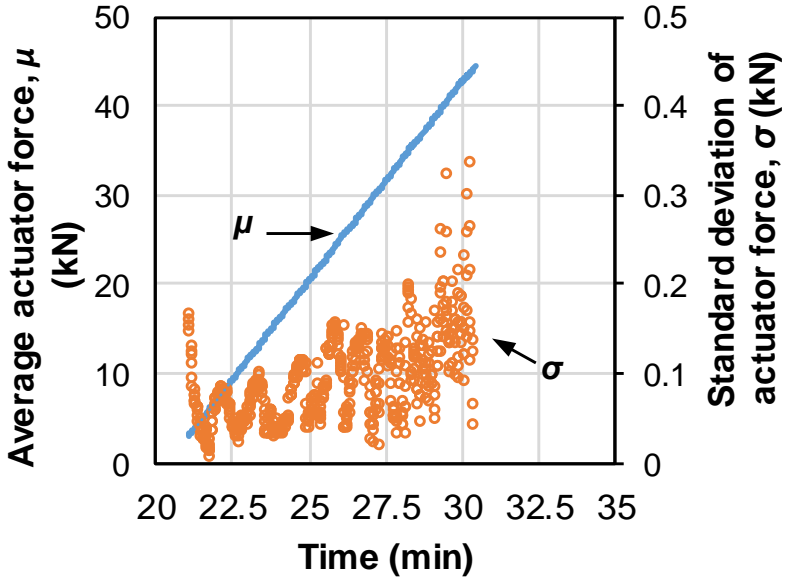

(a)

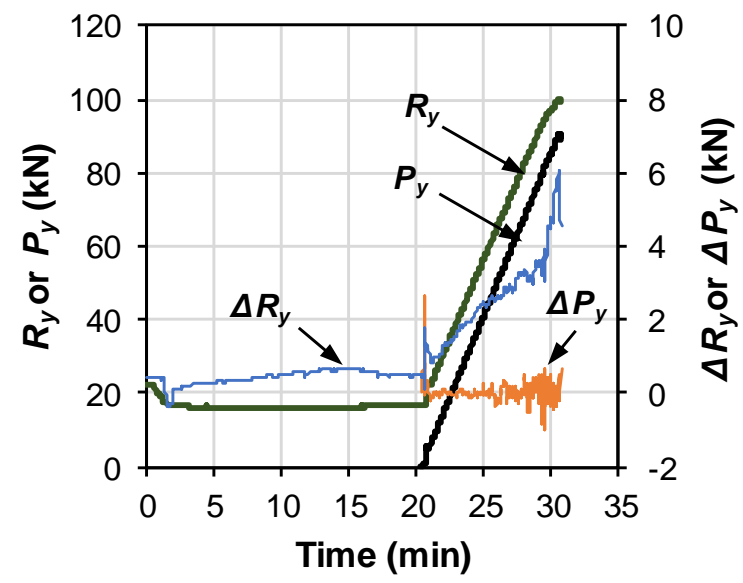

(b)

Figure 4-9 (a) Average actuator force and standard deviation as a function of test time and (b) average reaction force and point load as a function of test time along with the differences $\left(\Delta P_{y}\right)$ of two points loads at the location of loading beams and the difference $\left(\Delta R_{y}\right)$ in reaction forces at beam ends

Fig. 4-10 shows photographs of the beam specimen exposed to an open flame, natural gas fire at midspan, with views in the north-south and east-west directions. As described in Section 2.1.3, the 
$1 \mathrm{~m}^{2}$ natural gas burner was located at 1.1 . $\mathrm{m}$ below the lower flange of the beam specimen at midspan. As can be seen in Fig. 4-9, fire flames were symmetric in the north-south direction but slightly tilted toward the west. This caused the west side of the beam to be hotter than the east side. The resulting temperature distribution in the specimen is discussed in Section 4.3.3.
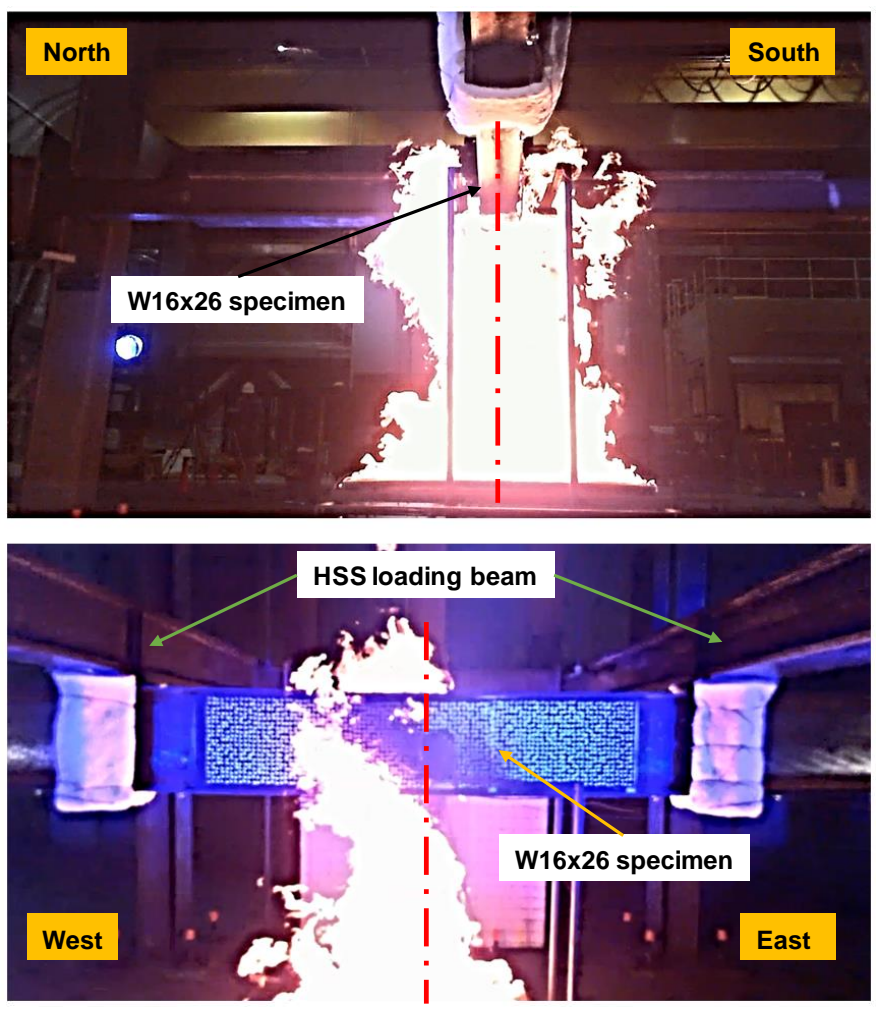

Figure 4-10 The beam specimen exposed to an open flame natural gas fire with the views looking toward the east direction (top) and the north direction (bottom).

\subsubsection{Test Results}

Fig. 4-11 shows the contour plots of temperatures to show the thermal gradient in the specimen at various time during the test. Refer to Fig. 4-8, the burner HRR was $600 \mathrm{~kW}$ at $10 \mathrm{~min}$ (no mechanical loading) and when it was $700 \mathrm{~kW}$ at 20 min (beginning of mechanical loading) and at 31 min (ending of mechanical loading). Each plot was developed using the temperature data obtained from thermocouples at various locations as shown in Fig. 4-7. In each plot, the vertical axis is the distance from the bottom to the top flanges of the specimen. The bottom horizontal axis is the distance from the west to the east ends of the specimen. The top horizontal axis indicates each location of thermocouple sections shown in Fig 4-7. A white line indicates the location of the specimen midspan. 
As can be seen in Fig. 4-11, non-uniform temperature distribution was developed both along the beam length and through the section depth. Due to proximity of the burner location, the midspan region (between sections 5 through 7) was hotter than other locations. During the structural loading from $20 \mathrm{~min}$ to $31 \mathrm{~min}$, however, the temperature rise was about $25{ }^{\circ} \mathrm{C}$ on average under the $700 \mathrm{~kW}$ fire. It was also observed that the temperature in the section 5 was higher than section 7 because of a flame lean toward the west (Fig. 4-9). The maximum lower flange temperature was measured at section 6, whereas the maximum upper flange temperature was observed at section 5 .
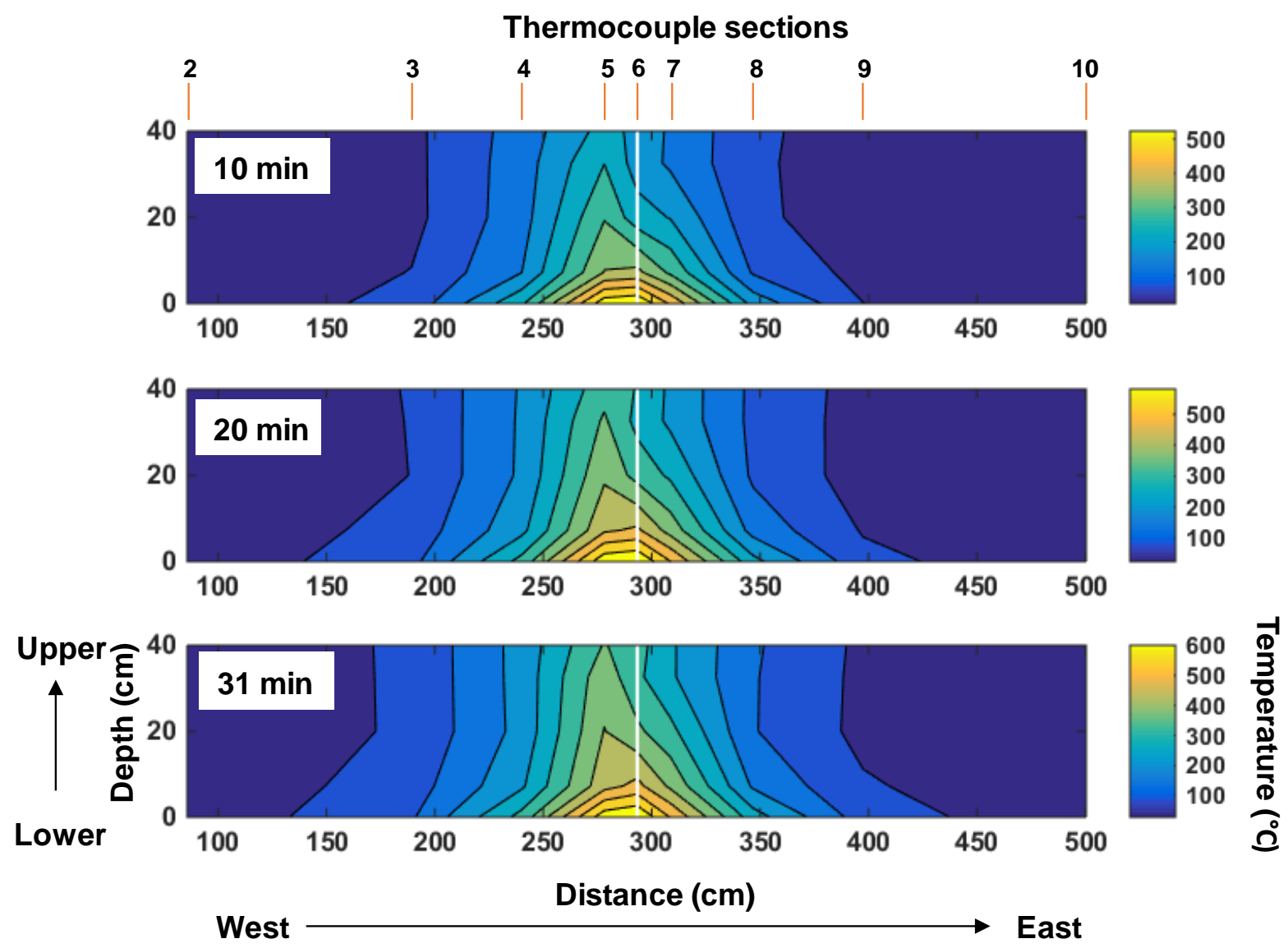

Figure 4-11 Temperature contours of the beam specimen in Test 7.

The temperature rise in the fire-exposed critical sections of the beam was further examined. Fig. 4-12(a) shows the locations of sections 5 through 7. Each section constitutes five different regions, including the upper flange (UF), the upper web (UW), the middle web (MW), the lower web (LW), and the lower flange (LF). Fig. 4-12(b) shows the temperature-time relation in the midspan region under a fire. The plotted data was the average temperature in the midspan region (sections 5 through 7) over the test period. It was observed that the temperature in the lower cross section 
(e.g., lower web and lower flange) rapidly increased following the ignition of fire. After 20 min passed, the heating rate became $2{ }^{\circ} \mathrm{C} / \mathrm{min}$. However, the temperature in the upper cross section (e.g., upper flange, upper web and middle web) continued to increase over time and the heating rate was $4{ }^{\circ} \mathrm{C} / \mathrm{min}$ on average.

Fig. 4-12(c) shows the average thermal gradient across the fire-exposed sections (sections 5 through 7) during the structural loading phase from $20 \mathrm{~min}$ to $31 \mathrm{~min}$. The error bars in this graph indicate the standard deviation of the measured temperatures during this period. As shown, thermal gradient across the section was nonlinear with the temperature ranging from $320^{\circ} \mathrm{C}$ to $620{ }^{\circ} \mathrm{C}$.

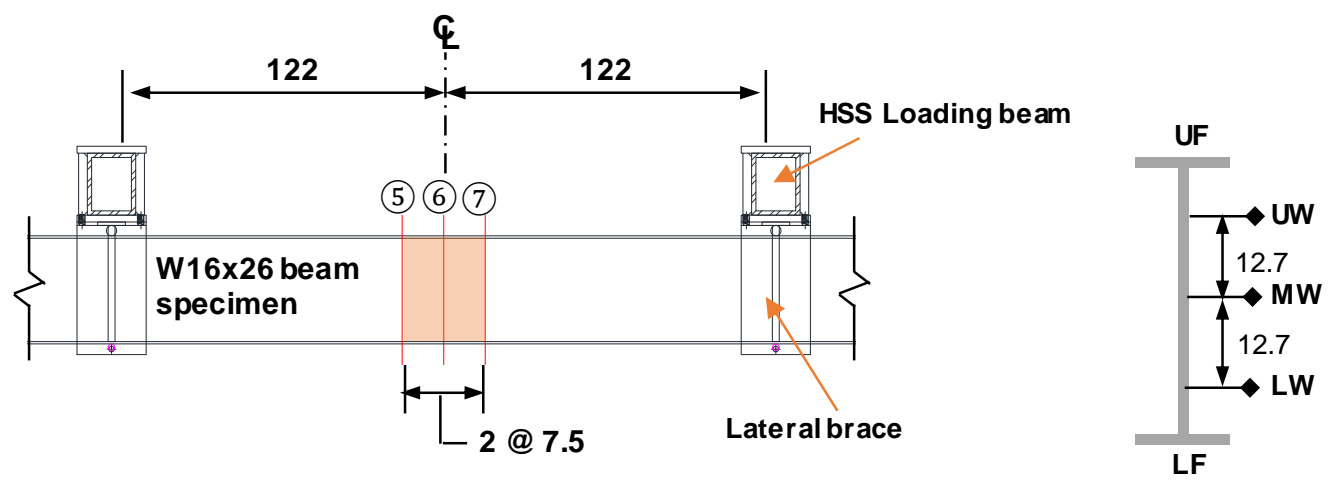

(a)

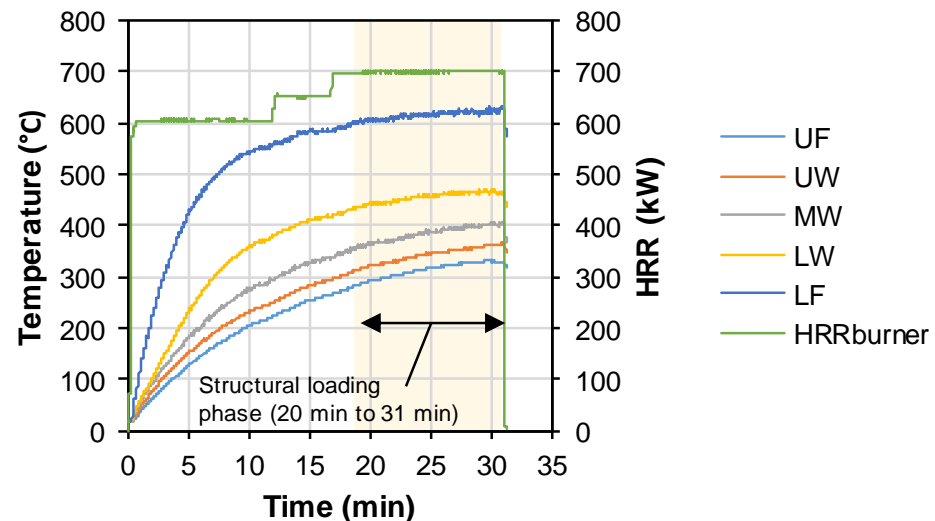

(b)

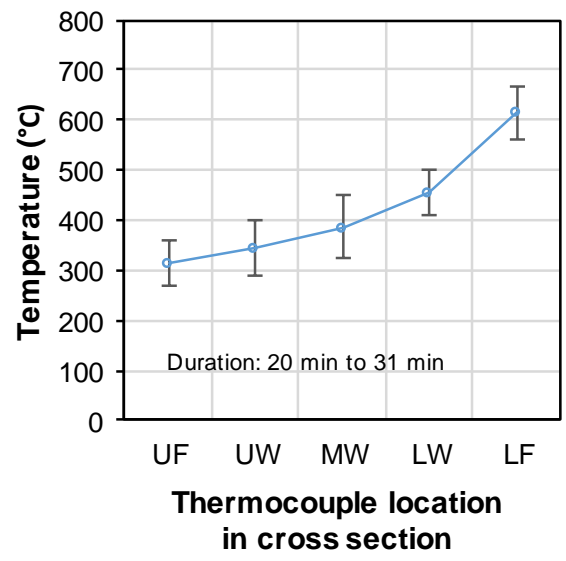

(c)

Figure 4-12 (a) Location of temperature measurement in fire-exposed midspan sections (unit: $\mathrm{cm}$ ), (b) time histories of temperatures in fire-exposed midspan sections, and (c) average temperatures in fire-exposed midspan sections under structural loading. The error bars indicate the standard deviation of temperature readings during the structural loading phase.

Fig. 4-13 shows the adiabatic surface temperature (AST) measured using plate thermometers located at each side of the lower flange near midspan (refer to Fig. 4-7 for the location of plate 
thermometers). As shown, the AST data became uniform over the test period and was not significantly affected by the change in the burner HRR level. During the structural loading (from $20 \mathrm{~min}$ to $31 \mathrm{~min}$ ), the measured AST was $670{ }^{\circ} \mathrm{C}$ on average, and the standard deviation was $5{ }^{\circ} \mathrm{C}$.

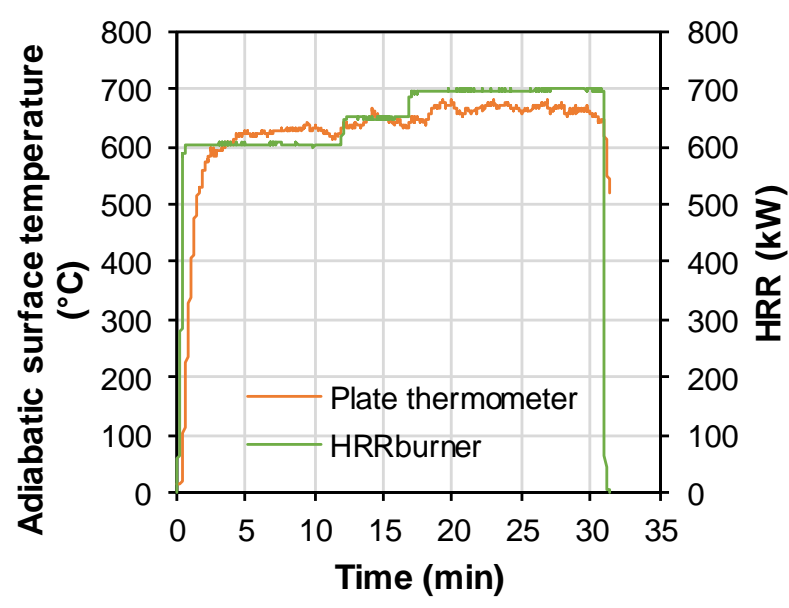

Figure 4-13 Time history of average adiabatic surface temperature measured using plate thermometers near the lower flange of the specimen at midspan.

Fig.4-14(a) shows some snapshots of a test video at $14 \mathrm{~min}, 20 \mathrm{~min}, 25 \mathrm{~min}$, and $30 \mathrm{~min}$ after the fire was ignited. A blue line was added later to show the overall deformation of the beam when subject to fire only (at $14 \mathrm{~min}$ ) and combined mechanical loading and fire (from $20 \mathrm{~min}$ to $31 \mathrm{~min}$ ). Fig. 4-14(b) shows the time history of applied loads and temperature condition, where $P_{y}$ is the average point load, UF temp and LF temp are the average temperature in the upper flange (UF) and the lower flange (LF) of the fire-exposed sections, respectively. As shown, while the beam was subjected to monotonically increasing load, the temperature in the fire-exposed sections maintained constant. The temperature variation over this period was about $1 \%$ of the average temperature.

Fig. 4-14(c) shows the point load-displacement relationship of the beam under the $700 \mathrm{~kW}$ fire. The value of $\delta_{L}$ and $\delta_{V}$ indicates the lateral displacement of the top flange and the vertical displacement of the bottom flange at midspan, respectively. As shown, only the vertical displacement increased linearly (elastic behavior) until the load increased to $60 \mathrm{kN}$. After that, both the displacements in both directions increased simultaneously as the stiffness of the beam decreased. At the peak load of $90 \mathrm{kN}$, which was approximately $67 \%$ of the capacity at ambient 
temperature, the beam could not support the imposed loads, and the displacement continued to increase with decreasing loads.

Fig. 4-14(d) shows the point load-the end rotation curve. As described in Section 2.2.2, the beam ends were simply supported, and both the rotation about the principal axes of the beam cross section and the axial displacement were unrestrained. As shown, the strong-axis rotation increased linearly while the point load increased to $60 \mathrm{kN}$, followed by non-linear rotational behavior. When the load exceeded $80 \mathrm{kN}$, the strong-axis rotation increased significantly until the beam failed. However, the lateral constraints at the location of HSS loading beams (i.e., the location of the point loads) prevented the weak-axis rotation of the beam ends.

Fig.4-15 shows photographs of the overall deformed shape of the beam specimen and the fireexposed midspan region after cooling. The beam was laterally deformed and twisted at its midspan. The top flange at midspan exhibited local buckling failure. Since the applied loading and fire condition was not immediately removed at the onset of the lateral-torsional buckling of the beam, the specimen exhibited permanent post-failure deformation. 

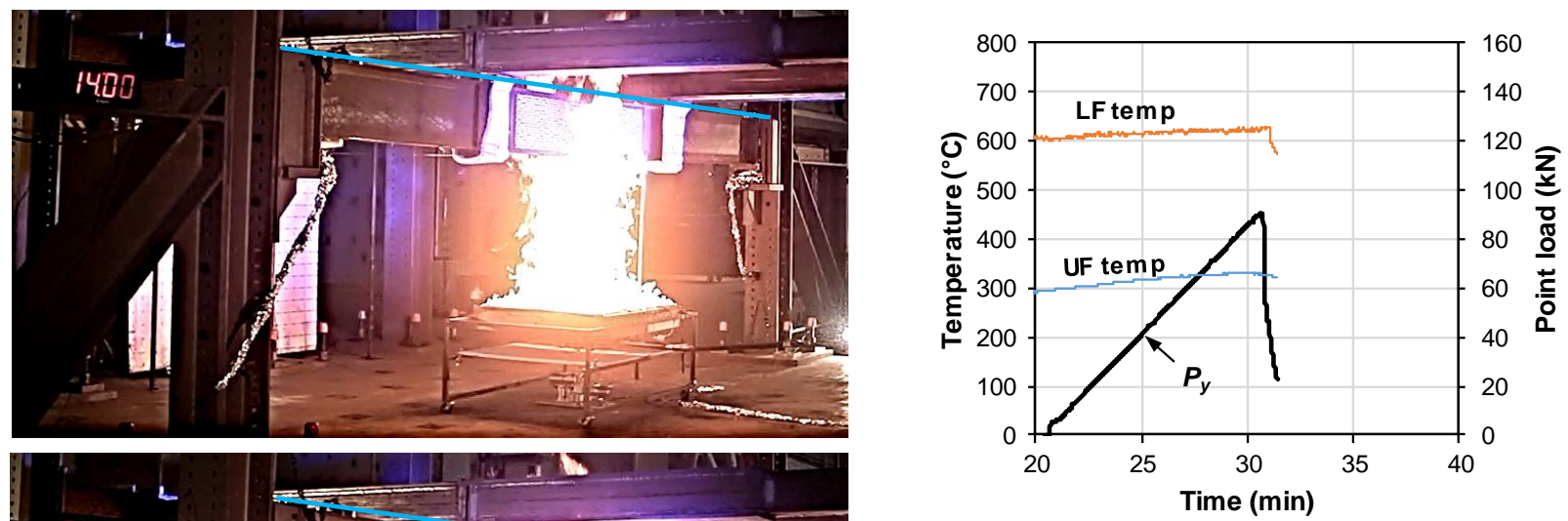

(b)

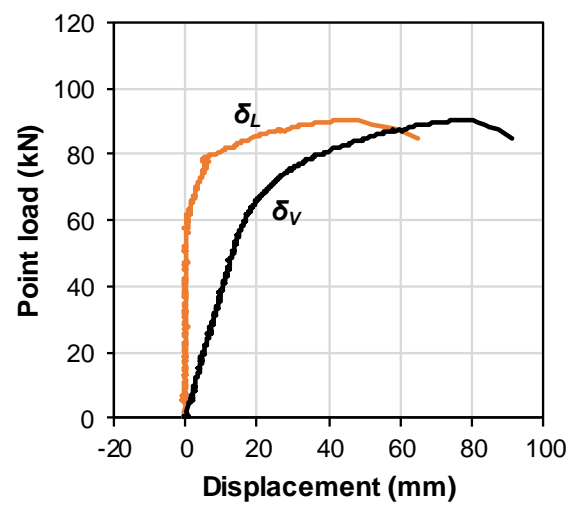

(c)

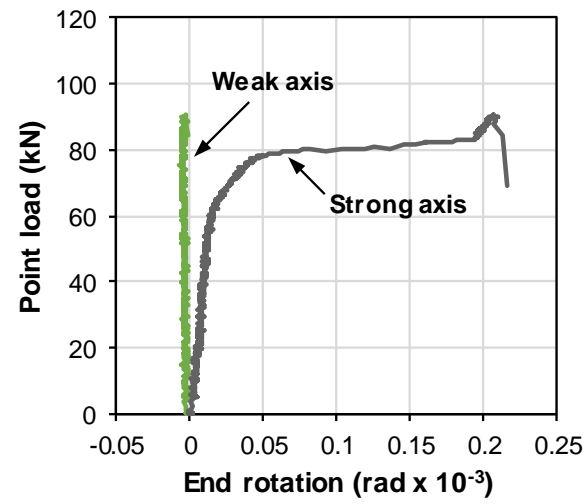

(d)

Figure 4-14 (a) Snapshots of a test video showing the specimen deformation at $14 \mathrm{~min}, 20 \mathrm{~min}, 25 \mathrm{mins}$, and $30 \mathrm{~min}$, (b) time histories of the upper (UF) and the lower flange (LF) temperatures in the fire-exposed sections and the point load $\left(P_{y}\right)$, (c) the point load versus displacement curves, and (d) the point load versus end rotations about the strong and the weak axes. 

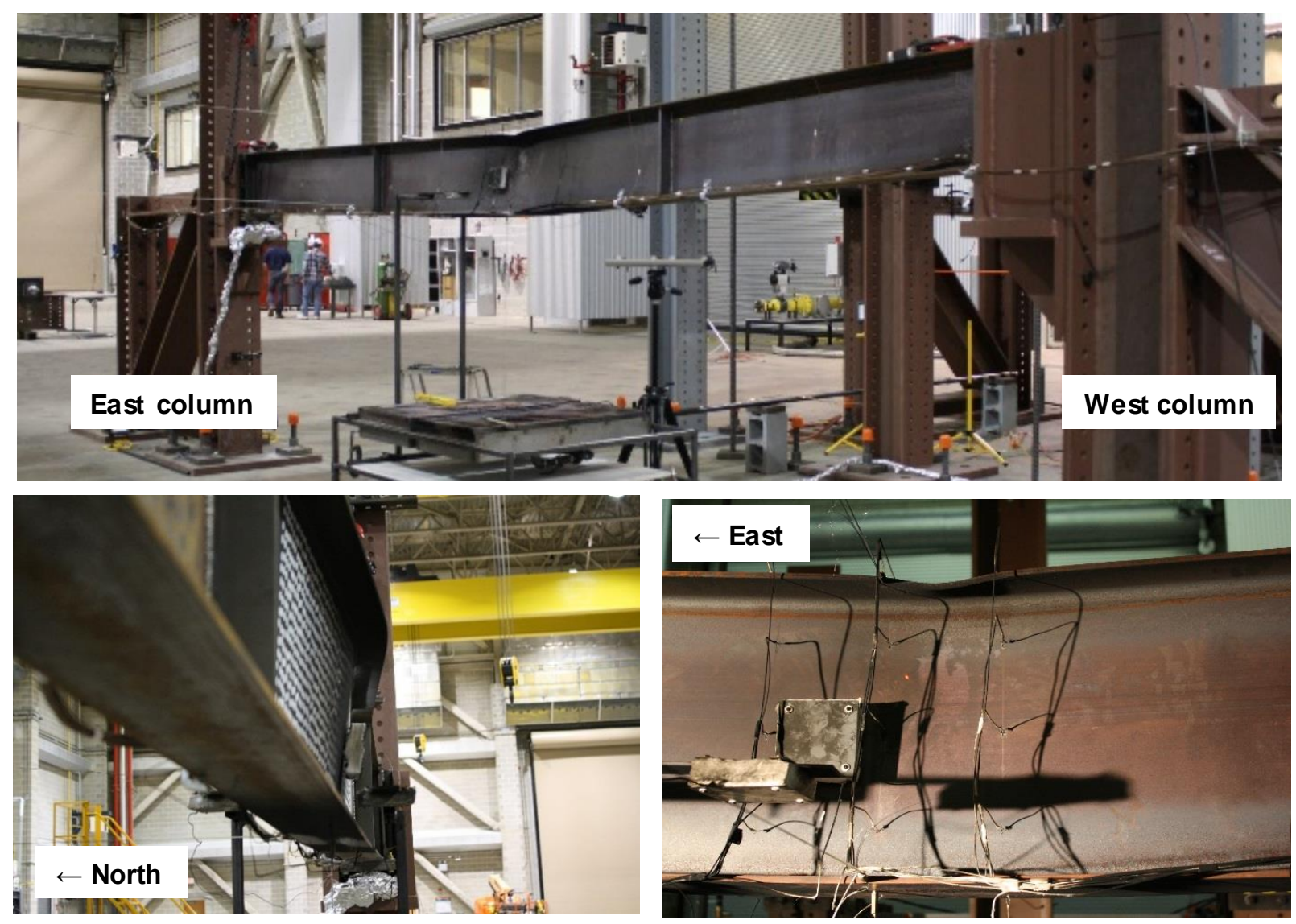

Figure 4-15 Photographs of overall deflected shape of the specimen after cooling (above) and local flange deformations in the fire-exposed midspan (below)

\section{$4.4 \quad$ TEST 8}

Test 8 was the transient fire test in which the $\mathrm{W} 16 \times 26$ beam specimen was heated under a growing fire while the magnitude of imposed loads remained constant. The location of the burner and the point loads were unchanged from Test 7 . The testing procedure was as follows:

1) Two equal concentrated loads were applied to the beam at ambient temperature. In this test, the magnitude of applied loads was that of the maximum point load measured in Test 7.

2) While the applied load was maintained constant, the burner HRR was increased following a quadratic function of time until the specimen failed.

The beam specimen was also simply supported so that free thermal elongation was allowed during the fire. Details of the support conditions, the room-temperature mechanical properties, and the structural load arrangement of the beam specimen are described in Section 2.2.2. 


\subsubsection{Instrumentation Layout}

Fig. 4-16 shows the instrumentation layout. A total of twenty-five thermocouples were installed at five different cross sections in the fire-exposed zone. The same actuators and load cells that were used in the previous tests were also used in this test. The string potentiometers with temperature compensation were installed at midspan to measure the global deformation of the beam. The conventional string potentiometers were also added to measure the vertical displacements of the lower flanges at location of two loading points.

\subsubsection{Test Conditions}

Fig. 4-17 shows the measured burner HRR, point load $\left(P_{y}\right)$, and vertical reaction force $\left(R_{y}\right)$ as a function of test time. The value of $P_{y}$ and $R_{y}$ is the average value of the east and west point loads and the average reaction forces at the beam ends. As shown, the point load increased to $90 \mathrm{kN}$ at ambient temperature and then remained unchanged. This load level was approximately equal to the magnitude of the maximum point load measured in Test 7 (steady-state fire test) and equal to $67 \%$ of the room-temperature capacity measured from Test 6 .

For fire loading, the burner HRR was initially increased to $270 \mathrm{~kW}$ which remained constant for five minutes, and then was increased following the programed quadratic function of time. The specimen failed at $38 \mathrm{~min}$. The corresponding peak HRR was $1280 \mathrm{~kW}$. It should be noted that the difference between the measured $P_{y}$ and $R_{y}$ values was caused by preloading from actuators and the weight imposed on the beam prior to loading. The magnitude of $\left(R_{y}-P_{y}\right)$ was about $15.7 \mathrm{kN}$ on average. 


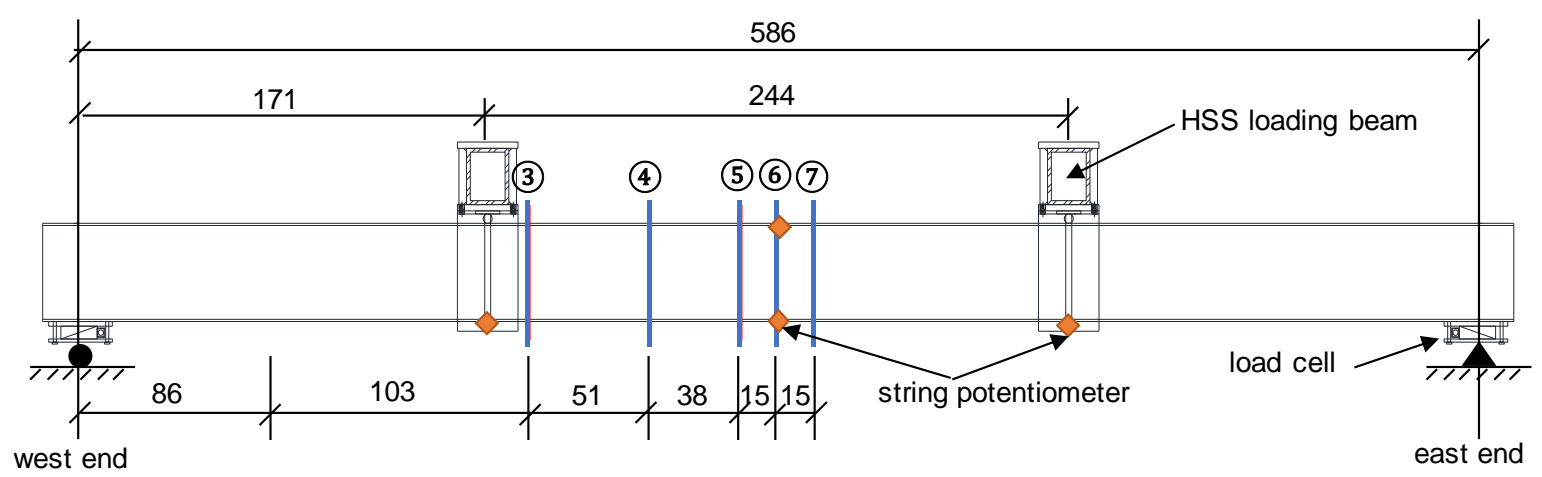

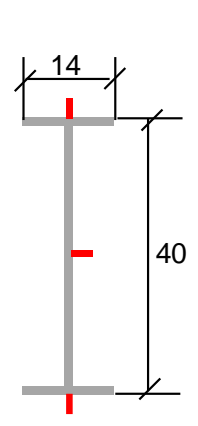

Section 3
Thermocouples

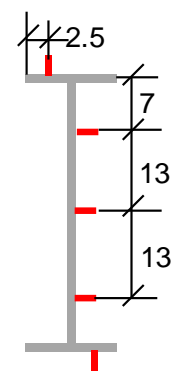

Sections 4,5,7

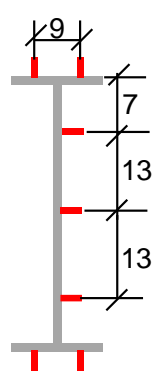

Section 6 (midpsan)
String potentiometers
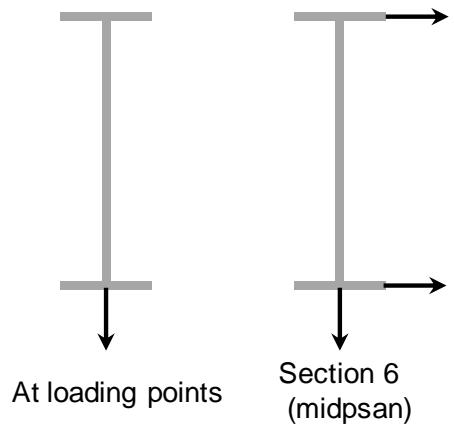

Figure 4-16 Instrumentation layout for Test 8. (unit: cm).

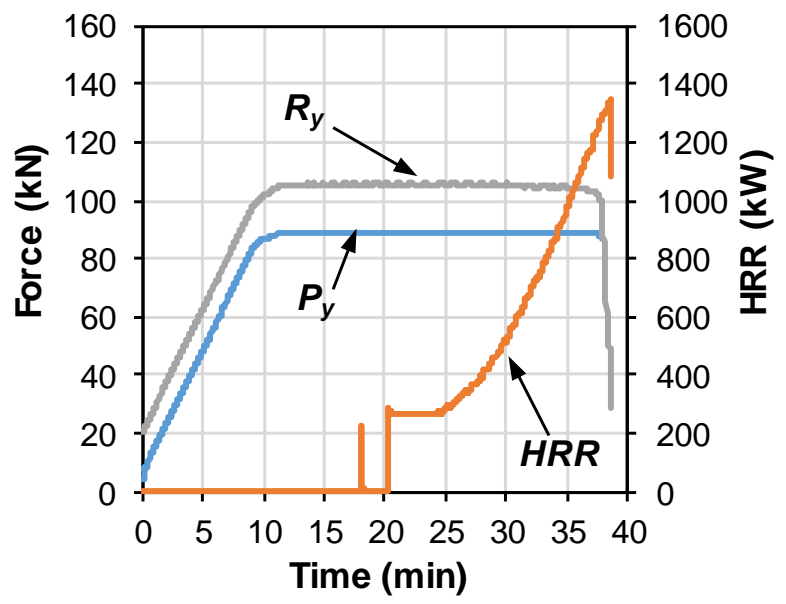

Figure 4-17 Measured HRR of the burner, average point load $\left(P_{y}\right)$, and average reaction force $\left(R_{y}\right)$ as a function of test time. The standard deviation of $P_{y}$ and $R_{y}$ values were $0.35 \mathrm{kN}$ and $1.2 \mathrm{kN}$, respectively. 
Fig. 4-18(a) shows the average $(\mu)$ and the standard deviation $(\sigma)$ of forces applied at the ends of the HSS loading beams using four actuators. With displacement control, the standard deviation in the loads applied by actuators was $2 \mathrm{kN}$ at ambient temperature but was reduced to $0.2 \mathrm{kN}$ because the actuators maintained the load by force control under the fire condition.

Two-point loads applied via two HSS loading beams were further compared as shown in Fig. 418(b). In this figure, the value of $\Delta P_{y}$ is the difference of the east and the west point loads, and $\Delta R_{y}$ is the difference of vertical reaction forces at the east and the west ends. As shown, during the heating phase (i.e., from $20 \mathrm{~min}$ to $38 \mathrm{~min}$ in test time), the value of $\Delta P_{y}$ was almost negligible but the value of $\Delta R_{y}$ started increasing greater than $4 \mathrm{kN}$ after $30 \mathrm{~min}$ when the beam exhibited inelastic behavior. However, the friction effect might influence the value of $\Delta R_{y}$ as mentioned in Sections 4.2.2 and 4.3.2.

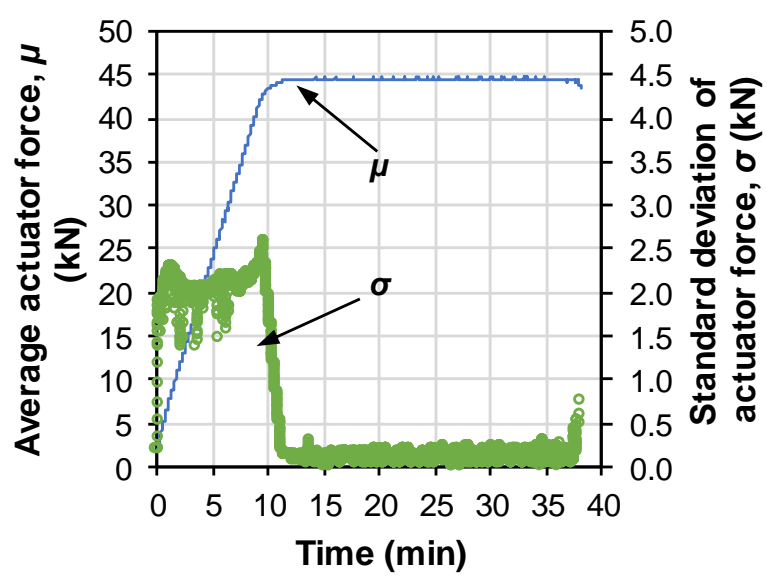

(a)

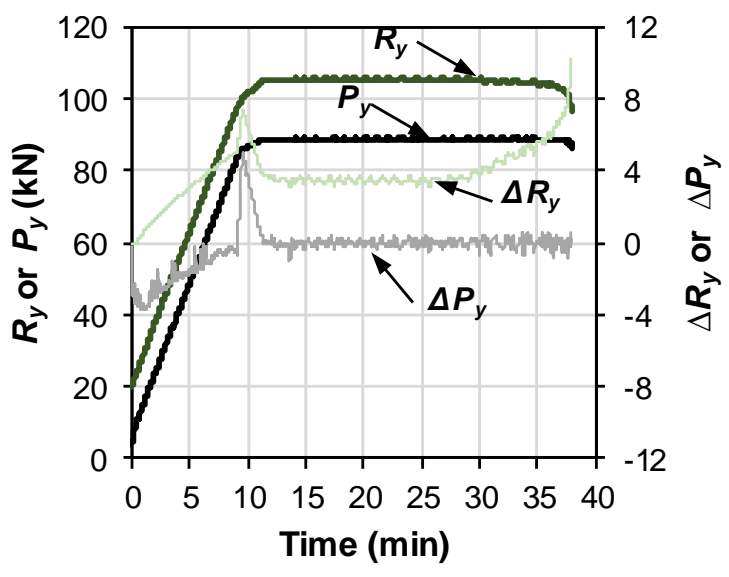

(b)

Figure 4-18 (a) Average actuator force and standard deviation as a function of test time and (b) average reaction force $\left(R_{y}\right)$ and point load $\left(P_{y}\right)$ over the test period along with the difference $\left(\Delta P_{y}\right)$ in two points loads and the difference $\left(\Delta R_{y}\right)$ in reaction forces at the beam ends.

The loaded beam specimen was exposed to an open flame, natural gas fire at its midspan (Fig. 419(a)). As shown in Fig. 4-19(a), it was observed that the upper flames leaned toward the west side of the beam midspan. The effect of flame lean on steel temperatures is discussed in the Section 4.4.3.

The burner HRR was increased following an arbitrary quadratic function to create the condition in which the beam specimen was exposed to a transient fire. Fig. 4-19(b) shows a comparison of the 
programmed and the measured HRR of the burner as a function of fire exposure time, $t$, in minutes. The burner control was programed such that the HRR was increased to $250 \mathrm{~kW}$ from ignition until $t=4 \mathrm{~min}$, and then increased following a $t$-squared function of HRR (in kilowatt) $=4.5 t^{2}+250$ until it reached $1600 \mathrm{~kW}$. In the test, the initial HRR value was measured as $270 \mathrm{~kW}$ which lasted about $4 \mathrm{~min}$, and then increased following the programed $t$-squared function until the beam specimen failed at $1280 \mathrm{~kW}$. It was found that the measured HRR value was $10 \%$ lower than the programed value on average

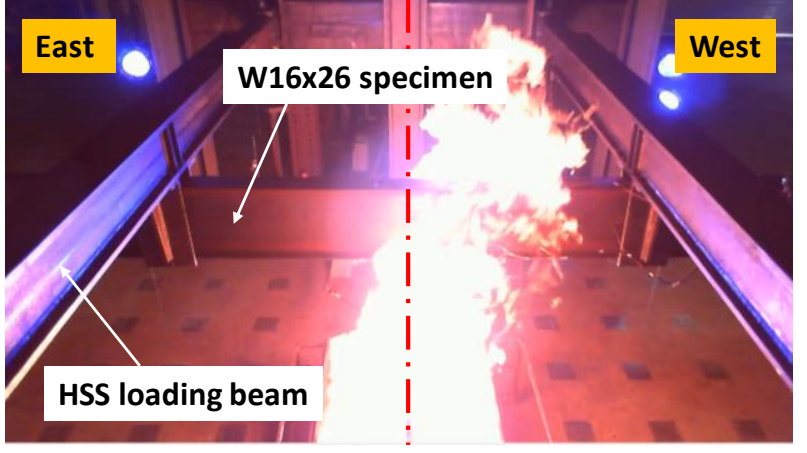

(a)

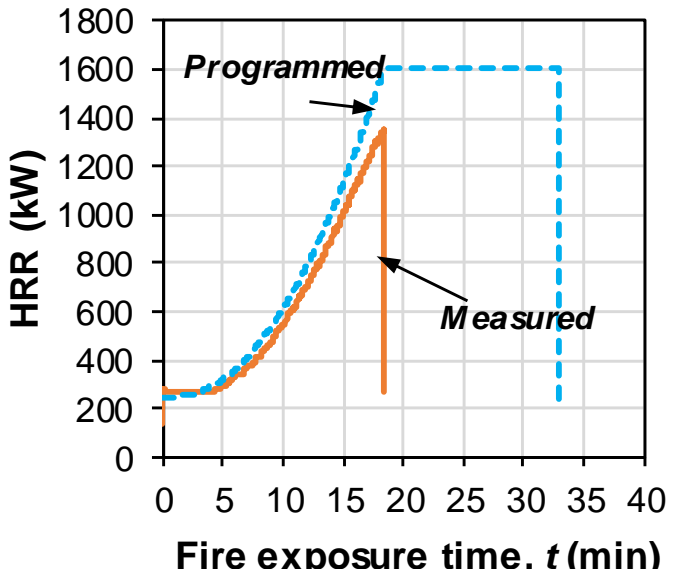

(b)

Figure 4-19 (a) a snapshot of Test 8 with view looking down to the beam specimen and (b) comparison of the programmed and measured HRR of the burner.

\subsubsection{Test Results}

Fig. 4-20 shows the temperature distribution developed in the specimen exposed to the transient fire. In each contour plot, the time outside and inside parenthesis is the total test time (including the duration of loading at ambient temperature) and the actual fire exposure time (recorded after the fire was ignited), respectively. The vertical axis of each plot is the distance from the lower flange (near fire) to the upper flange of the specimen. The top horizontal axis shows the location of five cross sections where thermocouples were installed as shown in Fig. 4-16. The bottom horizontal axis indicates the distance from the west end. A white vertical line locates the beam midspan. As shown, a non-uniform temperature distribution was developed through the section depth and along the fire exposed length. The flame tilt toward the west side of the beam midspan, as shown in Fig. 4-9(a), led the upper portion of section 5 to be hotter than that of section 6 . 
Fig. 4-21(a) shows the average temperature-time response in the fire-exposed midspan sections (i.e., sections 5 through 7 as shown in Fig. 4-16) at five different locations, including upper flange (UF), upper web (UW), middle web (MW), lower web (LW), and lower flange (LF). As shown, the temperature rapidly increased under the $t$-sqaure fire. After $8 \mathrm{~min}$ passed, the heating rate was $45^{\circ} \mathrm{C} / \mathrm{min}$ in the $\mathrm{LF}$ and $32{ }^{\circ} \mathrm{C} / \mathrm{min}$ in the upper flange on average. The specimen failed at $17.5 \mathrm{~min}$ with the peak HRR of $1270 \mathrm{~kW}$. Fig. 4-21(b) shows the 1-minute average temperature in the fireexposed sections near failure of the beam. The error bars indicate the standard deviation of the measured temperatures. As shown, the thermal gradient across the section was nonlinear, and the temperature ranged from $350{ }^{\circ} \mathrm{C}$ to $660{ }^{\circ} \mathrm{C}$.
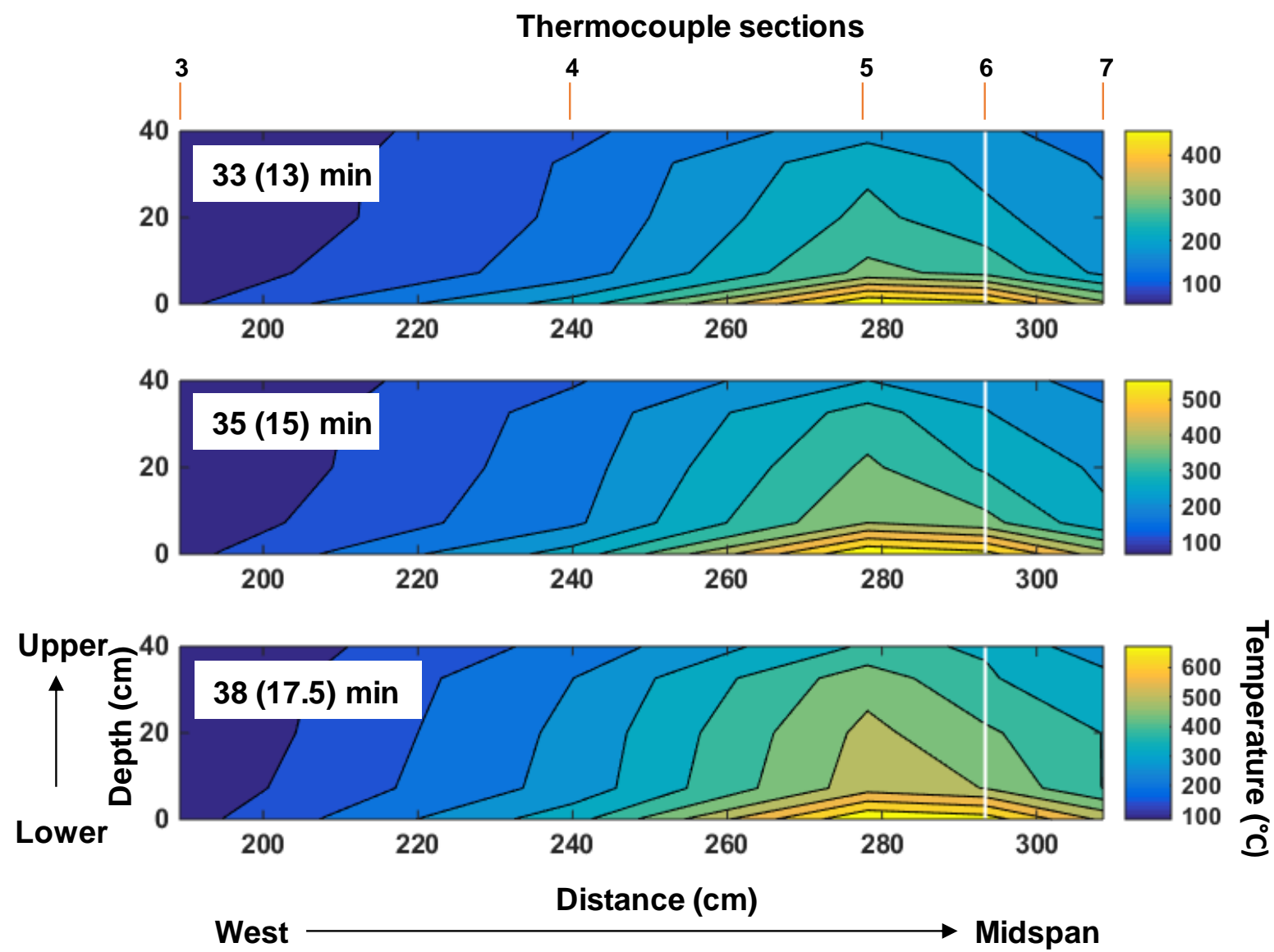

Figure 4-20 Temperature contours of the beam specimen in Test 8. 


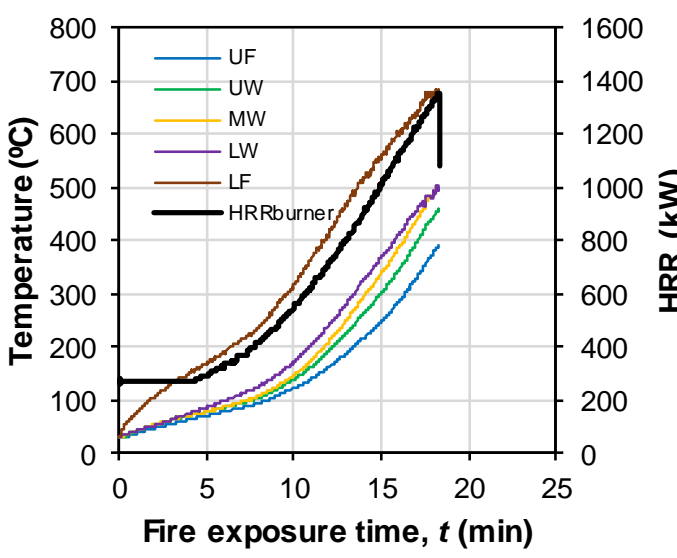

(a)

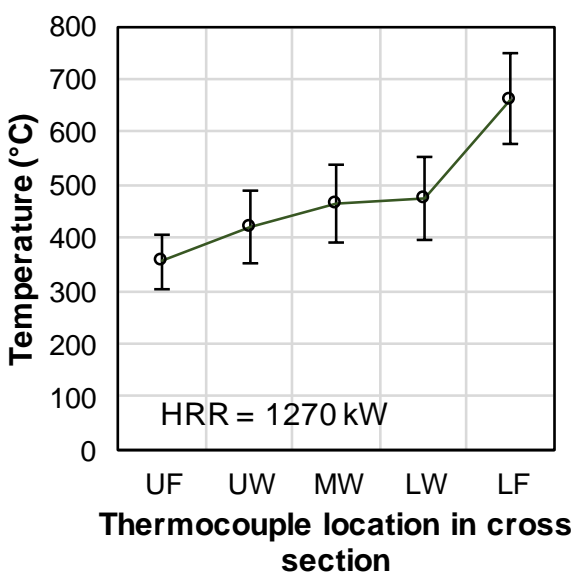

(b)

Figure 4-21(a) Measured steel temperatures in Test 8 and (b) 1 minute-average temperatures in fire exposed cross sections at the specimen failure.

Fig. 4-22(a) shows the specimen behavior captured at $4 \mathrm{~min}, 10 \mathrm{~min}, 15 \mathrm{~min}$, and $17.5 \mathrm{~min}$ after the fire was ignited. Fig. 4-22(b) shows the time series of the applied point load $\left(P_{y}\right)$ and the upper flange (UF) and the lower flange (LF) temperatures in the fire-exposed midspan. As shown, the point load was maintained at $90 \mathrm{kN}$ while the beam heated. At the fire exposure time of $17.5 \mathrm{~min}$, the applied load decreased since the specimen started losing its stability. In the heating phase, the thermal gradient was developed through the section depth. At the onset of failure of the beam, the average LF and UF temperatures in the fire-exposed sections was $660{ }^{\circ} \mathrm{C}$ and $350{ }^{\circ} \mathrm{C}$, respectively.

Fig. 4-22(c) shows the time series of displacements of the beam exposed to the fire. The values of $\delta_{v}$ and $\delta_{v 1}$ are the vertical displacement at midspan and at the loading point, respectively. The values of $\delta_{L}$ are the lateral displacement at the top flange at midspan. As shown, the vertical displacements increased from nonzero values since the beam was loaded to $90 \mathrm{kN}$ at ambient temperature. The maximum value of $\delta_{v 1}$ and $\delta_{v}$ prior to fire loading was $17.6 \mathrm{~mm}$ and $22.6 \mathrm{~mm}$, respectively. Immediately following the ignition of fire, the vertical displacement increased due to thermal bowing effect. The lateral displacement of the beam started increasing about 15 min later, followed by runaway displacements at $17.5 \mathrm{~min}$ when the beam failed. It is noted that an asterisk symbol on the graph of $\delta_{v}$ indicates the time when the displacement sensor failed.

Fig. 4-23 shows snapshots of the videos with the view of the fire-exposed region of the specimen near failure and immediately after the burner was turned off. A yellow reference line was added later to indicate the overall deflection induced by combined structural-fire loading effect. As shown, when the beam reached to its stability failure, the fire-exposed zone sagged and deflected 
laterally toward the north. A local buckling failure was also exhibited in the upper flange of the mid-section.
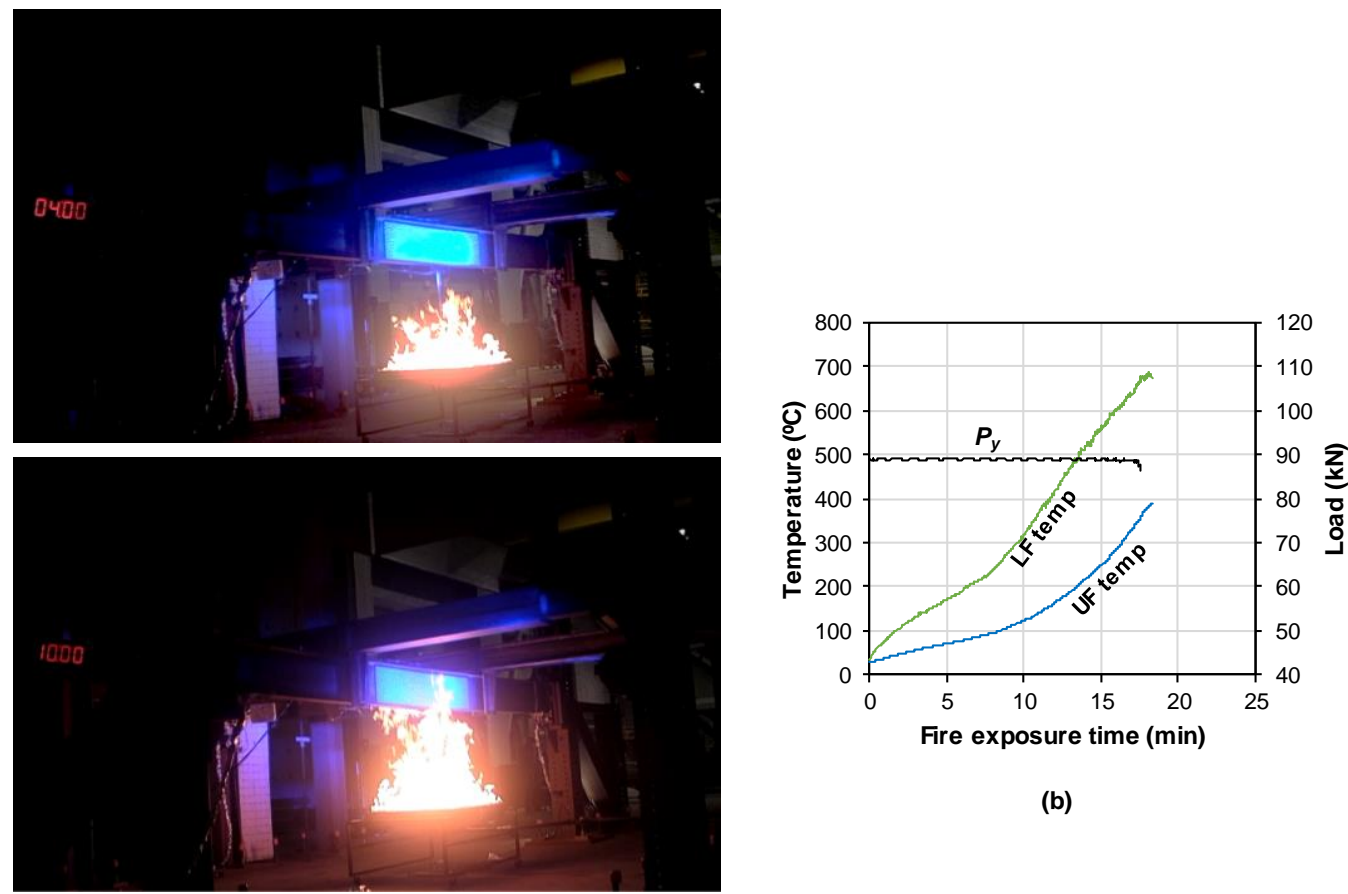

(b)
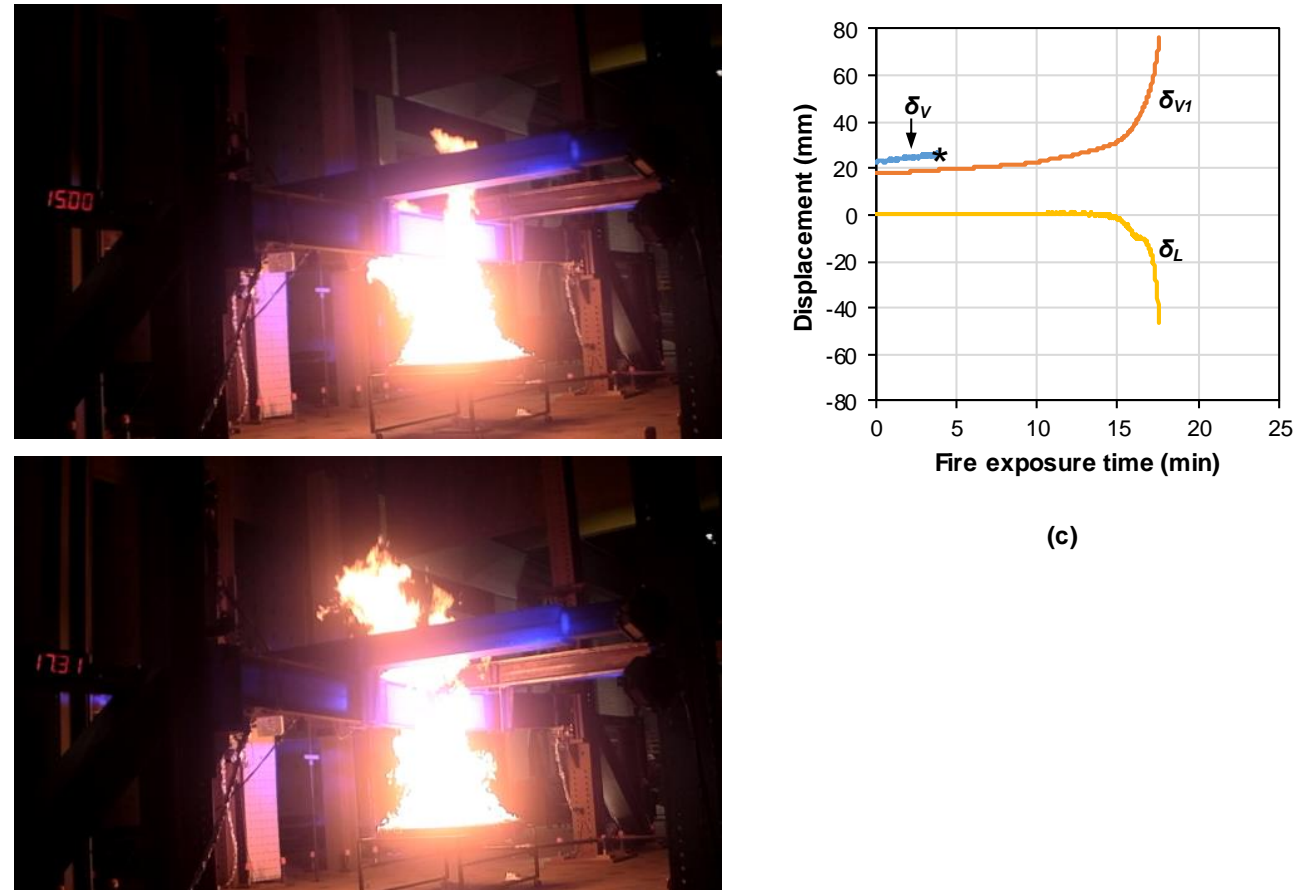

(c)

(a)

Figure 4-22(a) Snapshots of a video showing the specimen behavior, (b) time histories of the upper and the lower flange temperatures in the fire-exposed sections and the point load $\left(P_{y}\right)$, and $(c)$ the upper flange temperature versus displacement curves. 

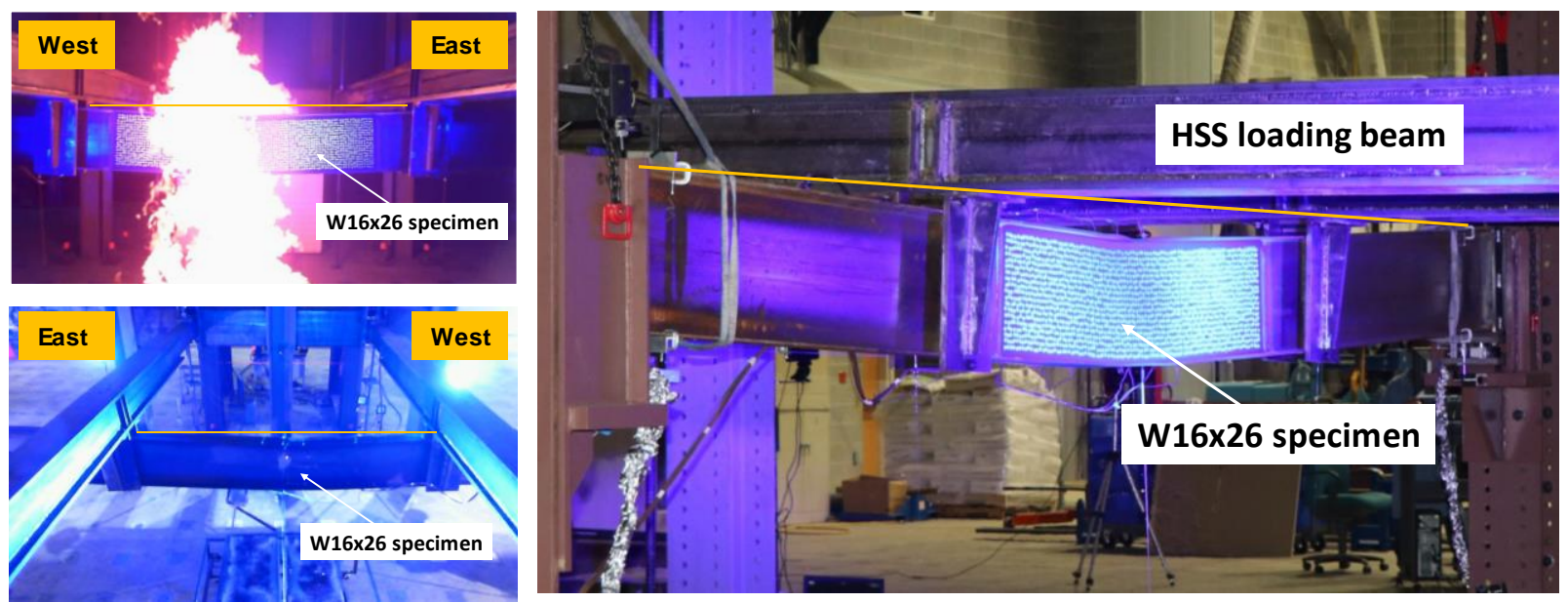

Figure 4-23 Snapshots of a test video showing the fire-exposed middle portion of the beam specimen (right) and the overall deflected shape of the specimen (left)

\subsection{TEST 9}

The only difference between Test 8 and Test 9 was the support conditions of the beam specimen. Test 8 used the simply supported beam specimen to allow free thermal elongation; in Test 9, the specimen ends were constrained with the double-angle bolted shear connections. Details of connection design is described in Section 2.2.2. Structural loading and fire conditions were unchanged from Test 8 . The testing was performed in two steps:

1) The specimen was loaded by two equal concentrated forces with a target value of $90 \mathrm{kN}$ each at ambient temperature

2) The same transient fire as used in Test 8 was applied to increase steel temperatures until the beam specimen failed.

\subsubsection{Instrumentation Layout}

Fig. 4-24 shows the instrumentation layout. The locations of thermocouples and displacement transducers were identical to those used in Test 8. Two inclinometers were added on the top flange at the beam ends. In the connection region, linear strain gauges were mounted to measure axial restraints induced by fire. The vertical reaction forces at the beam ends were not measured. 


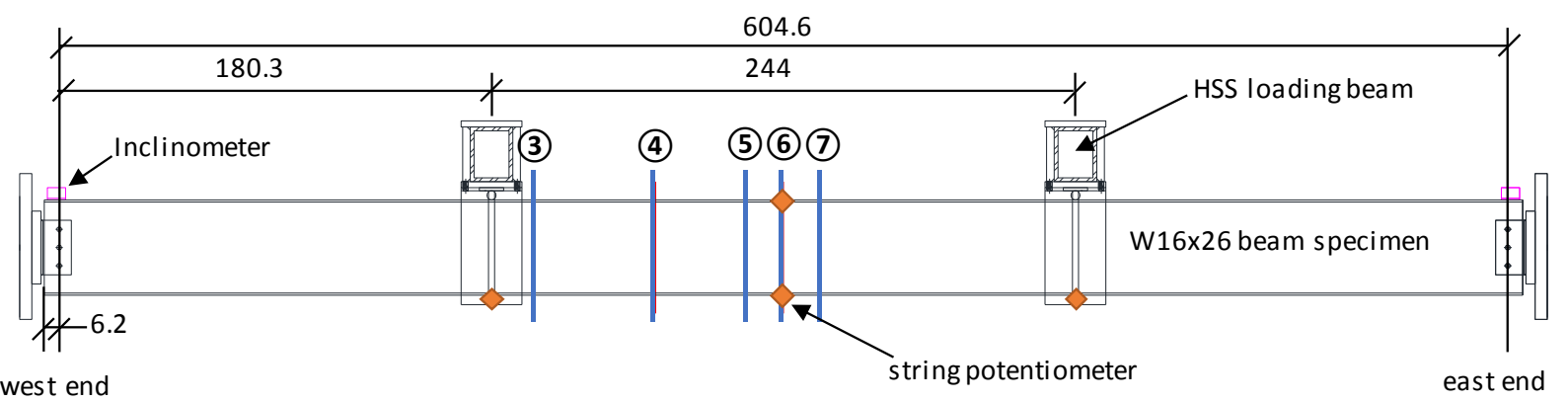

Thermocouples

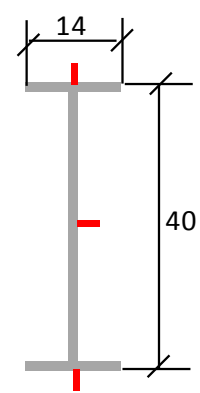

Section 3

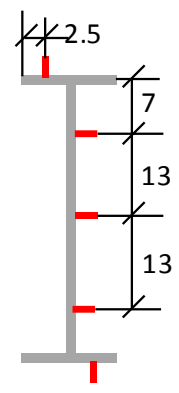

Sections $4,5,7$

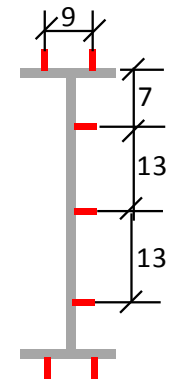

Section 6 (midpsan)
String potentiometers

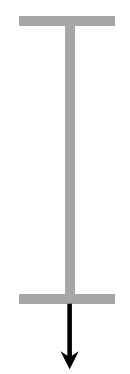

At loading points

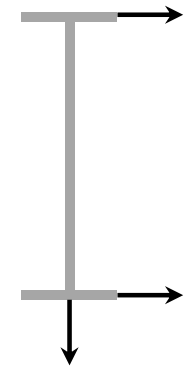

Sections 6 (midpsan)

Strain gauges at double-angle bolted connections

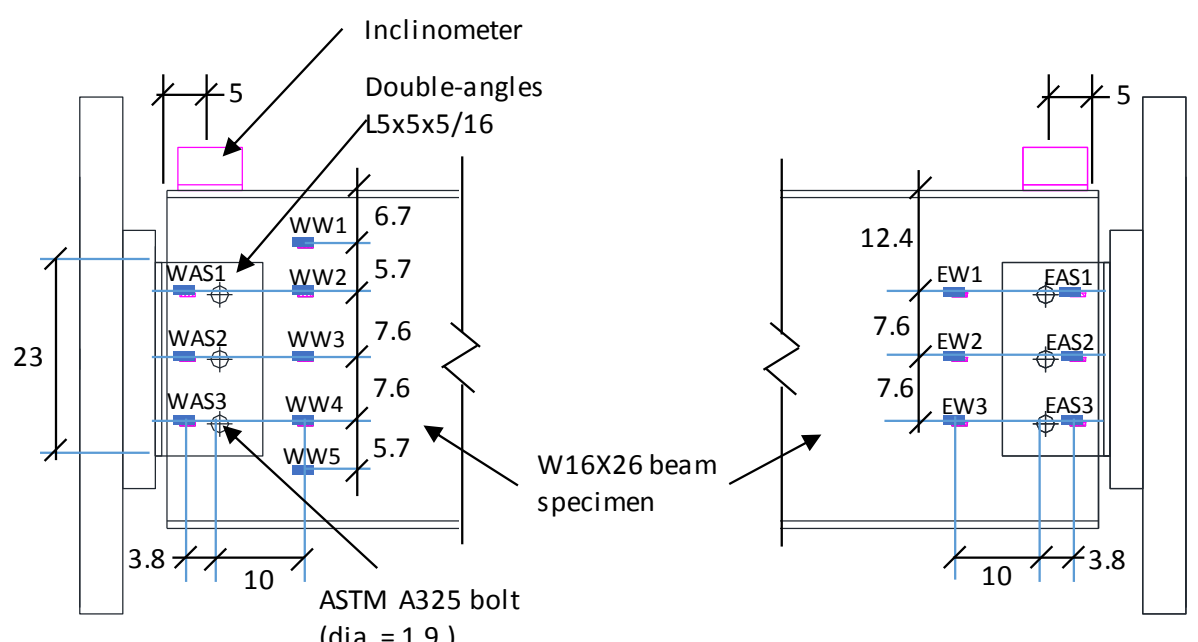

West end

East end

Figure 4-24 Instrumentation layout used in Test 9. (unit: cm). 


\subsubsection{Test Conditions}

Fig. 4-25 shows the time series of measured point loads $\left(P_{y}\right)$ and the burner HRR. The point load (at the location of the HSS loading beam shown in Fig. 4-24) increased to $90 \mathrm{kN}$ at ambient temperature, and then remained constant while the beam heated under fire. To produce a test fire, the burner HRR increased following the same $t$-square function as described in Test 8 (Fig. 419(b)). The applied point load started decreasing at 30.5 min when the beam failed, and the maximum burner HRR was approximately $940 \mathrm{~kW}$.

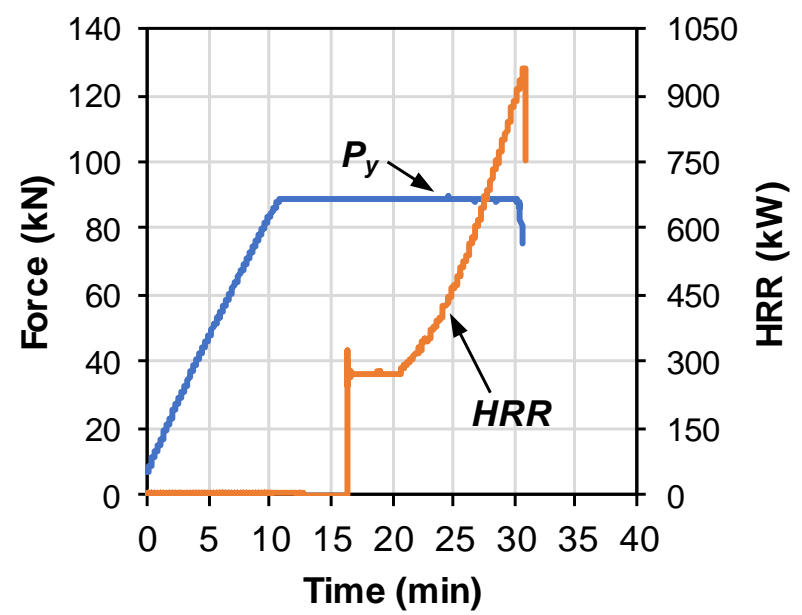

Figure 4-25 Measured HRR of the burner and the average point load $\left(P_{y}\right)$ as a function of test time. The standard deviation of $P_{y}$ values was $1.2 \mathrm{kN}$, respectively.

Fig. 4-26(a) shows the average $(\mu)$ and the standard deviation $(\sigma)$ of the forces applied at each end of two HSS loading beams using four actuators. All the actuators simultaneously increased the load at the programed rate of $2.54 \mathrm{~mm} / \mathrm{min}$. The maximum value of $\sigma$ was about $0.5 \mathrm{kN}$ as the load increased to the target value at ambient temperature but returned to almost zero afterward until the specimen failed at $30.5 \mathrm{~min}$. Fig. 4-26(b) shows the average values $\left(P_{y}\right)$ of the east and the west point loads and their differences $\left(\Delta P_{y}\right)$. As shown, because of displacement control of the actuators, the values of $\Delta P_{y}$ increased to $1.65 \mathrm{kN}$ at ambient temperature. During the heating phase, since the applied loads were maintained using force control of the actuators, the value of $\Delta P_{y}$ remained within $\pm 0.3 \mathrm{kN}$.

When each point load reached about $90 \mathrm{kN}$, the mid-portion of the beam heated as shown in Fig. 4-27(a). The location and the size of the burner and the ventilation condition was unchanged from previous tests. Like Tests 7 and 8, the upper flames slightly leaned toward the west side of the beam midspan. The effect of flame lean on steel temperatures is discussed in the Section 4.5.3. 
The $t$-square fire was produced using the same burner HRR-time relationship as used in Test 8 . Fig. 4-27(b) shows a comparison of the programed and measured HRR. As discussed in Section 4.3.2, the burner HRR initially ramped up to $270 \mathrm{~kW}$ and then increased by following the function of HRR $(\mathrm{kW})=4.5 \cdot t^{2}+250$ where $t=$ fire exposure time in minutes. The measured HRR was about $8.5 \%$ lower than the programed HRR on average.

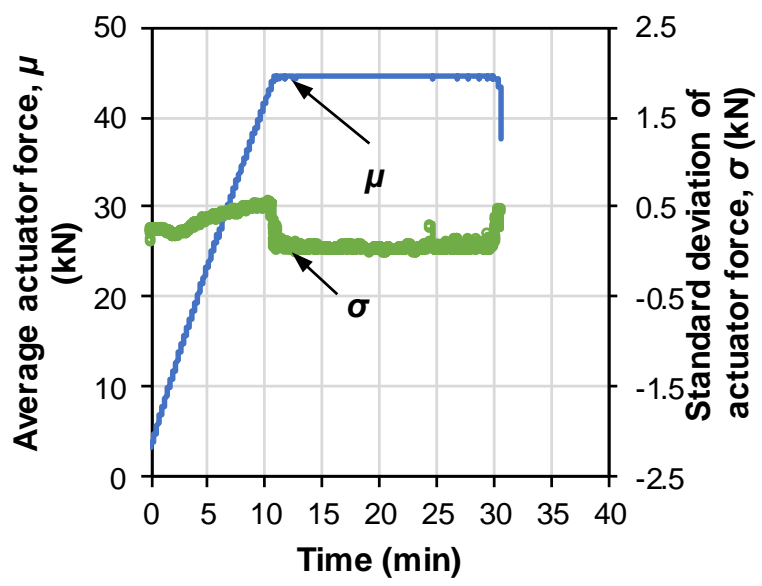

(a)

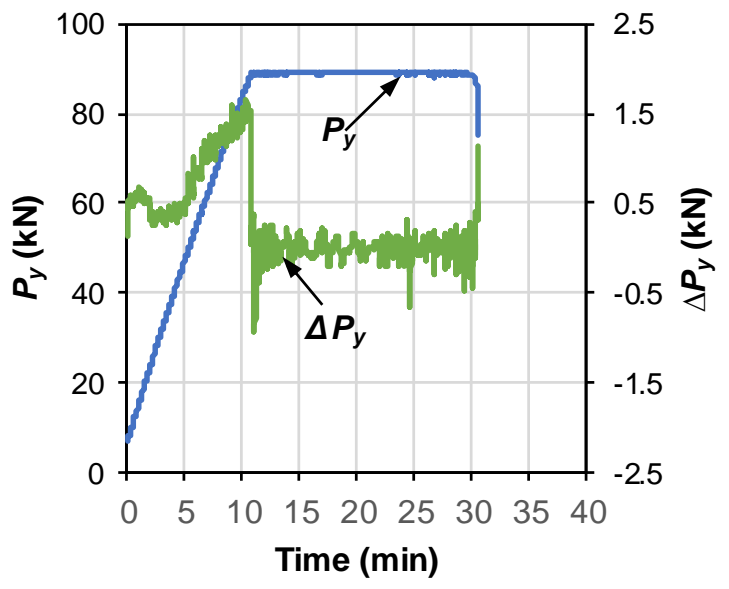

(b)

Figure 4-26 (a) The time series of average actuator force and standard deviation and (b) average point load $\left(P_{y}\right)$ over test period along with the differences $\left(\Delta P_{y}\right)$ of two points loads at the location of loading beams.
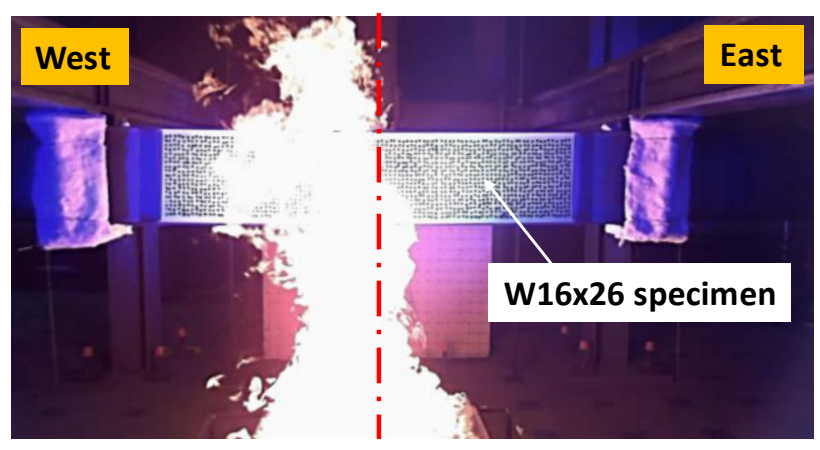

(a)

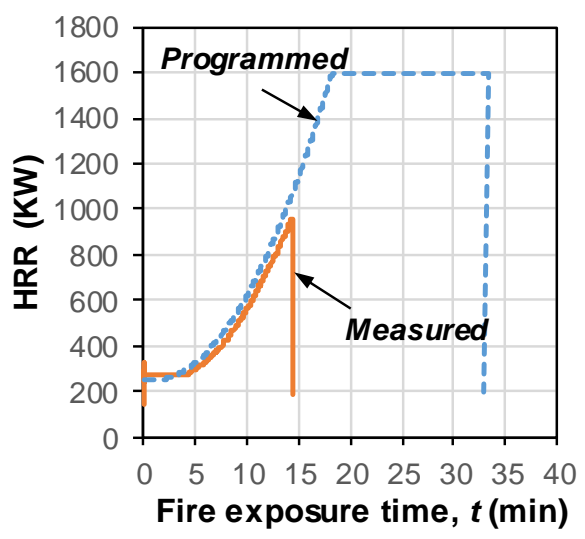

(b)

Figure 4-27(a) Snapshot of Test 9 with view looking down to the beam specimen and (b) comparison of the programmed and measured HRR of the burner. 


\subsubsection{Test Results}

Fig. 4-28 shows a temperature contour of the specimen under the transient fire. The time outside and inside parenthesis shown in each plot is the total test time (including the duration of loading at ambient temperature) and the actual fire exposure time, respectively. The left vertical axis indicates the distance from the lower flange (near fire) to the upper flange of the specimen. The upper and lower horizontal axes show the location of each thermocouple section shown in Fig. 424 and the distance measured from the west end of the beam. A white vertical line indicates the midspan of the beam. Like other previous tests presented in this report, non-uniform temperature distributions were developed through the section depth and along the beam length. As shown, the upper portion of section 5 was always hotter than that of section 6 (midspan) because the flames leaned toward the west side of the midspan (Fig. 4-27(a)).

Fig. 4-29(a) shows the temperature rise in the midspan of the beam under the transient fire. In this graph, the plotted values are the average temperatures in sections 5 through 7 at various locations in the beam section, including UF, UW, MW, LW, and LF shown in Fig. 4-12(a). As can be seen Fig. 4-29(a), after $8 \mathrm{~min}$ from ignition, the LF and UF temperatures increased at the rate of $51{ }^{\circ} \mathrm{C} / \mathrm{min}$ and $26^{\circ} \mathrm{C} / \mathrm{min}$, respectively. The specimen was failed about $14 \mathrm{~min}$ when the burner HRR was $940 \mathrm{~kW}$. Fig. 4-29(b) shows the temperature distribution in the fire-exposed midspan when the specimen failed by buckling. The error bars indicate the standard deviation of the measured temperatures in sections 5 through 7 . As shown, the nonlinear thermal gradient was developed with the temperature ranging from $230{ }^{\circ} \mathrm{C}$ to $560{ }^{\circ} \mathrm{C}$. 


\section{Thermocouple sections}
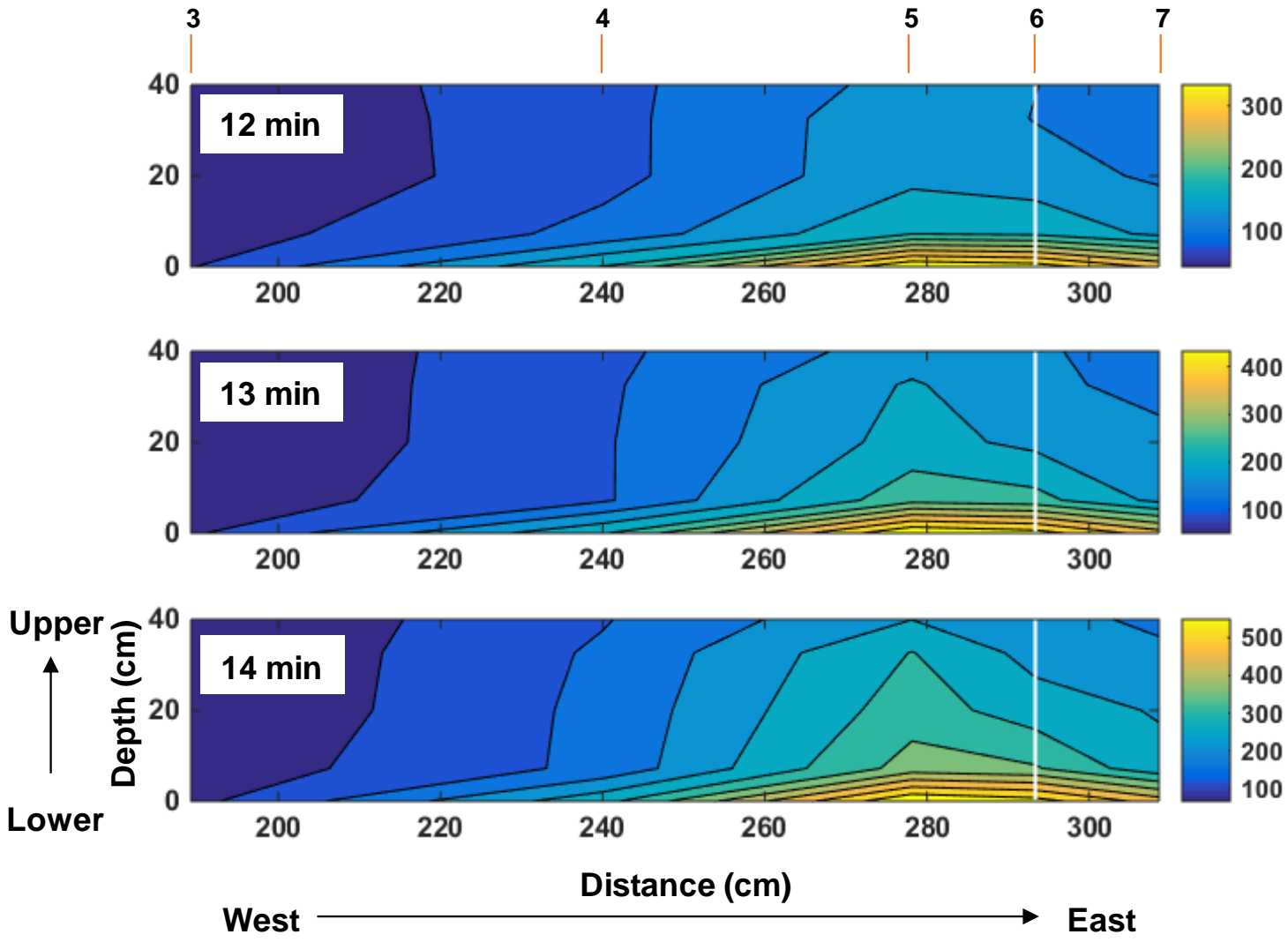

Figure 4-28 Temperature contours of the beam specimen in Test 9.

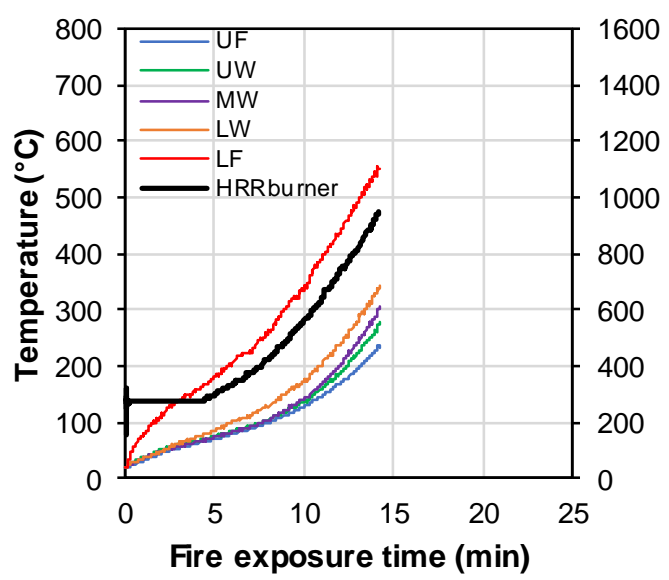

(a)

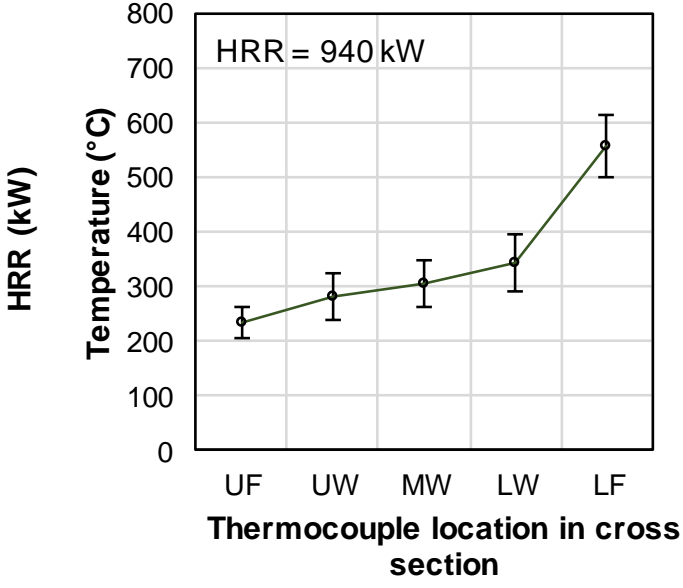

(b)

Figure 4-29 (a) Temperature rise in the fire-exposed midspan in Test 9 and (b) average thermal gradient in the fire exposed cross sections at the specimen failure. 


\section{(i) Specimen Behavior}

Fig.4-30(a) shows the snapshots of the specimen under the transient fire, which were recorded from $5 \mathrm{~min}$ to $14.3 \mathrm{~min}$ after the ignition of fire. Fig. 4-30(b) shows the time series of the applied point load $\left(P_{y}\right)$ and the upper flange (UF) and the lower flange (LF) temperatures in the fireexposed midspan. As shown, the applied point load was $90 \mathrm{kN}$ while the beam heated under the transient fire and started decreasing at 14 min after the ignition of fire. At the onset of failure of the beam, the average UF and LF temperatures in the fire-exposed sections was $230{ }^{\circ} \mathrm{C}$ and $560{ }^{\circ} \mathrm{C}$, respectively.

Figs. 4-30(c) and 4-30(d) present the time series of the displacement and end rotation of the specimen, respectively. The values of $\delta_{v}$, and $\delta_{v l}$ are the vertical displacement at midspan and at the location of the HSS loading beam, respectively. The values of $\delta_{L}$ are the lateral displacement of the top flange at midspan. The values of $\theta_{x}$, and $\theta_{y}$ are the beam end rotation about the strongaxis and the weak-axis of the cross section, respectively. As shown, the vertical displacements increased in response to increasing temperature in the beam. About $10 \mathrm{~min}$ passed from the ignition of fire, both the vertical and the lateral displacements increased simultaneously followed by runaway displacements at $14 \mathrm{~min}$. Similarly, the strong-axis rotation at the beam ends continued to increase during the heating phase, while the weak-axis rotation did not increase until the beam started deflecting laterally. The failure of the beam was indicated as runway rotations at the beam ends.

Fig. 4-31 shows the overall deflected shape of the specimen after cool-down and the ductile fracture failure of the upper flange at midspan, facing the strong wall. Like other previous tests, the steel beam specimen exhibited the permanent deformations in the combination of the strong axis bending and the lateral-torsional buckling. The compression side of the upper flange exhibited local distortion failure; the tension side of the upper flange (toward the north) showed ductile fracture failure which was initiated at the location of the threaded hole to connect the string potentiometer for displacement measurement. 

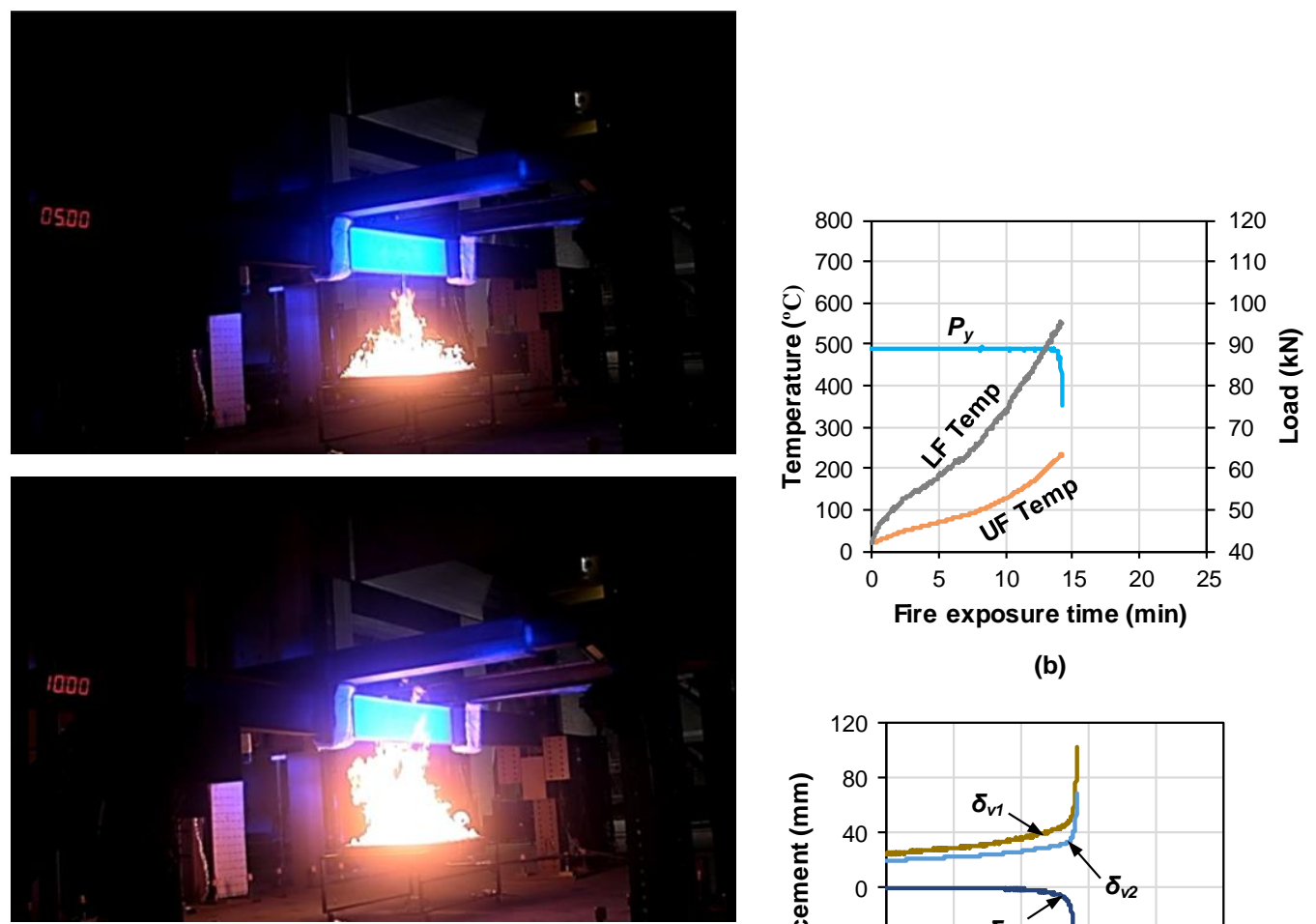

(b)

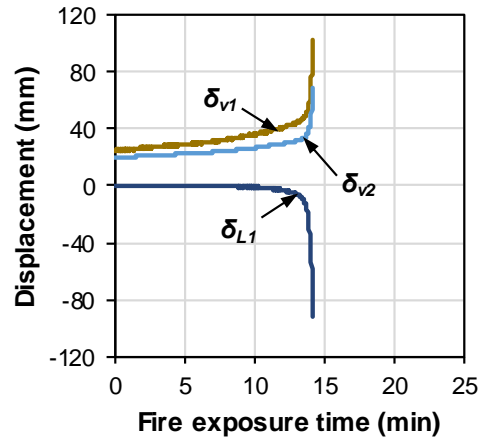

(c)

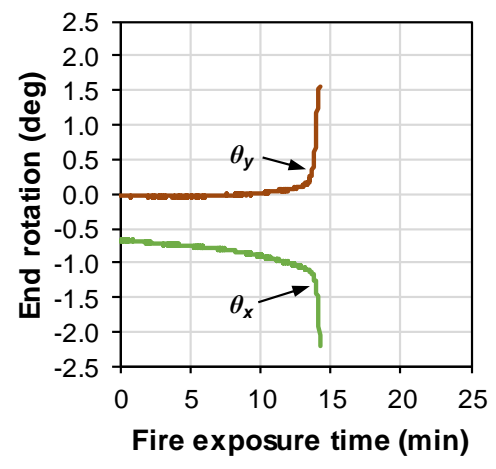

(d)
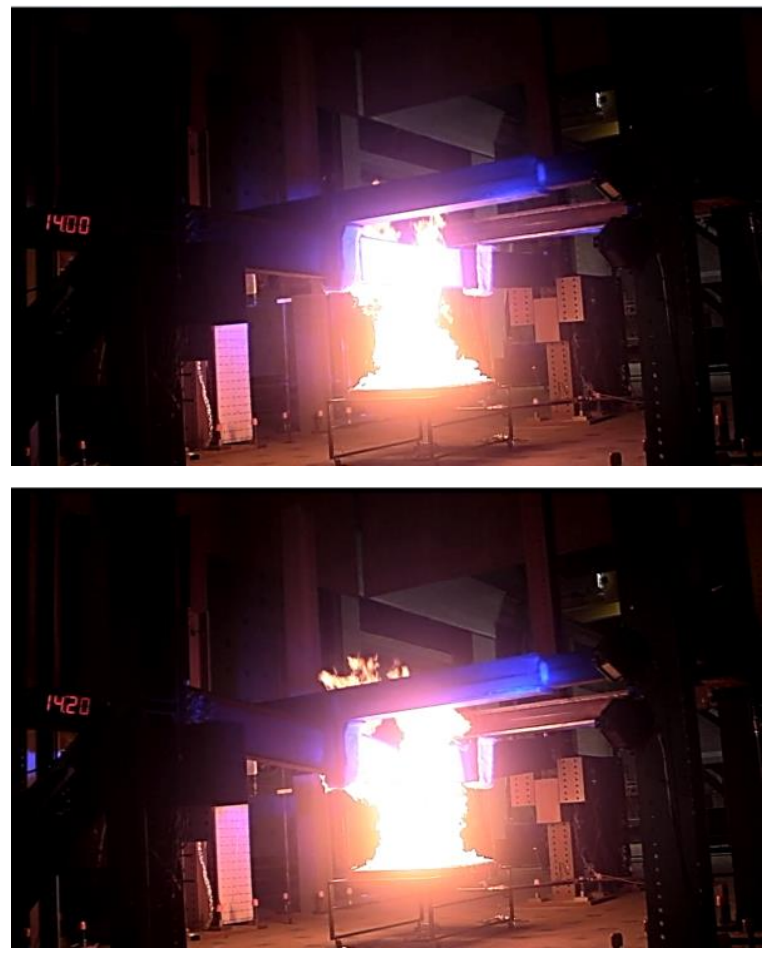

\begin{tabular}{l}
2 \\
\multirow{3}{8}{} \\
0 \\
0 \\
0
\end{tabular}

(a)

Figure 4-30 (a) Snapshots showing the specimen behavior under fire condition, the time histories of (b) the upper and the lower flange temperatures at midspan and the point load $\left(P_{y}\right)$, and (c) displacements, $(d)$ end rotations of the beam specimen. 

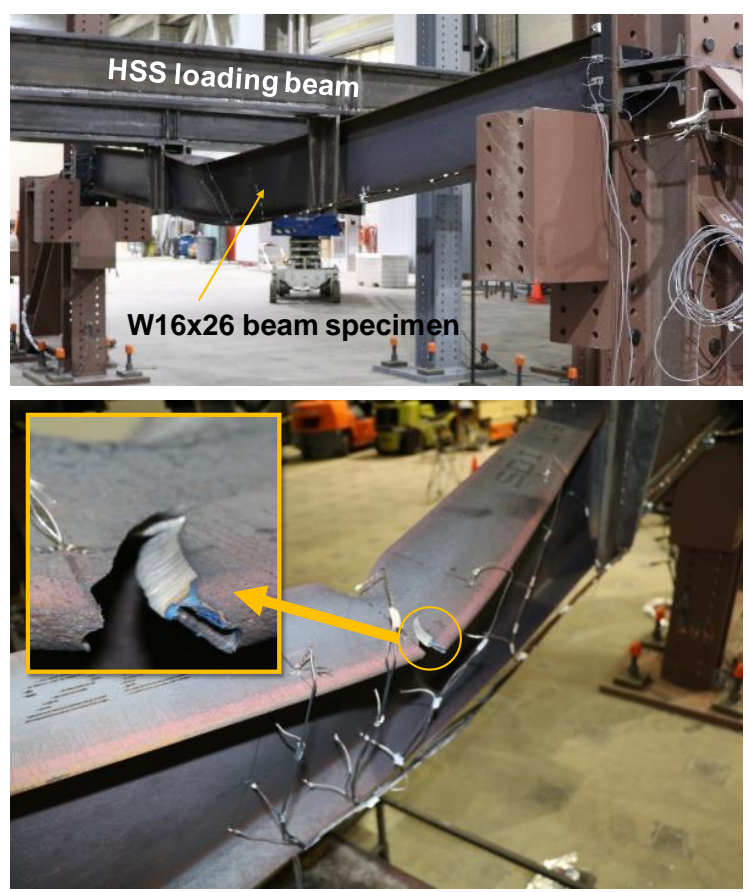

Figure 4-31 Deflected shape of the specimen after cool-down (top) and ductile fracture failure at midspan (bottom)

\section{(ii) Connection behavior}

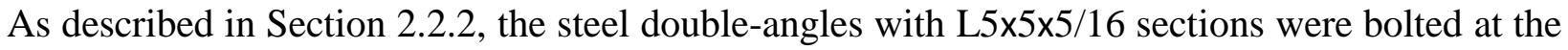
beam ends to connect the beam to the support columns. When heated under fire, this beam was subjected to additional forces induced by the axial restraint against thermal elongation. The temperature in the connection regions remained below $40{ }^{\circ} \mathrm{C}$.

Fig. 4-32 shows the strains in the steel angle at three discrete locations $\left(\varepsilon_{a 1}, \varepsilon_{a 2}\right.$, and $\left.\varepsilon_{a 3}\right)$ and a photograph of the final deflected shape after test. In the graph, the positive values of $\varepsilon_{a 1}, \varepsilon_{a 2}$, and $\varepsilon_{a 3}$ are the tensile strains. The error bars indicate the standard deviation of strains measured at two ends of the beam specimen. As shown, during flexural loading of the beam at ambient temperature (until $10 \mathrm{~min}$ ), the connected angles supported combined tensile forces and negative bending moments induced by flexural loading of the beam. When the loaded beam heated by fire at its midspan (starting at $17 \mathrm{~min}$ ), the reversal of strains occurred in the upper portion of the angles as a result of compressive forces caused by the restraint against thermal elongation. The strain gradient during the heating phase varied with time because of the thermal gradient in the beam section. After $25 \mathrm{~min}$, the connected bolts lost pretension forces, and slip occurred as the specimen bent downward. When the plastic hinging occurred at midspan of the beam (due to fracture of the upper flange as shown in Fig. 4-31), the connection region was subjected to a large tensile force 
in order to support the point loads imposed on the specimen. The increased tensile force resulted prying of the angle legs bolted to the supporting columns.

Fig. 4-33 shows the deflected shape of the angles after test. As shown, the angles allowed a large rotation, but neither tear-out failure of the bolt holes nor shear deformations in the connected bolts was observed.
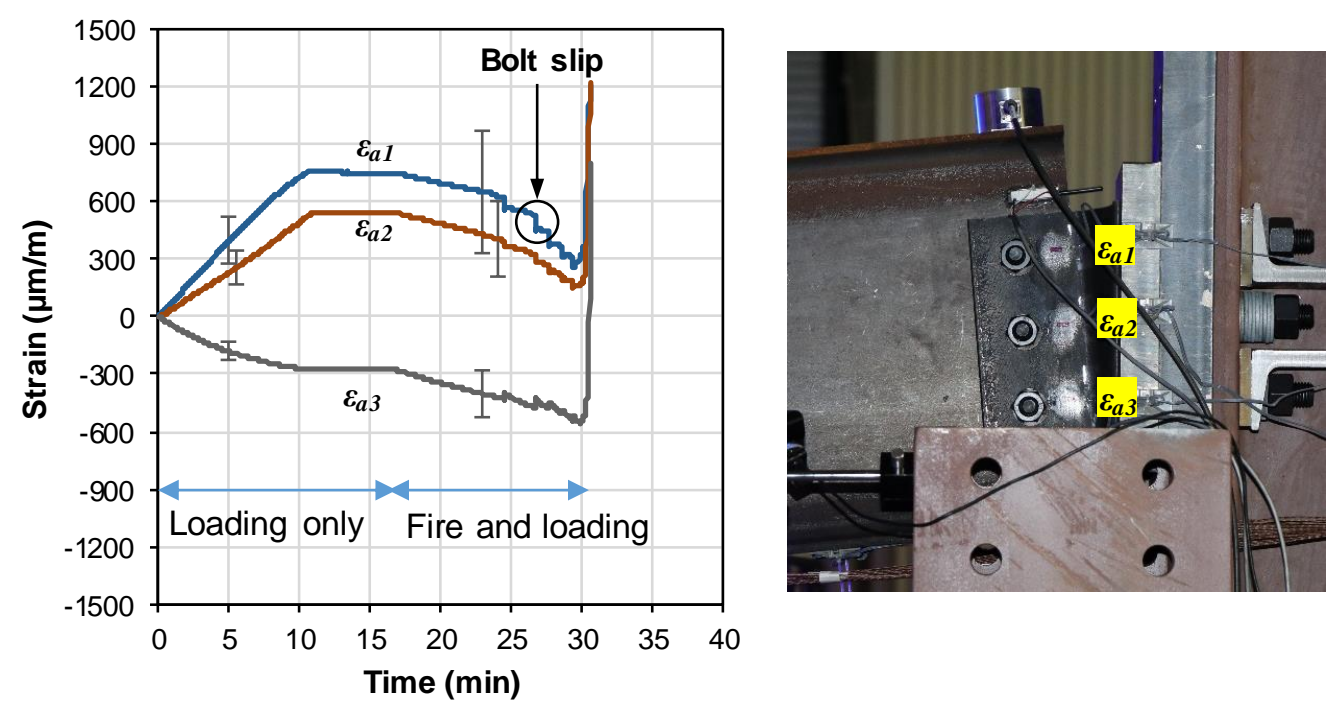

Figure 4-32 Strains developed in the steel angle (left) and pried steel angles after test (right)
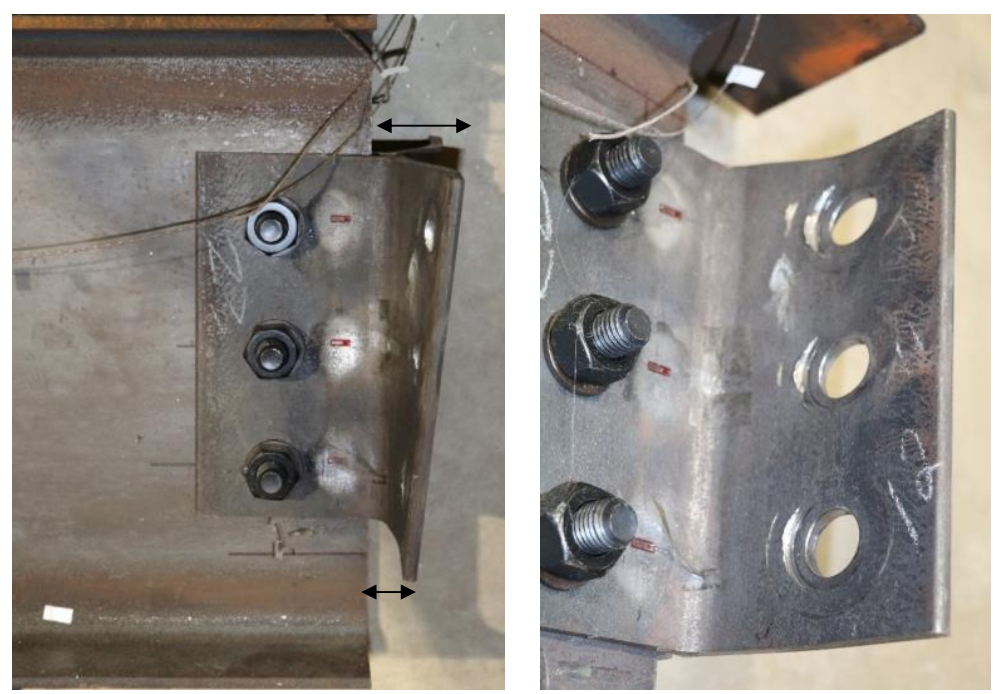

Figure 4-33 Double-angle connections at the beam end 


\subsubsection{Repeatability in Fire and Thermal Measurements}

The repeatability of the transient fire used in the test series was examined. Fig. 4-33 shows a comparison of the burner HRR values measured in Tests 8 and 9. The plotted values are the HRR values recorded at every one minute after the ignition of fire. Linear regression analysis showed that the burner HRR measured in Test 9 was about $4 \%$ higher than Test 8 on average.

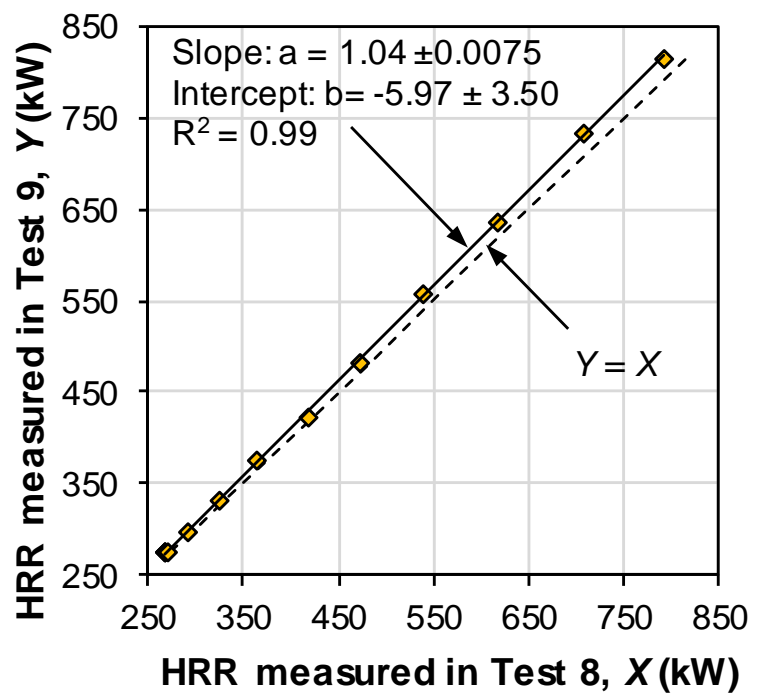

Figure 4-34 Comparison of the burner HRR measured in Tests 8 and 9

A similar approach can be used to evaluate the repeatability of the temperatures in the fire-exposed midspan of the beam. Fig. 4-33 shows comparisons of the temperatures measured in Tests 8 and 9. In each graph, the temperatures measured in Tests 8 and 9 are designated as $x$ and $y$, respectively. The locations of UF, UW, MW, LW, and LF are shown in Fig. 4-12(a). The plotted data points are the temperatures recorded at $1,3,6,9,12$, and 14 min after the ignition of fire. As shown, the flange temperatures in Test 9 was in the range of $6 \%$ to $9 \%$ higher than those in Test 8 . The deviation of the web temperatures between two tests was within $2 \%$. 

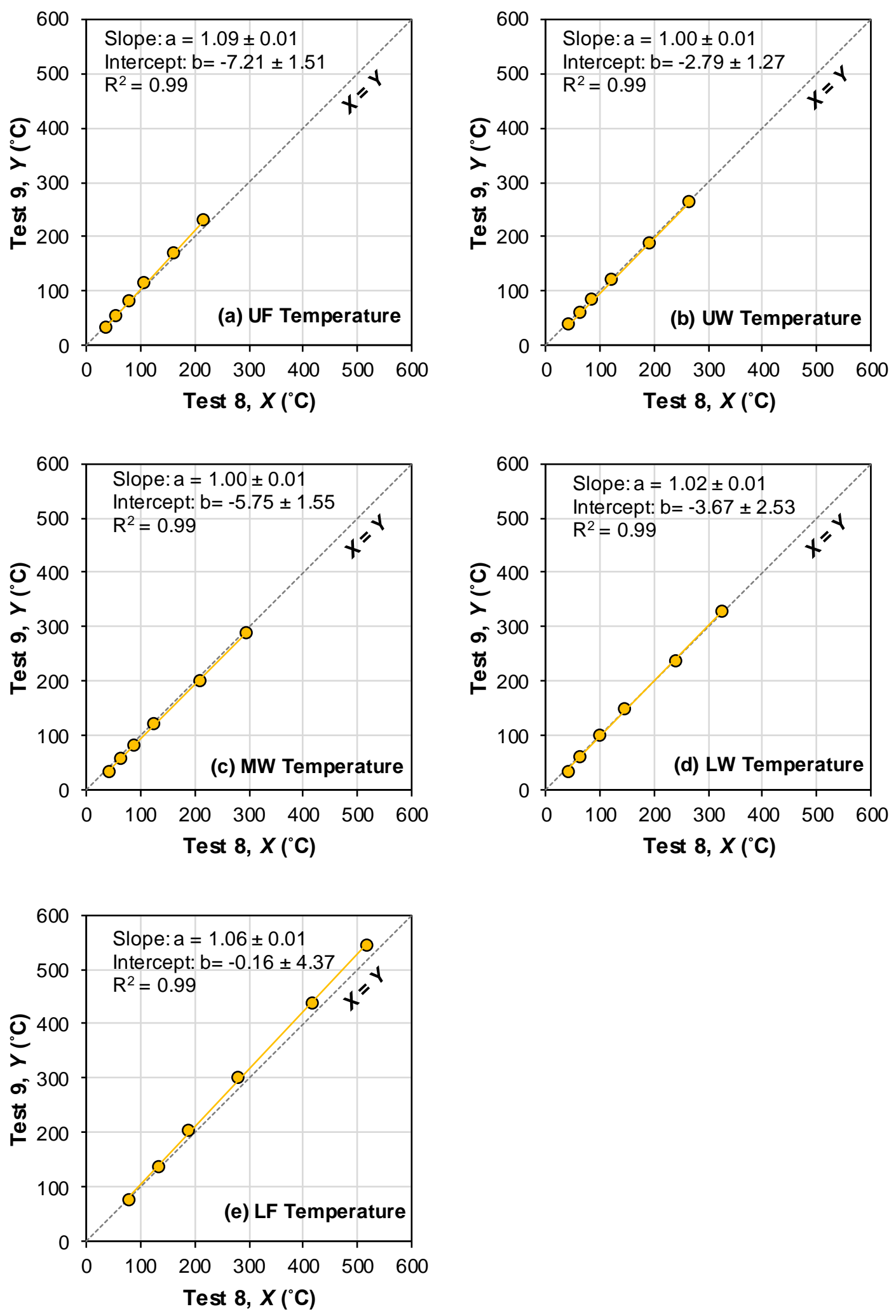

Figure 4-35 Comparison of the temperatures measured in Tests 8 and 9 


\section{Chapter 5 \\ SUMMARY AND CONCLUSIONS}

For the completion of commissioning the newly expanded NFRL, a series of fire tests were designed and conducted to verify the structural-fire testing and measurement capabilities. A total of nine tests were conducted on five 6.2-m long W16×26 steel beams under the localized fire conditions, including thermal tests and four-point bending tests on steel beams at room temperature and at elevated temperature. The fire in each test was produced and controlled by the $1 \mathrm{~m}^{2}$ natural gas burner. The burner was located $1.1 \mathrm{~m}$ below the bottom flange of the beam at midspan. A set of hydraulic actuators were used to apply the uniform bending moment in the middle portion of the beam, about $2.44 \mathrm{~m}$ in length around midspan, at room temperature and at elevated temperatures. Data included thermal and structural responses of the beam specimens, applied forces, and fires. The fire curve used in each test was defined as the heat release rate-time relations produced by the burner.

To evaluate the thermal behavior of the beam specimen under localized fire exposure and the repeatability of the temperature and displacement measurements, a total of five tests were conducted on the same specimen exposed to an open-flame fire at its midspan. Description of the thermal tests and results are summarized as follows:

- Tests 1 and 2 were the identical tests conducted by increasing the heat release rate in $100 \mathrm{~kW}$ increments approximately every $5 \mathrm{~min}$. The result from two repeated tests indicated that the standard deviation of the exposed (bottom) flange temperature and the vertical displacement at midspan was $28{ }^{\circ} \mathrm{C}$ and $2.5 \%$, respectively, when the heat release rate of the burner was set to $500 \mathrm{~kW}$.

- Tests 3 through 5 were the identical tests in which the heat release rate was fixed at $400 \mathrm{~kW}$ throughout the test period. The results from these fire tests indicated that the standard deviation of the exposed (bottom) flange temperature and the vertical displacement at midspan was $12^{\circ} \mathrm{C}$ and $4 \%$, respectively.

A total of four bending tests were conducted on the $\mathrm{W} 16 \times 26$ beam specimens under the roomtemperature and localized fire conditions. The room-temperature bending test (Test 6) was conducted on the simply supported beam to commission the loading apparatus and actuator controls and to measure its ultimate moment capacity and behavior as a baseline information for 
other tests. Tests 7 through 9 were the localized fire tests on the mechanically loaded beams. The effects of restraints at the beam ends (i.e., simply-supported versus double-angle connection) and various fire conditions (i.e., steady-state versus transient-state fire exposure) on the performance of the beams were measured. Overall, the test results showed that the heating rate of the specimen was sensitive to the prescribed heat release rate-time relationship. However, the thermal gradient developed in the fire-exposed cross sections of the beam never achieved linearity under the localized fire exposure. Regardless of the connection types and fire conditions (steady-state or transient-state fire), the beams exhibited a similar behavior and failure mode. At the early stage of the fire, the beam specimens were bent downwards due to thermal bowing induced by thermal gradients from a localized fire exposure. Near failure, due to combined fire and loading effects, the beam exhibited lateral-torsional buckling followed by runaway vertical displacements at its midspan.

Below summarizes the description of each test and the results.

- Test 6 was the room-temperature bending test on the simply-supported beam. The peak concentrated force on the beam was $130 \mathrm{kN}$ when the beam failed by inelastic lateral torsional buckling.

- Test 7 was the steady-state fire test in which the beam specimen was exposed to the constant heat flux from a $700 \mathrm{~kW}$ fire at its midspan and then the point loads on the beam were monotonically increased until failure occurred. During the mechanical loading phase, the temperature of the fire-exposed (bottom) flange was maintained to $(620 \pm 50){ }^{\circ} \mathrm{C}$. The peak concentrated force on the beam was $90 \mathrm{kN}$ measured at failure, which was about 67 $\%$ of its room-temperature strength.

- Test 8 was conducted in a reverse order of Test 7: The simply-supported beam was subjected to the similar magnitude of the peak load measured in Test 7 (with $\pm 1 \%$ difference) at ambient temperature. Then, the $t$-squared fire was applied to increase the steel temperature until failure occurred. The point loads were maintained to $(88.96 \pm 0.16)$ $\mathrm{kN}$ during the heating phase. The 1-minute average temperature in the fire-exposed flange at failure of the beam was $(660 \pm 80){ }^{\circ} \mathrm{C}$.

- Test 9 was conducted using the same test protocols as employed in Test 8. The only difference was the support conditions in which the beam was connected to the columns using double-angles. The point loads were maintained to $90 \mathrm{kN}$ during the heating phase. 
The 1-minute average temperature in the fire-exposed flange at failure of the beam was $(560 \pm 60){ }^{\circ} \mathrm{C}$.

The data generated from the tests may be used as application studies for computational models (e.g., computational fluid dynamics models and finite-element models) to predict the performance of structural steel members subjected to a localized fire. The measurement methods and uncertainties described in this report will be used for planning and documenting future tests at the NFRL. 
This page intentionally left blank. 


\section{REFERENCES}

American Society of Civil Engineers. (2016). Minimum design loads for buildings and other structures. ASCE 7-2016, Amer Society of Civil Engineers.

ASTM International. (2012). "Standard Specification for Structural Bolts, Alloy Steel, Heat Treated, 150 ksi Minimum Tensile Strength." ASTM A992/A992M-11, ASTM International, West Conshohocken, PA. doi: 10.1520/A0992_A0992M-11.

ASTM International. (2010). "Standard Specification for Structural Bolts, Steel, Heat Treated, 120/105 ksi Minimum Tensile Strength." ASTM A325-10e1, ASTM International, West Conshohocken, PA. doi: 10.1520/A0325.

ASTM International (2016) "Standard Test Methods for Tension Testing of Metallic Materials", ASTM.E8/E8M-16a, ASTM International, West Conshohocken, PA, 2016, doi:10.1520/E0008_E0008M-16A

Bundy, M., Hamins, A., Johnsson, E. L., Kim, S.C., Ko, G. H., and Lenhert, D. B. (2007). "Measurements of Heat and Combustion Products in Reduced-Scale Ventilation-Limited Compartment Fires.” NIST Technical Note TN-1483, National Institute of Standards and Technology, Gaithersburg, MD.

Choe, L. and Ramesh, S. (2017). "Measurement of the behavior of steel beams under localized fire exposure", NIST, Gaithersburg, MD, retrieved from the website: https://doi.org/10.18434/M37H4G

National Conference of Standards Laboratories (NCSL) RP-12. (1994). Determining and Reporting Measurement Uncertainties, Boulder, CO.

Hoehler, M. S., Smith, C. M. (2016). “Application of Blue Laser Triangulation Sensors for Displacement Measurement Through Fire." Measurement Science and Technology, 27(11), doi: 10.1088/0957-0233/27/11/115201

Taylor, B. N., and Kuyatt, C. E. (1994). "Guidelines for Evaluating and Expressing the Uncertainty of NIST Measurement Results." NIST Technical Note TN-1297, Gaithersburg, MD.

Zhang, C., Choe, L., Gross, J., Ramesh, S., Bundy, M. (2017) Engineering Approach for Designating a Thermal Test of Real-Scale Steel Beam Exposed to Localized Fire. Fire Technology,Vol53,Issue4.pp1535-1554. https://link.springer.com/article/10.1007/s10694016-0646-7) 
This page intentionally left blank. 


\section{APPENDIX A \\ Drawings For Test Setup, Specimens, And Connections}

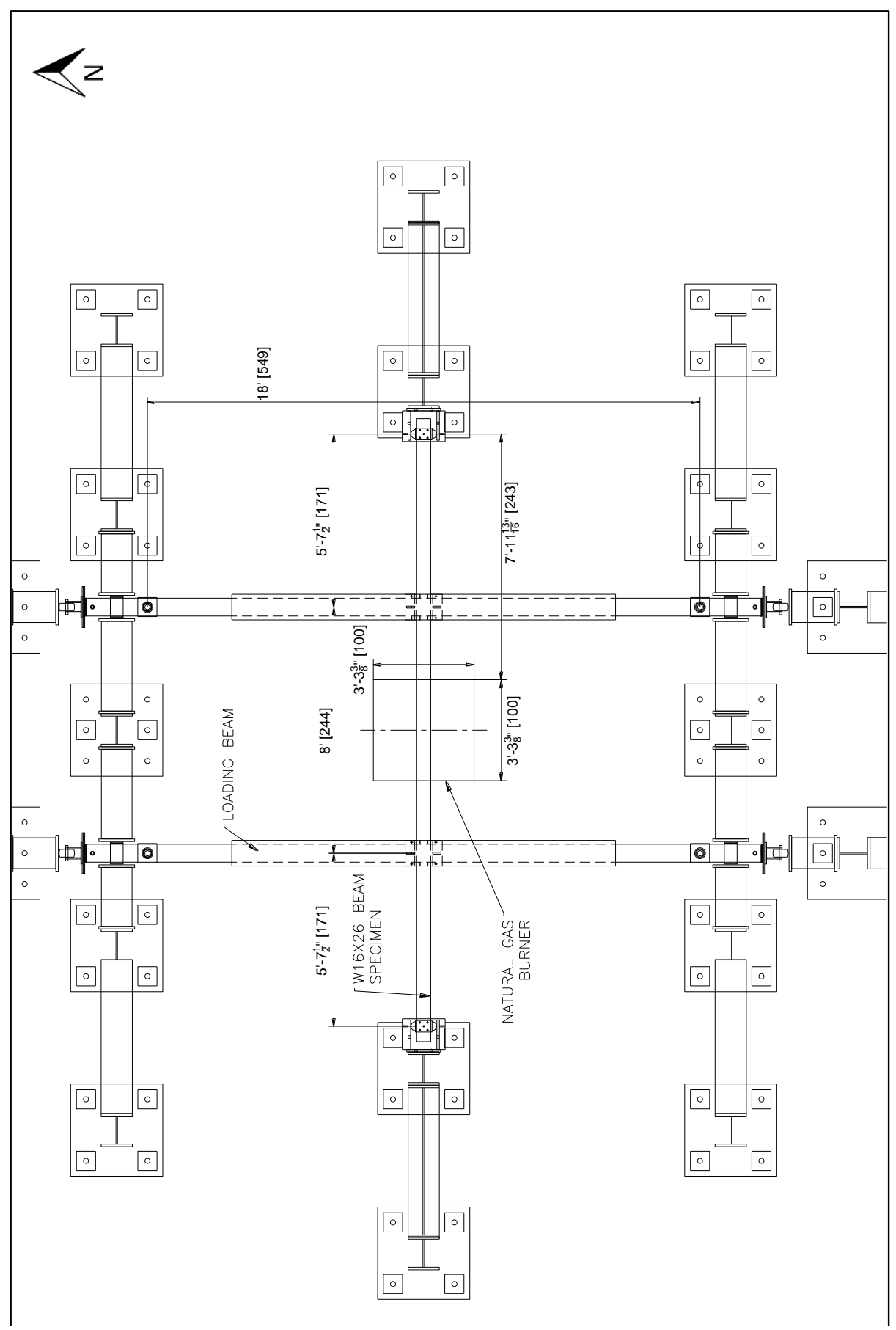

Figure A-1 Plan view of beam test setup (units in []$=\mathrm{cm}$ ). 


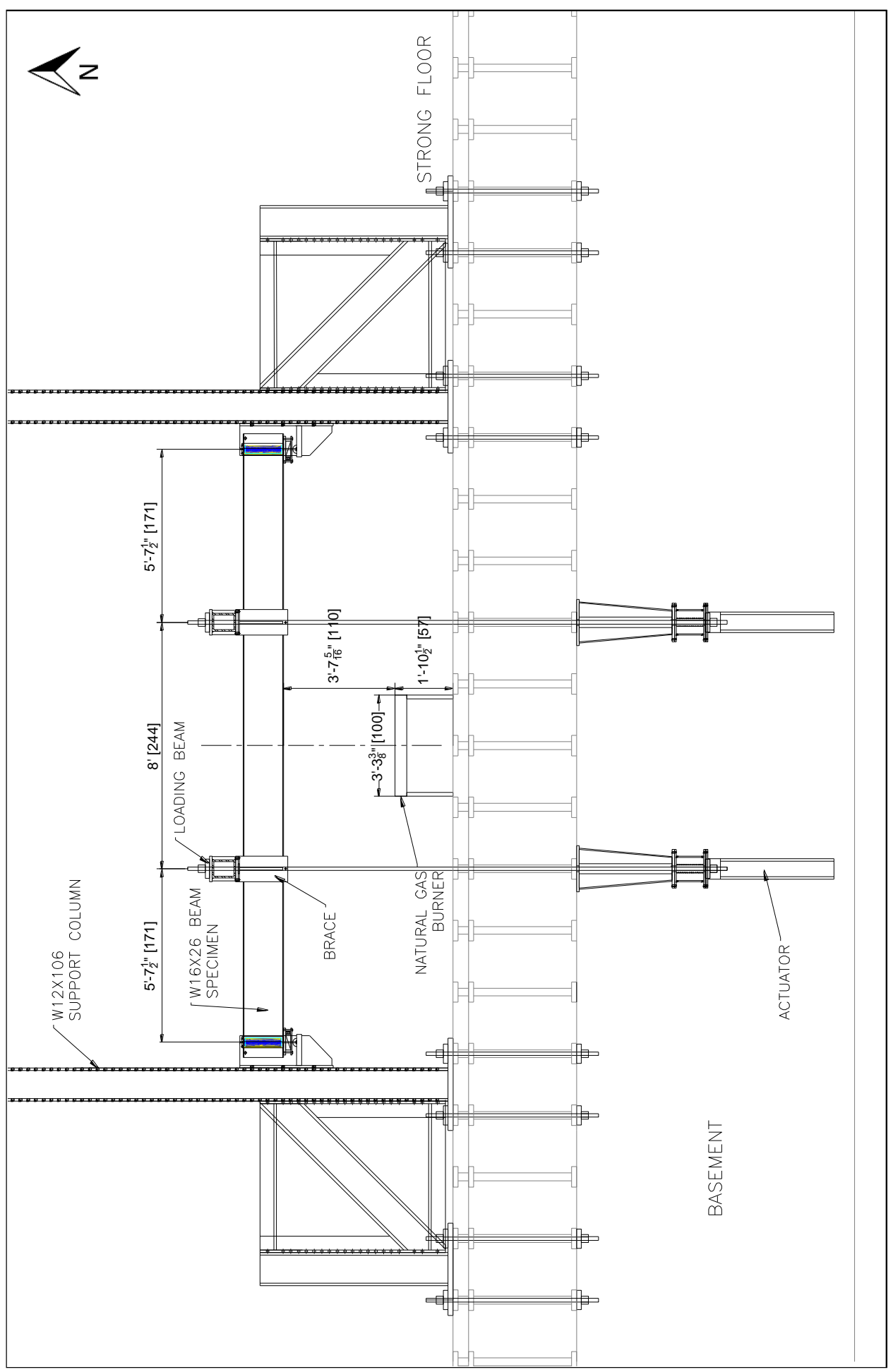

Figure A-2 Elevation view of test setup for simply-supported beam (units in [] = cm). 


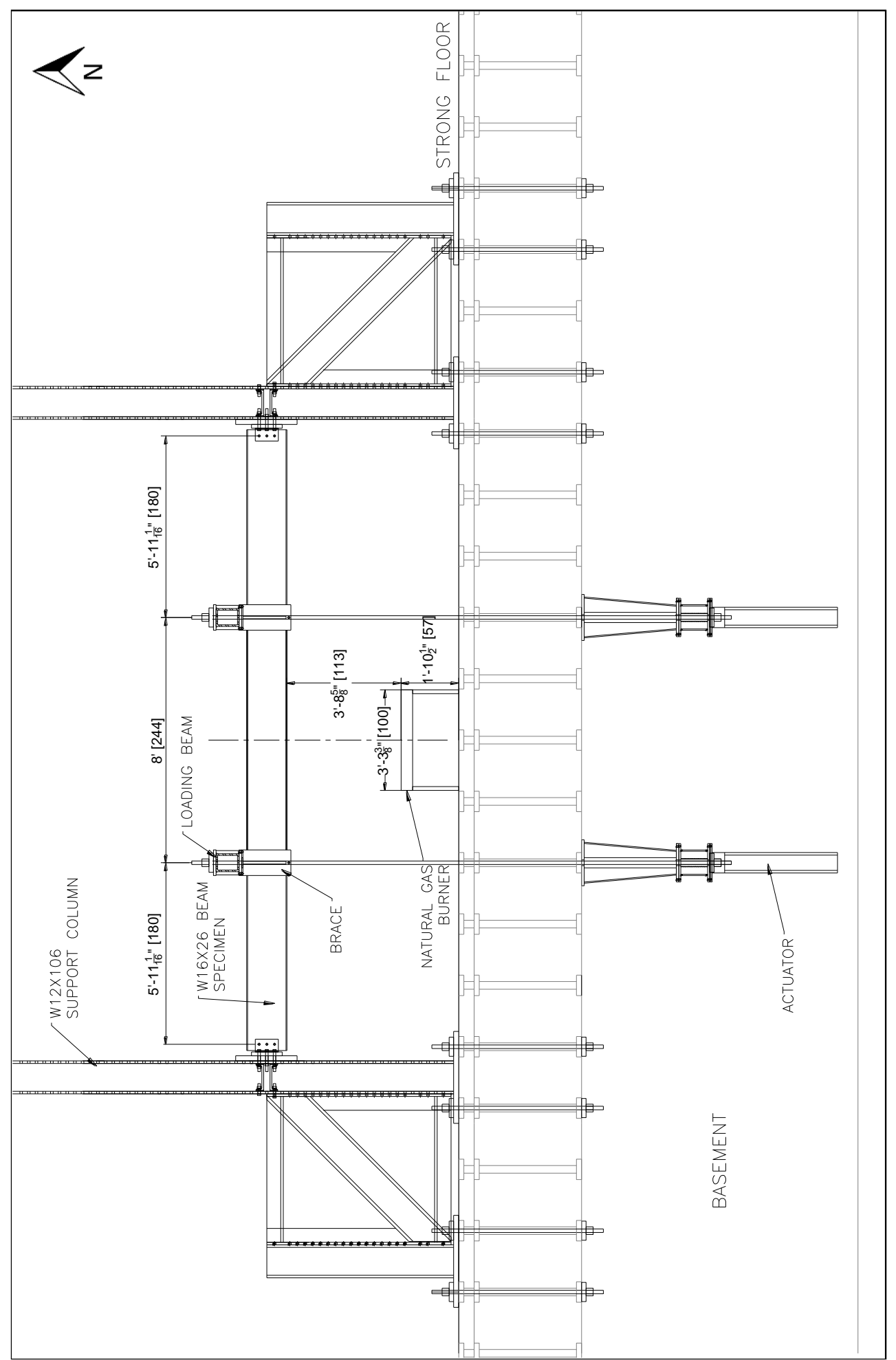

Figure A-3 Elevation view of test setup for the simply-supported beam (units in [] = cm). 


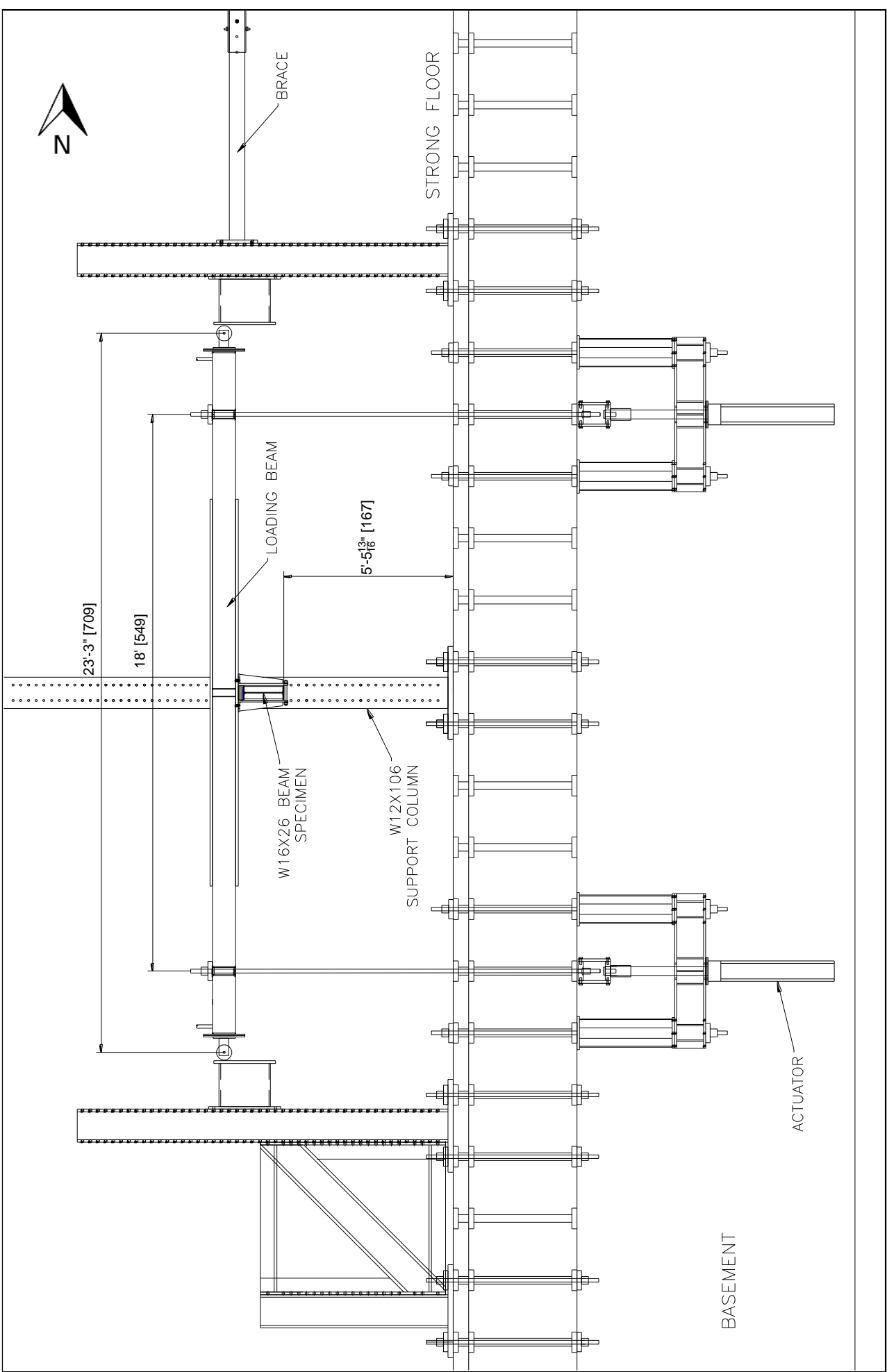

Figure A-4 Elevation view of buide frames for loading beam (units in [] = cm). 


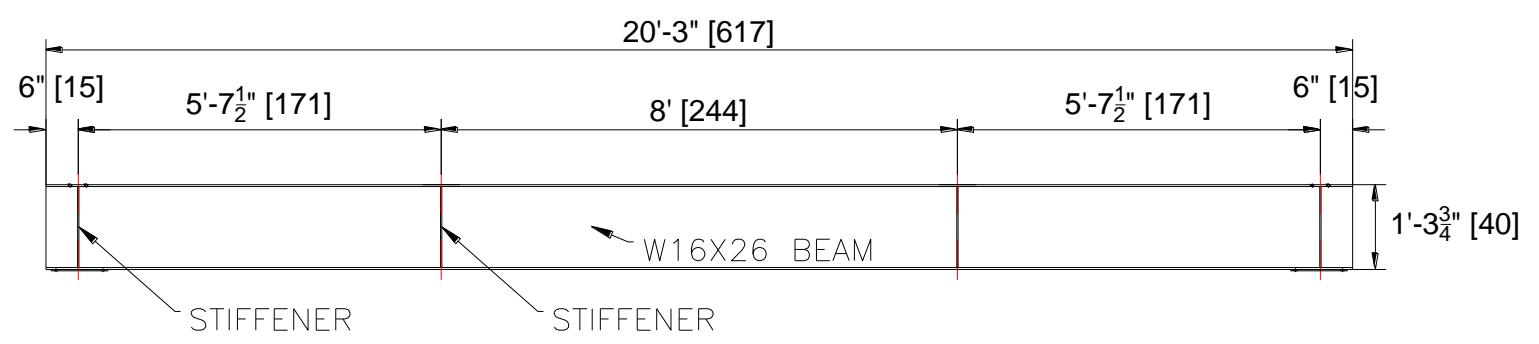

(a) Specimens used in Tests 1 through 8

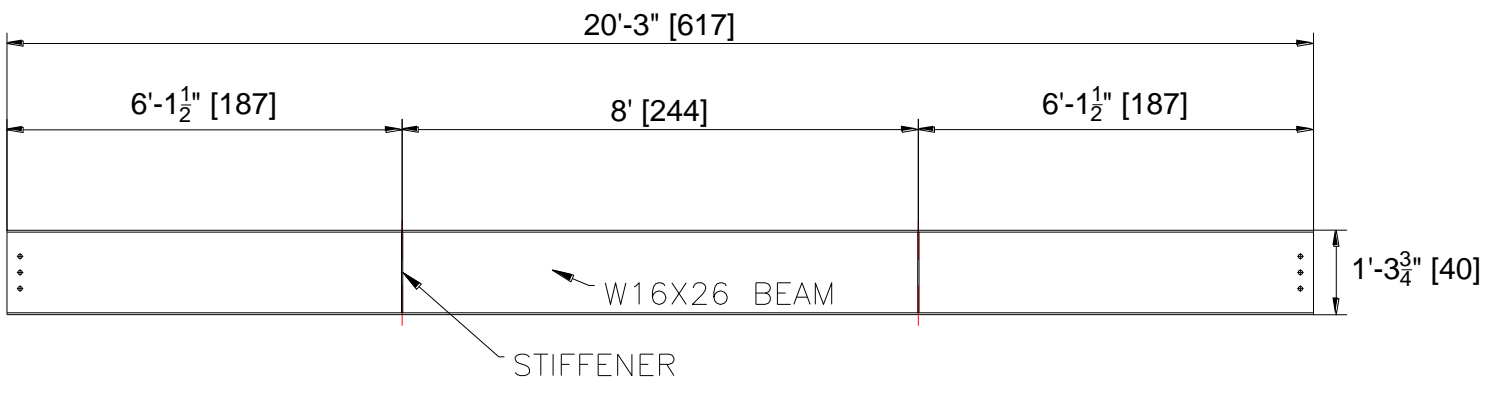

(b) Specimens used in Test 9

Figure A-5 Beam specimens (units in [] = cm).

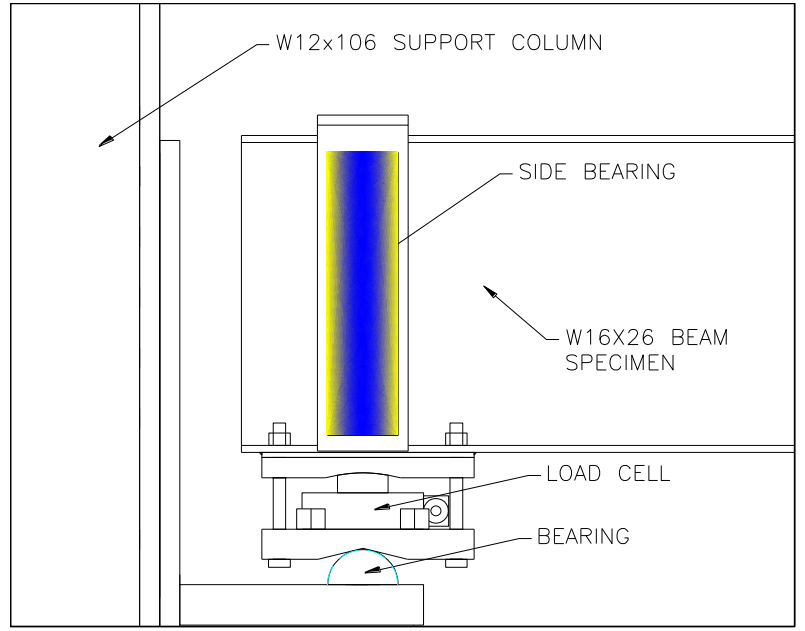

(a) Simple support (Tests 1 through 8)

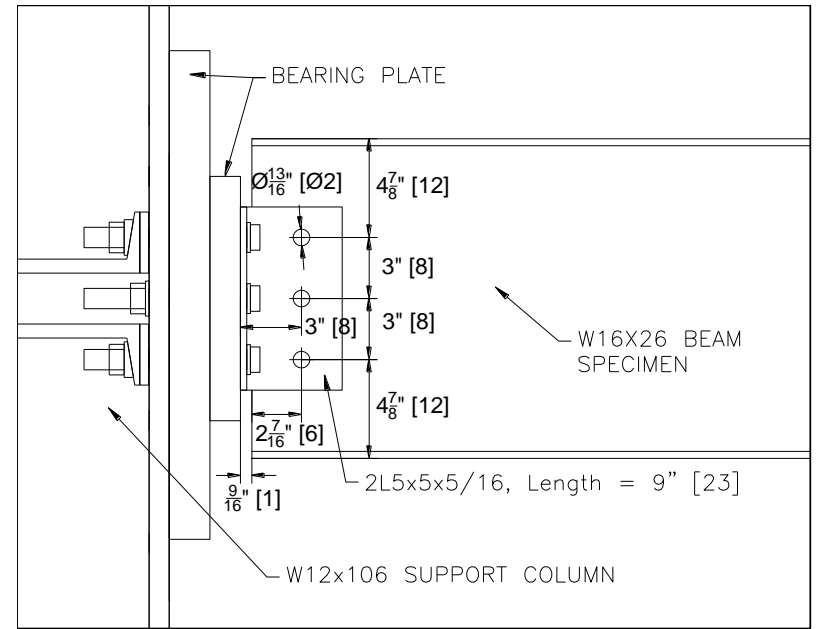

(b) Bolted double angle connection (Test 9)

Figure A-6 Beam end support conditions (units in []$=\mathrm{cm}$ ) 
This page intentionally left blank. 


\section{APPENDIX B \\ INSTRUMENTATION LAYOUT, SENSOR LABELS, AND MEASUREMENTS MADE IN THE TESTS}

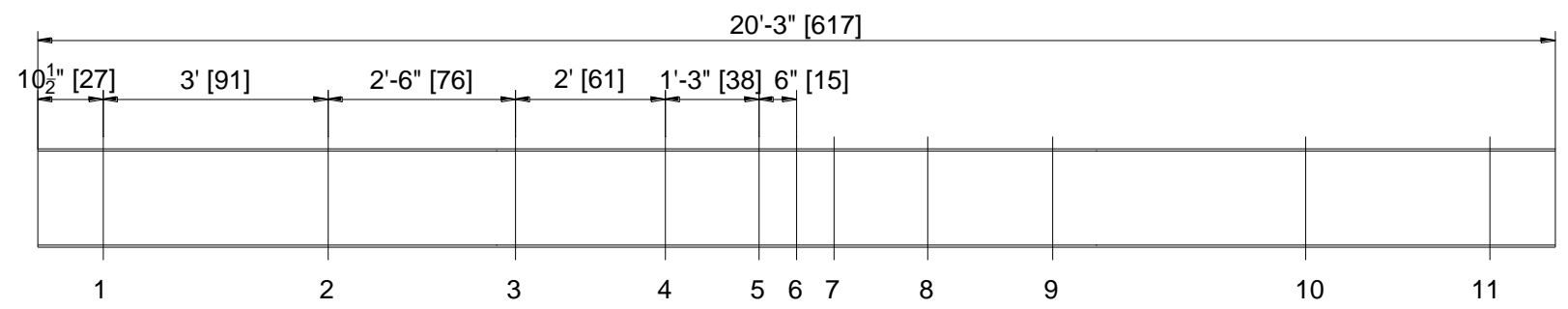

(a) Location of thermocouple sections 1 through 11 in the specimen (Tests 1 through 5)

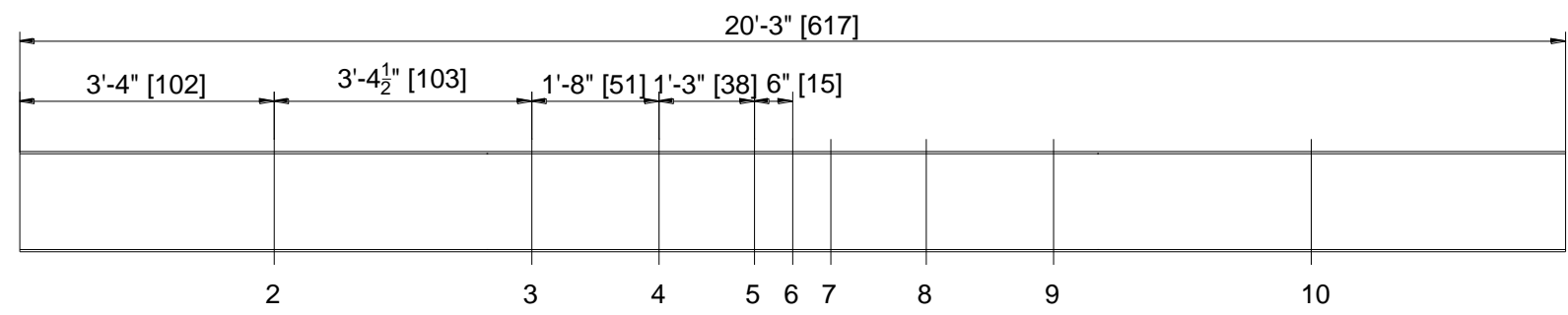

(b) Location of thermocouple sections 2 through 10 in the specimen (Tests 7 through 9)

Figure B-1 Locations of thermocouple sections in the W16X26 beam specimens (units in []$=\mathrm{cm}$ ).

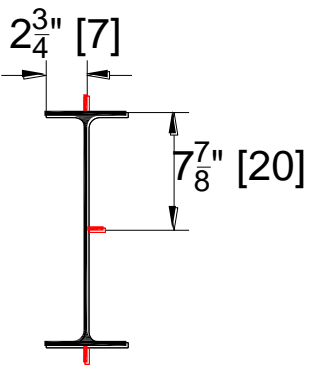

(a) Thermocouples in Sections 1 through 3 and 9 through 11

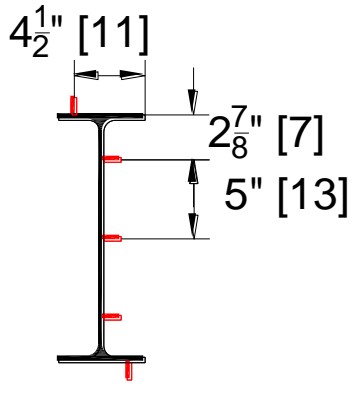

(b) Thermocouples in Sections $4,5,7$, and 8

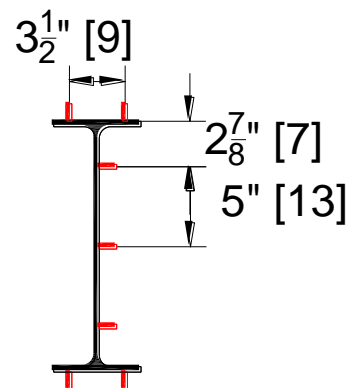

(c) Thermocouples in Section 6 (midspan)

Figure B-2 Location of thermocouples in beam cross-sections (units in [] $=\mathbf{c m}$ ). 


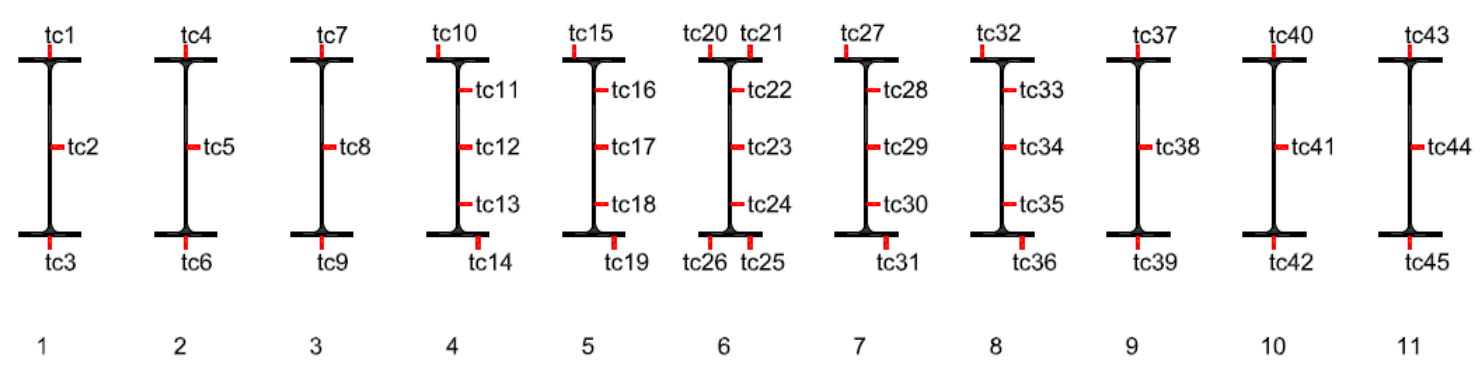

Figure B-3 Labels of thermocouples
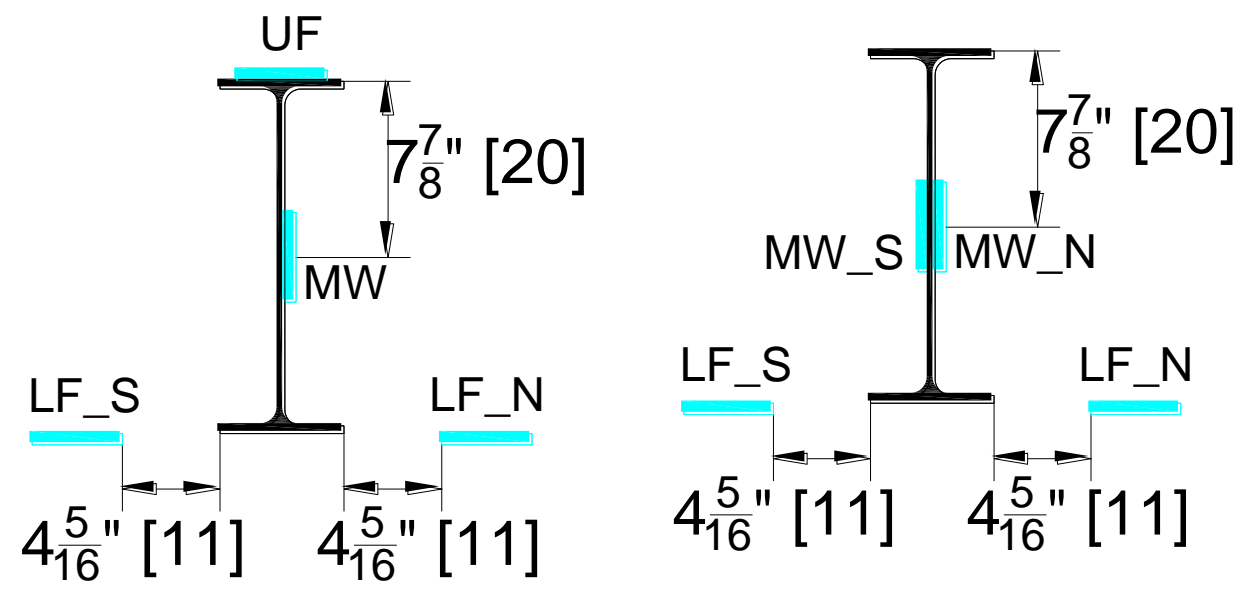

$\begin{array}{ll}\text { (a) Plate thermometers used in Tests } 3 & \text { (b) Plate thermometers used in Test } 7\end{array}$ through 5

Figure B-4 Locations and labels of plate thermometers mounted at halfway between Sections 6 and 7 (units in [] $=\mathbf{c m})$. 


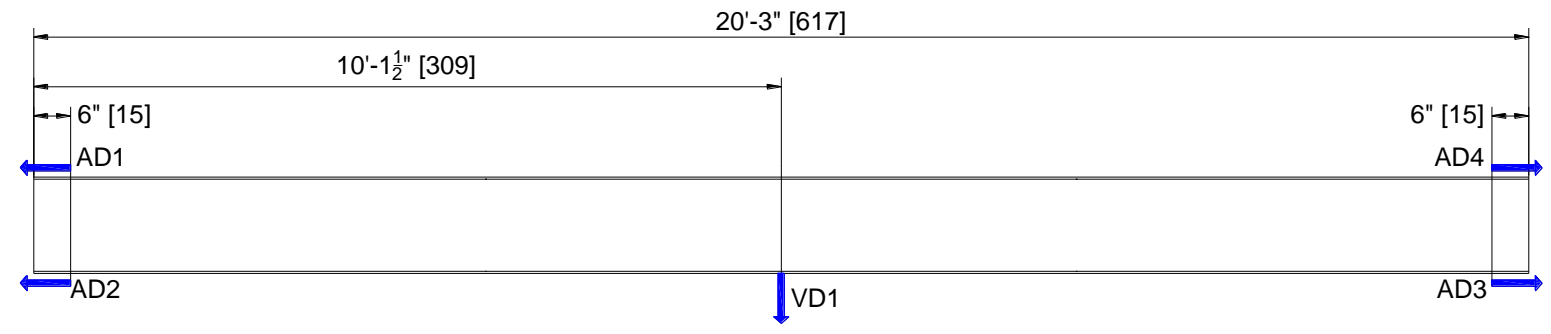

(a) Displacement transducers used in Tests 1 through 5

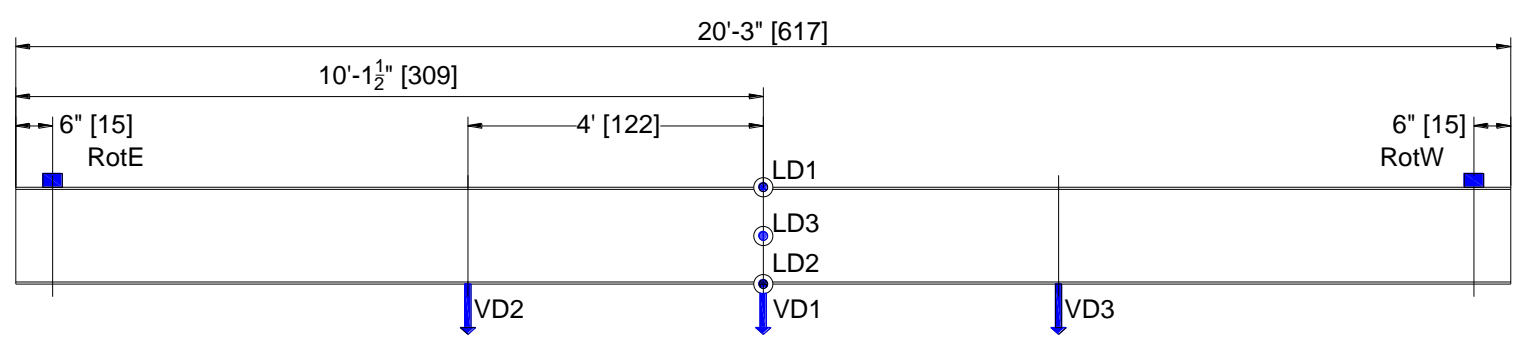

(b) Displacement and rotation transducers used in Tests 6 through 9

Figure B-5 Location and labels of displacement and rotation transducers (units in []$=\mathbf{c m}$ ). 


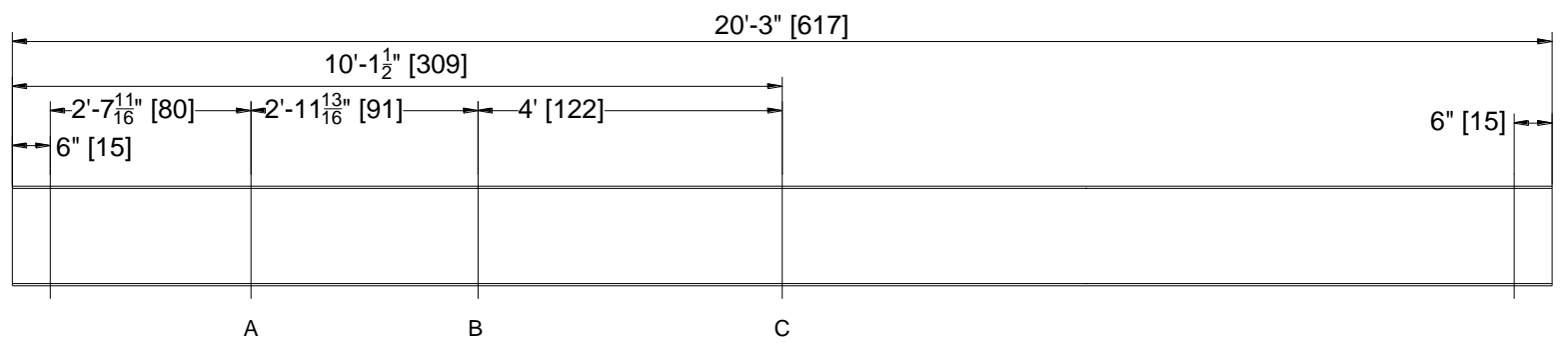

(a) Location of strain gauge sections $\mathrm{A}$ through $\mathrm{C}$

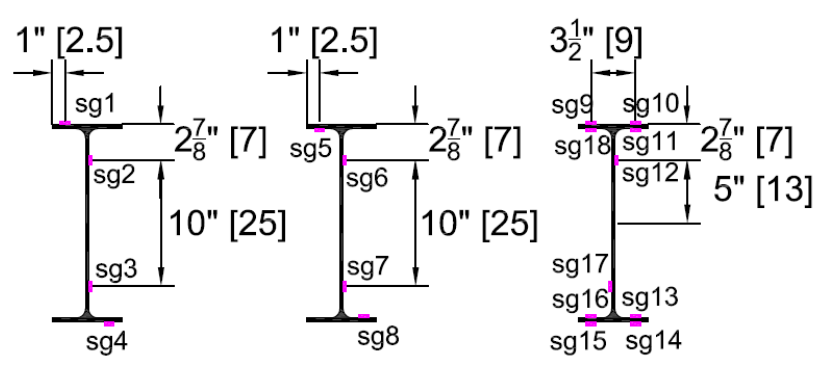
A
B
C

(b) Location and labels of strain gauges in sections A through C

Figure B-6 Locations and labels of strain gauges used in Test 6 (units in [] $=\mathbf{c m}$ ).

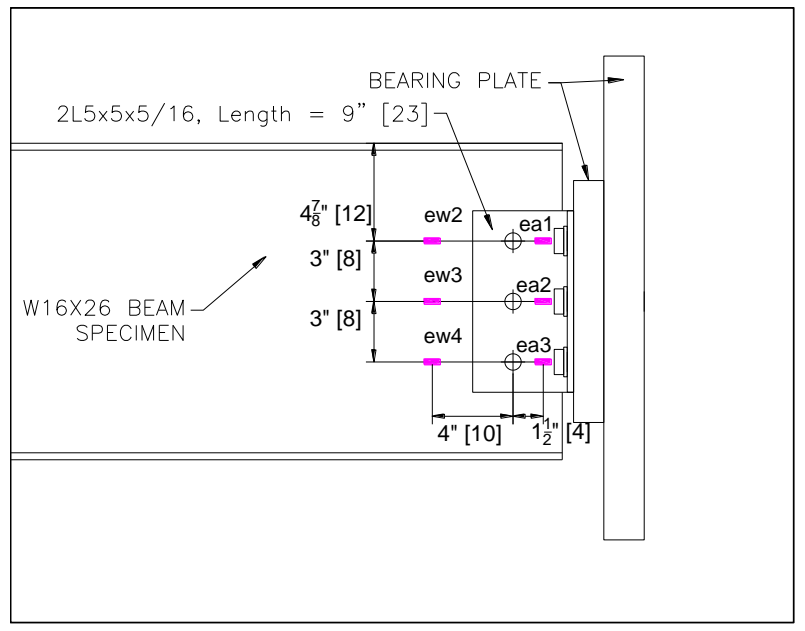

(a) East end

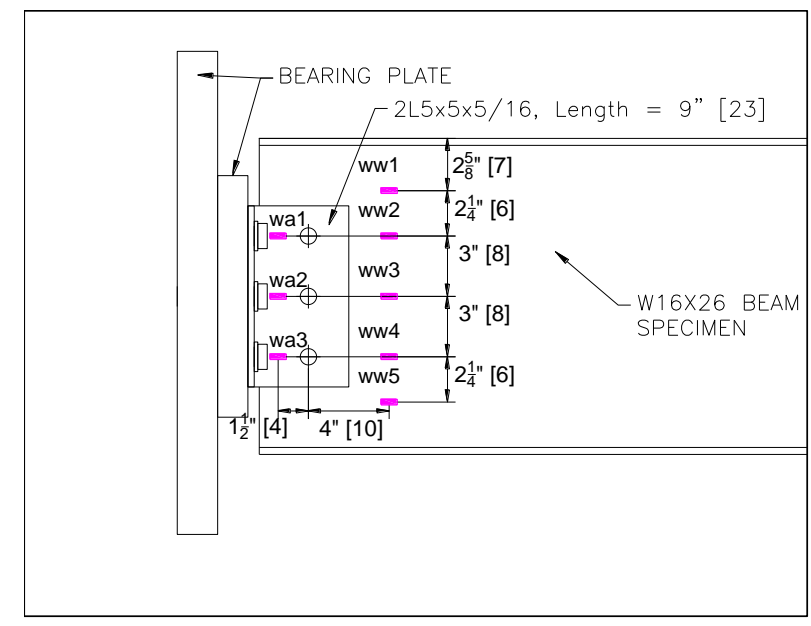

(b) West end

Figure B-7 Locations and labels of strain gauges used in Test 9 (units in [] = cm). 
Table B-1 Steel temperature measurements made in the tests (" $x$ " indicates the sensor used in the test).

\begin{tabular}{|c|c|c|c|c|c|c|c|c|c|}
\hline Sensor Name & Group Name & Test 1 & Test 2 & Test 3 & Test 4 & $\begin{array}{ll}\text { Test } 5 & \text { Test } 6\end{array}$ & Test 7 & Test 8 & Test 9 \\
\hline tc1 & Section 1 & $\mathrm{x}$ & $\mathrm{x}$ & $\mathrm{x}$ & $\mathrm{x}$ & $\mathrm{x}$ & & & \\
\hline $\mathrm{tc} 2$ & Section 1 & $\mathrm{x}$ & $\mathrm{x}$ & $\mathrm{x}$ & $\mathrm{x}$ & $\mathrm{x}$ & & & \\
\hline tc 3 & Section 1 & $\mathrm{x}$ & $\mathrm{x}$ & $\mathrm{x}$ & $\mathrm{x}$ & $\mathrm{x}$ & & & \\
\hline tc 4 & Section 2 & $\mathrm{x}$ & $\mathrm{x}$ & $\mathrm{x}$ & $\mathrm{x}$ & $\mathrm{x}$ & $\mathrm{x}$ & & \\
\hline tc5 & Section 2 & $\mathrm{x}$ & $\mathrm{x}$ & $\mathrm{x}$ & $\mathrm{x}$ & $\mathrm{x}$ & $\mathrm{x}$ & & \\
\hline tc 6 & Section 2 & $\mathrm{x}$ & $\mathrm{x}$ & $\mathrm{x}$ & $\mathrm{x}$ & $\mathrm{x}$ & $\mathrm{x}$ & & \\
\hline tc7 & Section 3 & $\mathrm{x}$ & $\mathrm{x}$ & $\mathrm{x}$ & $\mathrm{x}$ & $\mathrm{x}$ & $\mathrm{x}$ & $\mathrm{x}$ & $\mathrm{x}$ \\
\hline tc 8 & Section 3 & $\mathrm{x}$ & $\mathrm{x}$ & $\mathrm{x}$ & $\mathrm{x}$ & $\mathrm{x}$ & $\mathrm{x}$ & $\mathrm{x}$ & $\mathrm{x}$ \\
\hline tc 9 & Section 3 & $\mathrm{x}$ & $\mathrm{x}$ & $\mathrm{x}$ & $\mathrm{x}$ & $\mathrm{x}$ & $\mathrm{x}$ & $\mathrm{x}$ & $\mathrm{x}$ \\
\hline tc 10 & Section 4 & $\mathrm{x}$ & $\mathrm{x}$ & $\mathrm{x}$ & $\mathrm{x}$ & $\mathrm{x}$ & $\mathrm{x}$ & $\mathrm{x}$ & $\mathrm{x}$ \\
\hline tc 11 & Section 4 & $\mathrm{x}$ & $\mathrm{x}$ & $\mathrm{x}$ & $\mathrm{x}$ & $\mathrm{x}$ & $\mathrm{x}$ & $\mathrm{x}$ & $\mathrm{x}$ \\
\hline tc12 & Section 4 & $\mathrm{x}$ & $\mathrm{x}$ & $\mathrm{x}$ & $\mathrm{x}$ & $\mathrm{x}$ & $\mathrm{x}$ & $\mathrm{x}$ & $\mathrm{x}$ \\
\hline tc 13 & Section 4 & $\mathrm{x}$ & $\mathrm{x}$ & $\mathrm{x}$ & $\mathrm{x}$ & $\mathrm{x}$ & $\mathrm{x}$ & $\mathrm{x}$ & $\mathrm{x}$ \\
\hline tc 14 & Section 4 & $\mathrm{x}$ & $\mathrm{x}$ & $\mathrm{x}$ & $\mathrm{x}$ & $\mathrm{x}$ & $\mathrm{x}$ & $\mathrm{x}$ & $\mathrm{x}$ \\
\hline tc 15 & Section 5 & $\mathrm{x}$ & $\mathrm{x}$ & $\mathrm{x}$ & $\mathrm{x}$ & $\mathrm{x}$ & $\mathrm{x}$ & $\mathrm{x}$ & $\mathrm{x}$ \\
\hline tc 16 & Section 5 & $\mathrm{x}$ & $\mathrm{x}$ & $\mathrm{x}$ & $\mathrm{x}$ & $\mathrm{x}$ & $\mathrm{x}$ & $\mathrm{x}$ & $\mathrm{x}$ \\
\hline tc 17 & Section 5 & $\mathrm{x}$ & $\mathrm{x}$ & $\mathrm{x}$ & $\mathrm{x}$ & $\mathrm{x}$ & $\mathrm{x}$ & $\mathrm{x}$ & $\mathrm{x}$ \\
\hline tc 18 & Section 5 & $\mathrm{x}$ & $\mathrm{x}$ & $\mathrm{x}$ & $\mathrm{x}$ & $\mathrm{x}$ & $\mathrm{x}$ & $\mathrm{x}$ & $\mathrm{x}$ \\
\hline tc19 & Section 5 & $\mathrm{x}$ & $\mathrm{x}$ & $\mathrm{x}$ & $\mathrm{x}$ & $\mathrm{x}$ & $\mathrm{x}$ & $\mathrm{x}$ & $\mathrm{x}$ \\
\hline tc20 & Section 6 & $\mathrm{x}$ & $\mathrm{x}$ & $\mathrm{x}$ & $\mathrm{x}$ & $\mathrm{x}$ & $\mathrm{x}$ & $\mathrm{x}$ & $\mathrm{x}$ \\
\hline tc 21 & Section 6 & $\mathrm{x}$ & $\mathrm{x}$ & $\mathrm{x}$ & $\mathrm{x}$ & $\mathrm{x}$ & $\mathrm{x}$ & $\mathrm{x}$ & $\mathrm{x}$ \\
\hline tc 22 & Section 6 & $\mathrm{x}$ & $\mathrm{x}$ & $\mathrm{x}$ & $\mathrm{x}$ & $\mathrm{x}$ & $\mathrm{x}$ & $\mathrm{x}$ & $\mathrm{x}$ \\
\hline tc 23 & Section 6 & $\mathrm{x}$ & $\mathrm{x}$ & $\mathrm{x}$ & $\mathrm{x}$ & $\mathrm{x}$ & $\mathrm{x}$ & $\mathrm{x}$ & $\mathrm{x}$ \\
\hline tc 24 & Section 6 & $\mathrm{x}$ & $\mathrm{x}$ & $\mathrm{x}$ & $\mathrm{x}$ & $\mathrm{x}$ & $\mathrm{x}$ & $\mathrm{x}$ & $\mathrm{x}$ \\
\hline tc 25 & Section 6 & $\mathrm{x}$ & $\mathrm{x}$ & $\mathrm{x}$ & $\mathrm{x}$ & $\mathrm{x}$ & $\mathrm{x}$ & $\mathrm{x}$ & $\mathrm{x}$ \\
\hline tc 26 & Section 6 & $\mathrm{x}$ & $\mathrm{x}$ & $\mathrm{x}$ & $\mathrm{x}$ & $\mathrm{x}$ & $\mathrm{x}$ & $\mathrm{x}$ & $\mathrm{x}$ \\
\hline tc27 & Section 7 & $x$ & $\mathrm{x}$ & $\mathrm{x}$ & $\mathrm{x}$ & $\mathrm{x}$ & $\mathrm{x}$ & $\mathrm{x}$ & $\mathrm{x}$ \\
\hline $\mathrm{tc} 28$ & Section 7 & $\mathrm{x}$ & $\mathrm{x}$ & $\mathrm{x}$ & $\mathrm{x}$ & $\mathrm{x}$ & $\mathrm{x}$ & $\mathrm{x}$ & $\mathrm{x}$ \\
\hline tc 29 & Section 7 & $\mathrm{x}$ & $\mathrm{x}$ & $\mathrm{x}$ & $\mathrm{x}$ & $\mathrm{x}$ & $\mathrm{x}$ & $\mathrm{x}$ & $\mathrm{x}$ \\
\hline tc 30 & Section 7 & $\mathrm{x}$ & $\mathrm{x}$ & $\mathrm{x}$ & $\mathrm{x}$ & $\mathrm{x}$ & $\mathrm{x}$ & $\mathrm{x}$ & $\mathrm{x}$ \\
\hline tc 31 & Section 7 & $\mathrm{x}$ & $\mathrm{x}$ & $\mathrm{x}$ & $\mathrm{x}$ & $\mathrm{x}$ & $\mathrm{x}$ & $\mathrm{x}$ & $\mathrm{x}$ \\
\hline tc 32 & Section 8 & $\mathrm{x}$ & $\mathrm{x}$ & $\mathrm{x}$ & $\mathrm{x}$ & $\mathrm{x}$ & $\mathrm{x}$ & & \\
\hline tc 33 & Section 8 & $\mathrm{x}$ & $\mathrm{x}$ & $\mathrm{x}$ & $\mathrm{x}$ & $\mathrm{x}$ & $\mathrm{x}$ & & \\
\hline tc 34 & Section 8 & $\mathrm{x}$ & $\mathrm{x}$ & $\mathrm{x}$ & $\mathrm{x}$ & $\mathrm{x}$ & $\mathrm{x}$ & & \\
\hline tc 35 & Section 8 & $\mathrm{x}$ & $\mathrm{x}$ & $\mathrm{x}$ & $\mathrm{x}$ & $\mathrm{x}$ & $\mathrm{x}$ & & \\
\hline tc 36 & Section 8 & $\mathrm{x}$ & $\mathrm{x}$ & $\mathrm{x}$ & $\mathrm{x}$ & $\mathrm{x}$ & $\mathrm{x}$ & & \\
\hline tc37 & Section 9 & $\mathrm{x}$ & $\mathrm{x}$ & $\mathrm{x}$ & $\mathrm{x}$ & $\mathrm{x}$ & $\mathrm{x}$ & & \\
\hline tc 38 & Section 9 & $\mathrm{x}$ & $\mathrm{x}$ & $\mathrm{x}$ & $\mathrm{x}$ & $\mathrm{x}$ & $\mathrm{x}$ & & \\
\hline tc39 & Section 9 & $\mathrm{x}$ & $\mathrm{x}$ & $\mathrm{x}$ & $\mathrm{x}$ & $\mathrm{x}$ & $\mathrm{x}$ & & \\
\hline tc40 & Section 10 & $\mathrm{x}$ & $\mathrm{x}$ & $\mathrm{x}$ & $\mathrm{x}$ & $\mathrm{x}$ & $\mathrm{x}$ & & \\
\hline tc41 & Section 10 & $\mathrm{x}$ & $\mathrm{x}$ & $\mathrm{x}$ & $\mathrm{x}$ & $\mathrm{x}$ & $\mathrm{x}$ & & \\
\hline tc 42 & Section 10 & $\mathrm{x}$ & $\mathrm{x}$ & $\mathrm{x}$ & $\mathrm{x}$ & $\mathrm{x}$ & $\mathrm{x}$ & & \\
\hline tc43 & Section 11 & $\mathrm{x}$ & $\mathrm{x}$ & $\mathrm{x}$ & $\mathrm{x}$ & $\mathrm{x}$ & & & \\
\hline tc 44 & Section 11 & $\mathrm{x}$ & $\mathrm{x}$ & $\mathrm{x}$ & $\mathrm{x}$ & $\mathrm{x}$ & & & \\
\hline tc 45 & Section 11 & $\mathrm{x}$ & $\mathrm{x}$ & $\mathrm{x}$ & $\mathrm{x}$ & $\mathrm{x}$ & & & \\
\hline
\end{tabular}


Table B-2 Adiabatic surface temperature measurements made in the tests (" $x$ " indicates the sensor used in the test).

\begin{tabular}{|c|c|c|c|c|c|c|c|c|c|}
\hline Sensor Name & Group Name & Test 1 & Test 3 & Test 4 & Test 5 & Test 6 & Test 7 & Test 8 & Test 9 \\
\hline UF & Halfway b/w Sections 6-7 & & $\mathrm{x}$ & $\mathrm{x}$ & $\mathrm{x}$ & & & & \\
\hline MW & Halfway b/w Sections 6-7 & & $\mathrm{x}$ & $\mathrm{x}$ & $\mathrm{x}$ & & & & \\
\hline LF_S & Halfway b/w Sections 6-7 & & $\mathrm{x}$ & $\mathrm{x}$ & $\mathrm{x}$ & & $\mathrm{x}$ & & \\
\hline LF_N & Halfway b/w Sections 6-7 & & $\mathrm{x}$ & $\mathrm{x}$ & $\mathrm{x}$ & & $\mathrm{x}$ & & \\
\hline MW_S & Halfway b/w Sections 6-7 & & & & & & $\mathrm{x}$ & & \\
\hline MW_N & Halfway b/w Sections 6-7 & & & & & & $\mathrm{x}$ & & \\
\hline
\end{tabular}

Table B-3 Displacement and rotation measurement made in the tests (" $x$ " indicates the sensor used in the test).

\begin{tabular}{|c|c|c|c|c|c|c|c|c|c|c|}
\hline Sensor Name & Group Name & Test 1 & Test 2 & Test 3 & Test 4 & Test 5 & Test 6 & Test 7 & Test 8 & Test 9 \\
\hline AD1 & Axial displacement & $\mathrm{x}$ & $\mathrm{x}$ & $\mathrm{x}$ & $\mathrm{x}$ & $\mathrm{x}$ & & & & \\
\hline $\mathrm{AD} 2$ & Axial displacement & $\mathrm{x}$ & $\mathrm{x}$ & $\mathrm{x}$ & $\mathrm{x}$ & $\mathrm{x}$ & & & & \\
\hline AD3 & Axial displacement & $\mathrm{x}$ & $\mathrm{x}$ & $\mathrm{x}$ & $\mathrm{x}$ & $\mathrm{x}$ & & & & \\
\hline AD4 & Axial displacement & $\mathrm{x}$ & $\mathrm{x}$ & $\mathrm{x}$ & $\mathrm{x}$ & $\mathrm{x}$ & & & & \\
\hline VD1 & Vertical displacement & $\mathrm{x}$ & $\mathrm{x}$ & $\mathrm{x}$ & $\mathrm{x}$ & $\mathrm{x}$ & $\mathrm{x}$ & $\mathrm{x}$ & $\mathrm{x}$ & $\mathrm{x}$ \\
\hline VD2 & Vertical displacement & & & & & & $\mathrm{x}$ & & $\mathrm{x}$ & $\mathrm{x}$ \\
\hline VD3 & Vertical displacement & & & & & & $\mathrm{x}$ & & $\mathrm{x}$ & $\mathrm{x}$ \\
\hline LD1 & Lateral displacement & & & & & & $\mathrm{x}$ & $\mathrm{x}$ & $\mathrm{x}$ & $\mathrm{x}$ \\
\hline LD2 & Lateral displacement & & & & & & $\mathrm{x}$ & & & $\mathrm{x}$ \\
\hline LD3 & Lateral displacement & & & & & & $\mathrm{x}$ & & & \\
\hline RotEx & Rotation $\mathrm{x}-\mathrm{x}$ axis & & & & & & & & & $\mathrm{x}$ \\
\hline RotEy & Rotaion $y-y$ axis & & & & & & & & & $\mathrm{x}$ \\
\hline RotWx & Rotaion $\mathrm{x}-\mathrm{x}$ axis & & & & & & & & & $\mathrm{x}$ \\
\hline RotWy & Rotation $y-y$ axis & & & & & & & & & $\mathrm{x}$ \\
\hline
\end{tabular}


Table B-4 Strain and force measurements made in the tests (" $x$ " indicates the sensor used in the test).

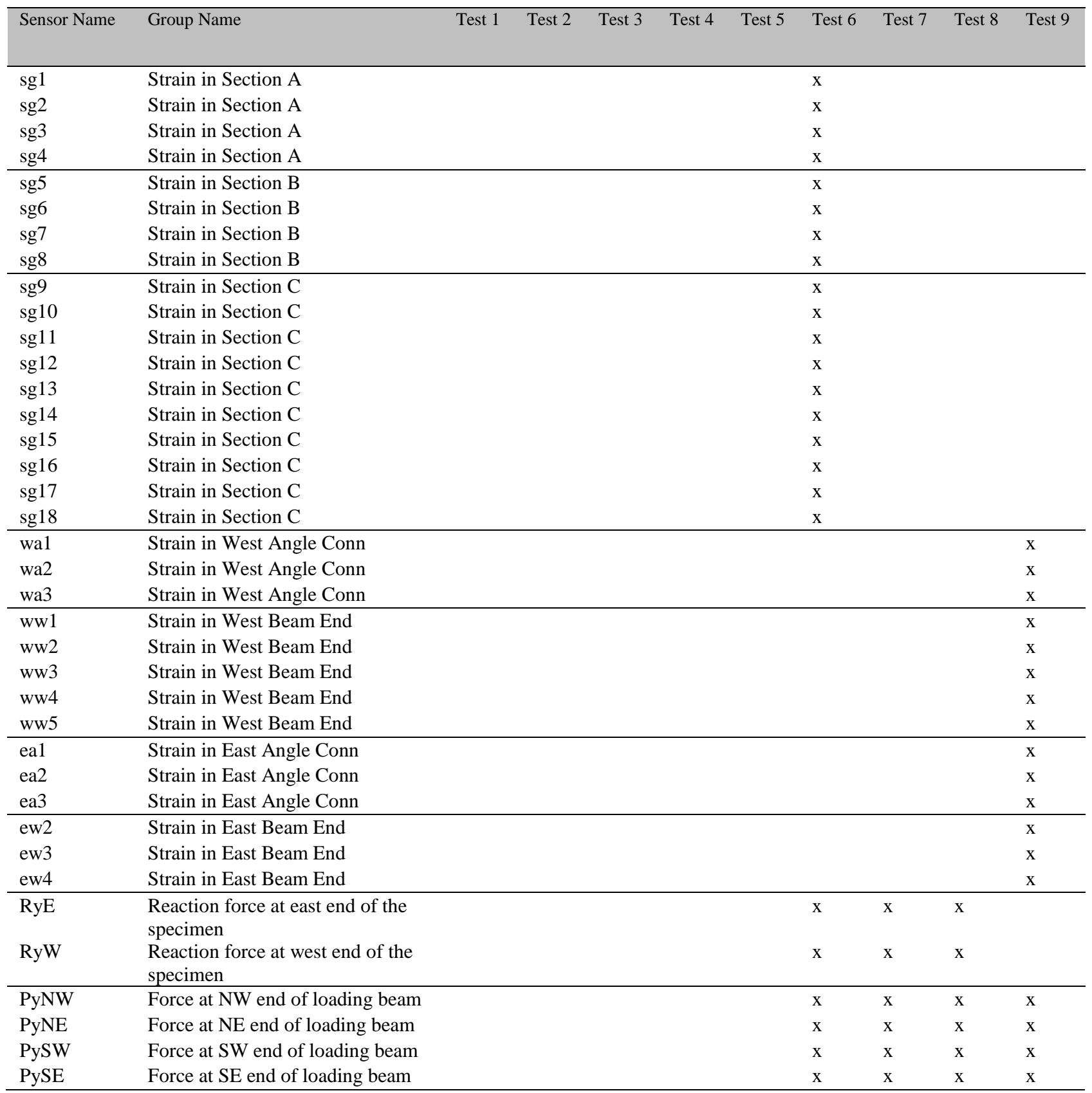

